\title{
Endovascular repair of acute and paraanastomotic abdominal aneurysms: clinical results and detection of complications
}

Citation for published version (APA):

ten Bosch, J. (2013). Endovascular repair of acute and paraanastomotic abdominal aneurysms: clinical results and detection of complications. [Doctoral Thesis, Maastricht University]. Datawyse / Universitaire Pers Maastricht. https://doi.org/10.26481/dis.20130927jb

Document status and date:

Published: 01/01/2013

DOI:

10.26481/dis.20130927jb

Document Version:

Publisher's PDF, also known as Version of record

\section{Please check the document version of this publication:}

- A submitted manuscript is the version of the article upon submission and before peer-review. There can be important differences between the submitted version and the official published version of record.

People interested in the research are advised to contact the author for the final version of the publication, or visit the DOI to the publisher's website.

- The final author version and the galley proof are versions of the publication after peer review.

- The final published version features the final layout of the paper including the volume, issue and page numbers.

Link to publication

\footnotetext{
General rights rights.

- You may freely distribute the URL identifying the publication in the public portal. please follow below link for the End User Agreement:

www.umlib.nl/taverne-license

Take down policy

If you believe that this document breaches copyright please contact us at:

repository@maastrichtuniversity.nl

providing details and we will investigate your claim.
}

Copyright and moral rights for the publications made accessible in the public portal are retained by the authors and/or other copyright owners and it is a condition of accessing publications that users recognise and abide by the legal requirements associated with these

- Users may download and print one copy of any publication from the public portal for the purpose of private study or research.

- You may not further distribute the material or use it for any profit-making activity or commercial gain

If the publication is distributed under the terms of Article $25 \mathrm{fa}$ of the Dutch Copyright Act, indicated by the "Taverne" license above, 
Endovascular repair of acute and paraanastomotic abdominal aneurysms clinical results and detection of complications 
(C) Copyright Jan Ten Bosch, Maastricht 2013

All rights reserved. No part of this publication may be reproduced, stored in retrieval system, or transmitted, in any form or by any means, without the permission from the copyright owner.

Layout: Tiny Wouters

Production: Datawyse | Universitaire Pers Maastricht

ISBN 978-94-6159-245-3

The publication of this thesis was financially supported by: Medtronic, W.L. Gore, Cook, Abbott, ABN AMRO, B. Braun Medical, ERBE, Esaote, ChipSoft, Krijnen Medical, Sigma Medical, Vascutec, Maatschap Heelkunde Atrium Medisch Centrum and DEMO productions. 


\title{
Endovascular repair of acute and paraanastomotic abdominal aneurysms clinical results and detection of complications
}

\author{
PROEFSCHRIFT
}

ter verkrijging van de graad van doctor

aan de Universiteit Maastricht,

op gezag van de Rector Magnificus, Prof. dr. L.L.G. Soete,

volgens het besluit van het College van Decanen,

in het openbaar te verdedigen

op vrijdag 27 september 2013 om 12.00 uur

door

Jan Ten Bosch

geboren op 3 augustus 1984

te Breda

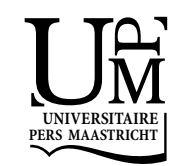




\section{Promotores}

Prof. dr. J.A.W. Teijink

Prof. dr. M.H. Prins

\section{Copromotor}

Dr. E.M. Willigendael, Medisch Centrum Alkmaar

\section{Beoordelingscommissie}

Prof. dr. G.W. Schurink, (voorzitter)

Prof. dr. R. de Bie

Prof. dr. M.W. de Haan

Dr. J.A. van Herwaarden, Universitair Medisch Centrum Utrecht

Dr. M.R.H.M. van Sambeek, Catharina Ziekenhuis Eindhoven 


\section{Contents}

Chapter 1 General introduction and outline of the thesis 7

Eurolntervention. 2011;7:852-858

PART I Acute abdominal aortic aneurysms and paraanastomotic

aneurysms, EVAR or open surgery?

Chapter 2 Endovascular repair is superior to open surgery for ruptured abdominal aortic aneurysms in EVAR-suitable patients J Vasc Surg. 2010;52:13-18

Chapter 3 Early and midterm results of a prospective observational 45 study comparing emergency EVAR with open surgery in both ruptured and unruptured acute abdominal aortic aneurysms Vascular. 2012;20:72-80

Chapter 4 EVAR suitability is not a predictor for early and midterm mortality after open ruptured AAA repair Eur J Vasc Endovasc Surg. 2011;41:647-651

Chapter 5 Symptomatic abdominal aortic aneurysm repair, to wait or not to wait J Cardiovasc Surg. Accepted for publication

Chapter 6 The durability of endovascular repair of paraanastomotic aneurysms after previous open aortic reconstruction J Vasc Surg. 2011;54:1571-1578

PART II Follow-up after endovascular aneurysm repair, depicting stent graft related complications

Chapter 7 Strategies for detection of endoleaks after endovascular abdominal aortic aneurysm repair Submitted

Chapter 8 Contrast-enhanced ultrasound versus computed 133 tomographic angiography for surveillance of endovascular abdominal aortic aneurysm repair J Vasc Interv Radiol. 2010;21:638-643 
Chapter 9 Plasma levels of matrix metalloproteinase-9: a possible diagnostic marker of successful endovascular aneurysm repair

Eur J Vasc Endovasc Surg. 2012;43:171-172

Chapter 10 General discussion

Summary

Samenvatting

Dankwoord

List of publications

Curriculum Vitae 


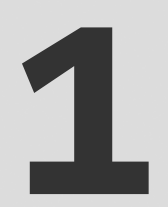

\section{General introduction and outline of the thesis}

Partly published as:

Current insights in endovascular repair of ruptured abdominal aortic aneurysms

JA Ten Bosch

PWM Cuypers

MRHM van Sambeek

JAW Teijink

Eurolntervention. 2011;7:852-858 



\section{General Introduction}

The incidence of Abdominal Aortic Aneurysms (AAA), defined as a permanent dilation of the abdominal aorta to at least 1.5 times its normal diameter, ${ }^{1}$ has persistently increased over the past decades. ${ }^{2}$ This can be attributed to the combined effects of aging of the population, improved diagnostic tools and the introduction of screening programmes. ${ }^{3}$ To date, AAAs are responsible for $1.3 \%$ of all deaths among men aged between 65-85 years in developed countries. ${ }^{3}$ This percentage is probably even higher due to underestimation of AAA related mortality, since AAAs generally exist without symptoms. ${ }^{4}$

Patients with an acute AAA could either present with a symptomatic (unruptured) AAA or with a ruptured AAA. In patients with a symptomatic AAA, defined as abdominal and/or back pain in combination with pain at aneurysm palpation, pending rupture of their aneurysm is generally assumed. However, evidence for a symptomatic AAA representing pending rupture is lacking. ${ }^{5}$

In patients with a ruptured AAA, the mortality rate is as high as $80 \% .^{6-8}$ Forty percent of the patients with a ruptured AAA do not reach the hospital alive ${ }^{8}$ and in patients reaching the hospital and undergoing surgery, the mortality rate is approximately $50 \% .^{9}$ Despite progression in surgical techniques, anesthetical management, vascular prostheses and perioperative care, there is only a gradual decline in operative mortality rate over the past decades. ${ }^{10,11}$

In 1991, a new minimally invasive technique to treat AAA was described by Parodi et al., endovascular aneurysm repair (EVAR). ${ }^{12}$ In the elective setting, EVAR showed an absolute and relative mortality risk reduction of approximately 3 and $75 \%$, respectively. ${ }^{13,14}$ In the acute setting, emergency EVAR (eEVAR) is a strategy that might allow for improvement in above-mentioned poor prognosis. Since 1994 an increasing amount of publications of eEVAR to treat acute AAA is published. Currently, eEVAR has become an accepted treatment option, which is increasingly being performed to treat acute AAA. However, the potential reduction in peri-operative mortality of eEVAR compared to conventional open repair in patients with an acute AAA is still open to debate.

In an era where EVAR and eEVAR are increasingly performed, drawbacks of this minimally invasive technique are more enlightened. A frequently mentioned disadvantage of EVAR is the requirement of long-term imaging surveillance after EVAR in order to detect stent graft related complications. ${ }^{15}$ Computed tomography angiography (CTA) is the most widely used technique for postEVAR surveillance. ${ }^{16}$ However, repetitive CTA has several important drawbacks, including cumulative radiation dose, and nephrotoxic contrast load. ${ }^{17}$ Therefore, a less harmful alternative for follow-up after EVAR is desirable. 


\section{PART I}

\section{Acute abdominal aortic aneurysms and paraanastomotic aneurysms, EVAR or open surgery?}

\section{Treatment options}

In patients presenting with an acute AAA, a choice can be made whether or not to offer treatment at all (selective treatment policy). When decided to perform an intervention, two treatment options are available; conventional "open" AAA repair or the minimally invasive endovascular AAA repair.

\section{Conventional 'open' acute AAA repair}

Conventional open repair of an AAA was performed for the first time in 1951, replacing the AAA by a homograft. ${ }^{18}$ Two years later, open repair was performed using synthetic grafts. ${ }^{19}$ The open procedure to treat ruptured as well as unruptured AAA has almost been consistent over time and known as being an invasive, but generally durable procedure. In case of a ruptured AAA, a laparotomy is performed immediately after induction of general anesthesia in patients often suffering from hypovolemic shock. Subsequently, the aorta and/or iliac arteries are clamped proximally and distally from the aneurysm. After clamping, the aneurysm is opened in order to provide access for placement of a polyester tube or bifurcated graft. The aneurysm sac is left in situ and secured around the graft in order to cover it.

This major operation carries a significant mortality and morbidity, due to the combined effects of general anesthesia, surgical exposure, hemorrhage, and aortic clamping with related lower torso ischemia-reperfusion injury. ${ }^{20}$ General anesthesia is required with associated inhibition of sympathetic arterial tone, which might lead to acute hemodynamical changes. Furthermore, loss of abdominal muscle tone during induction of general anesthesia might convert a retroperitoneal hematoma into an intraperitoneal bleeding with related hemodynamical consequences. ${ }^{21}$ During surgical exposure, blood loss is generally extensive. ${ }^{22}$ Hypotension and subsequent inadequate oxygenation might induce or accelerate cerebral en cardiac ischemia, resulting in poor clinical prognosis. Furthermore, after removing the clamps, considerable ischemia-reperfusion injury of the lower extremities and the intra-abdominal organs might occur. ${ }^{23}$ 


\section{Minimally invasive endovascular acute AAA repair}

In 1991, Parodi described a less invasive alternative to conventional 'open' aneurysm repair for the treatment of AAA, the so-called EVAR. ${ }^{12}$ EVAR implies groin incisions in order to expose the femoral arteries, whereas percutaneous techniques are also possible. Using a catheter and guidewire, a synthetic stent graft is fed through the artery up to the AAA neck until positioned correctly just below the renal arteries and subsequently unfolded, excluding the aneurysm sac from blood flow and pressure. Control angiography is performed to assure correct placement of the endovascular stent graft. Aorto-uni-iliac stent grafts, reaching one of the common iliac arteries as well as bifurcated stent grafts, reaching both iliac arteries are available. In case of an aorto-uni-iliac stentgraft, femoro-femoral bypass graft surgery has to be performed in order to restore blood flow to the contralateral leg. A controlateral endovascular occluder is used to stop retrograde bleeding up the iliac artery into the aneurysm sac. Due to increasing expertise and continuous improvement of both stent grafts and their delivery systems, increasing success rates and decreasing complications and reintervention rates are observed. ${ }^{24}$

After several years of experience in EVAR for unruptured AAAs this technique has gradually extended its indication and is currently used to treat feasible patients with acute AAA. ${ }^{25}$ The applicability for 'emergency EVAR' (eEVAR) depends on several anatomical and logistic conditions. Anatomical suitability for EVAR is assessed on a preoperative CTA scan and evaluated for infrarenal aortic neck length, neck angulation, amount of circular thrombus or atherosclerosis, and iliac and femoral access arteries. ${ }^{26}$ Approximately half of the acute AAA is considered anatomically suitable for eEVAR according to the preoperative CTA scan. ${ }^{27}$ However, logistic problems are often reported which frequently led to the exclusion of EVAR-suitable patients for undergoing endovascular repair. ${ }^{26,28-}$ ${ }^{33}$ Logistic criteria for eEVAR are the instant availability of a CT-scanner, the 24/7 availability of an operating room that is adequately equipped to perform endovascular procedures as well as an endovascular trained staff. Financial burden is sometimes the availability of a large variety of 'off-the-shelf' stentgrafts. $^{34}$

\section{EVAR versus open surgery}

In a recent systematic review of 61 controlled and uncontrolled clinical studies of patients with an unruptured AAA, EVAR is described as a feasible and safe technique, showing decreased mortality and morbidity rates compared to a conventional open procedure. ${ }^{35}$ Since its first description in 1994 by Yusuf et 
al., ${ }^{25}$ over 400 reports of eEVAR for patients with an acute AAA are available. Based on results of elective AAA studies and based on several pathophysiological and surgical theories, it seems reasonable to prefer endovascular repair in the acute setting as well.

The minimal invasive approach implies the opportunity to use local anesthesia, which has been proven to be feasible and effective in EVAR. ${ }^{36,37}$ Local anesthesia is not attended with the acute hemodynamical changes as seen during induction of general anaesthesia. ${ }^{21}$ However, these benefits did not lead to standard application of local anesthesia, since 19 comparative observational studies show considerable variation in the percentages of patients undergoing local anesthesia (0-97\%). Furthermore, eEVAR involves no crossclamping and minor surgical exposition compared to open surgery.

These advantageous consequences of the minimally invasive endovascular approach to treat acute AAA might reflect on perioperative mortality. Approximately 26 studies comparing EVAR with conventional open surgery in patients with an acute AAA can be identified, mostly concerning ruptured AAA. ${ }^{26,28-33,38-56}$ Twenty-four of these studies compared early mortality of EVAR with open surgery. ${ }^{26,28-33,38-42,44-51,53-56}$ One of these studies is a prospective randomized trial by Hinchliffe et al., which showed identical 30-day mortality rates in both treatment groups (9/17 in the open surgery group versus $8 / 15$ in the EVAR group). ${ }^{45}$ However, the study is underpowered and served as a pilot study for future randomized studies. The remaining 23 studies are observational studies of which 4 showed no reduction in early mortality compared to open surgery. ${ }^{45,49,53,54}$ Using Review Manager 4.2.10, provided by the Nordic Cochrane center, a forest-plot can be created (Figure 1.1). The overall effect of EVAR compared to open surgery, taking 1 randomized controlled trail and 23 available observational studies into account, showed a $38 \%$ decrease in 30-day or hospital mortality rate (peto-odds ratio $0.62 ; 95 \% \mathrm{Cl}$ 0.52 to 0.74$)$.

Additionally, the 30-day, or hospital mortality is reported in five recent systematic reviews (Table 1.1). ${ }^{22,57-60}$ Two reviews only discuss the results of the endovascular procedure ${ }^{58,59}$ and three reviews compared the endovascular with the open procedure. ${ }^{22,57,60}$ The first review showed a pooled mortality rate after EVAR of 24\% (95\% Cl 20-28\%) across 31 studies concerning 982 patients. ${ }^{59}$ In 18 observational studies describing 436 people who underwent EVAR, the second review found a pooled mortality of $21 \%(95 \% \mathrm{Cl} 13-29 \%){ }^{58}$ In two reviews comparing both treatment groups, pooled mortality was $18 \%{ }^{57}$ and $22 \%{ }^{60}$ in the EVAR group compared to $34 \%{ }^{57}$ and $38 \%{ }^{60}$ in the open surgery group. In the 
fifth review, Sadat et al. showed that EVAR is associated with a significant reduction in mortality with a pooled odds ratio of $0.62(95 \% \mathrm{Cl} 0.52-0.75){ }^{22}$ Visser et al. found similar results with an odds ratio of 0.45 (95\% BI 0.28-0.72). ${ }^{60}$ However, after adjustment for patients' hemodynamic condition, the odds ratio was 0.67 (95\% $\mathrm{Cl} 0.31-1.44)$ and therefore no longer significant.

In addition, the systematic reviews showed that EVAR is associated with significant reduction in blood loss, reduced procedure time, reduction in systemic complications and reduced intensive care and hospital stay compared to open surgery. ${ }^{22,57,58,60}$

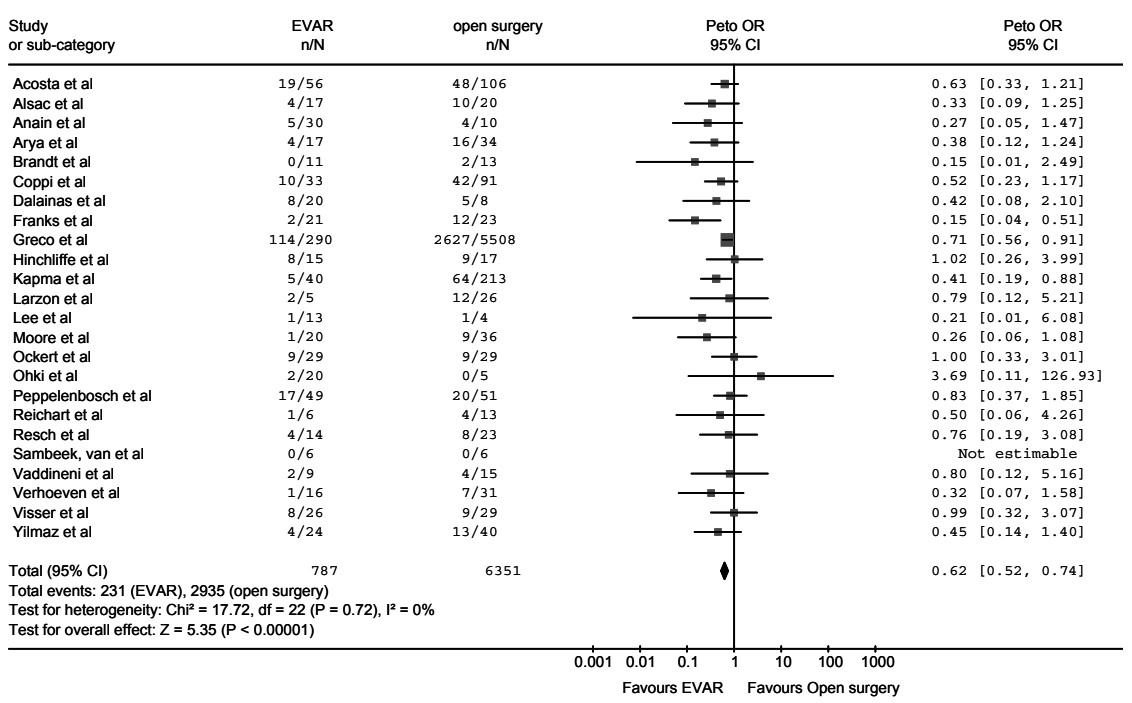

Figure 1.1 Forest plot of 30-day or hospital mortality in 24 studies comparing EVAR and open surgery in patients with a ruptured AAA.

Table 1.1 30-day or in-hospital mortality in patients treated with open or endovascular repair according to five systematic reviews.

\begin{tabular}{|c|c|c|c|c|c|}
\hline \multirow[t]{3}{*}{ Review } & \multirow{3}{*}{$\begin{array}{c}\text { Studies } \\
n\end{array}$} & \multirow{3}{*}{$\begin{array}{c}\text { Patients } \\
\mathrm{n}\end{array}$} & \multicolumn{3}{|c|}{ 30-day/in-hospital mortality } \\
\hline & & & EVAR & Open & Odds ratio \\
\hline & & & $\%(95 \% \mathrm{Cl})$ & $\%(95 \% \mathrm{Cl})$ & EVAR vs Open \\
\hline Rayt et al. ${ }^{59}$ & 31 & 982 & $24 \%(20-28)$ & - & - \\
\hline Mastracci et al. ${ }^{58}$ & 18 & 436 & $21 \%(13-29)$ & - & - \\
\hline Harkin et al. ${ }^{57}$ & 34 & 891 & $18 \%(0-53) *$ & $34 \%(0-70) *$ & - \\
\hline Visser et al. ${ }^{60}$ & 10 & 478 & $22 \%(16-29)$ & $38 \%(32-45)$ & $0.45(0.28-0.78)$ \\
\hline Sadat et al. ${ }^{22}$ & 23 & 7040 & - & - & $0.62(0.52-0.75)$ \\
\hline
\end{tabular}

$\mathrm{Cl}=$ confidence interval, vs = versus; ${ }^{*}=\%$ (range included studies) 


\section{Other potential indications for endovascular repair: paraanastomotic aneurysms}

A typical complication after conventional aortic prosthetic reconstruction is paraanastomotic aneurysm formation. Paraanastomotic aneurysms after previous open reconstruction may present as continuing dilatation of the aorta (true paraanastomotic aneurysms) or as disruption of the anastomosis leading to pseudoaneurysm formation (false paraanastomotic aneurysms). ${ }^{61}$ Most reinterventions after initial abdominal aortic prosthetic reconstruction are for repair of these anastomotic pseudoaneurysms and true paraanastomotic aneurysms, since they are at risk for rupture. ${ }^{62,63}$ The reported rupture rate in patients who did not receive surgery ranges from $15-55 \%{ }^{64-66}$ An open procedure in order to treat these paraanastomotic aneurysms in generally highrisk patients is technically challenging with mortality and morbidity rates (24$70 \%$ and $70-83 \%$, respectively) higher than those associated with primary prosthetic reconstructions. ${ }^{67-69}$ Endovascular repair however, allows for local or regional anesthesia without requiring dissection through previous scarred operative sites, potentially resulting in decreased mortality and morbidity rates compared to an open reintervention.

\section{PART II}

\section{Follow-up after endovascular aneurysm repair, depicting stent graft related complications}

Stent graft related complications might cause re-establishment of circulation in the aneurysm sac resulting in aneurysm expansion and ongoing rupture risk. ${ }^{13}$ Complications, including aneurysm growth, endoleak, migration, and kinking, are observed in approximately $40 \%$ of patients by 4 years after EVAR, resulting in a $20 \%$ reintervention rate to reduce the ongoing rupture risk. ${ }^{13}$ Long-term imaging surveillance in terms of CTA is required to detect stent graft related complications with related cumulative radiation dose, and nephrotoxic contrast load. ${ }^{15,17}$ Therefore, alternatives to CTA for surveillance after EVAR are desirable.

According to the practical guidelines of the Society of Interventional Radiology, three parameters should be included for imaging surveillance: diameter measurements of the aortic aneurysm, detection of morphologic details of the stent grafts, and detection and classification of endoleaks. ${ }^{70}$ 
Gradually decreasing AAA diameter after endovascular repair is presumed to reflect successful treatment and low rupture risk, ${ }^{15}$ whereas increasing AAA diameters in the follow-up after EVAR indicates continued rupture risk. ${ }^{71}$ Currently, maximal diameter is the most widely used parameter for aneurysm size measurements. Alteration of stent grafts, including migration, kinking and fracture, are the result of hemodynamic stress, aortic morphologic changes and/or device inadequacy. These stent graft deformations may cause endoleakage, continued rupture risk or obstruction of blood flow through the device.

Endoleak formation, defined as a blood flow external to the stent graft and inside the aneurysm sac, ${ }^{15,72,73}$ is the most common complication of EVAR with a reported incidence varying from 2 to $45 \% .{ }^{16,74-77}$ Based on the origin of the leak, endoleaks can be organized into five categories. Persistent endoleak is considered a procedural failure because it may cause enlargement and rupture of the aneurysm, representing the main indication for surgical late conversion. ${ }^{78}$ Since endoleakage may cause aneurysm expansion and ongoing rupture risk, modalities in order to identify them are essential in the post-EVAR surveillance. Among various imaging modalities, CTA is the most widely used technique for post-EVAR surveillance. ${ }^{16}$ However, repetitive CTA has several important drawbacks, including cumulative radiation dose, nephrotoxic contrast load, and high costs. ${ }^{17}$ Contrast enhanced or unenhanced ultrasonography, magnetic resonance angiography, digital subtraction angiography, and potential biomarkers might all have a role in endoleak detection and are therefore potential alternatives to CTA.

A number of studies have indicated that color Duplex ultrasound may be used for post-EVAR surveillance. ${ }^{79-82}$ Sonographic contrast agents enhance the capability of color duplex to detect endoleaks. ${ }^{83-87}$ However, accuracy and reproducibility of contrast-enhanced ultrasound (CEUS) as an alternative to CTA in the follow-up of patients after EVAR with regard to detection of changes in AAA dimensions and endoleaks is required for clinical applicability.

Regarding potential biomarkers, Sangiorgi et al. were the first to report that a decrease of plasma matrix metalloproteinase (MMP)-3 and MMP-9 during post EVAR surveillance might indicate successful EVAR and that an increase in MMP concentration after EVAR may help to identify patients with aneurysm sac growth and/or endoleakage. ${ }^{88}$ Since increased circulating concentrations of MMP-2, -9 and tissue inhibitor of MMP-1 (TIMP-1) are associated with presence and size of $A A A,{ }^{89-91}$ there might be a potential clinical applicability of MMP-2, -9 , and TIMP-1 as a diagnostic tool for presence of endoleakage. 


\section{Possibilities for research}

The reported reduction in early mortality after eEVAR in the treatment of rAAA compared to conventional 'open' surgery seems conclusive. However, the available studies have considerable heterogeneity and methodological limitations.

At first, heterogeneity is caused by differences in definitions: e.g. the definition of hemodynamical instability varied from a systolic blood pressure below 50 $\mathrm{mmHg}$ to $100 \mathrm{mmHg}$. Heterogeneity is further illustrated with the range of percentages of patients with a rAAA treated with eEVAR (15-50\%) as well as the percentage of hemodynamical unstable patients (33-73\%) within the eEVAR group.

Furthermore, in most studies a limited number of patients were included and comparative studies are flawed by methodological inadequacies such as high potential of selection bias and lack of randomisation. ${ }^{20}$ Selection bias is created by selecting patients for EVAR constituting a lower-risk category, presuming they need to be hemodynamically more stable for preoperative imaging and have a more favorable (EVAR-suitable) anatomic configuration. A wellconducted large randomized controlled trial (RCT) could provide useful data, but has not been published so far. Furthermore, a RCT may give ethical concerns, given the accumulation of superior results with EVAR based on the available observational studies. In addition, a RCT in an acute, severe condition like a ruptured AAA, appears difficult to perform. ${ }^{45}$

Research is needed to clarify certain aspects of endovascular repair in an era in which endovascular repair is increasingly performed for extending indications.

A large prospective controlled trial in which selection bias is made unlikely is needed to identify possible benefits of EVAR over open surgery in patients with an acute $A A A$.

Long-term results of patients treated either with EVAR or open repair for acute $A A A$ are lacking and desires further investigation.

A few small series of endovascular treatment of paraanastomotic aneurysms after primary conventional open aortic reconstruction are reported. However, larger study populations with longer follow-up are required to assess long-term feasibility.

Alternatives to CTA as life-long annual surveillance after EVAR is desirable in order to restrain the cumulative CTA related burden in patients, especially in an era in which endovascular repair is increasingly performed. 
Therefore, objectives addressed in this thesis can be summarized by:

1. To assess whether endovascular aneurysm repair decrease early and midterm mortality in patients with an acute AAA.

2. To evaluate the role of selection bias in the current available observational studies comparing EVAR with open repair in patients with a ruptured AAA.

3. To assess the widely assumed necessity for acute intervention in patients with a symptomatic acute AAA.

4. To evaluate the outcome of a multicenter series of patients who were treated with endovascular repair for paraanastomotic aneurysms after previous open reconstruction.

5. To describe and assess potential alternatives to CTA in post-EVAR surveillance. 


\section{Aim and outline of this thesis}

This thesis focuses on the refinement of the role of endovascular repair in 'patients with an acute (symptomatic or ruptured) $A A A^{\prime}$ ' or 'paraanastomotic AAA after previous conventional open surgery' and possibilities to replace the current repetitive CTA scans for surveillance after endovascular aneurysm repair by less harmful alternatives. A number of studies were performed focusing on type and timing of treatment in patients with an acute AAA, treatment of paraanastomotic aneurysms, as well as strategies and diagnostic accuracy to detect changes in AAA size and endoleaks during follow-up after endovascular aneurysm repair.

\section{PART I}

The minimally invasive endovascular procedure (EVAR) is likely to reduce early mortality in patients with an acute AAA. The majority of the studies comparing EVAR with conventional open surgery show a clear trend towards an improved short-term effect of EVAR and a significant reduction in early mortality compared to conventional open surgery. However, these results have to be interpreted with caution due to the likelihood of methodological inadequacies such as selection bias, heterogeneity, and lack of randomization.

Chapter 2 describes a study in which EVAR is compared to conventional open surgery in patients with a ruptured AAA. Selection bias to be treated with EVAR or open repair based on anatomical or hemodynamical criteria has been made unlikely, since all patients were suitable for EVAR and had the same preoperative imaging protocol. Mortality rates where determined at 30 days and 6 months of follow-up.

Chapter 3 contains an observational study in which EVAR is compared to conventional open surgery in all patients with an acute AAA (symptomatic or non-ruptured acute AAA as well as ruptured AAA). Follow-up was 1 year and mortality rates were divided in all cause mortality and aneurysm related mortality.

As mentioned before, observational studies, such as chapter 2, comparing EVAR with open surgery in patients with ruptured AAA, are generally flawed by methodological inadequacies. The main methodological aspect is selection bias by selecting patients for EVAR constituting a lower-risk category in terms of hemodynamic and anatomic condition. The weight of this selection bias on outcome after open repair is observed in chapter $\mathbf{4}$ by comparing EVAR-suitable 
with EVAR-unsuitable ruptured AAAs in patients who had the same preoperative imaging protocol and who all underwent conventional open repair.

In chapter 5 we investigated whether a symptomatic AAA needs acute intervention (within 12 hours after presentation). When operated within 12 hours, the risk of rupture prior to surgery with related worsening of prognosis might be reduced. On the other hand, in an acute setting there is little time for preoperative optimization of patients' and operative conditions. Chapter 4 compares patients with a symptomatic AAA who were treated within 12 hours after presentation with patients who were treated after 12 hours after presentation.

Most reinterventions after abdominal aortic prosthetic reconstruction are for repair of paraanastomotic pseudoaneurysms and true paraanastomotic aneurysms. These reoperations are technically challenging procedures requiring dissection through previous scarred operative sites in generally high-risk patients. Chapter 6 describes a multicenter series of patients treated with endovascular repair for paraanastomotic aneurysms after a previous open aorto-iliac reconstruction.

\section{PART II}

Endovascular aortic aneurysm repair is a less invasive alternative to open surgical repair in selected patients with AAA. In the elective setting, this technique has an initial postoperative benefit over open AAA repair due to decreased early morbidity and mortality. However, long-term imaging surveillance in terms of CTA is required to detect stent graft related complications. This lifelong requirement for patient surveillance accentuates certain drawbacks of CTA, including ionizing radiation burden and nephrotoxic contrast load. Are there clinically applicable alternatives to CTA in the follow-up after endovascular aneurysm repair?

Chapter 7 discusses the strategies for endoleak detection in the follow up after EVAR in terms of imaging techniques (CTA, CEUS, and MRA) and biochemical assays (MMP-2, and MMP-9).

Since no major side effects, including nephrotoxic effects and radiation burden, have been reported for ultrasound contrast agents, this favors the potential use of CEUS for post-EVAR follow-up. Chapter $\mathbf{8}$ describes a study comparing the diagnostic accuracy between contrast-enhanced ultrasound (CEUS) and CTA to detect changes in AAA size and endoleaks during follow-up after EVAR. 
Endoleakage is the most common complication of EVAR and it is clinically important since it may cause enlargement and eventually rupture of the aneurysm sac. Increased circulating concentrations of MMP-2, -9 and TIMP-1 are associated with presence and size of AAA. In Chapter 9 the potential clinical applicability of MMP-2, -9 , and TIMP-1 as a diagnostic tool for presence of endoleak was evaluated.

Conclusions of the thesis and prospects for the treatment of acute AAA and imaging follow-up after EVAR are outlined in a general discussion of the results of these studies in Chapter 10. 


\section{References}

1. van der Vliet JA, Boll AP. Abdominal aortic aneurysm. Lancet. 1997;349:863-866.

2. Best VA, Price JF, Fowkes FG. Persistent increase in the incidence of abdominal aortic aneurysm in Scotland, 1981-2000. Br J Surg. 2003;90:1510-1515.

3. Sakalihasan N, Limet R, Defawe OD. Abdominal aortic aneurysm. Lancet. 2005;365:1577-1589.

4. Acosta $S$, Ogren $M$, Bengtsson $H$, Bergqvist $D$, Lindblad $B$, Zdanowski Z. Increasing incidence of ruptured abdominal aortic aneurysm: a population-based study. J Vasc Surg. 2006;44: 237-243.

5. Scott RA, Kim LG, Ashton HA. Assessment of the criteria for elective surgery in screendetected abdominal aortic aneurysms. J Med Screen. 2005;12:150-154.

6. Gorham TJ, Taylor J, Raptis S. Endovascular treatment of abdominal aortic aneurysm. Br J Surg. 2004;91:815-827.

7. Veith FJ, Ohki T, Lipsitz EC, Suggs WD, Cynamon J. Treatment of ruptured abdominal aneurysms with stent grafts: a new gold standard? Semin Vasc Surg. 2003;16:171-175.

8. Semmens JB, Norman PE, Lawrence Brown MM, Holman CD. Influence of gender on outcome from ruptured abdominal aortic aneurysm. Br J Surg. 2000;87:191-194.

9. Sayers RD, Thompson MM, Nasim A, Healey P, Taub N, Bell PR. Surgical management of 671 abdominal aortic aneurysms: a 13 year review from a single centre. Eur J Vasc Endovasc Surg. 1997;13:322-327.

10. Bown MJ, Sutton AJ, Bell PR, Sayers RD. A meta-analysis of 50 years of ruptured abdominal aortic aneurysm repair. Br J Surg. 2002;89:714-730.

11. Heller JA, Weinberg A, Arons R, Krishnasastry KV, Lyon RT, Deitch JS, Schulick AH, Bush HL, Jr., Kent KC. Two decades of abdominal aortic aneurysm repair: have we made any progress? J Vasc Surg. 2000;32:1091-1100.

12. Parodi JC, Palmaz JC, Barone HD. Transfemoral intraluminal graft implantation for abdominal aortic aneurysms. Ann Vasc Surg. 1991;5:491-499.

13. Endovascular aneurysm repair versus open repair in patients with abdominal aortic aneurysm (EVAR trial 1): randomised controlled trial. Lancet. 2005;365:2179-2186.

14. Prinssen M, Verhoeven EL, Buth J, Cuypers PW, van Sambeek MR, Balm R, Buskens E, Grobbee $\mathrm{DE}$, Blankensteijn JD. A randomized trial comparing conventional and endovascular repair of abdominal aortic aneurysms. N Engl J Med. 2004;351:1607-1618.

15. Veith FJ, Baum RA, Ohki T, Amor M, Adiseshiah M, Blankensteijn JD, Buth J, Chuter TA, Fairman RM, Gilling Smith G, Harris PL, Hodgson KJ, Hopkinson BR, Ivancev K, Katzen BT, Lawrence Brown M, Meier GH, Malina M, Makaroun MS, Parodi JC, Richter GM, Rubin GD, Stelter WJ, White GH, White RA, Wisselink W, Zarins CK. Nature and significance of endoleaks and endotension: summary of opinions expressed at an international conference. J Vasc Surg. 2002;35:1029-1035.

16. Golzarian J, Dussaussois L, Abada HT, Gevenois PA, Van Gansbeke D, Ferreira J, Struyven J. Helical CT of aorta after endoluminal stent graft therapy: value of biphasic acquisition. AJR Am J Roentgenol. 1998;171:329-331.

17. Prinssen $M$, Wixon $C L$, Buskens $E$, Blankensteijn JD. Surveillance after endovascular aneurysm repair: diagnostics, complications, and associated costs. Ann Vasc Surg. 2004;18:421-427.

18. Dubost $\mathrm{C}$, Allary M, Oeconomos N. [Treatment of aortic aneurysms; removal of the aneurysm; re-establishment of continuity by grafts of preserved human aorta.]. Mem Acad Chir (Paris). 1951;77: 381-383.

19. DeBakey ME, Cooley DA. Successful resection of aneurysm of thoracic aorta and replacement by graft. JAMA. 1953;152:673-676.

20. Dillon $\mathrm{M}$, Cardwell C, Blair PH, Ellis $\mathrm{P}, \mathrm{Kee} \mathrm{F}$, Harkin DW. Endovascular treatment for ruptured abdominal aortic aneurysm. Cochrane Database Syst Rev. 2007(1):Cd005261.

21. Lachat ML, Pfammatter T, Witzke HJ, Bettex D, Kunzli A, Wolfensberger U, Turina MI. Endovascular repair with bifurcated stent grafts under local anaesthesia to improve outcome of ruptured aortoiliac aneurysms. Eur J Vasc Endovasc Surg. 2002;23:528-536. 
22. Sadat U, Boyle JR, Walsh SR, Tang T, Varty K, Hayes PD. Endovascular vs open repair of acute abdominal aortic aneurysms--a systematic review and meta-analysis. J Vasc Surg. 2008;48:227-236.

23. Bown MJ, Nicholson ML, Bell PR, Sayers RD. The systemic inflammatory response syndrome, organ failure, and mortality after abdominal aortic aneurysm repair. J Vasc Surg. 2003;37: 600-606.

24. Lovegrove RE, Javid M, Magee TR, Galland RB. A meta-analysis of 21,178 patients undergoing open or endovascular repair of abdominal aortic aneurysm. Br J Surg. 2008;95:677-684.

25. Yusuf SW, Whitaker SC, Chuter TA, Wenham PW, Hopkinson BR. Emergency endovascular repair of leaking aortic aneurysm. Lancet. 1994;344:1645.

26. Kapma MR, Verhoeven EL, Tielliu IF, Zeebregts CJ, Prins TR, Van der Heij B, Van den Dungen JJ. Endovascular treatment of acute abdominal aortic aneurysm with a bifurcated stent graft. Eur J Vasc Endovasc Surg. 2005;29:510-515.

27. Hoornweg LL, Wisselink W, Vahl A, Balm R. The Amsterdam Acute Aneurysm Trial: suitability and application rate for endovascular repair of ruptured abdominal aortic aneurysms. Eur J Vasc Endovasc Surg. 2007;33:679-683.

28. Acosta S, Lindblad B, Zdanowski Z. Predictors for outcome after open and endovascular repair of ruptured abdominal aortic aneurysms. Eur J Vasc Endovasc Surg. 2007;33:277-284.

29. Franks S, Lloyd G, Fishwick G, Bown M, Sayers R. Endovascular treatment of ruptured and symptomatic abdominal aortic aneurysms. Eur J Vasc Endovasc Surg. 2006;31:345-350.

30. Peppelenbosch N, Geelkerken RH, Soong C, Cao P, Steinmetz OK, Teijink JAW, Lepantalo M, De Letter J, Vermassen FE, DeRose G, Buskens E, Buth J. Endograft treatment of ruptured abdominal aortic aneurysms using the Talent aortouniiliac system: an international multicenter study. J Vasc Surg. 2006;43:1111-1123.

31. Reichart $M$, Geelkerken RH, Huisman $A B$, van Det RJ, de Smit P, Volker EP. Ruptured abdominal aortic aneurysm: endovascular repair is feasible in $40 \%$ of patients. Eur J Vasc Endovasc Surg. 2003;26: 479-486.

32. Visser JJ, Bosch JL, Hunink MG, van Dijk LC, Hendriks JM, Poldermans D, van Sambeek MR. Endovascular repair versus open surgery in patients with ruptured abdominal aortic aneurysms: clinical outcomes with 1-year follow-up. J Vasc Surg. 2006;44:1148-1155.

33. Yilmaz N, Peppelenbosch N, Cuypers PW, Tielbeek AV, Duijm LE, Buth J. Emergency treatment of symptomatic or ruptured abdominal aortic aneurysms: the role of endovascular repair. J Endovasc Ther. 2002;9:449-457.

34. Mehta M, Taggert J, Darling RC, 3rd, Chang BB, Kreienberg PB, Paty PS, Roddy SP, Sternbach Y, Ozsvath KJ, Shah DM. Establishing a protocol for endovascular treatment of ruptured abdominal aortic aneurysms: outcomes of a prospective analysis. J Vasc Surg. 2006;44:1-8.

35. Drury D, Michaels JA, Jones L, Ayiku L. Systematic review of recent evidence for the safety and efficacy of elective endovascular repair in the management of infrarenal abdominal aortic aneurysm. Br J Surg. 2005;92:937-946.

36. Bettex DA, Lachat M, Pfammatter T, Schmidlin D, Turina MI, Schmid ER. To compare general, epidural and local anaesthesia for endovascular aneurysm repair (EVAR). Eur J Vasc Endovasc Surg. 2001;21: 179-184.

37. Henretta JP, Hodgson KJ, Mattos MA, Karch LA, Hurlbert SN, Sternbach Y, Ramsey DE, Sumner DS. Feasibility of endovascular repair of abdominal aortic aneurysms with local anesthesia with intravenous sedation. J Vasc Surg. 1999;29:793-798.

38. Alsac JM, Desgranges P, Kobeiter H, Becquemin JP. Emergency endovascular repair for ruptured abdominal aortic aneurysms: feasibility and comparison of early results with conventional open repair. Eur J Vasc Endovasc Surg. 2005;30:632-639.

39. Anain PM, Anain JM, Sr., Tiso M, Nader ND, Dosluoglu HH. Early and mid-term results of ruptured abdominal aortic aneurysms in the endovascular era in a community hospital. J Vasc Surg. 2007;46:898-905.

40. Arya N, Makar RR, Lau LL, Loan W, Lee B, Hannon RJ, Soong CV. An intention-to-treat by endovascular repair policy may reduce overall mortality in ruptured abdominal aortic aneurysm. J Vasc Surg. 2006;44:467-471. 
41. Brandt M, Walluscheck KP, Jahnke T, Graw K, Cremer J, Muller Hulsbeck S. Endovascular repair of ruptured abdominal aortic aneurysm: feasibility and impact on early outcome. J Vasc Interv Radiol. 2005;16:1309-1312.

42. Coppi G, Silingardi R, Gennai S, Saitta G, Ciardullo AV. A single-center experience in open and endovascular treatment of hemodynamically unstable and stable patients with ruptured abdominal aortic aneurysms. J Vasc Surg. 2006;44:1140-1147.

43. Dillavou ED, Muluk SC, Makaroun MS. Improving aneurysm-related outcomes: nationwide benefits of endovascular repair. J Vasc Surg. 2006;43:446-451.

44. Greco G, Egorova N, Anderson PL, Gelijns A, Moskowitz A, Nowygrod R, Arons R, McKinsey J, Morrissey NJ, Kent KC. Outcomes of endovascular treatment of ruptured abdominal aortic aneurysms. J Vasc Surg. 2006;43:453-459.

45. Hinchliffe RJ, Bruijstens L, MacSweeney ST, Braithwaite BD. A randomised trial of endovascular and open surgery for ruptured abdominal aortic aneurysm - results of a pilot study and lessons learned for future studies. Eur J Vasc Endovasc Surg. 2006;32:506-513.

46. Larzon T, Lindgren R, Norgren L. Endovascular treatment of ruptured abdominal aortic aneurysms: a shift of the paradigm? J Endovasc Ther. 2005;12:548-555.

47. Lee WA, Hirneise CM, Tayyarah M, Huber TS, Seeger JM. Impact of endovascular repair on early outcomes of ruptured abdominal aortic aneurysms. J Vasc Surg. 2004;40:211-215.

48. Moore R, Nutley M, Cina CS, Motamedi M, Faris P, Abuznadah W. Improved survival after introduction of an emergency endovascular therapy protocol for ruptured abdominal aortic aneurysms. J Vasc Surg. 2007;45:443-450.

49. Ockert S, Schumacher H, Bockler D, Megges I, Allenberg JR. Early and midterm results after open and endovascular repair of ruptured abdominal aortic aneurysms in a comparative analysis. J Endovasc Ther. 2007;14:324-332.

50. Resch T, Malina M, Lindblad B, Dias NV, Sonesson B, Ivancev K. Endovascular repair of ruptured abdominal aortic aneurysms: logistics and short-term results. J Endovasc Ther. 2003;10:440-446.

51. Vaddineni SK, Russo GC, Patterson MA, Taylor SM, Jordan WD, Jr. Ruptured abdominal aortic aneurysm: a retrospective assessment of open versus endovascular repair. Ann Vasc Surg. 2005;19: 782-786.

52. Egorova N, Giacovelli J, Greco G, Gelijns A, Kent CK, McKinsey JF. National outcomes for the treatment of ruptured abdominal aortic aneurysm: Comparison of open versus endovascular repairs. J Vasc Surg. 2008;48:1092-1100.e1092.

53. Ohki T, Veith FJ. Endovascular grafts and other image-guided catheter-based adjuncts to improve the treatment of ruptured aortoiliac aneurysms. Ann Surg. 2000;232:466-479.

54. van Sambeek MR, van Dijk LC, Hendriks JM, van Grotel M, Kuiper JW, Pattynama PM, van Urk $H$. Endovascular versus conventional open repair of acute abdominal aortic aneurysm: feasibility and preliminary results. J Endovasc Ther. 2002;9:443-448.

55. Verhoeven EL, Prins TR, van den Dungen JJ, Tielliu IF, Hulsebos RG, van Schilfgaarde R. Endovascular repair of acute AAAs under local anesthesia with bifurcated endografts: a feasibility study. J Endovasc Ther. 2002;9:729-735.

56. Dalainas I, Nano G, Bianchi P, Stegher S, Casana R, Malacrida G, Tealdi DG. Endovascular techniques for the treatment of ruptured abdominal aortic aneurysms: 7-year intention-totreat results. World J Surg. 2006;30:1809-1814; discussion 1815-1806.

57. Harkin DW, Dillon M, Blair PH, Ellis PK, Kee F. Endovascular ruptured abdominal aortic aneurysm repair (EVRAR): a systematic review. Eur J Vasc Endovasc Surg. 2007;34:673-681.

58. Mastracci TM, Garrido Olivares L, Cina CS, Clase CM. Endovascular repair of ruptured abdominal aortic aneurysms: a systematic review and meta-analysis. J Vasc Surg. 2008;47:214-221.

59. Rayt HS, Sutton AJ, London NJ, Sayers RD, Bown MJ. A systematic review and meta-analysis of endovascular repair (EVAR) for ruptured abdominal aortic aneurysm. Eur J Vasc Endovasc Surg. 2008;36:536-544. 
60. Visser JJ, van Sambeek MR, Hamza TH, Hunink MG, Bosch JL. Ruptured abdominal aortic aneurysms: endovascular repair versus open surgery--systematic review. Radiology. 2007;245:122-129.

61. Abou-Zamzam AM, Jr., Ballard JL. Management of sterile para-anastomotic aneurysms of the aorta. Semin Vasc Surg. 2001;14:282-291.

62. Biancari F, Ylonen K, Anttila V, Juvonen J, Romsi P, Satta J, Juvonen T. Durability of open repair of infrarenal abdominal aortic aneurysm: a 15-year follow-up study. J Vasc Surg. 2002;35: 87-93.

63. Hallett JW, Jr., Marshall DM, Petterson TM, Gray DT, Bower TC, Cherry KJ, Jr., Gloviczki P, Pairolero PC. Graft-related complications after abdominal aortic aneurysm repair: reassurance from a 36-year population-based experience. J Vasc Surg. 1997;25:277-284; discussion 285-276.

64. Curl GR, Faggioli GL, Stella A, D'Addato M, Ricotta JJ. Aneurysmal change at or above the proximal anastomosis after infrarenal aortic grafting. J Vasc Surg. 1992;16:855-859; discussion 859-860.

65. Crawford ES, Beckett WC, Greer MS. Juxtarenal infrarenal abdominal aortic aneurysm. Special diagnostic and therapeutic considerations. Ann Surg. 1986;203:661-670.

66. Treiman GS, Weaver FA, Cossman DV, Foran RF, Cohen JL, Levin PM, Treiman RL. Anastomotic false aneurysms of the abdominal aorta and the iliac arteries. J Vasc Surg. 1988;8:268-273.

67. Locati P, Socrate AM, Costantini E. Paraanastomotic aneurysms of the abdominal aorta: a 15year experience review. Cardiovasc Surg. 2000;8:274-279.

68. Mulder EJ, van Bockel JH, Maas J, van den Akker PJ, Hermans J. Morbidity and mortality of reconstructive surgery of noninfected false aneurysms detected long after aortic prosthetic reconstruction. Arch Surg. 1998;133:45-49.

69. Kraus TW, Paetz B, Hupp T, Allenberg JR. Revision of the proximal aortic anastomosis after aortic bifurcation surgery. Eur J Vasc Surg. 1994;8:735-740.

70. Geller SC. Imaging guidelines for abdominal aortic aneurysm repair with endovascular stent grafts. J Vasc Interv Radiol. 2003;14:S263-264.

71. Buth J, Harris PL, van Marrewijk C. Causes and outcomes of open conversion and aneurysm rupture after endovascular abdominal aortic aneurysm repair: can type II endoleaks be dangerous? J Am Coll Surg. 2002;194(1 Suppl):S98-102.

72. Baum RA, Carpenter JP, Cope C, Golden MA, Velazquez OC, Neschis DG, Mitchell ME, Barker $\mathrm{CF}$, Fairman RM. Aneurysm sac pressure measurements after endovascular repair of abdominal aortic aneurysms. J Vasc Surg. 2001;33:32-41.

73. Walschot LH, Laheij RJ, Verbeek AL. Outcome after endovascular abdominal aortic aneurysm repair: a meta-analysis. J Endovasc Ther. 2002;9:82-89.

74. Schurink GW, Aarts NJ, van Bockel JH. Endoleak after stent graft treatment of abdominal aortic aneurysm: a meta-analysis of clinical studies. Br J Surg. 1999;86:581-587.

75. Cuypers P, Buth J, Harris PL, Gevers E, Lahey R. Realistic expectations for patients with stent graft treatment of abdominal aortic aneurysms. Results of a European multicentre registry. Eur J Vasc Endovasc Surg. 1999;17:507-516.

76. Gorich J, Rilinger N, Sokiranski R, Orend KH, Ermis C, Kramer SC, Brambs HJ, SunderPlassmann L, Pamler R. Leakages after endovascular repair of aortic aneurysms: classification based on findings at CT, angiography, and radiography. Radiology. 1999;213:767-772.

77. Drury D, Michaels JA, Jones L, Ayiku L. Systematic review of recent evidence for the safety and efficacy of elective endovascular repair in the management of infrarenal abdominal aortic aneurysm. Br J Surg. 2005;92:937-946.

78. Vallabhaneni SR, Harris PL. Lessons learnt from the EUROSTAR registry on endovascular repair of abdominal aortic aneurysm repair. Eur J Radiol. 2001;39:34-41.

79. Wolf YG, Johnson BL, Hill BB, Rubin GD, Fogarty TJ, Zarins CK. Duplex ultrasound scanning versus computed tomographic angiography for postoperative evaluation of endovascular abdominal aortic aneurysm repair. J Vasc Surg. 2000;32:1142-1148. 
80. Chaer RA, Gushchin A, Rhee R, Marone L, Cho JS, Leers S, Makaroun MS. Duplex ultrasound as the sole long-term surveillance method post-endovascular aneurysm repair: a safe alternative for stable aneurysms. J Vasc Surg. 2009;49:845-849; discussion 849-850.

81. lezzi R, Basilico R, Giancristofaro D, Pascali D, Cotroneo AR, Storto ML. Contrast-enhanced ultrasound versus color duplex ultrasound imaging in the follow-up of patients after endovascular abdominal aortic aneurysm repair. J Vasc Surg. 2009;49:552-560.

82. Manning BJ, O'Neill SM, Haider SN, Colgan MP, Madhavan P, Moore DJ. Duplex ultrasound in aneurysm surveillance following endovascular aneurysm repair: a comparison with computed tomography aortography. J Vasc Surg. 2009;49:60-65.

83. Bendick PJ, Bove PG, Long GW, Zelenock GB, Brown OW, Shanley CJ. Efficacy of ultrasound scan contrast agents in the noninvasive follow-up of aortic stent grafts. J Vasc Surg. 2003;37:381-385.

84. Heilberger P, Schunn C, Ritter W, Weber S, Raithel D. Postoperative color flow duplex scanning in aortic endografting. J Endovasc Surg. 1997;4:262-271.

85. McWilliams RG, Martin J, White D, Gould DA, Rowlands PC, Haycox A, Brennan J, Gilling Smith GL, Harris PL. Detection of endoleak with enhanced ultrasound imaging: comparison with biphasic computed tomography. J Endovasc Ther. 2002;9:170-179.

86. Napoli V, Bargellini I, Sardella SG, Petruzzi P, Cioni R, Vignali C, Ferrari M, Bartolozzi C. Abdominal aortic aneurysm: contrast-enhanced US for missed endoleaks after endoluminal repair. Radiology. 2004;233:217-225.

87. Sun Z. Diagnostic value of color duplex ultrasonography in the follow-up of endovascular repair of abdominal aortic aneurysm. J Vasc Interv Radiol. 2006;17:759-764.

88. Sangiorgi G, D'Averio R, Mauriello A, Bondio M, Pontillo M, Castelvecchio S, Trimarchi S, Tolva V, Nano G, Rampoldi V, Spagnoli LG, Inglese L. Plasma levels of metalloproteinases-3 and -9 as markers of successful abdominal aortic aneurysm exclusion after endovascular graft treatment. Circulation. 2001;104(12 Suppl 1):I288-295.

89. Hovsepian DM, Ziporin SJ, Sakurai MK, Lee JK, Curci JA, Thompson RW. Elevated plasma levels of matrix metalloproteinase- 9 in patients with abdominal aortic aneurysms: a circulating marker of degenerative aneurysm disease. J Vasc Interv Radiol. 2000;11:1345-1352.

90. Lindholt JS, Vammen S, Fasting H, Henneberg EW, Heickendorff L. The plasma level of matrix metalloproteinase 9 may predict the natural history of small abdominal aortic aneurysms. A preliminary study. Eur J Vasc Endovasc Surg. 2000;20:281-285.

91. Sakalihasan N, Delvenne P, Nusgens BV, Limet R, Lapiere CM. Activated forms of MMP2 and MMP9 in abdominal aortic aneurysms. J Vasc Surg. 1996;24:127-133. 

Acute abdominal aortic aneurysms and paraanastomotic aneurysms, EVAR or open surgery? 



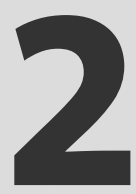

Endovascular repair is superior to open surgery for ruptured abdominal aortic aneurysms in EVAR-suitable patients

JA Ten Bosch

JAW Teijink

EM Willigendael

MH Prins

J Vasc Surg. 2010;52:13-18 


\section{Abstract}

\section{Objective}

Efficacy results of ruptured endovascular aneurysm repair (rEVAR) compared to open surgery for ruptured abdominal aortic aneurysms (rAAA) are based on several observational studies containing selection bias. In the present study rEVAR is compared with open surgery in EVAR-suitable patients with a ruptured abdominal aortic aneurysm (rAAA) who all underwent the same preoperative imaging protocol.

\section{Materials and Methods}

Our policy is to perform a CTA on all patients with a suspected rAAA. rEVAR was performed when the rEVAR-vascular surgeon was on call and the rAAA was EVARsuitable. Afterwards, two experienced independent blinded experts assessed all CTA scans on EVAR-suitability. Only EVAR-suitable patients were included in the main analyses. Outcome parameters included: intra-operative, 30-day and 6-month mortality, complications, re-interventions, and length of hospital stay.

\section{Results}

From April 2002 until March 2008, 132 consecutive patients with suspected rAAA were presented. In 104 patients rAAA was confirmed by preoperative CTA scan. Of these, 25 patients underwent rEVAR and 79 underwent open surgery. In retrospect all 25 rEVAR patients and 33 patients in the open group were judged EVAR-suitable by the experts. At baseline there was an equal distribution of patients' physiologic and anatomic characteristics as well as co-morbidity. In EVAR-suitable patients, the intra-operative, 30day and 6-month mortality was $4.0 \%(1 / 25), 20.0 \%(5 / 25)$ and $28.0 \%(7 / 25)$ after rEVAR compared to $6.1 \%(2 / 33)(P=1.00), 45.5 \%(15 / 33)(P=0.04)$ and $54.5 \%(18 / 33)(P=0.04)$ after open surgery, respectively. Median length of hospital stay was 9.5 days (interquartile range 5.0-20.5) after rEVAR and 17.0 days (interquartile range 9.5-28.0) after open surgery $(P=0.03)$.

\section{Conclusions}

In EVAR suitable patients, an absolute perioperative mortality reduction of $25.5 \%$ of rEVAR over open surgery was found, which was still present at 6 months follow-up. These data suggest that rEVAR is a superior treatment option for EVAR-suitable patients with a ruptured AAA compared to open surgery. 


\section{Introduction}

Until 1994 ruptured abdominal aortic aneurysms (rAAA) were treated with open surgery, carrying a significant mortality and morbidity. When rupture occurs, $40 \%$ of the patients do not reach the hospital alive. ${ }^{1}$. In patients reaching the hospital and undergoing conventional open surgery, reported 30-day mortality and morbidity rates are as high as $38-49 \%$ and $56-62 \%$, respectively. ${ }^{2-6}$ Despite medical and surgical progress, there has been only a gradual decline in mortality over the past fifty years. ${ }^{3}$ This might be due to the combined effects of general anesthesia, surgical exposure, hemorrhage, and aortic clamping with lower torso ischemia-reperfusion injury. ${ }^{7}$

In 1991 Parodi et al. introduced a minimally invasive technique for abdominal aortic aneurysm (AAA) repair. This so called endovascular aneurysm repair $(E V A R)^{8}$ can be performed under local anesthesia with less blood loss and no need for aortic cross-clamping. ${ }^{9}$ In the elective setting endovascular repair has been associated with lower 30-day mortality and morbidity rates compared to open repair. ${ }^{10,11}$ Since its first description by Yusuf et al. in 1994, EVAR has successfully been used in feasible patients to treat rAAA (rEVAR). ${ }^{12}$ However, it is still open to debate whether rEVAR will lead to important improvement in outcomes compared to conventional open surgery in patients with a rAAA. Several studies compare early mortality and morbidity in endovascular repair versus open repair, ${ }^{13-22}$ most of them showing a reduction in early complications and mortality. ${ }^{13-19,21}$ In acute conditions like rAAA, truly randomized studies are difficult to perform. As a result of lack of randomization, comparative studies so far are flawed by methodological inadequacies such as selection bias, which is created by inadequate control of potential confounding secondary to inadequate patient matching. ${ }^{7}$ Patients who are selected for rEVAR constitute a lower-risk category, presumably because they need to be hemodynamically more stable for preoperative imaging and have a more favorable anatomic configuration.

In the present study, selection bias due to inadequate patient matching is eliminated by reporting a comparison of emergency endovascular repair and open surgery in patients with a rAAA who all had the same preoperative imaging protocol, irrespective of hemodynamic condition, and who were all anatomically suitable for EVAR. 


\section{Materials and Methods}

\section{Population and treatment protocol}

All patients presenting at the emergency department of a non-academic teaching hospital (Atrium Medical Center, Heerlen, the Netherlands), with clinically suspected rAAA received immediate abdominal Ultrasonography to look for presence of an AAA and signs of rupture. In patients with a suspected rAAA a computed tomography angiography (CTA) scan (nonenhanced and arterial phase acquisition) was performed within 30 minutes after presentation in order to confirm rupture and to assess EVAR suitability and AAA diameter. A multidetector 16 slice spiral CT scanner (Somaton sensation; Siemens, Forccheim, Germany) was used with the following parameters: high-speed mode capability, rotation time 0.5 seconds, table speed $24 \mathrm{~mm}$ per rotation, collimation $1.5 \mathrm{~mm}$, and a slice thickness of $3 \mathrm{~mm}$. Rupture was defined as extravasation of blood or hematoma outside the AAA on CT examination and/or hematoma outside the AAA during open repair or at autopsy. Patients with a confirmed rAAA on CTA were eligible for the study. In patients with a rAAA, the emergency treatment protocol allows hypotension to a systolic blood pressure of $70 \mathrm{~mm} \mathrm{Hg}$ to reduce the risk of ongoing bleeding, if consciousness is maintained (permissive hypotension). While the CTA scan was being performed, the vascular surgeon on call was informed. In the Atrium MC we have a mean annual rAAA rate of 22 and three vascular surgeons, two with experience in open rAAA repair (non-rEVAR-vs, both $>20$ years of experience) and one with

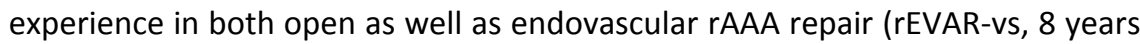
of experience). rEVAR was performed when the rEVAR-vs was on call and the CTA was suitable for EVAR according to the rEVAR-vs. Conventional open surgery was performed when the rEVAR-vs was not on call, irrespective of CTA findings (Figure 2.1). Informed consent was waved by the Institutional Review Board because the analyzed patient data was documented as part of routine clinical care. Patients' formal written informed consent was not necessary for use of data according to good clinical practice in The Netherlands.

\section{Definitions}

rEVAR was described as the endovascular repair of a rAAA. Suitability rate for rEVAR was defined as the percentage of patients with a rAAA evaluated by CTA scan, who were anatomically candidates for rEVAR. A systolic blood pressure lower than $100 \mathrm{mmHg}$ was defined as hemodynamically unstable. Cardiovascular co-morbidity included history of ischemic heart disease, cerebro- 
vascular accident (CVA) or transient ischemic attack (TIA), hypertension, cardiac failure, coronary arterial bypass graft, percutaneous transluminal coronary angioplasty, valvular disease, rhythm disorders and a history of aortic operation. Pulmonary co-morbidity was defined as the presence of at least one of the following: asthma, chronic obstructive pulmonary disease (COPD), emphysema, or lung carcinoma. Renal dysfunction was defined as a blood creatinine level higher than $140 \mu \mathrm{mol} / \mathrm{l}$. We defined diabetes mellitus (DM) as receiving either oral medication and/or insulin therapy.

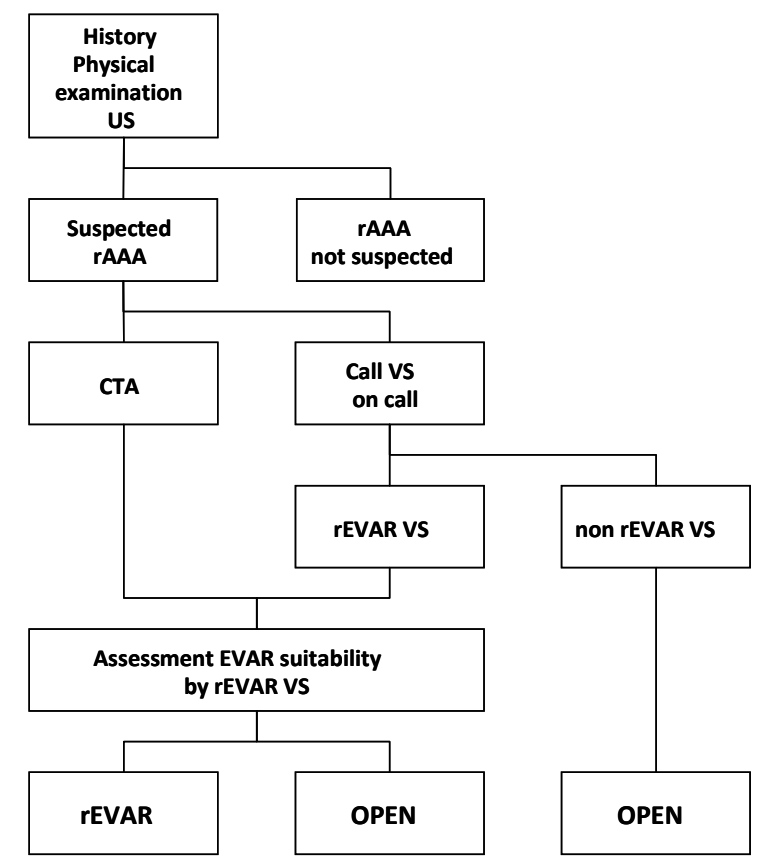

Figure 2.1 Clinical flowchart.

US=Ultrasonography, CTA=Computed Tomography Angiography, VS=vascular surgeon.

\section{Procedure}

A fully equipped operation room (OR) with a mobile C-arm imaging system (Philips Endura, Philips Medical Systems, Eindhoven, the Netherlands), trained OR-staff with EVAR experience and two angiography assistants are permanently available. Patients with a rAAA who underwent open repair received general anesthesia, whereas patients who underwent endovascular repair preferentially received local anesthesia. Open repair was performed using the regular inlay 
technique, replacing the aneurysm by a bifurcated or tube-graft and leaving the aneurysmal sac in situ. rEVAR was performed by the rEVAR-vs without the aid of an interventional radiologist, by bilateral groin incision to provide access to the common femoral artery. In case of aorto-uni-iliac stentgrafting, femoro-femoral bypass graft surgery was performed under local anesthesia in order to restore blood flow to the contralateral leg. Correct infrarenal placement of the aortouni-iliac or aorto-bi-iliac endograft was obtained with fluoroscopy and intraoperative angiography. A control angiography was performed after completion of the procedure.

Since April 2002 a standard emergency set of aorto-uni-iliac endografts and distal extender iliac device limbs (Talent ${ }^{\circledR}$, Medtronic, Santa Rosa, CA) was available, as described previously. ${ }^{19}$ Since April 2006 a full stock of bifurcated devices (Talent ${ }^{\circledR}$, Medtronic, Santa Rosa, CA) was permanently available in the OR.

\section{Clinical follow-up and outcomes}

Follow-up after rAAA repair consisted of visiting the vascular surgery outpatients department at 2 weeks, 3 and 12 months after discharge, and yearly thereafter. Follow-up imaging after open rAAA repair (ultrasound) and rEVAR (multiphasic CTA imaging - nonenhanced, arterial, and delayed phase acquisition 70 seconds after intravenous contrast medium injection) were scheduled at 3 and 12 months follow-up and yearly thereafter.

At baseline, gender, age, Body Mass Index (BMI), blood pressure, mean heart rate, blood creatinine levels and co-morbidity were recorded. The outcomes evaluated were intra-operative, 30-day and 6-month mortality, all complications, re-interventions, and length of stay in hospital. Complications were classified in deployment/procedure-related complications, implantrelated complications and systemic complications according to Reporting Standards for Endovascular Aortic Aneurysm Repair. ${ }^{23}$

\section{CTA evaluation for EVAR-suitability}

Two independent experienced external experts (product specialists of Medtronic ${ }^{\circledR}$ ), blinded for earlier evaluation and intervention as well as outcome, assessed all preoperative CTA scans on EVAR-suitability. In case of disagreement between the experts, consensus was found in collaboration with an arbiter who was also blinded for earlier evaluation, intervention, and outcome. Suitability for endovascular repair, based on CTA, was evaluated according to guidelines for elective EVAR including proximal neck length of at least $15 \mathrm{~mm}$, neck 
diameter less than $32 \mathrm{~mm}$ with less than $90^{\circ}$ angulation and less than $50 \%$ of circumferential thrombus and calcification. A conical shaped neck towards the aneurysm was considered to be unfavorable for endovascular repair, but was addressed in the view of other anatomical contra-indications. Furthermore, access vessels had to be larger than $6 \mathrm{~mm}$ without severe iliac tortuosity to accommodate the introducer sheaths.

\section{Patients and study design}

Inclusion criteria for the main analyses were ruptured AAA, availability of a preoperative computed tomography angiography (CTA) scan and suitability for endovascular repair on CTA scan according to the experts. The primary comparison of this prospective controlled study concerned consecutive patients with a ruptured AAA on preoperative CTA who were considered suitable for endovascular repair. EVAR suitable patients who received rEVAR were compared to EVAR suitable patients who received open surgery.

\section{Data analysis}

Statistical analyses were performed with the SPSS statistical software package for Windows (Microsoft, Redmond, Wash), version 15.0 (SPSS inc, Chicago, III). Patient characteristics, clinical outcomes and follow-up were compared in patients with a rAAA undergoing rEVAR versus conventional open repair using the Chi-square test or Fisher's Exact test, student's $t$-test, and Mann Whitney Utest (two-sided; $\alpha=0.05$ ). Categorical variables were presented as frequency with percentages. Nominal variables were expressed as mean \pm standard deviation (SD) for a normal distribution and for a skewed distribution in terms of median and inter-quartile-range (IQR). Values of $P<0.05$ were considered statistically significant.

\section{Results}

\section{Population}

Between April 2002 and March 2008, 132 patients had a suspected rAAA. In 28 patients (21\%) a CTA was not performed: 6 patients were deemed unfit for any treatment, in 7 cases the CTA scanner was not instantly available within 30 minutes after presentation, in 1 case the rAAA was revealed during surgery since preoperative US did not show an AAA. In the other 14 cases preoperative CTA scanning was not performed due to protocol violation by a non-rEVAR-vs, 
since CTA scanning did not influence treatment selection (rEVAR or open repair) when a non-rEVAR-vs was on call. In 104 patients a preoperative CTA scan was performed of which 58 rAAAs were considered EVAR-suitable according to the external experts (55.8\% suitability rate). Of 46 patients who were considered unsuitable, 33 (72\%) had inadequate neck length, 5 (11\%) had a neck diameter $>32 \mathrm{~mm}, 8(17 \%)$ had severe neck angulation, and $9(20 \%)$ patients had unsuitable iliac access. In patients with an EVAR-suitable rAAA, mean age was 73 years (SD 8) and $93.1 \%$ were male.

Baseline characteristics for both treatment groups were comparable (Table 2.1).

Table 2.1 Baseline characteristics.

\begin{tabular}{lccc}
\hline & rEVAR & Open surgery & P-value \\
& $\mathrm{n}=25$ & $\mathrm{n}=33$ & \\
\hline Mean age in years (SD) & $72.2(8.2)$ & $74.3(7.1)$ & 0.312 \\
Male & $22 / 25(88.0 \%)$ & $32 / 33(97.0 \%)$ & 0.305 \\
Mean BMI (SD) & $27.5(5.5)$ & $25.3(2.1)$ & 0.416 \\
Cardiovascular co-morbidity & $16 / 25(64.0 \%)$ & $24 / 33(72.7 \%)$ & 0.477 \\
Pulmonary co-morbidity & $7 / 25(28.0 \%)$ & $6 / 33(18.2 \%)$ & 0.375 \\
Renal dysfunction (creat $>140 \mu \mathrm{mol} / \mathrm{I})$ & $10 / 24(41.7 \%)$ & $9 / 33(27.3 \%)$ & 0.255 \\
Diabetes Mellitus & $3 / 25(12.0 \%)$ & $4 / 33(12.1 \%)$ & 1.000 \\
Mean AAA diameter mm (SD) & $70.8(16.7)$ & $70.4(17.6)$ & 0.932 \\
SBP <100 mmHg & $9 / 16(56.3 \%)$ & $13 / 24(54.2 \%)$ & 0.897 \\
Mean heart rate (SD) & $93.0(21.8)$ & $92.9(22.1)$ & 0.995 \\
\hline
\end{tabular}

$\mathrm{SD}=$ standard deviation, $\mathrm{BMI}=$ body-mass index, creat=blood creatinine level, $\mathrm{mm}=$ millimeter, $\mathrm{SBP}=$ systolic blood pressure, $\mathrm{mmHg}=$ millimeter Mercury.

\section{Treatment}

The rEVAR-vs was on call in 25 of the 58 EVAR suitable rAAA cases and thus rEVAR was performed (Figure 2.2, group 1; mean age 72.2 years (SD 8.2)). All 25 patients who were considered suitable for EVAR by the rEVAR-vs were considered suitable by the experts as well. None of the EVAR suitable patients, according to the experts, who presented during the time that the rEVAR-vs was on call underwent open repair. Local, spinal and general anesthesia was used in $12(48.0 \%), 5(20.0 \%)$ and $8(32.0 \%)$ patients, respectively. In 9 cases (36.0\%) a Talent bifurcated endograft was placed and in 16 cases (64.0\%) a Talent aortouni-iliac endograft, mainly because of the later introduction of the bifurcated graft.

In 33 of the 58 EVAR suitable rAAA cases open surgery was performed (Figure 2.2, group 2; mean age 74.3 years (SD 7.1)). All 33 patients received general anesthesia. In none of the patients suprarenal aortic clamping was needed, 
since all patients had aortic neck lengths that would have been suitable for rEVAR. Twenty-eight patients (84.8\%) received a tube-graft and 5 patients $(15.2 \%)$ received a bifurcated prosthesis.

\section{Mortality}

All outcomes are presented in Table 2.2. Thirty-day mortality rate after rEVAR and conventional open surgery was $20.0 \%$ (5/25) and $45.5 \%$ (15/33), respectively; accounting for a difference in mortality of $25.5 \%, 95 \% \mathrm{Cl} 0.8$ to 43.6\% ( $P=0.04)$. In the rEVAR group three patients died from progressive cardiac failure, one patient from a septic state with multi-organ failure and one patient from extensive ischemia of the sigmoid for which no further treatment was instigated.

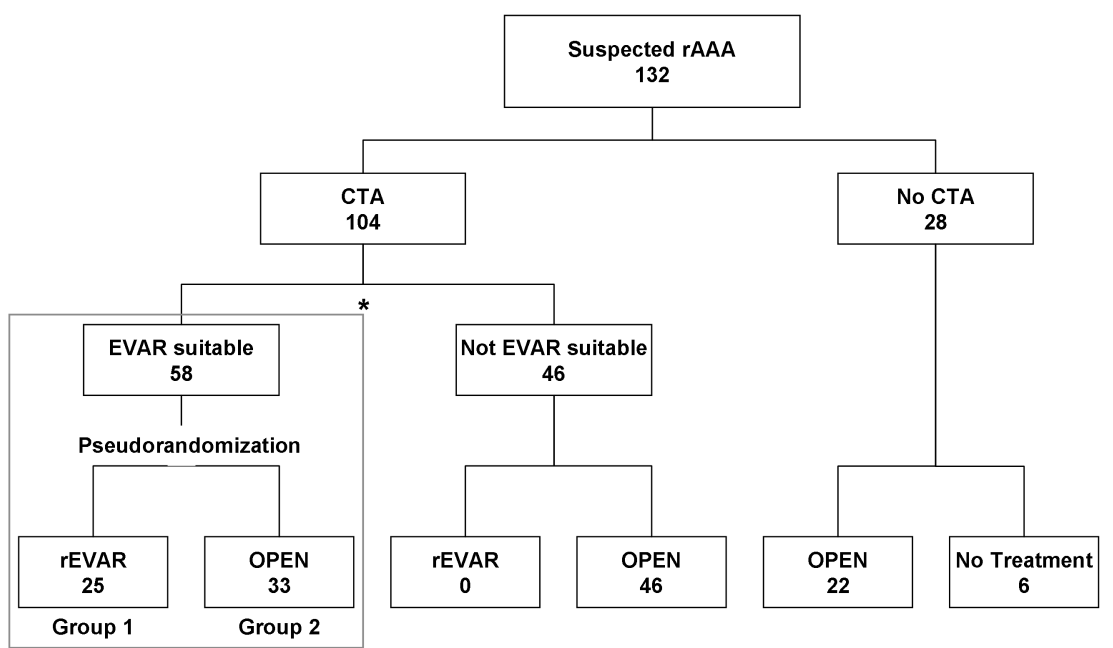

Figure 2.2 Study flowchart.

CTA=Computed Tomography Angiography.

* = assessment on EVAR suitability in retrospect by 2 independent experienced reviewers.

For the patients in the open surgery group the causes of death were cardiac arrest $(n=6)$, infectious complications $(n=4)$, ongoing bleeding resulting in multi organ failure $(n=3)$, abdominal compartment syndrome $(n=1)$ and respiratory failure $(n=1)$. After 6 months of follow-up, the difference in mortality rate 
remained (28.0\% after rEVAR and $54.5 \%$ after open surgery) with a difference of $26.5 \%, 95 \% \mathrm{Cl} 0.8$ to $47.6 \%(P=0.04)$.

\section{Complications}

Follow-up varied from 6 months to 6 years. In both treatment groups 6 patients needed a re-intervention with a re-intervention rate of $24.0 \%$ after rEVAR and $18.2 \%$ after open surgery, which was not statistically significant $(P=0.59)$. Reinterventions in the rEVAR group were performed for endoleak $(n=3)$, endograft infection needing replacement by a rifampicin soaked bifurcated prosthesis $(n=1)$, endograft obstruction $(n=1)$, and ischemia of the sigmoid colon $(n=1)$. Reinterventions after open repair of the rAAA were performed for intra-abdominal bleeding $(n=2)$, ischemic colon $(n=1)$, anastomotic aneurysm with an aortoenteral fistula $(n=1)$, and increasing renal dysfunction needing a dialysis catheter $(n=1)$. One patient required two re-interventions for both intraabdominal bleeding and an ischemic colon.

Overall complication rates were similar in both treatment groups, 56.0\% after endovascular repair and $63.6 \%$ after open repair $(P=0.56)$. No statistical significance was found between the treatment groups regarding deployment/procedure related complications, implant related complications and systemic complications.

In 6 patients $(24.0 \%)$ treated with endovascular repair an endoleak was detected during follow-up, showing a type II endoleak in 5 patients (20.0\%) and a type I endoleak for which an extension was placed in 1 patient (4.0\%). Median postoperative length of hospital stay was significantly reduced in patients treated with rEVAR compared to open surgery, 9.5 (IQR: 5.0-20.5) days and 17.0 (IQR: 9.5-28.0) respectively $(P=0.03)$.

\section{Additional findings}

Of the 46 patients (Figure 2.2) who were not EVAR suitable on pre-operative CTA scan, 30-day and 6-month mortality rates were $47.8 \%(n=22)$ and $58.7 \%$ $(n=27)$, respectively. Of the 28 patients who had no pre-operative CTA scan, 30day and 6-month mortality rates were $50.0 \%(n=14)$ and $71.4 \% \quad(n=20)$, respectively. 
Table 2.2 Intra-operative, 30-day and 6-month mortality, complications, re-interventions and admissions.

\begin{tabular}{|c|c|c|c|}
\hline & $\begin{array}{c}\text { rEVAR } \\
n=25\end{array}$ & $\begin{array}{c}\text { Open surgery } \\
n=33\end{array}$ & $\overline{P \text {-value }}$ \\
\hline Intra-operative mortality & $1(4.0 \%)$ & $2(6.1 \%)$ & 1.000 \\
\hline 30-day mortality & $5(20.0 \%)$ & $15(45.5 \%)$ & 0.043 \\
\hline 6-month mortality & $7(28.0 \%)$ & $18(54.5 \%)$ & 0.043 \\
\hline Overall complication rate* & $14(56.0 \%)$ & $21(63.6 \%)$ & 0.556 \\
\hline Complications requiring surgical intervention & $6(24.0 \%)$ & $6(18.2 \%)$ & 0.588 \\
\hline Deployment/procedure related complications* & $7(28.0 \%)$ & $11(33.3 \%)$ & 0.664 \\
\hline Extensive peroperative bleeding & $2(8,0 \%)$ & $8(24.2 \%)$ & 0.163 \\
\hline Aortic dissection & $0(0 \%)$ & $0(0 \%)$ & - \\
\hline Arterial perforation or rupture & $1(4.0 \%)$ & $2(6.1 \%)$ & 1.000 \\
\hline Peripheral embolization & $0(0 \%)$ & $0(0 \%)$ & - \\
\hline Access site hematoma & $1(4.0 \%)$ & $0(0 \%)$ & 0.431 \\
\hline False aneurysm & $0(0 \%)$ & $0(0 \%)$ & - \\
\hline Access site lymphocele/lymphorrhea/lymphedema & $0(0 \%)$ & $0(0 \%)$ & - \\
\hline Access site infection & $3(12.0 \%)$ & $0(0 \%)$ & 0.075 \\
\hline Fever of unknown origin ( $<6$ days after surgery) & $3(12.0 \%)$ & $2(6.1 \%)$ & 0.643 \\
\hline Implant related complications* & $4(16.0 \%)$ & $5(15.2 \%)$ & 1.000 \\
\hline Anastomotic aneurysm & $0(0 \%)$ & $1(3.0 \%)$ & 1.000 \\
\hline Graft migration & $0(0 \%)$ & $0(0 \%)$ & - \\
\hline Graft infection & $1(4.0 \%)$ & $0(0 \%)$ & 0.431 \\
\hline Postoperative graft limb obstruction & $1(4.0 \%)$ & $1(3.0 \%)$ & 1.000 \\
\hline Buttock/leg claudication/ischemia & $1(4.0 \%)$ & $0(0 \%)$ & 0.431 \\
\hline Leaking prosthesis & $1(4.0 \%)$ & $3(9.1 \%)$ & 0.627 \\
\hline Systemic complications* & $7(28.0 \%)$ & $15(45.5 \%)$ & 0.175 \\
\hline Cardiac & $3(12.0 \%)$ & $5(15.2 \%)$ & 1.000 \\
\hline Pulmonary & $2(8.0 \%)$ & $5(15.2 \%)$ & 0.687 \\
\hline Renal insufficiency & $0(0 \%)$ & $1(3.0 \%)$ & 1.000 \\
\hline Bowel ischemia & $2(8.0 \%)$ & $3(9.1 \%)$ & 1.000 \\
\hline Sepsis & $1(4.0 \%)$ & $3(9.1 \%)$ & 0.627 \\
\hline Abdominal compartment syndrome & $0(0 \%)$ & $1(3.0 \%)$ & 1.000 \\
\hline Postoperative days in hospital (IQR) † & $9.5(5.0-20.5)$ & $17(9.5-28.0)$ & 0.032 \\
\hline
\end{tabular}

* Number of patients with one or more complications. + Data is presented as median (interquartile-range)

\section{Discussion}

We found a reduced 30-day mortality of rEVAR compared to open repair which remained for 6 months after surgery in patients with a ruptured AAA who underwent preoperative CTA scanning and who were all anatomically suitable for endovascular repair. The mortality rate among the EVAR suitable patients treated with open surgery was similar to the rate in patients who were anatomically unsuitable for EVAR or in patients without preoperative CTA scan. 
Open surgery as well as endovascular repair showed early mortality rates corresponding with the literature. ${ }^{13-17,19,20,24-35}$ However, most of these studies did not report on patients' co-morbidity. Note that in our setting we have the intention to treat all patients presenting with a ruptured AAA, irrespective of patients' co-morbidity and hemodynamic stability. Furthermore, these studies have a higher potential for selection bias, assigning patients who were hemodynamically stable enough to undergo preoperative imaging and who had a potentially more favorable anatomic configuration to the EVAR group. Two Dutch studies attempted to compare rEVAR versus open repair more adequately, one by focusing on hemodynamically stable patients ${ }^{20}$ and the other by relying on an intention-to-treat by EVAR protocol. ${ }^{32}$ However, despite these methodological adjustments, the potential for selection bias was still present.

Our study was based on the fact that of three vascular surgeons in the Atrium $M C$, only one performed EVAR in patients with a ruptured AAA. Furthermore, all patients underwent preoperative CTA as part of a uniform protocol in our emergency department. However, patients who were considered EVAR-suitable could only be treated by EVAR if the rEVAR-vs was on call. Suitability for EVAR was retrospectively determined (confirmed for the rEVAR treated group) in all patients by experienced, external, blinded experts.

Although this study is not randomized, selection bias regarding to anatomical or hemodynamical criteria in the presented setup is highly unlikely. Moreover, all outcomes were recorded prospectively. Therefore, the present study provides a fair comparison between EVAR and open repair.

\section{Limitations of the study}

In 28 patients (21\%) no CTA was performed. These patients could not be evaluated for EVAR suitability. Furthermore, suitability for EVAR was assessed in retrospect based on anatomical criteria, whereas EVAR suitability in daily practice is also based on logistic considerations. Furthermore, this study is limited to one non-academic teaching hospital, so individual experience of the three involved surgeons could be of influence.

\section{Future need of a RCT}

Based on the mentioned limitations of this study, results from a randomized controlled trial comparing rEVAR with open surgery in patients with a ruptured AAA are needed. However, a pilot study showed that it is challenging to perform such a randomized study. ${ }^{22}$ Problems include obtaining informed 
consent in hemodynamically unstable patients, inclusion of patients unsuitable for either open surgery or EVAR, instant accessibility of a CT-scanner at all times, permanent availability of a vascular surgeon who is capable of performing emergency EVAR, permanent availability of a vascular team dedicated to EVAR, availability of an OR that is adequately equipped to perform EVAR and availability of a variety 'off-the-shelf' stent grafts. ${ }^{22,36,37}$ Yet, based on its relative non-invasiveness, endovascular repair is gradually more performed and data on its effectiveness in comparison to the conventional surgical approach are much needed. ${ }^{38}$

\section{Conclusion}

The present study showed an absolute 30-day and 6-month mortality reduction of $25.5 \%$ and $26.5 \%$ respectively of rEVAR over open surgery in EVAR suitable patients who underwent preoperative CTA scanning. rEVAR is accompanied with a significant reduction in postoperative length of hospital stay compared to open repair. Complication rates and re-intervention rates did not differ significantly. These data strongly suggest that rEVAR is a valuable treatment option for EVAR suitable patients with a ruptured AAA. 


\section{References}

1. Semmens JB, Norman PE, Lawrence Brown MM, Holman CD. Influence of gender on outcome from ruptured abdominal aortic aneurysm. Br J Surg 2000;87:191-194.

2. Visser JJ, van Sambeek MR, Hamza TH, Hunink MG, Bosch JL. Ruptured abdominal aortic aneurysms: endovascular repair versus open surgery--systematic review. Radiology 2007;245:122-129.

3. Bown MJ, Sutton AJ, Bell PR, Sayers RD. A meta-analysis of 50 years of ruptured abdominal aortic aneurysm repair. Br J Surg 2002;89:714-730.

4. Visser P, Akkersdijk GJ, Blankensteijn JD. In-hospital operative mortality of ruptured abdominal aortic aneurysm: a population-based analysis of 5593 patients in The Netherlands over a 10-year period. Eur J Vasc Endovasc Surg 2005;30:359-364.

5. Mureebe L, Egorova N, Giacovelli JK, Gelijns A, Kent KC, McKinsey JF. National trends in the repair of ruptured abdominal aortic aneurysms. J Vasc Surg 2008;48:1101-1107.

6. Hoornweg LL, Storm Versloot MN, Ubbink DT, Koelemay MJ, Legemate DA, Balm R. Meta analysis on mortality of ruptured abdominal aortic aneurysms. Eur J Vasc Surg. 2008;35: 558-570.

7. Dillon M, Cardwell C, Blair PH, Ellis P, Kee F, Harkin DW. Endovascular treatment for ruptured abdominal aortic aneurysm. Cochrane Database Syst Rev 2007: Cd005261.

8. Parodi JC, Palmaz JC, Barone HD. Transfemoral intraluminal graft implantation for abdominal aortic aneurysms. Ann Vasc Surg 1991;5:491-499.

9. Balm R. Endovascular repair of ruptured abdominal aortic aneurysm. Br J Surg 2008;95: 133-134.

10. Greenhalgh RM, Brown LC, Kwong GP, Powell JT, Thompson SG. Comparison of endovascular aneurysm repair with open repair in patients with abdominal aortic aneurysm (EVAR trial 1), 30-day operative mortality results: randomised controlled trial. Lancet 2004;364:843-848.

11. Prinssen M, Verhoeven EL, Buth J, Cuypers PW, van Sambeek MR, Balm R, Buskens E, Grobbee $\mathrm{DE}$, Blankensteijn JD. A randomized trial comparing conventional and endovascular repair of abdominal aortic aneurysms. N Engl J Med 2004;351:1607-1618.

12. Yusuf SW, Whitaker SC, Chuter TA, Wenham PW, Hopkinson BR. Emergency endovascular repair of leaking aortic aneurysm. Lancet 1994;344:1645.

13. Acosta S, Lindblad B, Zdanowski Z. Predictors for outcome after open and endovascular repair of ruptured abdominal aortic aneurysms. Eur J Vasc Endovasc Surg 2007;33:277-284.

14. Alsac JM, Desgranges $P$, Kobeiter $H$, Becquemin JP. Emergency endovascular repair for ruptured abdominal aortic aneurysms: feasibility and comparison of early results with conventional open repair. Eur J Vasc Endovasc Surg 2005;30:632-639.

15. Greco G, Egorova N, Anderson PL, Gelijns A, Moskowitz A, Nowygrod R, Arons R, Mckinsey J, Morrissey NJ, Kent KC. Outcomes of endovascular treatment of ruptured abdominal aortic aneurysms. J Vasc Surg 2006;43:453-459.

16. Kapma MR, Verhoeven EL, Tielliu IF, Zeebregts CJ, Prins TR, Van der Heij B, Van den Dungen JJ. Endovascular treatment of acute abdominal aortic aneurysm with a bifurcated stentgraft. Eur J Vasc Endovasc Surg 2005;29:510-515.

17. Moore R, Nutley M, Cina CS, Motamedi M, Faris P, Abuznadah W. Improved survival after introduction of an emergency endovascular therapy protocol for ruptured abdominal aortic aneurysms. J Vasc Surg 2007;45:443-450.

18. Coppi G, Silingardi R, Gennai S, Saitta G, Ciardullo AV. A single-center experience in open and endovascular treatment of hemodynamically unstable and stable patients with ruptured abdominal aortic aneurysms. J Vasc Surg 2006;44:1140-1147.

19. Peppelenbosch N, Geelkerken RH, Soong C, Cao P, Steinmetz OK, Teijink JAW, Lepantalo M, De Letter J, Vermassen FE, DeRose G, Buskens E, Buth J. Endograft treatment of ruptured abdominal aortic aneurysms using the Talent aortouniiliac system: an international multicenter study. J Vasc Surg 2006;43:1111-1123. 
20. Visser JJ, Bosch JL, Hunink MG, van Dijk LC, Hendriks JM, Poldermans D, van Sambeek MR. Endovascular repair versus open surgery in patients with ruptured abdominal aortic aneurysms: clinical outcomes with 1-year follow-up. J Vasc Surg 2006;44:1148-1155.

21. Arya N, Makar RR, Lau LL, Loan W, Lee B, Hannon RJ, Soong CV. An intention-to-treat by endovascular repair policy may reduce overall mortality in ruptured abdominal aortic aneurysm. J Vasc Surg 2006;44:467-471.

22. Hinchliffe RJ, Bruijstens L, MacSweeney ST, Braithwaite BD. A randomised trial of endovascular and open surgery for ruptured abdominal aortic aneurysm - results of a pilot study and lessons learned for future studies. Eur J Vasc Endovasc Surg 2006;32:506-513.

23. Chaikof EL, Blankensteijn JD, Harris PL, White GH, Zarins CK, Bernhard VM, Matsumura JS, May J, Veith FJ, Fillinger MF, Rutherford RB, Kent KC. Reporting standards for endovascular aortic aneurysm repair. J Vasc Surg 2002;35:1048-1060.

24. Brandt M, Walluscheck KP, Jahnke T, Graw K, Cremer J, Muller Hulsbeck S. Endovascular repair of ruptured abdominal aortic aneurysm: feasibility and impact on early outcome. J Vasc Interv Radiol 2005;16:1309-1312.

25. Castelli P, Caronno R, Piffaretti G, Tozzi M, Lagana D, Carrafiello G, Cuffari S, Bacuzzi A. Ruptured abdominal aortic aneurysm: endovascular treatment. Abdom Imaging 2005;30: 263-269.

26. Franks S, Lloyd G, Fishwick G, Bown M, Sayers R. Endovascular treatment of ruptured and symptomatic abdominal aortic aneurysms. Eur J Vasc Endovasc Surg 2006;31:345-350.

27. Hechelhammer L, Lachat ML, Wildermuth S, Bettex D, Mayer D, Pfammatter T. Midterm outcome of endovascular repair of ruptured abdominal aortic aneurysms. J Vasc Surg 2005;41:752-757.

28. Larzon T, Lindgren R, Norgren L. Endovascular treatment of ruptured abdominal aortic aneurysms: a shift of the paradigm? J Endovasc Ther 2005;12:548-555.

29. Lee WA, Hirneise CM, Tayyarah M, Huber TS, Seeger JM. Impact of endovascular repair on early outcomes of ruptured abdominal aortic aneurysms. J Vasc Surg 2004;40:211-215.

30. Oranen BI, Bos WT, Verhoeven EL, Tielliu IF, Zeebregts CJ, Prins TR, van den Dungen JJ. Is emergency endovascular aneurysm repair associated with higher secondary intervention risk at mid-term follow-up? J Vasc Surg 2006;44:1156-1161.

31. Peppelenbosch N, Cuypers PW, Vahl AC, Vermassen F, Buth J. Emergency endovascular treatment for ruptured abdominal aortic aneurysm and the risk of spinal cord ischemia. J Vasc Surg 2005;42: 608-614.

32. Peppelenbosch N, Yilmaz N, van Marrewijk C, Buth J, Cuypers P, Duijm L, Tielbeek A. Emergency treatment of acute symptomatic or ruptured abdominal aortic aneurysm. Outcome of a prospective intent-to-treat by EVAR protocol. Eur J Vasc Endovasc Surg 2003;26:303-310.

33. Reichart $M$, Geelkerken $\mathrm{RH}$, Huisman $\mathrm{AB}$, van Det RJ, de Smit $\mathrm{P}$, Volker EP. Ruptured abdominal aortic aneurysm: endovascular repair is feasible in $40 \%$ of patients. Eur J Vasc Endovasc Surg 2003;26: 479-486.

34. Resch T, Malina M, Lindblad B, Dias NV, Sonesson B, Ivancev K. Endovascular repair of ruptured abdominal aortic aneurysms: logistics and short-term results. J Endovasc Ther 2003;10:440-446.

35. Vaddineni SK, Russo GC, Patterson MA, Taylor SM, Jordan WD, Jr. Ruptured abdominal aortic aneurysm: a retrospective assessment of open versus endovascular repair. Ann Vasc Surg 2005;19: 782-786.

36. Collaborators AAAT. Amsterdam Acute Aneurysm trial: background, design, and methods. Vascular 2006;14:130-135.

37. Mehta M, Taggert J, Darling RC, 3rd, Chang BB, Kreienberg PB, Paty PS, Roddy SP, Sternbach Y, Ozsvath KJ, Shah DM. Establishing a protocol for endovascular treatment of ruptured abdominal aortic aneurysms: outcomes of a prospective analysis. J Vasc Surg 2006;44:1-8.

38. Hinchliffe RJ, Powell JT, Cheshire NJ, Thompson MM. Endovascular repair of ruptured abdominal aortic aneurysm: A strategy in need of definitive evidence. J Vasc Surg 2009;49:1077-1080. 



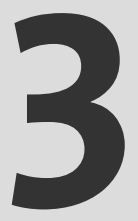

Early and midterm results of a prospective observational study comparing emergency EVAR with open surgery in both ruptured and unruptured acute abdominal aortic aneurysms

JA Ten Bosch

EM Willigendael

LM Kruidenier

ER de Loos

MH Prins

JAW Teijink

Vascular. 2012;20:72-80 


\section{Abstract}

\section{Objective}

To prospectively describe early and midterm outcomes for emergency endovascular aneurysm repair (eEVAR) versus open surgery in acute abdominal aortic aneurysms (aAA), both unruptured (symptomatic) and ruptured.

\section{Materials and Methods}

We enrolled all consecutive patients treated for aAAA at our center between April 2002 and April 2008. Main outcome parameters: 30-day, 6-, and 12-month mortality (all cause and aneurysm-related).

\section{Results}

240 patients were enrolled in the study. In the unruptured aAAA group ( $n=111), 47$ (42\%) underwent eEVAR. The 30-day, 6 - and 12 -month mortality rates were $6 \%, 13 \%, 15 \%$ in the eEVAR group versus $11 \%$ (NS), $13 \%$ (NS), $16 \%$ (NS) in the open group, respectively. In the ruptured aAAA group ( $n=129), 25$ (19\%) underwent eEVAR (mortality rates: 20\%, $28 \%, 36 \%$, respectively) compared to $104(81 \%)$ patients who underwent open surgery (mortality rates: $45 \%(P=0.021), 60 \%(P=0.004), 63 \%(P=0.014)$, respectively).

\section{Conclusions}

The present study showed a reduced 30-day, 6- and 12-month mortality of eEVAR compared to open surgery in all patients with aAAA, mainly due to a lower mortality in the ruptured aAAA group. Late aneurysm-related mortality occurred only in the eEVAR group. 


\section{Introduction}

In patients with an acute abdominal aortic aneurysm (aAAA) who are treated with conventional open surgery, perioperative morbidity and mortality remain high. Despite advances in surgical and anesthetic techniques, aortic graft materials and design, and perioperative care, mortality has declined only gradually in recent decades. ${ }^{1,2} \mathrm{~A}$ review of the literature on emergency open surgical repair for symptomatic unruptured aAAA found a 30-day or in-hospital mortality rate of $15.8 \%$ (207 of 1312 patients). ${ }^{3}$ For patients with ruptured AAA who do arrive at the hospital alive and undergo emergency open surgery, operative mortality has been estimated at approximately $48 \%{ }^{2}$

Since the first reported successful endovascular aneurysm repair (EVAR) in 1991 by Parodi et al, ${ }^{4}$ this technique has been embraced for repair of AAA in the elective setting, with reduced early morbidity and mortality compared to conventional open surgical repair. ${ }^{5-7}$ In the setting of aAAA, emergency EVAR (eEVAR) has successfully been introduced to treat feasible patients since $1994 .^{8}$ Several observational studies have compared eEVAR with open surgery, ${ }^{9-17}$ and most observed a reduction in early complications and mortality with eEVAR. $^{9-13,15,17}$ Systematic reviews of these studies have estimated an absolute reduction in early mortality of approximately $16 \%$ with eEVAR versus open surgery. ${ }^{18-20}$ This reduction has been attributed to the combined effect of minimal surgical exposure, the use of local anesthesia, and avoidance of aortic cross clamping. $^{21}$

However, in patients treated with EVAR, the aneurysm is left intact. Late stent graft related complications, as observed in approximately $40 \%$ of patients by 4 years after EVAR in the elective setting according to the EVAR 1 trial $^{7}$ might result in ongoing risk of rupture and therefore ongoing risk of implant or procedure related (aneurysm-related) mortality. However, in the acute setting, most studies only report 30-day or in-hospital mortality. Furthermore, these studies focused mainly on patients who underwent emergency repair of ruptured aAAA leaving unruptured aAAA out of consideration. ${ }^{3}$. Despite of lacking evidence, emergency open repair of unruptured acute aneurysm, in order to prevent hemodynamic instability related to aneurysm rupture, is a widely accepted practice. ${ }^{22,23}$ Therefore, not only short but also longer-term efficacy results of patients treated with eEVAR or open repair for unruptured as well as ruptured aAAA are needed. 
The present study expands upon a previous report ${ }^{24}$ and describes the early and 1-year results of a prospective single-center observational study comparing emergency EVAR with open surgery for both ruptured and unruptured acute AAA.

\section{Materials and Methods}

\section{Patients and baseline characteristics}

All consecutive patients treated for aAAA between April 2002 and April 2008 were eligible for the study. After 4 months of gaining experience with performing endovascular repair in patients with an aAAA, April 2002 marked the initiation of routinely performing eEVAR.

Acute AAA was categorized as either unruptured or ruptured. An unruptured (symptomatic) aAAA was defined as the existence of an AAA with acute onset of abdominal or back pain combined with pain at aneurysm palpation. Rupture was defined as extravasation of blood/contrast or hematoma outside the AAA on computed tomography angiography (CTA) examination and/or hematoma outside the AAA during open repair.

Systolic blood pressure was recorded at arrival at the emergency department. Baseline comorbidities that were tracked included cardiovascular and pulmonary comorbidity, renal dysfunction, and diabetes mellitus. Cardiovascular comorbidity included history of ischemic heart disease, cerebrovascular accident or transient ischemic attack, hypertension, cardiac failure, coronary artery bypass graft, percutaneous transluminal coronary angioplasty, valvular disease, rhythm disorders, or history of aortic operation. Pulmonary comorbidity included the presence of at least one of the following: asthma, chronic obstructive pulmonary disease, emphysema, or lung carcinoma. Renal dysfunction was defined as a blood creatinine level higher than $140 \mu \mathrm{mol} / \mathrm{l}$. To be characterized as diabetic, the patient had to be receiving oral medication and/or insulin therapy.

\section{Treatment protocol}

Our policy is to perform a CTA scan in all patients presenting with an aAA, with the purpose of assessing EVAR suitability and/or performing the visual preparation for conventional open surgery. EVAR suitability was initially defined as a proximal neck length $>15 \mathrm{~mm}$ with $<60$ degrees angulation and access vessels large enough to accommodate the introducer sheaths. ${ }^{13}$ As time went 
by, we began accepting patients for eEVAR with more challenging anatomies, including proximal neck lengths as low as $10 \mathrm{~mm}$ and more severe angulations of aortic neck and aneurysm. Patients who were judged to be hemodynamically too unstable to undergo a CTA scan according to the attending vascular surgeon were treated with immediate open surgical repair.

The protocol allowed for permissive hypotension ${ }^{25}$ : patients with hypotension (systolic pressure $<100 \mathrm{mmHg}$ ) were accepted without massive fluid resuscitation in order to prevent further bleeding, but with maintenance of consciousness. Overall, our policy is to treat all patients with either eEVAR or open surgery, regardless of age, comorbidity, or hemodynamic condition. It was only in exceptional cases that neither treatment was provided.

\section{Procedure}

The operating room (OR) was fully equipped for EVAR as well as open surgical repair, with a mobile C-arm imaging system (Philips Endura, Philips Medical Systems, Eindhoven, the Netherlands). Patients who underwent open surgical repair received general anesthesia. Patients who underwent eEVAR preferentially received local or regional (spinal) anesthesia. In order to perform eEVAR, a bilateral groin incision was made to provide access to the common femoral artery. Correct infrarenal placement of the bifurcated or aorto-uni-iliac device was guided by fluoroscopy and intra-operative angiography. After completion of the procedure, control angiography was performed. The OR staff was trained and experienced with EVAR, and angiography staff was available 24/7. The initiation of eEVAR procedures in our center occurred with the use of the Talent aorto-uni-iliac emergency kit (Medtronic Vascular, Santa Rosa, CA). ${ }^{26}$ Since January 2006, the Talent bifurcated stent graft (Medtronic Vascular, Santa Rosa, CA) was available in a broad range of sizes and the preferred choice for treatment.

\section{Data collection}

Patient data were obtained prospectively with the use of a paper case record form added to the patient chart. Since December 2007 an electronic case record form was available.

\section{Follow-up}

Follow-up for patients who underwent open surgical repair consisted of ultrasonography and visits to the vascular surgery outpatient department 
scheduled at 3 months and 12 months post-operatively. Follow-up for patients who underwent eEVAR consisted of CTA at 3 and 12 months following the procedure and yearly thereafter. The time of follow-up ranged from 1 to 6 years.

\section{Outcome measures}

The outcomes evaluated were intra-operative, 30-day, 6- and 12-month overall as well as aneurysm-related mortality; all complications (as delineated by the reporting standards published by the Society for Vascular Surgery/American Association for Vascular Surgery ${ }^{27}$ ); re-interventions; and postoperative hospital length of stay. Complications were classified as deployment/procedure-related, implant-related, and systemic. ${ }^{27}$

\section{Data analysis}

Data were collected and analyzed using SPSS 15.0 for Windows. Patient characteristics, mortality, complications, reinterventions, and admissions were compared using the chi-square test, Student $t$-test, Mann Whitney $U$ test (twosided; $\partial=0.05$ ), and ANOVA for trends. If during subgroup analysis the estimated patient group size was below 5, a 2-sided Fisher's exact test was used. Mortality rates during follow-up were calculated on the basis of absolute patient numbers due to minimal loss to follow-up. Categorical variables are presented as frequency with percentages. Nominal variables are presented as mean \pm standard deviation (SD) for a normal distribution or as median and interquartile-range (IQR) for a skewed distribution. Values of $P<0.05$ were considered statistically significant.

\section{Results}

\section{Patient characteristics}

Between April 2002 and April 2008, a total of 246 patients presented at our center's emergency department with an aAAA. Six patients with ruptured aAAA were considered unsuitable for an intervention because of severe comorbidity in combination with a quick deterioration of hemodynamic condition (2\%). Of the remaining 240 patients, 111 (46\%) presented with unruptured aAAA and 129 (54\%) with ruptured aAAA (Figure 3.1). In 22 patients (17\%) with a ruptured aAAA a pre-operative CTA scan was not performed (in 7 cases the CTA scanner was not instantly available within 30 minutes after presentation, in 1 case the 
ruptured aAAA was revealed during surgery since preoperative US did not show an $\mathrm{AAA}$, and in the other 14 cases preoperative CTA scanning was not performed at the discretion of the attending surgeon. There was no baseline difference in mean systolic blood pressure between patients with and without pre-operative CTA scanning $(P=0.347)$. Patients who presented with unruptured aAAA were slightly younger, had a lower prevalence of renal dysfunction and a smaller diameter of the AAA compared to patients with ruptured AAA (Table 3.1). Among the patients who presented with unruptured AAA, there were significantly more males in the eEVAR group than in the open surgery group (92\% vs. $77 \%, P=0.039$ ). Otherwise, no significant differences at baseline were recorded in both unruptured and ruptured aAAA group. Among those with ruptured AAA, approximately $55 \%$ had a systolic blood pressure of $<100 \mathrm{mmHg}$.

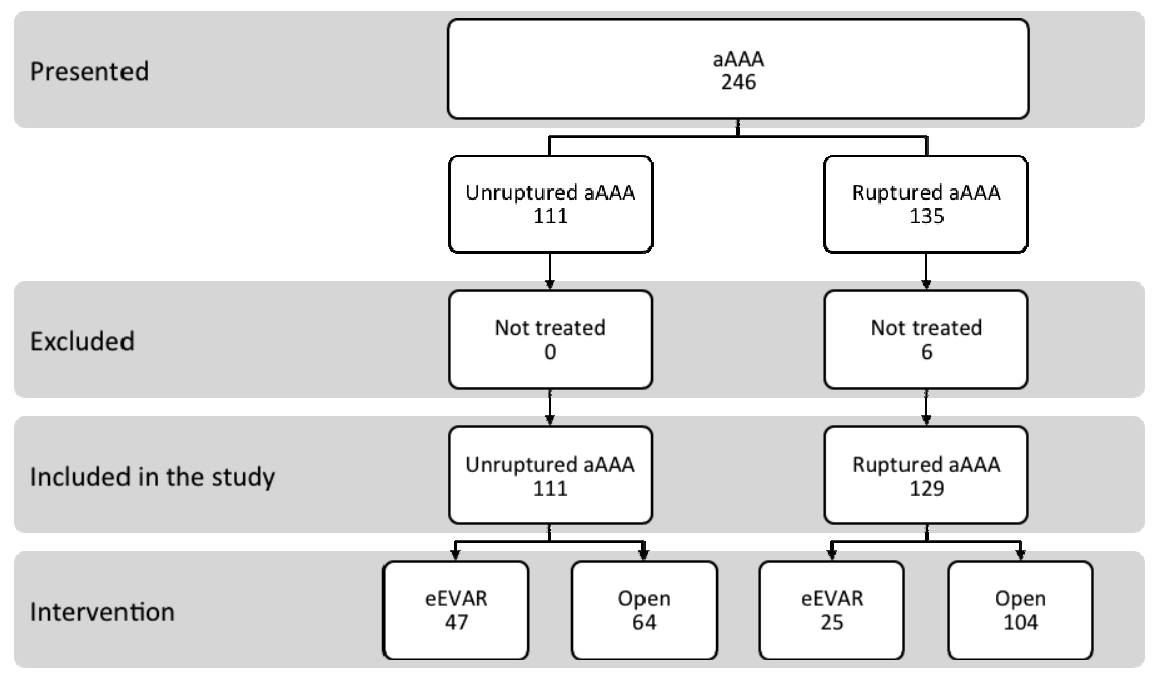

Figure 3.1 Patients with unruptured and ruptured aAAA enrolled between April 2002 and April 2008 for treatment with emergency endovascular aneurysm repair (eEVAR) or open surgery. 
Table 3.1 Baseline characteristics in 240 patients presenting with unruptured and ruptured aAAA.

\begin{tabular}{|c|c|c|c|c|c|c|c|c|}
\hline \multirow{3}{*}{ Variable } & \multicolumn{4}{|c|}{ Unruptured aAAA } & \multicolumn{4}{|c|}{ Ruptured aAAA } \\
\hline & Total & eEVAR & $\begin{array}{l}\text { Open } \\
\text { surgery }\end{array}$ & $P$ & Total & eEVAR & $\begin{array}{c}\text { Open } \\
\text { surgery }\end{array}$ & $P$ \\
\hline & $\mathrm{n}=111$ & $n=47$ & $n=64$ & & $n=129$ & $n=25$ & $n=104$ & \\
\hline $\begin{array}{l}\text { Mean age in years } \\
\text { (SD) }\end{array}$ & $\begin{array}{l}71.4 \\
(8.3)\end{array}$ & $\begin{array}{l}71.7 \\
(8.2)\end{array}$ & $\begin{array}{l}71.1 \\
(8.3)\end{array}$ & 0.725 & $\begin{array}{l}73.4 \\
(7.8)\end{array}$ & $\begin{array}{l}72.2 \\
(8.2)\end{array}$ & $\begin{array}{l}73.7 \\
(7.7)\end{array}$ & 0.416 \\
\hline Male & $\begin{array}{l}92 / 111 \\
(82.9 \%)\end{array}$ & $\begin{array}{c}43 / 47 \\
(91.5 \%)\end{array}$ & $\begin{array}{c}49 / 64 \\
(76.6 \%)\end{array}$ & 0.039 & $\begin{array}{l}114 / 129 \\
(88.4 \%)\end{array}$ & $\begin{array}{c}22 / 25 \\
(88.0 \%)\end{array}$ & $\begin{array}{l}92 / 104 \\
(88.5 \%)\end{array}$ & 1.000 \\
\hline $\begin{array}{l}\text { Mean body mass } \\
\text { index (SD) }\end{array}$ & $\begin{array}{l}25.8 \\
(4.2)\end{array}$ & $\begin{array}{l}26.1 \\
(4.5)\end{array}$ & $\begin{array}{l}25.4 \\
(3.8)\end{array}$ & 0.542 & $\begin{array}{l}26.6 \\
(4.5)\end{array}$ & $\begin{array}{l}27.5 \\
(5.5)\end{array}$ & $\begin{array}{l}26.0 \\
(3.6)\end{array}$ & 0.410 \\
\hline $\begin{array}{l}\text { Cardiovascular } \\
\text { comorbidity }\end{array}$ & $\begin{array}{l}85 / 111 \\
(76.6 \%)\end{array}$ & $\begin{array}{c}38 / 47 \\
(80.9 \%)\end{array}$ & $\begin{array}{c}47 / 64 \\
(73.4 \%)\end{array}$ & 0.362 & $\begin{array}{l}89 / 129 \\
(69.0 \%)\end{array}$ & $\begin{array}{c}16 / 25 \\
(64.0 \%)\end{array}$ & $\begin{array}{l}73 / 104 \\
(70.2 \%)\end{array}$ & 0.548 \\
\hline $\begin{array}{l}\text { Pulmonary } \\
\text { comorbidity }\end{array}$ & $\begin{array}{l}22 / 111 \\
(19.8 \%)\end{array}$ & $\begin{array}{c}12 / 47 \\
(25.5 \%)\end{array}$ & $\begin{array}{c}10 / 64 \\
(15.6 \%)\end{array}$ & 0.196 & $\begin{array}{l}29 / 129 \\
(22.5 \%)\end{array}$ & $\begin{array}{c}7 / 25 \\
(28.0 \%)\end{array}$ & $\begin{array}{l}22 / 104 \\
(21.2 \%)\end{array}$ & 0.462 \\
\hline Renal dysfunction ${ }^{a}$ & $\begin{array}{l}12 / 109 \\
(11.0 \%)\end{array}$ & $\begin{array}{c}7 / 46 \\
(15.2 \%)\end{array}$ & $\begin{array}{c}5 / 63 \\
(7.9 \%)\end{array}$ & 0.230 & $\begin{array}{l}45 / 127 \\
(35.4 \%)\end{array}$ & $\begin{array}{c}10 / 24 \\
(41.7 \%)\end{array}$ & $\begin{array}{l}35 / 103 \\
(34.0 \%)\end{array}$ & 0.478 \\
\hline Diabetes mellitus & $\begin{array}{l}11 / 111 \\
(9.9 \%)\end{array}$ & $\begin{array}{c}7 / 47 \\
(14.9 \%)\end{array}$ & $\begin{array}{c}4 / 64 \\
(6.3 \%)\end{array}$ & 0.198 & $\begin{array}{l}14 / 129 \\
(10.9 \%)\end{array}$ & $\begin{array}{c}3 / 25 \\
(12.0 \%)\end{array}$ & $\begin{array}{l}11 / 104 \\
(10.6 \%)\end{array}$ & 0.734 \\
\hline $\begin{array}{l}\text { Mean AAA diameter } \\
\mathrm{mm}(\mathrm{SD})\end{array}$ & $\begin{array}{c}64.3 \\
(16.9)\end{array}$ & $\begin{array}{c}63.3 \\
(19.0)\end{array}$ & $\begin{array}{c}65.0 \\
(15.2)\end{array}$ & 0.617 & $\begin{array}{c}73.9 \\
(17.2)\end{array}$ & $\begin{array}{c}70.8 \\
(16.7)\end{array}$ & $\begin{array}{c}74.9 \\
(17.2)\end{array}$ & 0.293 \\
\hline $\begin{array}{l}\text { Systolic BP<100 } \\
\mathrm{mmHg}\end{array}$ & $\begin{array}{c}0 / 60 \\
(0.0 \%)\end{array}$ & $\begin{array}{c}0 / 23 \\
(0.0 \%)\end{array}$ & $\begin{array}{c}0 / 37 \\
(0.0 \%)\end{array}$ & - & $\begin{array}{c}51 / 93 \\
(54.8 \%)\end{array}$ & $\begin{array}{c}9 / 16 \\
(56.3 \%)\end{array}$ & $\begin{array}{c}42 / 77 \\
(54.5 \%)\end{array}$ & 0.901 \\
\hline
\end{tabular}

$\mathrm{BP}=$ blood pressure; eEVAR=emergency endovascular aneurysm repair; $\mathrm{SD}=$ standard deviation.

${ }^{\text {a }}$ Serum creatinine level $>140 \mu \mathrm{mol} / \mathrm{l}$

\section{Procedures}

Overall, 72 of the 240 patients (30\%) were treated with eEVAR and 168 patients (70\%) with open surgical repair. Of the 111 patients with unruptured aAAA, 47 (42\%) underwent eEVAR and $64(58 \%)$ underwent open surgical repair; of the 129 patients with ruptured AAA, 25 (19\%) underwent eEVAR and 104 (81\%) underwent open surgical repair (Figure 3.1).

All 64 patients who underwent open surgery for unruptured aAAA repair had general anesthesia. Among the 47 patients treated with eEVAR, $3(6 \%)$ had local anesthesia, 40 (85\%) had spinal anesthesia, and 4 (9\%) had general anesthesia.

All 104 patients who underwent open surgery for ruptured aAAA repair had general anesthesia. Among the 25 patients with ruptured AAA treated with eEVAR, 12 (48\%) had local anesthesia, 5 (20\%) had spinal anesthesia, and 8 (32\%) had general anesthesia. 


\section{Mortality}

The intra-operative, 30-day, 6- and 12-month all cause mortality rates are listed in Table 3.2 and the aneurysm-related mortality rates are listed in Table 3.3. Two patients were lost to follow-up, one patient in the unruptured aAAA group after 8 months of follow-up and one patient in the ruptured aAAA group after 7 months of follow-up, both due to geographical inaccessibility. Among all 240 patients, the intra-operative, 30-day, 6- and 12-month mortality rates were $9(4 \%), 62(26 \%), 83(35 \%)$, and $91(38 \%)$, respectively. The mortality rate was significantly lower for aAAA patients treated with eEVAR than for those treated with open surgery at 30 -day follow-up ( $11 \%$ vs. $32 \%, P=0.001$ ), 6-month followup ( $18 \%$ vs. $42 \%, P<0.001)$, and 12 -month follow-up ( $22 \%$ vs $45 \%, P=0.001$ ). Intra-operatively, at 30 days, 6 months, and 12 months of follow-up, overall mortality was dramatically lower for patients with unruptured aAAA than for those with ruptured aAAA. This difference was registered almost entirely in the group treated with open surgery.

For the 111 patients with unruptured aAAA, all cause intra-operative, 30-day, 6and 12-month mortality rates were $0(0 \%), 10(9 \%), 14$ (13\%), and $17(16 \%)$, respectively. All cause mortality rates for patients treated with eEVAR were $0 \%$, $6 \%, 13 \%$, and $15 \%$ vs. $0 \%, 11 \%(P=0.514), 13 \%(P=0.967)$, and $16 \%(P=0.888)$ for patients treated with open surgery, respectively (Table 3.2). Increasing aneurysm-related mortality results during follow-up were observed in the eEVAR group $(0 \%, 6 \%, 9 \%, 11 \%$, respectively), whereas aneurysm-related mortality in the open repair group was stable between 1 and 12 months of follow-up (11\%) (Table 3.3, Figure 3.2). A test for comparing trends using a regression model showed significance $(P=0.028)$. No statistical differences in aneurysm-related mortality between eEVAR and open repair were observed in patients with an unruptured aAAA.

For the 129 patients with ruptured aAAA, overall intra-operative, 30-day, 6- and 12-month mortality rates were 9 (7\%), 52 (40\%), 69 (54\%), and 74 (58\%), respectively. Mortality rates for patients treated with eEVAR were $4 \%, 20 \%$, $28 \%$, and $36 \%$ vs. $8 \%(P=1.000), 45 \%(P=0.021), 60 \%(P=0.004)$, and $63 \%$ $(P=0.014)$ for patients treated with open surgery, respectively (Table 3.2). Increasing aneurysm-related mortality results during the 12 months of followup were observed in the eEVAR group (4\%, 20\%, $28 \%$ and $32 \%$, respectively), whereas aneurysm-related mortality in the open repair group seemed to be stabilized between 6 and 12 months of follow-up at approximately 58\% (Table 3.3, Figure 3.3), but trends were not significant $(P=0.349)$. Significant 
differences in aneurysm-related mortality between the treatment groups were observed at 30 days, 6 months and 12 months of follow-up.

Table 3.2 All cause mortality rates of patients with unruptured and ruptured aAAA.

\begin{tabular}{llrrrrr}
\hline & & \multicolumn{2}{c}{ eEVAR } & \multicolumn{2}{c}{ Open surgery } & \\
\cline { 2 - 5 } & & $\mathrm{n}$ & Mortality & $\mathrm{n}$ & Mortality & $P$ \\
\hline Intra-operative mortality & Unruptured aAAA & 47 & $0(0.0 \%)$ & 64 & $0(0.0 \%)$ & - \\
& Ruptured aAAA & 25 & $1(4.0 \%)$ & 104 & $8(7.7 \%)$ & 1.000 \\
& Total & 72 & $1(1.4 \%)$ & 168 & $8(4.8 \%)$ & 0.285 \\
& & & & & & \\
30-day mortality & Unruptured aAAA & 47 & $3(6.4 \%)$ & 64 & $7(10.9 \%)$ & 0.514 \\
& Ruptured aAAA & 25 & $5(20.0 \%)$ & 104 & $47(45.2 \%)$ & 0.021 \\
& Total & 72 & $8(11.1 \%)$ & 168 & $54(32.1 \%)$ & 0.001 \\
& & & & & & \\
6-month mortality & Unruptured aAAA & 47 & $6(12.8 \%)$ & 64 & $8(12.5 \%)$ & 0.967 \\
& Ruptured aAAA & 25 & $7(28.0 \%)$ & 104 & $62(59.6 \%)$ & 0.004 \\
& Total & 72 & $13(18.1 \%)$ & 168 & $70(41.7 \%)$ & $<0.001$ \\
& Unruptured aAAA & 47 & $7(14.9 \%)$ & 63 & $10(15.9 \%)$ & 0.888 \\
12-month mortality & Ruptured aAAA & 25 & $9(36.0 \%)$ & 103 & $65(63.1 \%)$ & 0.014 \\
& Total & 72 & $16(22.2 \%)$ & 166 & $75(45.2 \%)$ & 0.001 \\
\hline & & & & & &
\end{tabular}

Table 3.3 Aneurysm-related mortality rates of patients with unruptured and ruptured aAAA.

\begin{tabular}{llccccc}
\hline & & \multicolumn{2}{c}{ eEVAR } & \multicolumn{2}{c}{ Open surgery } & \\
\cline { 2 - 5 } & & $\mathrm{n}$ & Mortality & $\mathrm{n}$ & Mortality & $P$ \\
\hline Intra-operative mortality & Unruptured aAAA & 47 & $0(0.0 \%)$ & 64 & $0(0.0 \%)$ & - \\
& Ruptured aAAA & 25 & $1(4.0 \%)$ & 104 & $8(7.7 \%)$ & 1.000 \\
& Total & 72 & $1(1.4 \%)$ & 168 & $8(4.8 \%)$ & 0.285 \\
& & & & & & \\
30-day mortality & Unruptured aAAA & 47 & $3(6.4 \%)$ & 64 & $7(10.9 \%)$ & 0.514 \\
& Ruptured aAAA & 25 & $5(20.0 \%)$ & 104 & $47(45.2 \%)$ & 0.021 \\
& Total & 72 & $8(11.1 \%)$ & 168 & $54(32.1 \%)$ & 0.001 \\
& & & & & & \\
6-month mortality & Unruptured aAAA & 47 & $4(8.5 \%)$ & 64 & $7(10.9 \%)$ & 0.757 \\
& Ruptured aAAA & 25 & $7(28.0 \%)$ & 104 & $60(57.7 \%)$ & 0.008 \\
& Total & 72 & $10(13.9 \%)$ & 168 & $67(39.9 \%)$ & $<0.001$ \\
& & & & & & \\
12-month mortality & Unruptured aAAA & 47 & $5(10.6 \%)$ & 63 & $7(11.1 \%)$ & 0.937 \\
& Ruptured aAAA & 25 & $8(32.0 \%)$ & 103 & $60(58.3 \%)$ & 0.018 \\
& Total & 72 & $12(16.7 \%)$ & 166 & $67(40.4 \%)$ & $<0.001$ \\
\hline
\end{tabular}




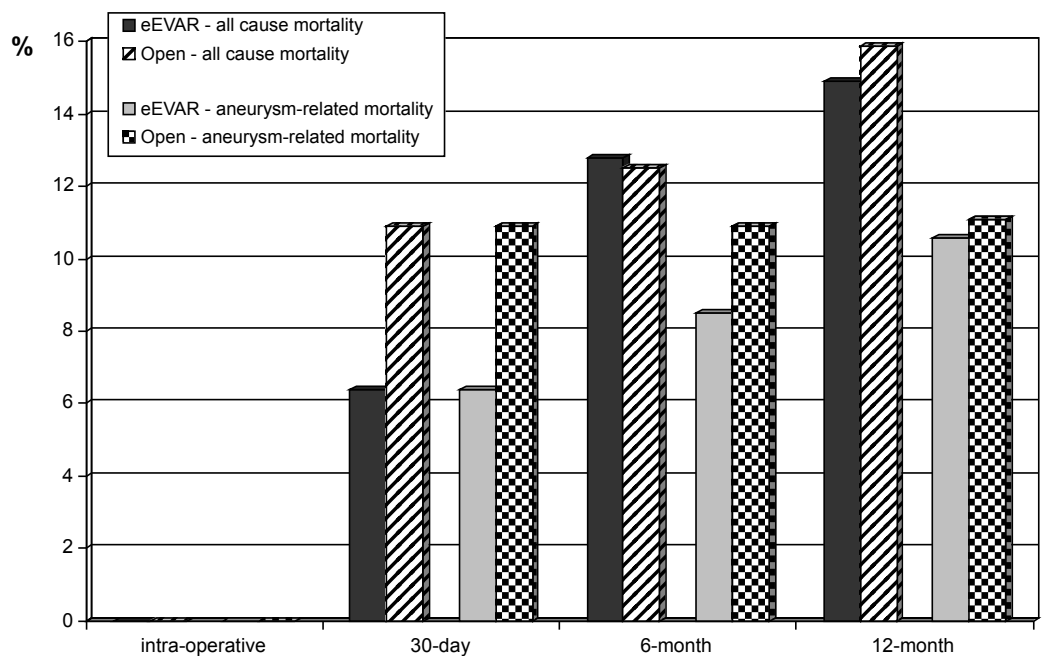

Figure 3.2 All cause and aneurysm-related mortality results of eEVAR compared to open surgery in patients with an unruptured acute (symptomatic) AAA.

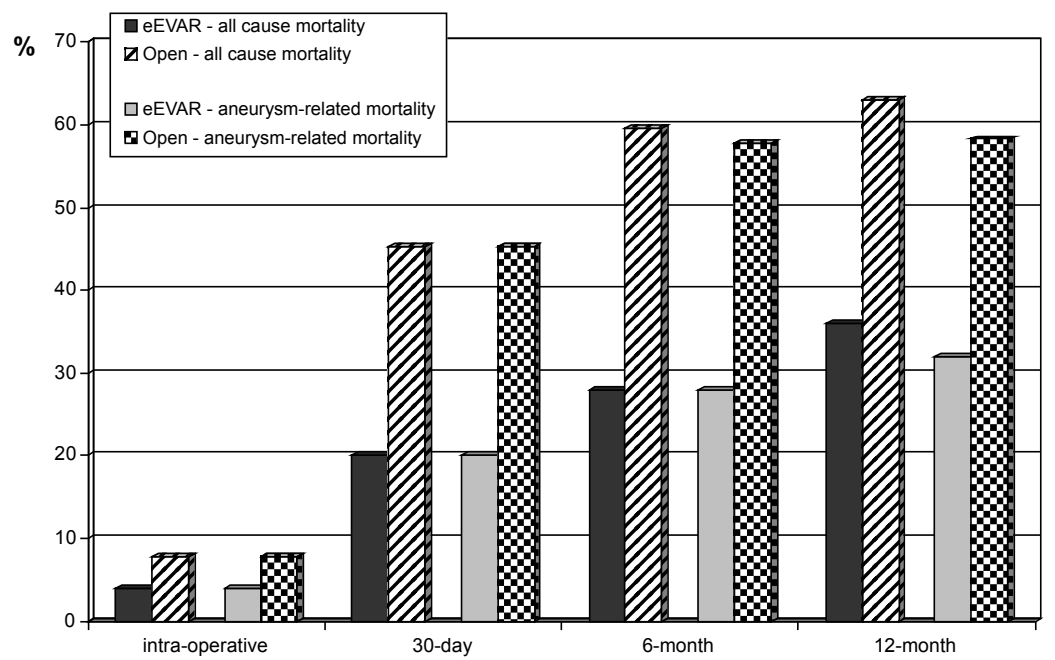

Figure 3.3 All cause and aneurysm-related mortality results of eEVAR compared to open surgery in patients with a ruptured AAA.

\section{Complications}

All complications are listed in Table 3.4. Among all patients, the overall complication rate was $47 \%(110 / 235)$, with $21 \%$ (50/240) of all patients requiring surgical re-intervention. Overall complication rates were higher in 
patients treated for ruptured aAAA (58\%) than in patients treated for unruptured aAAA (34\%).

Among patients with unruptured aAAA, the overall complication rate was similar in patients treated with eEVAR and open surgery $(P=0.935)$. However, extensive intra-operative bleeding was significantly reduced $(P=0.039)$ and postoperative fever of unknown origin was significantly more common in patients treated with eEVAR $(P=0.031)$. Surgical re-intervention was required more often in patients treated with eEVAR (13 of $47 ; 28 \%$ ) compared to those treated with open surgery ( 8 of $64 ; 13 \%)(P=0.044)$. Indications for surgical reintervention included: postoperative hemorrhage of a femoro-femoral crossover bypass $(n=2)$, thrombectomy after occlusion of a femoro-femoral crossover bypass $(n=1)$, endoleakage $(n=5)$, aortic rupture at the origin of the right renal artery $(n=1)$, sigmoidal ischemia $(n=1)$, in-stent occlusion $(n=1)$, reexploration because of severe septic shock $(n=1)$, and migration of the endograft $(n=1)$ for eEVAR and severe postoperative bleeding $(n=6)$ (in 2 cases followed by abdominal compartment syndrome), anastomotic aneurysm ( $n=1)$, and cicatricial hernia $(n=1)$ for open repair. An endoleak occurred in 15 of the $47(32 \%)$ patients treated with eEVAR: 2 type I endoleaks (4\%), and 13 type II endoleaks (28\%).

Among patients with ruptured aAAA, the overall complication rate was similar in patients treated with eEVAR and open surgery $(P=0.838)$. However, the incidence of access site infection was significantly greater for those treated with eEVAR $(P=0.007)$. Surgical re-intervention rates were comparable for both the eEVAR $(6 / 25 ; 24 \%)$ and open surgery group $(23 / 104 ; 22 \%)(P=0.839)$. An endoleak occurred in 6 of the 25 (24\%) patients treated with eEVAR, including 1 type I endoleak (4\%) for which an extension was placed and 5 type II endoleaks (20\%).

\section{Duration of hospital stay}

In patients with unruptured aAAA, median postoperative days in hospital were 3 (IQR: 2.0-7.0) after eEVAR vs. 8 (IQR: 7.0-13.8) after open surgery $(P<0.001)$ (Table 3.4). Similar results were observed in the ruptured aAAA group, showing median postoperative days in hospital of 9.5 (IQR: 5.0-20.5) after eEVAR vs. 16 (IQR: 9.0-27.0) after open surgery $(P=0.023)$. 


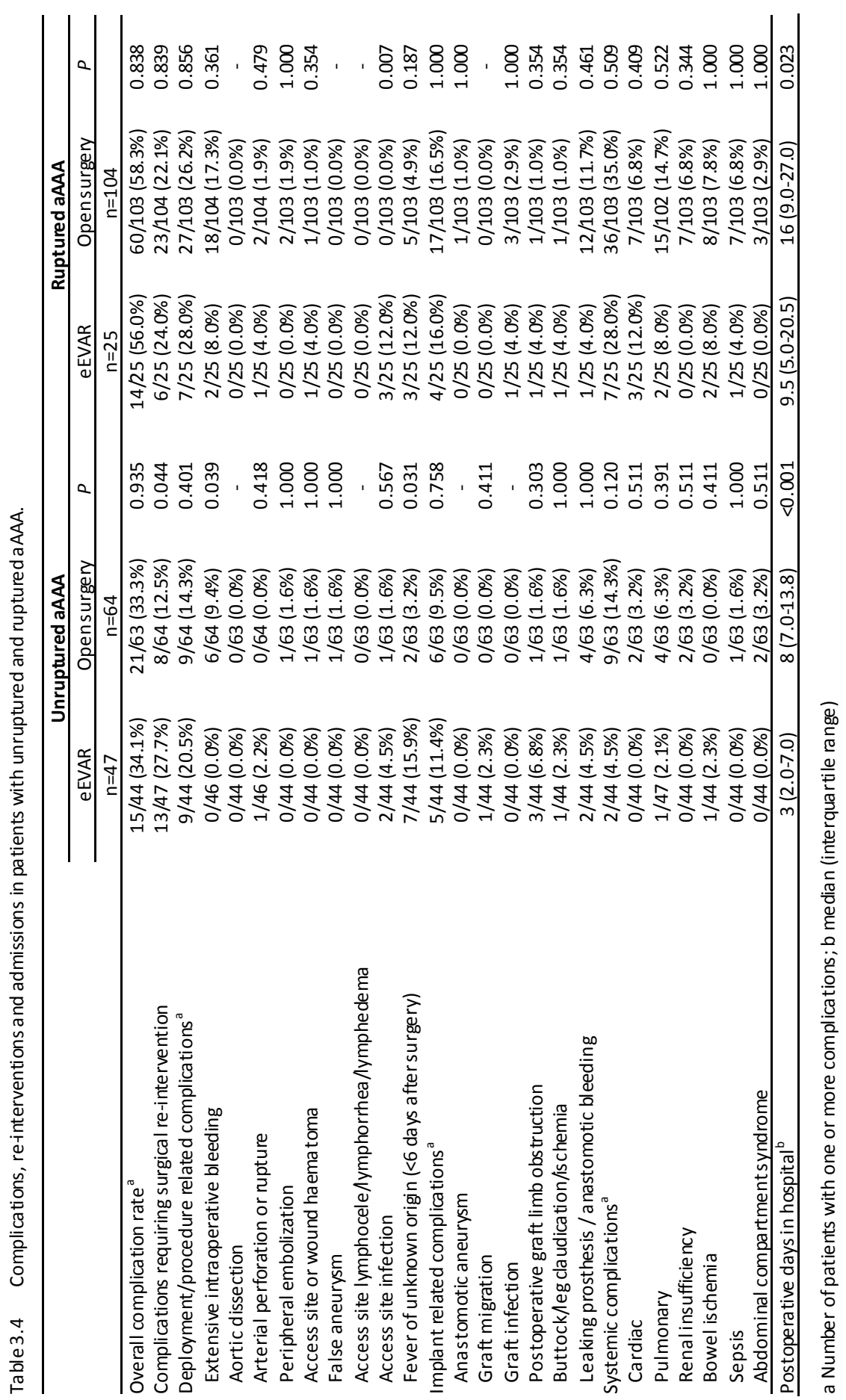




\section{Discussion}

The present study showed a reduced 30-day, 6- and 12-month all cause mortality of eEVAR compared to open surgery in all patients with acute AAA. This reduction was almost entirely due to a lower mortality in the ruptured aAAA group, while comparable mortality results were observed in patients with an unruptured aAAA. Note that late aneurysm-related mortality occurred only in the eEVAR group. Furthermore, the duration of hospitalization after eEVAR compared to open surgery in patients with unruptured aAAA and ruptured aAAA was reduced by 5 and 6.5 days, respectively.

In the present study, the ratio of unruptured to ruptured aAAA was 111:129. However, Kapma et al. described a smaller proportion of patients with unruptured aAAA (56:197). ${ }^{13}$ This difference in proportion might be attributed to a variation in definitions employed for unruptured acute AAA. We defined unruptured acute AAA as the existence of an AAA with acute onset of abdominal or back pain combined with pain at aneurysm palpation, as described by Peppelenbosch et al. ${ }^{9}$ However, abdominal pain and pain at aneurysm palpation might have causes other than an aneurysm in a state of pending rupture indicating potential false positive diagnoses. The lack of definitive criteria for acute unruptured AAA may explain the differences in incidence between studies.

In patients with ruptured aAAA, only $19 \%$ (25 of 129 ) were treated with eEVAR since availability of a vascular surgeon who is capable of performing emergency EVAR could not be guaranteed 24 hours each day. However, in case of an unruptured acute $A A A$, which can be treated more easily within routine working hours, the availability of an EVAR-experienced operating team is less problematic. Therefore, $42 \%$ (47 of 111 ) were treated by eEVAR in the unruptured aAAA group, which corresponds with the EVAR suitability rates in other studies. $^{26,28}$

The present study had several limitations. Intention to treat by eEVAR protocol was not part of the study design because availability of a vascular surgeon performing emergency EVAR in patients with ruptured AAA could not be guaranteed. Secondly, differences in baseline characteristics with more males in the unruptured eEVAR group due to a nonrandomized allocation of patients over the treatment groups prevented a proper comparison, since female gender is associated with increased mortality after both AAA and ruptured AAA repair. ${ }^{29,30}$ A third limitation involved selection bias, with anatomically favorable patients and patients with severe comorbidity preferably treated with eEVAR. In 
the present study, a non-significant trend toward a higher number of patients with severe comorbidity treated with eEVAR was observed.

The increasing trend of centers adopting an eEVAR-first approach whenever feasible is supported by comparative studies with improved outcomes regarding early morbidity, mortality, and length of hospital stay. ${ }^{17,31}$ However, there is much heterogeneity between studies, as well as selection bias and lack of generally accepted reporting standards, making comparisons and conclusions regarding the value of eEVAR in acute AAAs cumbersome. The heterogeneity includes the number of patients excluded from the studies, the percentage of patients treated by endovascular repair, the fraction of patients that undergo preoperative CTA scanning, the use of local anesthesia, the percentage of hemodynamically unstable patients, and the definition of hemodynamic stability. Furthermore, in most comparative studies, patient cohorts are small $(\mathrm{n}<50)$, especially regarding ruptured AAA. ${ }^{10-12,15}$

To withstand selection bias, randomized controlled trials are needed. Hinchliffe et al described the possibility of recruiting patients with ruptured AAA for eEVAR and open repair in a randomized study setting. ${ }^{32}$ However, to date, no large randomized controlled trials for ruptured AAA have been published. We await results from the randomized controlled Amsterdam Acute Aneurysm Trial. $^{33}$ At the same time, based on the observation of Benson et al. $^{34}$ that observational studies and randomized controlled trials usually produce similar results, and given the fact that most observational studies show reduction in early mortality after eEVAR compared to open surgery, there might be ethical issues associated with trials that randomize patients to these treatments.

In conclusion, this study showed an overall reduction in early and midterm mortality, associated with eEVAR compared to conventional open surgical repair in ruptured AAA. eEVAR is associated with a reduction of hospital stay in all acute AAA presentations, but also with a significant increase in the need for later surgical re-interventions with ongoing aneurysm-related mortality. However, due to the methodological limitations we have discussed, cautious interpretation of the results is urged. 


\section{References}

1. Heller JA, Weinberg A, Arons R, Krishnasastry KV, Lyon RT, Deitch JS, Schulick AH, Bush HL, Jr., Kent KC. Two decades of abdominal aortic aneurysm repair: have we made any progress? J Vasc Surg. 2000;32:1091-1100.

2. Bown MJ, Sutton AJ, Bell PR, Sayers RD. A meta-analysis of 50 years of ruptured abdominal aortic aneurysm repair. Br J Surg. 2002;89:714-730.

3. Leo E, Biancari F, Kechagias A, Ylonen K, Rainio P, Romsi $P$, Juvonen $T$. Outcome after emergency repair of symptomatic, unruptured abdominal aortic aneurysm: results in 42 patients and review of the literature. Scand Cardiovasc J. 2005;39:91-95.

4. Parodi JC, Palmaz JC, Barone HD. Transfemoral intraluminal graft implantation for abdominal aortic aneurysms. Ann Vasc Surg. 1991;5:491-499.

5. Prinssen M, Verhoeven EL, Buth J, Cuypers PW, van Sambeek MR, Balm R, Buskens E, Grobbee $\mathrm{DE}$, Blankensteijn JD. A randomized trial comparing conventional and endovascular repair of abdominal aortic aneurysms. N Engl J Med. 2004;351:1607-1618.

6. EVAR-trial-participants. Endovascular aneurysm repair versus open repair in patients with abdominal aortic aneurysm (EVAR trial 1): randomised controlled trial. Lancet. 2005;365:2179-2186.

7. Lederle FA, Kane RL, MacDonald R, Wilt TJ. Systematic review: repair of unruptured abdominal aortic aneurysm. Ann Intern Med. 2007;146:735-741.

8. Yusuf SW, Whitaker SC, Chuter TA, Wenham PW, Hopkinson BR. Emergency endovascular repair of leaking aortic aneurysm. Lancet. 1994;344:1645.

9. Peppelenbosch N, Yilmaz N, van Marrewijk C, Buth J, Cuypers P, Duijm L, Tielbeek A. Emergency treatment of acute symptomatic or ruptured abdominal aortic aneurysm. Outcome of a prospective intent-to-treat by EVAR protocol. Eur J Vasc Endovasc Surg. 2003;26:303-310.

10. Lee WA, Hirneise CM, Tayyarah M, Huber TS, Seeger JM. Impact of endovascular repair on early outcomes of ruptured abdominal aortic aneurysms. J Vasc Surg. 2004;40:211-215.

11. Alsac JM, Desgranges P, Kobeiter H, Becquemin JP. Emergency endovascular repair for ruptured abdominal aortic aneurysms: feasibility and comparison of early results with conventional open repair. Eur J Vasc Endovasc Surg. 2005;30:632-639.

12. Brandt M, Walluscheck KP, Jahnke T, Graw K, Cremer J, Muller Hulsbeck S. Endovascular repair of ruptured abdominal aortic aneurysm: feasibility and impact on early outcome. J Vasc Interv Radiol. 2005;16:1309-1312.

13. Kapma MR, Verhoeven EL, Tielliu IF, Zeebregts CJ, Prins TR, Van der Heij B, Van den Dungen JJ. Endovascular treatment of acute abdominal aortic aneurysm with a bifurcated stent graft. Eur J Vasc Endovasc Surg. 2005;29:510-515.

14. Coppi G, Silingardi R, Gennai S, Saitta G, Ciardullo AV. A single-center experience in open and endovascular treatment of hemodynamically unstable and stable patients with ruptured abdominal aortic aneurysms. J Vasc Surg. 2006;44:1140-1147.

15. Franks S, Lloyd G, Fishwick G, Bown M, Sayers R. Endovascular treatment of ruptured and symptomatic abdominal aortic aneurysms. Eur J Vasc Endovasc Surg. 2006;31:345-350.

16. Acosta S, Lindblad B, Zdanowski Z. Predictors for outcome after open and endovascular repair of ruptured abdominal aortic aneurysms. Eur J Vasc Endovasc Surg. 2007;33:277-284.

17. Moore R, Nutley M, Cina CS, Motamedi M, Faris P, Abuznadah W. Improved survival after introduction of an emergency endovascular therapy protocol for ruptured abdominal aortic aneurysms. J Vasc Surg. 2007;45:443-450.

18. Harkin DW, Dillon M, Blair PH, Ellis PK, Kee F. Endovascular ruptured abdominal aortic aneurysm repair (EVRAR): a systematic review. Eur J Vasc Endpvasc Surg. 2007;34:673-681.

19. Visser JJ, van Sambeek MR, Hamza TH, Hunink MG, Bosch JL. Ruptured abdominal aortic aneurysms: endovascular repair versus open surgery--systematic review. Radiology. 2007;245:122-129. 
20. Sadat U, Boyle JR, Walsh SR, Tang T, Varty K, Hayes PD. Endovascular vs open repair of acute abdominal aortic aneurysms--a systematic review and meta-analysis. J Vasc Surg. 2008;48:227-236.

21. Balm R. Endovascular repair of ruptured abdominal aortic aneurysm. Br J Surg. 2008;95: 133-134.

22. Johnson G, Jr., McDevitt NB, Proctor HJ, Mandel SR, Peacock JB. Emergent or elective operation for symptomatic abdominal aortic aneurysm. Arch Surg. 1980;115:51-53.

23. Soisalon-Soininen S, Salo JA, Perhoniemi V, Mattila S. Emergency surgery of non-ruptured abdominal aortic aneurysm. Ann Chir Gynaecol. 1999;88:38-43.

24. Ten Bosch JA, Teijink JA, Willigendael EM, Prins MH. Endovascular aneurysm repair is superior to open surgery for ruptured abdominal aortic aneurysms in EVAR-suitable patients. J Vasc Surg. 2010;52: 13-18.

25. Visser JJ, Bosch JL, Hunink MG, van Dijk LC, Hendriks JM, Poldermans D, van Sambeek MR. Endovascular repair versus open surgery in patients with ruptured abdominal aortic aneurysms: clinical outcomes with 1-year follow-up. J Vasc Surg. 2006;44:1148-1155.

26. Peppelenbosch N, Geelkerken RH, Soong C, Cao P, Steinmetz OK, Teijink JAW, Lepantalo M, De Letter J, Vermassen FE, DeRose G, Buskens E, Buth J. Endograft treatment of ruptured abdominal aortic aneurysms using the Talent aortouniiliac system: an international multicenter study. J Vasc Surg. 2006;43:1111-1123.

27. Chaikof EL, Blankensteijn JD, Harris PL, White GH, Zarins CK, Bernhard VM, Matsumura JS, May J, Veith FJ, Fillinger MF, Rutherford RB, Kent KC. Reporting standards for endovascular aortic aneurysm repair. J Vasc Surg. 2002;35:1048-1060.

28. Hoornweg LL, Wisselink W, Vahl A, Balm R. The Amsterdam Acute Aneurysm Trial: suitability and application rate for endovascular repair of ruptured abdominal aortic aneurysms. Eur J Vasc Endovasc Surg. 2007;33:679-683.

29. McPhee JT, Hill JS, Eslami MH. The impact of gender on presentation, therapy, and mortality of abdominal aortic aneurysm in the United States, 2001-2004. J Vasc Surg. 2007;45:891-899.

30. Mureebe L, Egorova N, McKinsey JF, Kent KC. Gender trends in the repair of ruptured abdominal aortic aneurysms and outcomes. J Vasc Surg. 2010;51(4 suppl):9S-13S.

31. Mehta M, Taggert J, Darling RC, 3rd, Chang BB, Kreienberg PB, Paty PS, Roddy SP, Sternbach Y, Ozsvath KJ, Shah DM. Establishing a protocol for endovascular treatment of ruptured abdominal aortic aneurysms: outcomes of a prospective analysis. J Vasc Surg. 2006;44:1-8.

32. Hinchliffe RJ, Bruijstens L, MacSweeney ST, Braithwaite BD. A randomised trial of endovascular and open surgery for ruptured abdominal aortic aneurysm - results of a pilot study and lessons learned for future studies. Eur J Vasc Endovasc Surg. 2006;32:506-513.

33. Amsterdam Acute Aneurysm trial: background, design, and methods. Vascular. 2006;14: 130-135.

34. Benson K, Hartz AJ. A comparison of observational studies and randomized, controlled trials. N Engl J Med. 2000;342:1878-1886. 



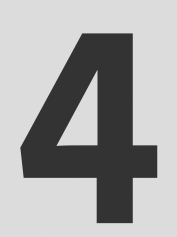

EVAR suitability is not a predictor for early and midterm mortality after open ruptured AAA repair

JA Ten Bosch

EM Willigendael

MRHM van Sambeek

ER de Loos

MH Prins

JAW Teijink

Eur J Vasc Endovasc Surg. 2011;41:647-651 


\section{Abstract}

\section{Objective}

The reported mortality reduction of emergency endovascular aneurysm repair (eEVAR) compared to open repair in patients with a ruptured abdominal aortic aneurysm (rAAA), as observed in observational studies, might be flawed by selection bias based on anatomical suitability for eEVAR. In the present study, we compared mortality in EVAR suitable versus non EVAR suitable patients with a ruptured AAA who were all treated with conventional open repair.

\section{Materials and Methods}

In all patients presenting with a suspected rAAA CTA scanning was performed. All consecutive patients with a confirmed rAAA on preoperative CTA scan and treated with open repair between April 2002 and April 2008, were included. Anatomical suitability for eEVAR was determined by two blinded independent reviewers. Outcomes evaluated were mortality (intra-operative, 30-day, and 6-month), morbidity, complications requiring re-intervention, and length of hospital stay.

\section{Results}

A total of 107 consecutive patients presented with a rAAA and underwent pre-operative CTA scanning. In 25 patient eEVAR was performed. In the 82 patients who underwent open repair CTA showed an EVAR suitable rAAA in 33 patients (40.2\%) and a non EVAR suitable rAAA in 49 patients. Thirty-day and 6-month mortality rate was 15/33 (45.5\%; $95 \% \mathrm{Cl} 28.1-63.7)$ and $18 / 33$ (54.5\%; 95\% $\mathrm{Cl} 36.4-71.9)$ in the EVAR suitable group versus 24/49 (49.0\%; 95\% Cl 34.4-63.7) ( $P=0.75)$ and 29/49 (59.2\%; 95\% Cl 44.2-73.0) $(P=0.68)$ in the non EVAR suitable group, respectively.

\section{Conclusions}

The present study suggests that anatomical suitability for EVAR is not associated with lower early and midterm mortality in patients treated with open ruptured AAA repair. Therefore, the reported reduction in mortality between eEVAR and open repair is unlikely due to selection bias based on anatomical AAA configuration. 


\section{Introduction}

Since 1994 emergency endovascular aneurysm repair (eEVAR) has successfully been used in suitable patients to treat ruptured abdominal aortic aneurysms (rAAA). ${ }^{1}$ Several comparative studies showed a reduction in early mortality from $34-46 \%$ with open surgery to $18-24 \%$ with eEVAR. ${ }^{2-7}$ However, due to lack of randomization and the potential for selection bias it is uncertain whether this mortality benefit is due to the less invasive treatment or to patient characteristics such as hemodynamic condition or anatomic considerations. ${ }^{8}$

Hemodynamical condition is reported to be associated with early mortality after open repair in several prediction models. Loss of consciousness, presence of shock and preoperative systolic blood pressure are independent predictors for mortality after rAAA repair in the Hardman Index ${ }^{9}$, Glasgow Aneurysm Score ${ }^{10}$ and the Edinburgh Ruptured Aneurysm Score ${ }^{11}$, respectively. In a systematic review of Visser et al. approximately $24 \%$ of the patients underwent open ruptured AAA repair instead of eEVAR due to hemodynamic instability. ${ }^{7}$ Therefore, comparison was biased due to an over-representation of hemodynamic unstable patients in the open repair group.

Approximately half of the patients with a rAAA are suitable for eEVAR based on anatomic considerations. ${ }^{7,12}$ Patients who are anatomically unsuitable for EVAR are treated with open repair. There is a theoretical possibility that anatomical suitability for EVAR as assessed on a preoperative computed tomography angiography (CTA) scan is independently associated with improved early and midterm mortality. However, no clear evidence supporting this assumption is available.

In the present study, we compared mortality in EVAR suitable versus non EVAR suitable patients with a ruptured AAA, who all underwent preoperative CTA imaging and who were all treated with conventional open repair.

\section{Materials and Methods}

\section{Patients}

All consecutive patients with a suspected rAAA, as confirmed by preoperative CTA scan and treated with open repair in a non-academic large teaching hospital between April 2002 and April 2008, were included. Hypotension in patients was accepted with minimal resuscitation to a systolic blood pressure of $>70 \mathrm{mmHg}$ to maintain consciousness and to prevent further bleeding (permissive hypotension). At baseline, gender, age, Body Mass Index (BMI), 
blood pressure, renal function, Hardman index, ${ }^{9}$ AAA diameter, and comorbidity were recorded.

Baseline co-morbidity was classified in cardiovascular, pulmonary, and diabetes mellitus (DM). Cardiovascular co-morbidity was defined as a history of ischemic heart disease, cerebrovascular accident (CVA) or transient ischemic attack (TIA), hypertension, cardiac failure, coronary arterial bypass graft, percutaneous transluminal coronary angioplasty, valvular disease, rhythm disorders or history of aortic operation. Pulmonary co-morbidity included presence of at least one of the following: asthma, chronic obstructive pulmonary disease (COPD), emphysema, or lung carcinoma. DM was defined as receiving either oral medication and/or insulin therapy.

\section{Definitions}

Rupture was defined as extravasation of blood or hematoma outside the AAA on CT examination, confirmed at open repair. Shock was defined as a systolic pressure lower than $100 \mathrm{mmHg}$. Suitability for endovascular repair, based on CTA, was evaluated according to guidelines for elective EVAR including proximal neck length of at least $15 \mathrm{~mm}$, neck diameter less than $32 \mathrm{~mm}$ with less than $90^{\circ}$ angulation and less than $50 \%$ of circumferential thrombus and calcification. A conical shaped neck towards the aneurysm was considered to be unfavorable for endovascular repair, but was addressed in the view of other anatomical contraindications. Furthermore, access vessels had to be larger than $6 \mathrm{~mm}$ without severe iliac tortuosity to accommodate the introducer sheaths.

\section{Methods}

In the study hospital (Atrium medical center), three vascular surgeons were experienced in open rAAA repair, one of them (eEVAR-vs) performed both open repair as well as eEVAR. All patients presenting with a suspected rAAA underwent CTA scanning. Conventional open surgery was performed when the eEVAR-vs was not on call or when the rAAA was not EVAR suitable. This strategy, instigated for logistical reasons, resulted in a number of CTA scans of patients that underwent open repair with EVAR suitable anatomy.

Retrospectively, two independent experienced reviewers, blinded for earlier evaluation, intervention, and outcome, assessed all preoperative CTA scans on suitability for EVAR. In case of disagreement between the reviewers, consensus was found in collaboration with an arbiter. Group 1 consists of patients treated with open repair who were considered suitable for eEVAR according to both 
reviewers. Group 2 consists of patients treated with open repair who were considered unsuitable for eEVAR by the reviewers.

Follow-up after open repair was performed at 2 weeks, 3 months and 1 year after hospital discharge.

\section{Clinical outcomes}

The outcomes evaluated were intra-operative, 30-day and 6-month mortality, morbidity during follow-up, complications requiring re-intervention during follow-up (as delineated by the reporting standards published by the Society for Vascular Surgery/American Association for Vascular Surgery) ${ }^{13}$, and length of hospital stay.

\section{Data analysis}

Data was collected prospectively and statistical analyses were performed with the SPSS statistical software package for Windows (Microsoft, Redmond, Wash), version 15.0 (SPSS inc, Chicago, III). Patients characteristics, clinical outcomes and follow-up were compared in rAAA patients treated with open repair who were EVAR suitable versus non EVAR suitable using the chi-square test, Fisher's exact test, Student's $t$-test, and Mann Whitney U-test (two-sided; $\alpha=0.05$ ). Categorical variables are presented as frequency with percentages. Nominal variables are expressed as mean \pm standard deviation (SD) for a normal distribution and for a skewed distribution in terms of median and inter-quartilerange (IQR). Values of $P<0.05$ were considered statistically significant. Analyses were by intention to treat.

\section{Results}

\section{Patients}

Between April 2002 and April 2008, 135 consecutive patients presented with suspected rAAA. In 28 patients (21\%) a pre-operative CTA scan was not performed ( 6 patients were deemed unfit for any treatment, in 7 cases the CTA scanner was not instantly available within 30 minutes after presentation, in 1 case the rAAA was revealed during surgery since preoperative US did not show an AAA, and in the other 14 cases preoperative CTA scanning was not performed due to protocol violation by a non-eEVAR vascular surgeon, since CTA scanning did not influence treatment selection when a non-eEVAR vascular surgeon was on call). In 107 patients a pre-operative CTA was performed, 
25 patient received eEVAR and 82 patients were treated with open repair. Of all 82 patients treated with open repair, CTA showed an EVAR suitable rAAA in 33 patients $(40.2 \%)$ and a non EVAR suitable rAAA in 49 patients, according to both external reviewers.

Baseline characteristics are listed in Table 4.1. Significantly more male patients were considered EVAR suitable on CTA. Other variables did not differ significantly at baseline. Although the mean AAA diameter was larger in patients unsuitable for eEVAR, the difference did not reach statistical significance.

Table 4.1 Baseline characteristics.

\begin{tabular}{lccccc}
\hline & \multicolumn{2}{c}{ EVAR suitable } & \multicolumn{2}{c}{ Non EVAR suitable } & P-value \\
\cline { 2 - 5 } & $\mathrm{n}=33$ & $\begin{array}{c}\text { Missing } \\
\text { values }\end{array}$ & $\mathrm{n}=49$ & $\begin{array}{c}\text { Missing } \\
\text { values }\end{array}$ \\
\hline Male & $32(97.0 \%)$ & 0 & $39(79.6 \%)$ & 0 & 0.043 \\
Mean age in years (SD) & $74.3(7.1)$ & 0 & $73.5(8.1)$ & 0 & 0.664 \\
Mean AAA diameter in mm (SD) & $70.4(17.6)$ & 0 & $76.2(17.5)$ & 0 & 0.147 \\
Mean blood creatinine level (SD) & $123.1(38.2)$ & 0 & $135.3(43.5)$ & 1 & 0.197 \\
Mean SBP in mmHg (SD) & $106.0(34.7)$ & 9 & $102.5(30.6)$ & 12 & 0.677 \\
Mean Hardman Index (SD) & $2.4(0.8)$ & 10 & $2.5(0.6)$ & 15 & 0.589 \\
Cardiovascular co-morbidity & $24(72.7 \%)$ & 0 & $35(71.4 \%)$ & 0 & 0.898 \\
Pulmonary co-morbidity & $6(18.2 \%)$ & 0 & $12(24.5 \%)$ & 0 & 0.499 \\
Diabetes Mellitus & $4(12.1 \%)$ & 0 & $4(8.2 \%)$ & 0 & 0.708 \\
\hline
\end{tabular}

$\mathrm{BMI}=$ body-mass index, $\mathrm{mm}=$ millimeter, $\mathrm{SBP}=$ systolic blood pressure, $\mathrm{mmHg}=$ millimeter Mercury.

\section{Mortality and admission}

Primary and secondary outcome results are listed in Table 4.2 and 4.3, respectively. Intra-operative, 30-day and 6-month mortality rates as well as postoperative days of hospital stay were comparable for both groups (Table 4.2). Intra-operative mortality was 2/33 (6.1\%; 95\% Cl 0.7-20.2) and 5/49 (10.2\%; 95\% Cl 3.4-22.2) in the EVAR suitable and the non EVAR suitable group, respectively $(P=0.70)$. The difference in intra-operative mortality between the groups was $4.1 \%$ (95\% Cl $0.7-20.2 \%)$. Thirty-day and 6-month mortality rate was 15/33 (45.5\%; 95\% Cl 28.1-63.7) and 18/33 (54.5\%; 95\% Cl 36.4-71.9) in the EVAR suitable group versus $24 / 49$ (49.0\%; 95\% Cl 34.4-63.7) ( $P=0.75)$ and 29/49 (59.2\%; 95\% Cl 44.2-73.0) $(P=0.68)$ in the non EVAR suitable group, respectively. The difference in mortality between the treatment groups was therefore $4.5 \%(95 \% \mathrm{Cl}-24.7-18.2 \%)$ and $4.7 \%(95 \% \mathrm{Cl}-25.9-16.6)$ after 30 days and 6 months, respectively. 
Table 4.2 Mortality rates and admissions.

\begin{tabular}{lccc}
\hline & $\begin{array}{c}\text { EVAR suitable } \\
\mathrm{n}=33\end{array}$ & $\begin{array}{c}\text { Non EVAR suitable } \\
\mathrm{n}=49\end{array}$ & $\boldsymbol{P}$-value \\
\hline Intra-operative mortality & $2(6.1 \%)$ & $5(10.2 \%)$ & 0.696 \\
30-day mortality & $15(45.5 \%)$ & $24(49.0 \%)$ & 0.754 \\
6-month mortality & $18(54.5 \%)$ & $29(59.2 \%)$ & 0.677 \\
Median postoperative days in hospital (IQR) & $17.0(9.5-28.0)$ & $15.0(9.5-33.5)$ & 0.981 \\
\hline
\end{tabular}

$I Q R=$ inter-quartile range.

Table 4.3 Re-interventions and morbidity.

\begin{tabular}{lccc}
\hline & EVAR suitable & Non EVAR suitable & P-value \\
& $\mathrm{n}=33$ & $12(24.5 \%)$ & 0.499 \\
\hline Re-intervention rate & $6(18.2 \%)$ & $17(34.7 \%)$ & 0.149 \\
Morbidity * & $17(51.5 \%)$ & $1(2.0 \%)$ & \\
Cardiac & $5(15.2 \%)$ & $5(10.2 \%)$ & \\
Pulmonary & $5(15.2 \%)$ & $4(8.2 \%)$ & \\
Renal insufficiency & $1(3.0 \%)$ & $4(8.2 \%)$ & \\
Bowel ischemia & $3(9.1 \%)$ & $3(6.1 \%)$ & \\
Sepsis & $3(9.1 \%)$ & $1(2.0 \%)$ & \\
Abdominal compartment syndrome & $1(3.0 \%)$ & $1(2.0 \%)$ & \\
Wound infection/hematoma & $0(0.0 \%)$ & $3(6.1 \%)$ & \\
Continued bleeding & $3(9.1 \%)$ & & \\
\hline
\end{tabular}

$*=$ Number of patients with one or more morbidities.

\section{Morbidity and reintervention rates}

During follow-up, which varied from 6 months to 6 years, the re-intervention rate was $18.2 \%$ and $24.5 \%$ in EVAR suitable patients and EVAR unsuitable patients, respectively $(P=0.50)$. Morbidity rate, mainly consisting of cardiac and pulmonary complications, was higher in EVAR suitable patients (51.5\%) compared to EVAR unsuitable patients (34.7\%), although not significantly $(P=0.15)$.

\section{Discussion}

Selection bias is often mentioned as a limitation in observational studies comparing endovascular with open ruptured AAA repair. The present study shows that in patients who all underwent preoperative imaging, anatomical suitability for EVAR was not associated with a lower mortality after open rAAA repair. In addition, the lower limit of the confidence interval of the 30-day mortality (28\%) in EVAR suitable patients who were treated with open repair indicates that a mortality rate of $18-24 \%$, as reported for eEVAR, ${ }^{2-5,7}$ would be 
unlikely. Hence, while hemodynamic stability to undergo preoperative imaging might favor mortality for eEVAR in observational studies, it is unlikely that the reported difference in mortality between eEVAR and open repair can (partially) be explained by treating patients with a favorable anatomic configuration with eEVAR.

In a recent meta-analysis of Hoornweg et al., including 116 observational studies, the reported overall early mortality rate of 60,822 patients undergoing open ruptured aneurysm repair was $48.5 \%$ (95\% Cl: $48.1-48.9 \%) .{ }^{14}$ The mortality observed in the current study compared well. Especially considering the fact that only 6 patients did not receive any treatment, due to severe comorbidity in combination with a quick deterioration of hemodynamic condition and old age. A recent study of Perrott et al. showed that anatomical suitability for EVAR might beneficially affect outcome following open repair in patients with a ruptured AAA (30-day mortality rate $6.9 \%$ versus $30.4 \%, P=0.066) .{ }^{15}$ However, this retrospective study had limited sample size and only $41 \%$ of the patients treated with open repair received pre-operative CTA scanning. Therefore, patients included in the main analyses were presumably hemodynamically more stable, which might influence mortality results. On the other hand, in patients treated with eEVAR for both symptomatic and ruptured AAA, Richards et al. demonstrated that adverse anatomy was associated with significant increase in graft related mortality. ${ }^{16}$ Therefore, in the acute situation, anatomical and clinical guidelines are important to be obeyed.

In the present study, all patients underwent preoperative imaging in order to assess EVAR suitability, irrespective of the patients' hemodynamical condition and irrespective of the availability of the eEVAR-vs. Primary reason was the establishment of a uniform (logistic) protocol for the intake and diagnostics of patients with a ruptured AAA in the emergency setting. Furthermore, CTA in patients treated with open repair appeared to be valuable for the assessment of the vascular anatomy prior to operation. Preoperative CTA scanning and assessment for endovascular repair is often considered to delay treatment, as patients undergoing eEVAR tend to be more hemodynamically stable compared with open repair in several observational studies. ${ }^{5}$ However, in the only randomized trial available, Hinchliffe et al. concluded that preoperative CTA scanning does not delay treatment. Furthermore, they state that patients who were so unstable that the surgeon deemed CT scanning unethical did badly with open repair and might even be those who have most to gain from endovascular repair. ${ }^{17}$ Lloyd et al. investigated the interval between admission and death in patients with a ruptured AAA who did not undergo surgery because of 
advanced age and/or comorbidities, showing a median interval of 10 hours 45 minutes (range, 1 hour 1 minute to 143 hours 55 minutes). ${ }^{18}$ This indicates that most patients with a ruptured AAA who reach the hospital alive are sufficiently stable to undergo CTA and consideration for eEVAR, as confirmed by a systematic review of Sadat et al. ${ }^{5}$

In a recent systematic review, 23 studies comparing eEVAR with open repair were identified, including only one randomized controlled trial. ${ }^{5}$ The randomized controlled trial of Hinchliffe et al. was a pilot study, including only 32 patients and showing comparable mortality results for both treatment options. ${ }^{17}$ Therefore, 22 non-randomized, mostly larger observational studies, with earlier mentioned limitations, are available. These show reduced early mortality results of eEVAR compared to open repair. ${ }^{5}$ Despite the potential methodological inadequacies, there is evidence that observational studies in general do provide valid information. In a study of Benson et al. ${ }^{19}$ the estimates of the treatment effects from observational studies were compared with well conducted randomized controlled trials identifying 136 reports published between 1985 and 1998 about 19 diverse treatments. In 17 of the 19 analyses, the estimates of the treatment effects were similar. Therefore, though not adjusted for hemodynamic condition at presentation, it is likely that the observational studies comparing endovascular with open ruptured AAA repair provide a reasonable estimation of the treatment effect. Especially since the present study shows that suitability for EVAR might not be associated with lower mortality rates.

In the present study, all patients underwent preoperative imaging making selection bias based on hemodynamic condition unlikely. This is substantiated by comparable systolic blood pressure rates at baseline for both treatment groups (Table 4.1). Furthermore, anatomical suitability for EVAR was assessed afterwards by two independent experts, blinded for earlier evaluation, intervention, and outcome. Both external experts work for Medtronic Endovascular since 1997 and advised vascular surgeons (throughout the world, but especially in the Netherlands for the last 5 years) about the most appropriate choice of endograft based on their sizing, in more than 2000 cases each. Documented sizing, as well as actual attendance, of more than 1000 Talent EVAR cases is available for both experts. Mortality data was recorded prospectively. However, some aspects in the present study deserve a comment. At baseline, significantly more patients in the EVAR suitable group were male. Although it is well established that women receive less EVAR treatment than men, ${ }^{20,21}$ there are contradictory reports whether this is due to their anatomical 
suitability. ${ }^{22,23}$ Since women with a ruptured AAA are reported to have an increased mortality risk after EVAR compared to men, the baseline gender difference might theoretically influence mortality results. ${ }^{24}$ Secondly, non EVAR suitable patients treated with open repair by all three participating vascular surgeons were compared to EVAR suitable patients, who were treated with open repair by the non eEVAR-vs. All three vascular surgeons are experienced in open rAAA repair.

In conclusion, the present study suggests that anatomical suitability for EVAR, assessed on preoperative CTA scan, is not associated with lower early and midterm mortality in patients treated with open rAAA repair. Therefore, the reported reduction in mortality between eEVAR and open repair, as observed in the cohort observational studies, is unlikely due to selection bias based on anatomical AAA configuration. 


\section{References}

1. Yusuf SW, Whitaker SC, Chuter TA, Wenham PW, Hopkinson BR. Emergency endovascular repair of leaking aortic aneurysm. Lancet. 1994;344:1645.

2. Harkin DW, Dillon M, Blair PH, Ellis PK, Kee F. Endovascular ruptured abdominal aortic aneurysm repair (EVRAR): a systematic review. Eur J Vasc Endovasc Surg. 2007;34:673-681.

3. Mastracci TM, Garrido Olivares L, Cina CS, Clase CM. Endovascular repair of ruptured abdominal aortic aneurysms: a systematic review and meta-analysis. J Vasc Surg. 2008;47:214-621.

4. Rayt HS, Sutton AJ, London NJ, Sayers RD, Bown MJ. A systematic review and meta-analysis of endovascular repair (EVAR) for ruptured abdominal aortic aneurysm. Eur J Vasc Endovasc Surg. $2008 \mathrm{Nov} ; 36: 536-544$.

5. Sadat U, Boyle JR, Walsh SR, Tang T, Varty K, Hayes PD. Endovascular vs open repair of acute abdominal aortic aneurysms--a systematic review and meta-analysis. J Vasc Surg. 2008;48: 227-236.

6. Ten Bosch JA, Teijink JA, Willigendael EM, Prins MH. Endovascular aneurysm repair is superior to open surgery for ruptured abdominal aortic aneurysms in EVAR-suitable patients. J Vasc Surg. 2010;52:13-18.

7. Visser JJ, van Sambeek MR, Hamza TH, Hunink MG, Bosch JL. Ruptured abdominal aortic aneurysms: endovascular repair versus open surgery--systematic review. Radiology. 2007;245:122-129.

8. Dillon M, Cardwell C, Blair PH, Ellis P, Kee F, Harkin DW. Endovascular treatment for ruptured abdominal aortic aneurysm. Cochrane Database Syst Rev. 2007:Cd005261.

9. Hardman DT, Fisher CM, Patel MI, Neale M, Chambers J, Lane R, et al. Ruptured abdominal aortic aneurysms: who should be offered surgery? J Vasc Surg. 1996;23:123129.

10. Samy AK, Murray G, MacBain G. Glasgow aneurysm score. Cardiovasc Surg. 1994;2:41-44.

11. Tambyraja A, Murie J, Chalmers R. Predictors of outcome after abdominal aortic aneurysm rupture: Edinburgh ruptured aneurysm score. World J Surg. 2007;31:2243-2247.

12. Hoornweg LL, Wisselink W, Vahl A, Balm R. The Amsterdam Acute Aneurysm Trial: suitability and application rate for endovascular repair of ruptured abdominal aortic aneurysms. Eur J Vasc Endovasc Surg. 2007;33:679-683.

13. Chaikof EL, Blankensteijn JD, Harris PL, White GH, Zarins CK, Bernhard VM, et al. Reporting standards for endovascular aortic aneurysm repair. J Vasc Surg. 2002;35:1048-1060.

14. Hoornweg LL, Storm Versloot MN, Ubbink DT, Koelemay MJ, Legemate DA, Balm R. Meta analysis on mortality of ruptured abdominal aortic aneurysms. Eur J Vasc Endovasc Surg. 2008;35:558-570.

15. Perrott S, Puckridge PJ, Foreman RK, Russell DA, Spark JI. Anatomical suitability for endovascular AAA repair may affect outcomes following rupture. Eur J Vasc Endovasc Surg. 2010;40:186-190.

16. Richards T, Goode SD, Hinchliffe R, Altaf N, Macsweeney S, Braithwaite B. The importance of anatomical suitability and fitness for the outcome of endovascular repair of ruptured abdominal aortic aneurysm. Eur J Vasc Endovasc Surg. 2009;38:285-290.

17. Hinchliffe RJ, Bruijstens L, MacSweeney ST, Braithwaite BD. A randomised trial of endovascular and open surgery for ruptured abdominal aortic aneurysm - results of a pilot study and lessons learned for future studies. Eur J Vasc Endovasc Surg. 2006;32:506-513.

18. Lloyd GM, Bown MJ, Norwood MG, Deb R, Fishwick G, Bell PR, et al. Feasibility of preoperative computer tomography in patients with ruptured abdominal aortic aneurysm: a time-to-death study in patients without operation. J Vasc Surg. 2004;39:788-791.

19. Benson K, Hartz AJ. A comparison of observational studies and randomized, controlled trials. N Engl J Med. 2000;342:1878-1886.

20. Dillavou ED, Muluk SC, Makaroun MS. A decade of change in abdominal aortic aneurysm repair in the United States: Have we improved outcomes equally between men and women? J Vasc Surg. 2006; 43:230-238. 
21. McPhee JT, Hill JS, Eslami MH. The impact of gender on presentation, therapy, and mortality of abdominal aortic aneurysm in the United States, 2001-2004. J Vasc Surg. 2007;45:891-899.

22. Simons $P$, van Overhagen $H$, Nawijn A, Bruijninckx B, Knippenberg B. Endovascular aneurysm repair with a bifurcated endovascular graft at a primary referral center: influence of experience, age, gender, and aneurysm size on suitability. J Vasc Surg. 2003;38:758-761.

23. Slater BJ, Harris EJ, Lee JT. Anatomic suitability of ruptured abdominal aortic aneurysms for endovascular repair. Ann Vasc Surg. 2008;22:716-722.

24. Mureebe L, Egorova N, McKinsey JF, Kent KC. Gender trends in the repair of ruptured abdominal aortic aneurysms and outcomes. J Vasc Surg. 2010;51:9S-13S. 


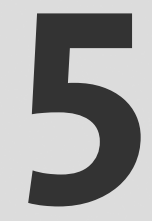

\title{
Symptomatic abdominal aortic aneurysm repair, to wait or not to wait
}

\author{
JA Ten Bosch \\ SW Koning \\ EM Willigendael \\ MRHM van Sambeek \\ RA Stokmans \\ MH Prins \\ JAW Teijink
}

J Cardiovasc Surg. Accepted for publication 


\section{Abstract}

\section{Objective}

In patients with a symptomatic abdominal aortic aneurysm (sAAA), acute intervention theoretically reduces rupture risk prior to surgery whereas delayed intervention provides surgery under optimized conditions. In the present study we evaluated differences in 30day mortality in patients with a SAAA operated within 12 hours compared to patients who received treatment after 12 hours and who were optimized for surgery.

\section{Materials and Methods}

All patients with a SAAA who were treated within one week after presentation were included in the analyses. The 30-day mortality rates of patients operated within 12 hours were compared to those operated after 12 hours, adjusted for type of operation and for all potential confounders.

\section{Results}

Of the 89 included patients, 37 patients received surgery within 12 hours. In patients treated within 12 hours, 30-day mortality rate was $6(16.2 \%)$ compared to $3(5.8 \%)$ in patients treated after 12 hours (odds ratio 0.316; $\mathrm{Cl} 0.074-1.358$ ). When adjusted for type of operation and other confounders, odds ratios were $0.305(\mathrm{Cl} 0.066-1.405)$ and 0.270 (Cl 0.015-4.836), respectively.

\section{Conclusion}

In a substantial amount of patients with an alleged symptomatic AAA, delayed surgery with patient optimization might be justified. However, specific criteria in order to select patients that might benefit from delayed surgery need further investigation. 


\section{Introduction}

It is widely accepted that a so-called symptomatic AAA (sAAA) represents imminent rupture. ${ }^{1}$ A sAAA is defined as the presence of an AAA with symptoms of back and/or abdominal pain in combination with pain at aneurysm palpation and no evidence of rupture on Computed Tomography Angiography (CTA) scan. $^{2}$ In order to prevent rupture with associated poor prognosis, acute treatment of patients with a sAAA is generally performed. ${ }^{34}$

Advocates of acute intervention claim that the risk of rupture prior to surgery might be reduced. ${ }^{3,4}$ However, in an acute setting there is little time for preoperative optimization of patients' and operative condition. Therefore, patients are likely to suffer from a higher peri-operative risk compared to patients who are operated upon in an elective setting., ${ }^{3,5-9}$ Since there is uncertainty of the time interval between initiation of symptoms and rupture in patients with a $\mathrm{SAAA}^{6,10}$ a strategy to postpone surgery in order to optimize patients' and operative condition might be permitted. Hence, a balance is needed between the benefits of surgery under optimized conditions and the risk of rupture prior to surgery.

The aim of this study was to evaluate 30-day mortality in patients with a sAAA treated within 12 hours after presentation compared to patients treated after 12 hours.

\section{Materials and Methods}

\section{Patients}

All consecutive patients, who presented with a sAAA between April 2002 and February 2009 at the emergency department or outpatient clinic at a tertiary vascular referral center, were eligible for the study. Patients who received an intervention more than one week after presentation were excluded from the analysis. Analyses were performed retrospectively on a prospective database. A sAAA was diagnosed based on the following criteria: the existence of an AAA with acute onset of abdominal and/or back pain in combination with pain at aneurysm palpation. ${ }^{2}$ Furthermore, no sign of rupture had to be present on preoperative CTA scan.

Ethical approval was obtained from the Local Ethics Committee. The Institutional Review Board waived the requirement for informed consent because the analyzed patient data were documented as part of routine clinical care. 


\section{Treatment protocol}

In all patients, medical history was taken, a physical examination was performed and blood pressure was measured at the upper arm. In most patients with a suspected SAAA an abdominal ultra sound was made prior to CTA scanning in order to identify the presence of an AAA.

The policy in our center is to perform a CTA scan in all patients presenting with a sAAA in order to assess suitability for EVAR and to rule out rupture. EVAR suitability was initially defined as a proximal neck length $>15 \mathrm{~mm}$ with $<60$ degrees angulation and access vessels large enough to accommodate the introducer sheaths. ${ }^{11}$ As time went by, we began accepting patients for EVAR with more challenging anatomies, including proximal neck lengths as low as $10 \mathrm{~mm}$ and more severe angulations of aortic neck and aneurysm.

All patients with a SAAA who did not receive immediate intervention were admitted to a medium care unit with bed rest, close blood pressure monitoring, and optimization of patients' operative conditions. Blood glucose was monitored and regulated in patients with Diabetes Mellitus. A cardiologist was consulted for active lowering of blood pressure and pre-operative cardiac optimization. A pulmonologist was consulted for pre-operative pulmonary optimization. In patients with chronic obstructive pulmonary disease, ipratropium bromide and albuterol sulphate inhalation was provided. In patients with renal insufficiency who were eligible for endovascular repair a pre-operative prehydration protocol was started in order to reduce the risk of contrast-induced nephropathy. Furthermore, in all patients carbasalate calcium and a statin were administered.

\section{Procedure}

The operating room (OR) is fully equipped for EVAR as well as open surgical repair. Patients who underwent open surgical repair received general anesthesia, whereas patients who underwent EVAR preferentially received local or regional (spinal) anesthesia. The OR staff is trained and experienced with EVAR, and angiography assistance was always available. The operation procedure and materials that were used have been described in detail in a previous report. ${ }^{12}$

\section{Methods}

For all included patients the time between presentation and operation was recorded. Patients who received intervention within 12 hours were compared 
to patients who received AAA repair after 12 hours but within one week. The decision to postpone surgical treatment in order to optimize patients' and operative conditions was based on the professional judgement of the surgical team. The primary outcome was 30-day mortality. Secondary outcomes were complications, re-interventions and length of hospital stay. Furthermore, present mortality results were added to previous results in literature in a forest plot.

\section{Data collection}

The detailed data collection is described in a previous report, with addition of 10 more months of inclusion in the present study. ${ }^{12}$ Recorded baseline characteristics were time of arrival, cardiovascular and pulmonary comorbidity, renal dysfunction, diabetes mellitus, and AAA diameter. Cardiovascular comorbidity included history of ischemic heart disease, angina pectoris, hypertension, cardiac failure, coronary artery bypass graft, percutaneous transluminal coronary angioplasty, cerebrovascular accident or transient ischemic attack, valvular disease, rhythm disorders, or history of aortic operation. Pulmonary comorbidity included the presence of at least one of the following: asthma, chronic obstructive pulmonary disease, or lung carcinoma. Renal dysfunction was defined as a blood creatinine level higher than 140 $\mu \mathrm{mol} / \mathrm{L}$. To be characterized as present diabetic, the patient had to be receiving oral medication and/or insulin therapy.

\section{Statistical analyses}

Statistical analyses were performed using SPSS 15.0.1 for Windows (SPSS INC., Chicago, IL, USA). A chi-square or Fisher's exact test was used for categorical variables, presented as frequency with percentages. Nominal variables were presented as mean \pm standard deviation (SD) for a normal distribution or as median and inter-quartile-range (IQR) for a skewed distribution. $P$-values of $<0.05$ were considered significant. Differences in mortality rate were expressed using the odds ratio. A multiple regression analysis was performed to adjust for type of operation (EVAR or open surgery) and subsequently for other potential confounders. Type of operation, time of arrival (within or outside regular working hours; $8.00 \mathrm{~h}$ till $17.00 \mathrm{~h}$ ), gender, cardiovascular comorbidity, pulmonary comorbidity, history of CVA or TIA, Diabetes Mellitus, preoperative creatinine levels, and AAA diameter were considered as potential confounders. 
A summary of the available evidence on mortality in patients with a sAAA was listed in a forest plot using review manager 4.2 for Windows developed by the Nordic Cochrane center.

\section{Results}

\section{Patients}

Between April 2002 and February 2009, a total of 89 patients presented with suspected SAAA and were treated within one week after presentation. Of these patients, 37 were treated within 12 hours after presentation (mean age $72 \pm 10$ years) and 52 patients were treated after 12 hours (mean age $71 \pm 8$ years). Baseline characteristics were comparable for both treatment groups and are listed in Table 5.1.

Table 5.1 Baseline and treatment characteristics.

\begin{tabular}{|c|c|c|c|}
\hline & $\begin{array}{c}\text { Operated within } 12 \\
\text { hours } \\
(n=37)\end{array}$ & $\begin{array}{c}\text { Operated after } 12 \\
\text { hours } \\
(n=52)\end{array}$ & $P$-value \\
\hline \multicolumn{4}{|l|}{ Baseline } \\
\hline Mean age in years (SD) & $71.6 \pm 9.5$ & $71.2 \pm 7.6$ & 0.733 \\
\hline Male & $33(89.2 \%)$ & $38(73.1 \%)$ & 0.062 \\
\hline Cardiovascular comorbidity & $29(78.4 \%)$ & $39(75.0 \%)$ & 0.711 \\
\hline Pulmonary comorbidity & $10(27.0 \%)$ & $10(19.2 \%)$ & 0.385 \\
\hline \multicolumn{4}{|l|}{ Renal dysfunction } \\
\hline - Creatinine (umol/L) (SD) & $120.6 \pm 68.5$ & $111.6 \pm 68.1$ & 0.541 \\
\hline - Serum Creatinine $>140 \mathrm{mmol} / \mathrm{I}$ & $7(18.9 \%)$ & $5(9.6 \%)$ & 0.225 \\
\hline Diabetes & $5(13.5 \%)$ & $4(7.7 \%)$ & 0.481 \\
\hline Mean aneurysmal diameter in $\mathrm{cm}$ (SD) & $6.7 \pm 2.4$ & $6.4 \pm 1.4$ & 0.386 \\
\hline \multicolumn{4}{|l|}{ Symptoms } \\
\hline - Abdominal pain & $27(73.0 \%)$ & $36(70.6 \%)$ & 0.807 \\
\hline - Back pain & $22(59.5 \%)$ & $28(54.9 \%)$ & 0.670 \\
\hline - Flank pain & $5(13.5 \%)$ & $5(9.8 \%)$ & 0.736 \\
\hline - Groin pain & $1(2.7 \%)$ & $0(0.0 \%)$ & 0.420 \\
\hline - Chest Pain & $1(2.7 \%)$ & $1(2.0 \%)$ & 1.000 \\
\hline \multicolumn{4}{|l|}{ Abdominal examination } \\
\hline - Pulsatile mass & $8(21.6 \%)$ & $7(13.7 \%)$ & 0.331 \\
\hline - Pain at aneurysm palpation & $16(43.2 \%)$ & $23(45.1 \%)$ & 0.863 \\
\hline \multicolumn{4}{|l|}{ Treatment } \\
\hline Open & $29(78.4 \%)$ & $26(50.0 \%)$ & 0.007 \\
\hline EVAR & $8(21.6 \%)$ & $26(50.0 \%)$ & \\
\hline
\end{tabular}




\section{Procedures and clinical courses}

Time between presentation and surgery is depicted in Figure 5.1. Among the patients who were treated within 12 hours (median 3, IQR 2-5), 8 (21.6\%) were treated with EVAR and 29 (78.4\%) patients were treated with open surgical repair. In one patient a contained rupture was found during open surgical repair that was not identified on preoperative CTA scan.

Among the 52 patients who received their intervention after 12 hours (median 45, IQR 25-78), 26 (50.0\%) were treated with EVAR and 26 (50.0\%) patients were treated with open surgical repair. In this group, two patients became hemodynamically unstable during the admission period due to rupture of their sAAA while waiting for surgery at one and two days after presentation. In a third patient the aneurysm ruptured during open repair directly after opening the peritoneum. A fourth patient who was treated with open surgical repair appeared to have a contained rupture.

All 55 patients who underwent open surgery had general anesthesia. Among the 34 patients who were operated with EVAR, 2 (6.1\%) patients received local anesthesia, $3(3.4 \%)$ general anesthesia, and 28 (84.8\%) patients received spinal anesthesia.

The distribution of the number of patients who were treated within and after 12 hours after presentation during the study period is shown in Figure 5.2.

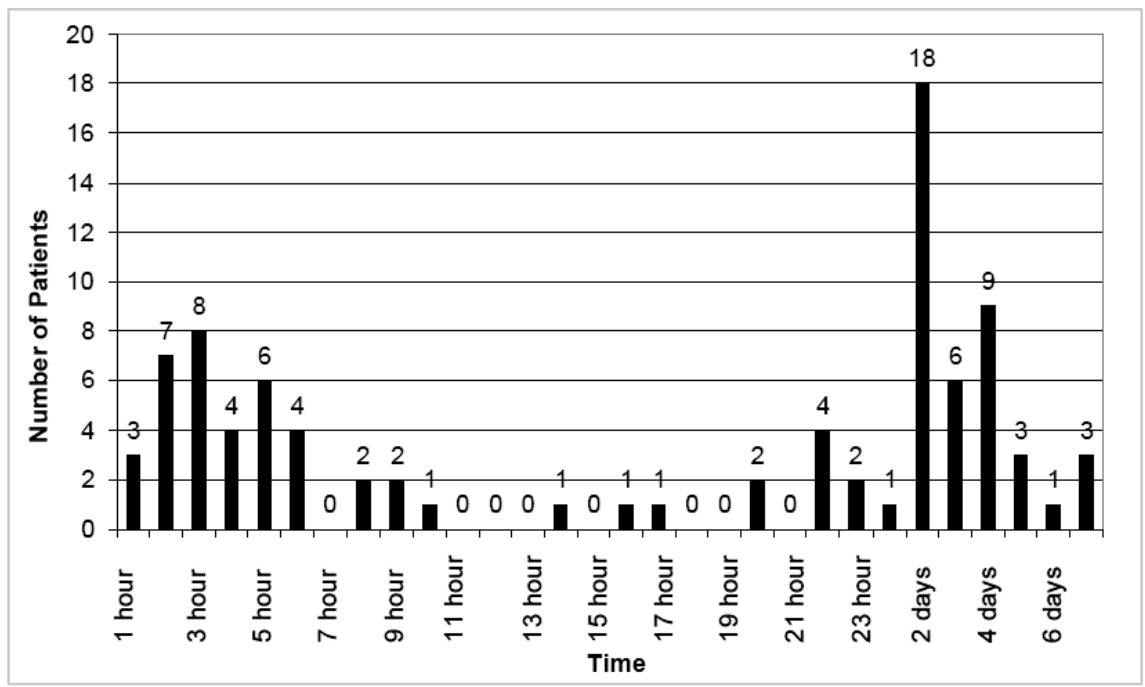

Figure 5.1 Time between presentation and surgery. 


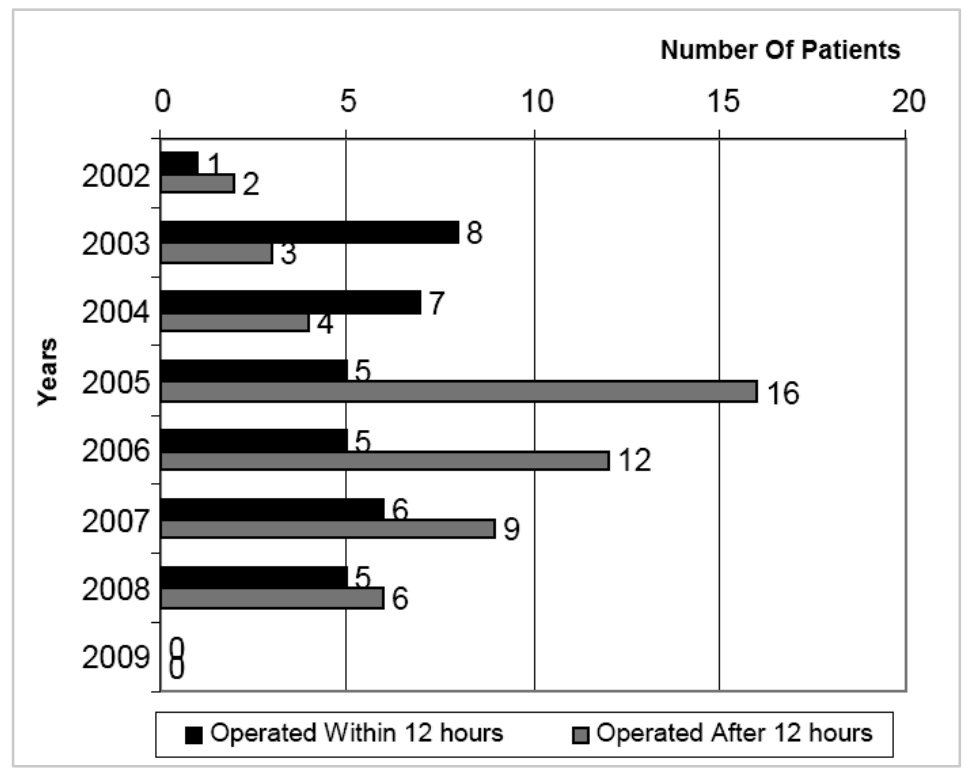

Figure $5.2 \quad$ Patients included during the study period.

\section{Mortality}

The 30-day mortality rates are listed in Table 5.2. In total, 9 of the 89 (10.1\%) patients died within 30 days. In the group operated within 12 hours, 6 out of 37 (16.2\%) patients died due to: urosepsis in combination with severe comorbidity $(n=1)$, renal failure after open surgical repair in combination with a pneumonia eventually leading to multi organ failure $(n=1)$, acute myocardial infarction $(n=3)$, and graft limb obstruction resulting in leg ischemia for which a surgical reintervention was not performed due to the patient's irreversible poor condition $(n=1)$. In the group operated after 12 hours, 3 out of 52 (5.8\%) patients died due to: extensive retroperitoneal hemorrhage one day after open surgical repair with clinical deterioration for which a reintervention was performed $(n=1)$, acute myocardial infarction $(n=1)$, and one patient whose aneurysm ruptured during admission prior to intervention died within 30 days

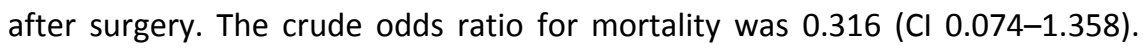
When adjusted for type of surgery (open and EVAR) and other potential confounders, adjusted odds ratios were $0.305(\mathrm{Cl} 0.066-1.405)$ and $0.270(\mathrm{Cl}$ 0.015-4.836), respectively.

When we repeated our analyses using 24 hours as a cut-off point, crude odds ratio was 0.131 ( $\mathrm{Cl} 0.016-1.100)$, consistent with the analyses using 12 hours as 
a cut-off point. When adjusted for type of operation and other potential confounders, adjusted odds ratios were $0.124(\mathrm{Cl} 0.014-1.083)$ and $0.002(\mathrm{Cl}$ 0.000-88.505), respectively.

Figure 5.3 shows the combined mortality results of multiple studies including the present study using a forest plot of the available evidence in patients with a sAAA. Combined odds ratio was $1.73(\mathrm{Cl}$ 0.74-4.03) and therefore not significant.

Table $5.2 \quad$ 30-day mortality.

\begin{tabular}{cccccc}
\hline & $\begin{array}{c}\text { Within 12 hours } \\
(\mathrm{n}=37)\end{array}$ & $\begin{array}{c}\text { After 12 hours } \\
(\mathrm{n}=52)\end{array}$ & $\begin{array}{c}\text { ODDS ratio } \\
(\mathrm{Cl})\end{array}$ & $\begin{array}{c}\text { Adj ODDS ratio } \\
\text { a }\end{array}$ & $\begin{array}{c}\text { Adj ODDS ratio } \\
(\mathrm{Cl})\end{array}$ \\
\hline Mortality & $6(16.2 \%)$ & $3(5.8 \%)$ & 0.316 & 0.305 & 0.270 \\
& & & $(0.074-1.358)$ & $(0.066-1.405)$ & $(0.015-4.836)$ \\
\hline
\end{tabular}

${ }^{a}$ Adjusted for type of operation; ${ }^{b}$ Adjusted for all potential cofounders.

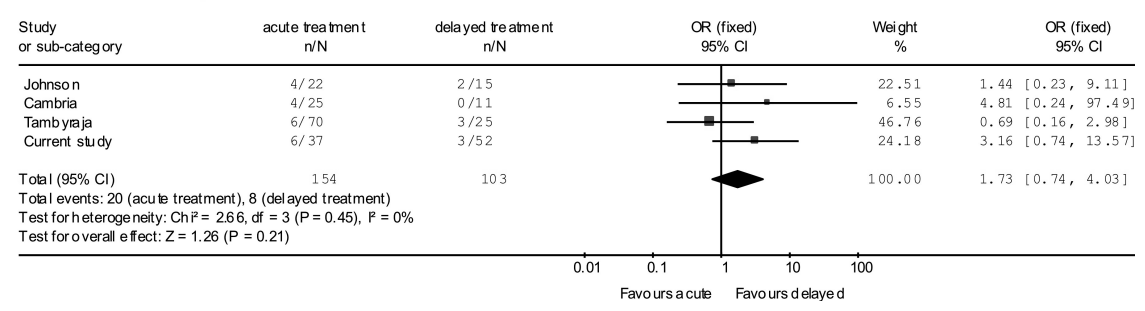

Figure 5.3 Mortality results in literature.

\section{Complications, re-interventions and admissions}

All complications, re-interventions and the duration of hospital stay are listed in Table 5.3. Follow-up varied from 13 months to 6 years (mean 3.8 years). In patients operated within 12 hours, the overall complication rate was $56.8 \%$ $(21 / 37)$ compared to $46.2 \%(24 / 52)$ of the patients who received surgery after 12 hours.

Five (13.5\%) patients operated within 12 hours versus 18 patients (34.6\%) operated after 12 hours needed a re-intervention ( $P=0.029)$. Re-interventions in patients operated within 12 hours were performed for postoperative hemorrhage $(n=3)$, correction of a cicatricial hernia $(n=1)$, and ileus $(n=1)$. Reinterventions for patients who received the intervention after 12 hours were performed for postoperative recurrent hemorrhage $(n=5)$, correction of a 
Table 5.3 Complications, re-interventions and admission.

\begin{tabular}{|c|c|c|c|}
\hline & $\begin{array}{l}\text { Within } 12 \text { hours } \\
(n=37)\end{array}$ & $\begin{array}{l}\text { After } 12 \text { hours } \\
\quad(n=52)\end{array}$ & $P$-value \\
\hline Rupture & $1(2.7 \%)$ & $4(7.7 \%)$ & 0.397 \\
\hline Overall complication rate ${ }^{a}$ & $21(56.8 \%)$ & $24(46.2 \%)$ & 0.324 \\
\hline - Deployment/procedure related complications ${ }^{a}$ & $6(16.2 \%)$ & $9(17.3 \%)$ & 0.892 \\
\hline Extensive peroperative bleeding & $4(10.8 \%)$ & $3(5.8 \%)$ & 0.443 \\
\hline Aortic dissection & $0(0.0 \%)$ & $0(0.0 \%)$ & 1.000 \\
\hline Arterial perforation or rupture & $0(0.0 \%)$ & $1(1.9 \%)$ & 1.000 \\
\hline Peripheral embolization & $1(2.7 \%)$ & $2(3.8 \%)$ & 1.000 \\
\hline Access site hematoma & $1(2.7 \%)$ & $0(0.0 \%)$ & 1.000 \\
\hline False aneurysm & $0(0.0 \%)$ & $1(1.9 \%)$ & 1.000 \\
\hline Access site lymphocele/lymphorrhea/lymphedema & $0(0.0 \%)$ & $0(0.0 \%)$ & 1.000 \\
\hline Access site infection & $1(2.7 \%)$ & $1(1.9 \%)$ & 1.000 \\
\hline Fever of unknown origin ( $<6$ days after surgery) & $2(5.4 \%)$ & $5(9.6 \%)$ & 0.695 \\
\hline - Implant related complications ${ }^{a}$ & $6(16.2 \%)$ & $10(19.2 \%)$ & 0.715 \\
\hline Anastomotic aneurysm & $0(0.0 \%)$ & $0(0.0 \%)$ & 1.000 \\
\hline Graft migration & $1(2.7 \%)$ & $3(5.8 \%)$ & 0.638 \\
\hline Graft infection & $0(0.0 \%)$ & $0(0.0 \%)$ & 1.000 \\
\hline Postoperative graft limb obstruction & $1(2.7 \%)$ & $4(7.7 \%)$ & 0.397 \\
\hline Buttock/leg claudication/ischemia & $1(2.7 \%)$ & $0(.0 \%)$ & 0.416 \\
\hline Leaking prosthesis & $4(10.8 \%)$ & $5(9.6 \%)$ & 1.000 \\
\hline - Systemic complications ${ }^{a}$ & $8(21.6 \%)$ & $7(13.5 \%)$ & 0.311 \\
\hline Cardiac & $0(0.0 \%)$ & $2(3.8 \%)$ & 0.509 \\
\hline Pulmonary & $4(10.8 \%)$ & $2(3.8 \%)$ & 0.229 \\
\hline Renal insufficiency & $4(10.8 \%)$ & $2(3.8 \%)$ & 0.229 \\
\hline Bowel ischemia & $0(0.0 \%)$ & $1(1.9 \%)$ & 1.000 \\
\hline Sepsis & $1(2.7 \%)$ & $0(0.0 \%)$ & 0.416 \\
\hline Abdominal compartment syndrome & $1(2.7 \%)$ & $0(0.0 \%)$ & 0.416 \\
\hline Complications requiring surgical re-intervention & $5(13.5 \%)$ & $18(34.6 \%)$ & 0.029 \\
\hline Hemorrhage & $3(8.1 \%)$ & $5(9.6 \%)$ & 1.000 \\
\hline Cicatricial hernia & $1(2.7 \%)$ & $1(1.9 \%)$ & 1.000 \\
\hline lleus & $1(2.7 \%)$ & $0(0.0 \%)$ & 0.416 \\
\hline Stent graft occlusion & $0(0.0 \%)$ & $4(7.7 \%)$ & 0.138 \\
\hline Endoleak type 1 & $0(0.0 \%)$ & $3(5.8 \%)$ & 0.263 \\
\hline Endoleak type 2 & $0(0.0 \%)$ & $3(5.8 \%)$ & 0.263 \\
\hline Endoleak type 3 & $0(0.0 \%)$ & $1(1.9 \%)$ & 1.000 \\
\hline Aortic rupture post EVAR & $0(0.0 \%)$ & $1(1.9 \%)$ & 1.000 \\
\hline Postoperative days in hospital $^{b}$ & $8(6.5-16.0)$ & $7(2.0-10.5)$ & 0.065 \\
\hline
\end{tabular}

${ }^{\mathrm{a}}$ Number of patients with one or more complications; ${ }^{\mathrm{b}}$ median (interquartile range)

cicatricial hernia $(n=1)$, occluded prosthesis $(n=4)$, aneurysm rupture after EVAR $(n=1)$, and endoleakage $(n=7)$.

The median postoperative days in hospital were 8.0 (IQR: 6.5-16.0) grouping patients treated within 12 hours and 7.0 (IQR: 2.0-10.75) for patients treated after 12 hours ( $P=0.065)$. 


\section{Discussion}

In the present study, 30-day mortality rates in patients with a sAAA were lower in patients operated more than 12 hours after presentation compared to patients treated within 12 hours, though not significantly (odds ratio 0.316; $\mathrm{Cl}$ 0.074-1.358). Similar results were obtained after adjustment for type of operation and other potential confounders. These results suggest that delayed treatment in certain patients with a sAAA may be justified.

Results of the present study have to be interpreted with caution due to methodological limitations. In order to gain results that were statistically significant, more patients had to be included in the analyses. Due to lack of statistical power only a trend could be seen towards a lower mortality rate in patients that were treated under optimized conditions more than 12 hours after presentation. Furthermore, analyses were performed retrospectively on a prospective database. Therefore, patients were not allocated to the treatment groups in a randomized way and selection bias, based on subjective criteria, is likely to have occurred. Postponing surgical treatment has occurred for several reasons including the assembling of an EVAR dedicated team in case of EVAR suitability, the need for optimization of patients' and operative conditions in case of severe comorbidity, and logistical reasons. Despite potential selection bias, baseline characteristics were comparable in patients treated before and after 12 hours after the initial presentation.

In the acute setting (treated within 12 hours), EVAR was performed in patients who were suitable for endovascular repair depending to the attending vascular surgeon (78.4\% open repair versus $21.6 \%$ treated by EVAR), since not all vascular surgeons were capable of performing endovascular aneurysm repair in the acute setting. Therefore, intention to treat by eEVAR protocol was not part of the study design. In patients who underwent delayed treatment, the distribution between patients who received open repair versus endovascular repair corresponds with the EVAR suitability rate. ${ }^{13}$ On one hand, this difference in proportion treated by EVAR might emphasize heterogeneity. Furthermore, it might affect mortality results in favor of the delayed group since EVAR is potentially associated with decreased 30-day mortality rates compared to conventional open repair in sAAA patients. ${ }^{2,11}$

On the other hand, it might underline a theoretical advantage for delayed treated patients who are more likely to receive endovascular repair in case of EVAR-suitability. Logistic regression analyses were performed with type of operation as well as other potential confounders as variables. These adjusted analyses showed similar results. Though, given the limited number of patients, 
conclusions of these analyses have to be interpreted with caution.

In the delayed group, rupture of the sAAA occurred in two patients while waiting for surgery. In another patient rupture occurred during open repair directly after opening the peritoneum, which was probably a free rupture of a contained retroperitoneal hematoma due to the effect of general anaesthesia with related loss of abdominal muscle tone. A contained rupture was found in a fourth patient during open surgical repair. Despite the occurrence of preoperative aneurysm rupture in the delayed surgery group, no increase in mortality was observed, which support the conclusion that delayed surgery with optimization of patients' and operative conditions might be justified in selected patients with a sAAA.

Optimization of patients' and operative conditions was accomplished subjectively by best individual clinical care: admission to a medium care unit with close monitoring and optimization of patients' operative pulmonary, cardiac, renal, and internal condition. There is no fixed protocol or data available in literature. We stuck to our own optimization protocol as described in the methods section. Nevertheless, risk of heterogeneity in terms of optimization methods used in the delayed treatment group seemed inevitable.

A summary of the available evidence is listed in a forest plot (Figure 5.3). Three studies describing acute treatment (within 24 hours) and delayed treatment (after 24 hours) in patients with a sAAA are available., ${ }^{4,6,10}$ Two small studies by Johnson et al. ${ }^{6}$ and Cambria et al. ${ }^{10}$ showed similar mortality results to the current study in favor of delayed treatment. On the other hand, mortality results of Tambyraja et al., ${ }^{4}$ who used a comparable sample size to our study, were in favor of acute treatment. Overall, in contrast with the general opinion, there seems to be a trend in the available literature including the present study towards lower early mortality rates in patients receiving delayed treatment, though not significantly (odds ratio 1.73; $\mathrm{Cl}$ 0.74-4.03) (Figure 5.3). As distinct from earlier studies, the analyses in the present study were based on prospective data and 30-day mortality results were adjusted for all potential confounders. Furthermore, in our main analyses we used 12 hours as the cut-off point between acute and delayed treatment based on the distribution of time to operation (Figure 5.1), instead of 24 hours as used by Tambyraja et al. ${ }^{4}$ Though, when we repeated our analyses using 24 hours as a cut-off point, results were consistent with the analyses using 12 hours as a cut-off point.

There is a wide variation of definitions employed for sAAA. Kapma et al. defined sAAA as any AAA requiring treatment within 24 hours and not classified as a ruptured $A A A .{ }^{11}$ In the present study SAAA was defined as the existence of an 
AAA with acute onset of abdominal and/or back pain combined with pain at aneurysm palpation, as described by Peppelenbosch et al. ${ }^{2}$ However, abdominal pain and pain at aneurysm palpation might have causes other than an aneurysm in a state of pending rupture indicating potential false positive diagnoses.

So far, studies comparing acute with delayed treatment in patients with a sAAA are flawed by methodological inadequacies such as lack of randomization and potential selection bias. As stated, despite the adjustments for multiple potential confounders in the present study, results have to be interpreted with caution. Although delayed treatment seems to be justified according to the results of the present study, a large prospective controlled trial in which patients are allocated to the acute or delayed treatment group in a randomized study setting is required to confirm the results of the present study. If this randomized controlled trial shows similar results to the present study, the contemporary assumption to treat patients with a sAAA in an acute setting in order to prevent rupture might be adjusted. Preoperative optimization of patients' and operative condition could improve prognosis in selected patients with a SAAA. However, given the relatively small number of patients with a sAAA, a randomized controlled trial might be difficult to perform.

\section{Conclusions}

In conclusion, delayed surgical treatment in order to optimize patients' and operative conditions does not result in higher mortality rates in a substantial amount of patients presenting with a symptomatic AAA. A trend towards a lower 30-day mortality rate was found for sAAA patients treated after 12 hours after presentation compared to patients treated within 12 hours. However, the present study was underpowered and results have to be interpreted with caution due to methodological limitations such as selection bias. Specific criteria in order to select patients that might benefit from delayed surgery need further investigation. Therefore, a large well-conducted randomized controlled trial is needed. 


\section{References}

1. Franks S, Lloyd G, Fishwick G, Bown M, Sayers R. Endovascular treatment of ruptured and symptomatic abdominal aortic aneurysms. Eur J Vasc Endovasc Surg 2006;31:345-350.

2. Peppelenbosch N, Yilmaz N, van Marrewijk C, Buth J, Cuypers P, Duijm L, et al. Emergency treatment of acute symptomatic or ruptured abdominal aortic aneurysm. Outcome of a prospective intent-to-treat by EVAR protocol. Eur J Vasc Endovasc Surg 2003;26:303-310.

3. Buss RW, Clagett GP, Fisher DF, Jr., Fry RE, Eidt JF, Humble TH, et al. Emergency operation in patients with symptomatic abdominal aortic aneurysms. Am J Surg 1988;156:470-473.

4. Tambyraja AL, Raza Z, Stuart WP, Murie JA, Chalmers RT, Tambyraja AL, et al. Does immediate operation for symptomatic non-ruptured abdominal aortic aneurysm compromise outcome? Eur J Vasc Endovasc Surg 2004;28:543-546.

5. Haug ES, Romundstad P, Aadahl P, Myhre HO, Haug ES, Romundstad P, et al. Emergency nonruptured abdominal aortic aneurysm. Eur J Vasc Endovasc Surg 2004;28:612-618.

6. Johnson G, Jr., McDevitt NB, Proctor HJ, Mandel SR, Peacock JB, Johnson G, Jr., et al. Emergent or elective operation for symptomatic abdominal aortic aneurysm. Arch Surg 1980;115:51-53.

7. Soisalon-Soininen S, Salo JA, Perhoniemi V, Mattila S, Soisalon-Soininen S, Salo JA, et al. Emergency surgery of non-ruptured abdominal aortic aneurysm. Ann Chir Gynaecol 1999;88:38-43.

8. Sullivan CA, Rohrer MJ, Cutler BS, Sullivan CA, Rohrer MJ, Cutler BS. Clinical management of the symptomatic but unruptured abdominal aortic aneurysm. J Vasc Surg 1990;11:799-803.

9. Tochii M, Ogino H, Matsuda H, Minatoya K, Sasaki H, Kitamura S. Is prompt surgical treatment of an abdominal aortic aneurysm justified for someone in their eighties? Ann Thorac Cardiovasc Surg 2009;15:23-30.

10. Cambria RA, Gloviczki P, Stanson AW, Cherry KJ, Jr., Hallett JW, Jr., Bower TC, et al. Symptomatic, nonruptured abdominal aortic aneurysms: are emergent operations necessary? Ann Vasc Surg 1994;8:121-126.

11. Kapma MR, Verhoeven EL, Tielliu IF, Zeebregts CJ, Prins TR, Van der Heij B, et al. Endovascular treatment of acute abdominal aortic aneurysm with a bifurcated stentgraft. Eur J Vasc Endovasc Surg 2005;29:510-515.

12. Ten Bosch JA, Willigendael EM, Kruidenier LM, de Loos ER, Prins MH, Teijink JA. Early and midterm results of a prospective observational study comparing emergency endovascular aneurysm repair with open surgery in both ruptured and unruptured acute abdominal aortic aneurysms. Vascular 2012;20:72-80.

13. Armon MP, Yusuf SW, Latief K, Whitaker SC, Gregson RH, Wenham PW, et al. Anatomical suitability of abdominal aortic aneurysms for endovascular repair. Br J Surg 1997;84:178-180. 


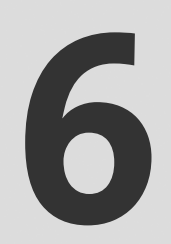

\section{The durability of endovascular repair of paraanastomotic aneurysms after previous open aortic reconstruction}

JA Ten Bosch

EJ Waasdorp

JPPM de Vries

FL Moll

JAW Teijink

JA van Herwaarden

J Vasc Surg. 2011;54:1571-1578 


\section{Abstract}

\section{Objective}

Anastomotic pseudoaneurysms and true paraanastomotic aneurysms after initial open abdominal aortic prosthetic reconstruction often need reintervention because they are at risk for rupture. However, open surgical reinterventions are technically challenging procedures with high mortality and morbidity rates. In the present multicenter study, we describe the long-term clinical course in an expanded number of patients who underwent endovascular repair of paraanastomotic aneurysms after previous open reconstruction.

\section{Materials and Methods}

The study included all patients who were treated with an endovascular stent graft between July 1999 and July 2009 for an aortoiliac anastomotic pseudoaneurysm or a true paraanastomotic aneurysm after previous aortic prosthetic reconstruction for aneurysmal or occlusive disease in one of the four participating centers. Main outcomes were long-term complications, reinterventions and conversion rate, mortality, and hospital length of stay.

\section{Results}

An endovascular stent graft was used to treat 58 patients (53 [91\%] men; mean age $71 \pm 9$ years) with 80 aortic or iliac pseudo or true paraanastomotic aneurysms, or both. Bifurcated stent grafts were used in 32 patients, endovascular tube grafts in 8, aortouniiliac stent grafts in 7, and iliac extension grafts in 11 . Stent graft deployment was successful in 55 patients, for a technical success rate of $95 \%$. Median hospital admission was 3 days (range, 1-122 days). The 30-day and in-hospital mortality rates were $3.4 \%$ $(n=2)$ and $6.9 \%(n=4)$, respectively. The 30-day clinical success rate was $91 \%(n=53)$. Median follow-up was 41 months (range, 0-106 months). The cumulative and procedural-related mortality during follow-up was $19 \% \quad(n=11)$ and $10 \% \quad(n=6)$, respectively. During follow-up, computed tomography angiography revealed nine endoleaks ( 3 type I and 6 type II endoleaks) in eight patients and endotension in two patients. The overall reintervention and conversion rate during follow-up was $26.9 \%$ $(n=15)$ and $6.9 \%(n=4)$, respectively. Life-table analysis showed reduced freedom from reintervention for aortouniiliac and tube stent grafts. Type I endoleaks were observed in $25 \%$ of patients with endovascular aortic tube grafts for proximal anastomotic aneurysms.

\section{Conclusions}

The present study demonstrates that in patients with an appropriate anatomy, endovascular repair of paraanastomotic aortic and iliac aneurysms after initial prosthetic aortic surgery is safe and durable. On the long-term, fewer complications occurred after procedures with bifurcated stent grafts compared with procedures with tube grafts, aortouniiliac or iliac extension stent grafts. 


\section{Introduction}

Conventional aortic prosthetic reconstruction for repairs of abdominal aortic aneurysm (AAA) or aortoiliac obstructive disease is considered to be a durable procedure and is still widely performed. A typical complication after conventional aortic prosthetic reconstruction is paraanastomotic aneurysm formation. Paraanastomotic aneurysms after previous open reconstruction may present as continuing dilatation of the aortoiliac arteries adjacent to the anastomosis (true paraanastomotic aneurysms) or as disruption of the anastomosis leading to pseudoaneurysm formation (false paraanastomotic aneurysms). ${ }^{1}$ The reported incidence varies widely. In a retrospective 15 -year follow-up study of 208 patients, proximal and distal aortic paraanastomotic aneurysms occurred in $6(2.9 \%)$ and 18 patients $(8.7 \%)$, respectively. ${ }^{2}$

Most open reinterventions after initial abdominal aortic prosthetic reconstruction are for repairs of anastomotic pseudoaneurysms and true paraanastomotic aneurysms because they are at risk for rupture. ${ }^{2,3}$ However, these open surgical reinterventions are technically challenging, with mortality rates varying from $8 \%$ to $70 \%$ and morbidity rates of $70 \%$ to $83 \%$, which are considerably higher than those associated with primary prosthetic reconstructions. ${ }^{4-8}$

Endovascular paraanastomotic aneurysm repair (EVPAR) allows for local or regional anesthesia without requiring dissection through the scars of previous operations and might be preferred instead of renewed open repair. ${ }^{9}$ Except for case reports, a few small case series have suggested that endovascular exclusion of noninfected paraanastomotic aneurysms after previous abdominal aortoiliac surgery is feasible, with low perioperative mortality and morbidity. ${ }^{9-15}$ Earlier, we showed that endovascular paraanastomotic aneurysm repair is effective with bifurcated stent grafts. ${ }^{9}$ However, larger series with longer-term follow-up are necessary to confirm the long-term effectiveness of this approach. ${ }^{9,10,12}$

In the present multicenter study, we describe the long-term clinical course in an expanded number of patients who underwent EVPAR after previous open reconstruction. 


\section{Materials and Methods}

\section{Patients}

Four Dutch centers participated in the study (AmcP, UMCU, St AHN, CHE). The study included all patients who were treated with an endovascular stent graft between July 1999 and July 2009 for an aortic or iliac false paraanastomotic or true paraanastomotic aneurysm after previous aortic prosthetic reconstruction for aneurysmal or occlusive disease. The short-term follow-up of 14 patients included in the current study has been described previously. ${ }^{9}$

Variables analyzed included age, gender, comorbidities, initial aortic pathology, graft configuration at the initial open reconstruction, time between initial open prosthetic reconstruction and endovascular repair, paraanastomotic aneurysm characteristics, stent graft configuration at endovascular repair, hospital admissions, survival, complications, reinterventions (freedom from reinterventions), and conversion rate during follow-up.

\section{Diagnostics and operative technique}

All patients underwent a preoperative contrast enhanced spiral computed tomography angiography (CTA) scan with a slice thickness of 1.5 to $3 \mathrm{~mm}$ or digital subtraction angiography (DSA), or both, to confirm the presence of a paraanastomotic aneurysm and to evaluate its anatomic characteristics. Criteria for intervention of paraanastomotic aneurysms were 1.5 times the diameter of the nondiseased aorta or iliac artery at that segment, symptoms of acute onset of abdominal or back pain combined with pain at aneurysm palpation (symptomatic paraanastomotic aneurysm), and signs of (contained) rupture on preoperative CTA or DSA. ${ }^{16}$

Criteria for endovascular repair were proximal aortic neck length of $\geq 10 \mathrm{~mm}$ between the lowest renal artery and the beginning of the aneurysm, proximal aortic neck or iliac artery angulation $<90^{\circ}$, lack of circumferential calcification or thrombus of the aortic neck or iliac arteries, and adequate iliac-femoral access to the paraanastomotic aneurysm. During the entire study period, endovascular repair was preferentially performed in anatomically suitable paraanastomotic aneurysms. The exclusion criterion for endovascular repair was anatomic unsuitability for endovascular repair.

General, regional, or local anesthesia was used. Groin incisions with open femoral arteriotomy were performed to gain access to the common femoral 
artery. Endovascular devices used were AneuRx (Medtronic, Sunnyvale, CA), Endurant (Medtronic, Sunnyvale, CA), Excluder (Gore, Arizona, US), Quantum LP/Fortron (Cordis Corp., Warren, NJ), Relay (Bolton Medical, Sunrise, FL), Talent (Medtronic, Sunnyvale, CA), Valiant (Medtronic, Sunnyvale, CA) and Zenith (Cook Vascular, Bloomington, IN). Tube grafts, aortouniiliac stent grafts, and bifurcated stent grafts were used. The device type was chosen according to anatomic suitability, preferences of the vascular surgeon, availability of the type of stent graft of suitable caliber at the time of the procedure in each participating center, and paraanastomotic aneurysm location and configuration, including aortic neck diameter and length, as well as the presence of iliac stenosis or occlusion.

Tube grafts were used exclusively for proximal paraanastomotic aneurysms, whereas bifurcated or aortouniiliac stent grafts were used to treat patients with proximal or distal paraanastomotic aneurysms, or both. Aortouniiliac stent grafting was combined with a femorofemoral crossover bypass to restore blood flow to the contralateral leg and with an occluder in the contralateral common iliac artery to prevent backbleeding into the aneurysm sac. In patients with a single paraanastomotic iliac aneurysm and a proximal iliac sealing zone of at least $0.5 \mathrm{~cm}$, exclusion was obtained by placement of an endovascular iliac extender graft.

In patients with a proximal paraanastomotic aneurysm of the abdominal aorta, the (covered portion of the) endovascular device was proximally anchored just below the lowest renal artery for optimal sealing in the native aortic neck above the lesion. In case of an endovascular tube graft, the distal fixation was in the previous graft, with overlap of the endovascular device and the previous graft of at least two stent rings. For a bifurcated or aortouniiliac stent graft, the common iliac artery was used as distal landing zone in most patients. In patients with a paraanastomotic aneurysm near the hypogastric artery, the stent graft was extended in the external iliac artery after embolization of the hypogastric artery. According to the instructions for use all stent grafts were oversized at least $10 \%$ to $20 \%$.

\section{Surveillance protocol}

Postoperatively, all electively treated patients went to a regular ward or medium care unit where they were fed a normal diet and started ambulating on the first postoperative day. Some patients who were endovascularly treated for a ruptured paraanastomotic aneurysm initially went to an intensive care unit 
for close monitoring. Postdischarge surveillance after EVPAR included basic laboratory testing for renal function, physical examination, and triple-phase (nonenhanced, arterial, and delayed phase) CTA scans before discharge or within 3 months, at 12 months, and yearly thereafter. In patients with significant renal insufficiency (GFR $<40 \mathrm{ml} / \mathrm{min}$ ), a renal protection protocol consisting of prehydration and administration of acetylcysteine was used before and after CTA. Otherwise, non-contrast CT scanning combined with contrastenhanced ultrasonography was performed at the discretion of the vascular surgeon and scheduled at the same time intervals as the regular EVAR protocol.

\section{Statistical analyses}

Data were collected and analyzed using SPSS 15.0 software (SPSS Inc, Chicago, IL). Categoric variables are presented as frequency and percentages. Continuous variables are presented as mean \pm standard deviation for a normal distribution, or as median and range for a skewed distribution. Survival and freedom from reintervention after endovascular repair of anastomotic aneurysms was evaluated using Kaplan-Meier curves, log-rank tests, and annual risk with related standard error (SE).

\section{Results}

\section{Patients}

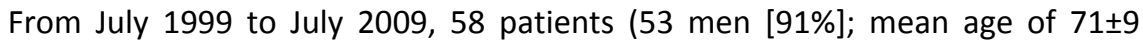
years) with 80 aortic or iliac pseudo or true paraanastomotic aneurysms, or both, were treated with an endovascular stent graft. Of these, 54 patients (93\%) were initially treated for aneurysmal disease and 4 (7\%) for occlusive aortoiliac disease (two of them had end-to-end and two end-to-side anastomosis). Twenty-eight patients were conventionally treated with a tube graft to exclude an AAA and 30 with a previous bifurcated prosthesis or bifurcated bypass. Baseline characteristics and clinical details of these patients are described in Table 6.1. In patients with a previous tube graft, 42 paraanastomotic aneurysms were present, including pseudoaneurysms at the proximal $(n=9)$ or distal $(n=7)$ anastomosis, and true iliac aneurysms at one $(n=6)$ or both sides $(n=10)$ (Figure 6.1). In patients initially treated with a conventional bifurcated prosthesis, 38 paraanastomotic aneurysms were present, including pseudoaneurysms at the proximal aortic anastomosis $(n=10)$, at one $(n=19)$ or both $(n=3)$ distal iliac anastomosis, and unilateral $(n=1)$ or bilateral $(n=1)$ true iliac aneurysms. 
Diameters of the aneurysms ranged from 3.4 to $11.0 \mathrm{~cm}$ for aortic pseudoaneurysms, from 1.5 to $8.3 \mathrm{~cm}$ for iliac pseudoaneurysms, and from 2.1 to $7.5 \mathrm{~cm}$ for true iliac aneurysms.

In 40 patients, the paraanastomotic aneurysms were detected by a routine surveillance protocol that included ultrasound imaging 1 year after open aortic surgery and every 3 or 5 years thereafter. In five patients, the paraanastomotic aneurysms were incidentally detected by diagnostic imaging that was performed for purposes other than surveillance after open AAA repair. Eight patients presented with a symptomatic paraanastomotic aneurysm, and five presented with a ruptured paraanastomotic aneurysm. None of the patients in this series had symptoms or signs at CT suggesting graft infection.

Through preoperative risk assessment of pre-existent disease, 17 patients were classified as American Society of Anesthesiologists (ASA) II, 22 patients as ASA III, and 19 patients as ASA IV. At baseline, cardiovascular and pulmonary comorbidity was present in 50 (86\%) and 21 (36\%) patients, respectively.

Table 6.1 Baseline characteristics and clinical details after initial open conventional tube and bifurcated graft. Data are presented as number (\%) or as median (IQR).

\begin{tabular}{|c|c|c|c|}
\hline Variables & $\begin{array}{c}\text { Tube graft } \\
(n=28)\end{array}$ & $\begin{array}{l}\text { Bifurcated graft } \\
(n=30)\end{array}$ & $\begin{array}{c}\text { All } \\
(n=58)\end{array}$ \\
\hline \multicolumn{4}{|l|}{ Baseline characteristics } \\
\hline Age & $68(62-78)$ & $74(65-78)$ & $73(63-78)$ \\
\hline Male & $26(93 \%)$ & 27 (90\%) & $53(91 \%)$ \\
\hline Comorbidity & $25(89 \%)$ & $26(87 \%)$ & $51(88 \%)$ \\
\hline Cardiovascular $^{\mathrm{a}}$ & $25(89 \%)$ & $25(83 \%)$ & $50(86 \%)$ \\
\hline Pulmonary & $8(29 \%)$ & $12(40 \%)$ & $20(35 \%)$ \\
\hline Renal & $5(18 \%)$ & $6(20 \%)$ & $11(19 \%)$ \\
\hline Serum creatinine level $(\mu \mathrm{mol} / \mathrm{L})$ & $95(91-115)$ & $116(98-165)$ & $115(95-161)$ \\
\hline ASA class & $3(2-4)$ & $3(2-4)$ & $3(2-4)$ \\
\hline 1 & $0(0 \%)$ & $0(0 \%)$ & $0(0 \%)$ \\
\hline ॥ & $9(32 \%)$ & $8(27 \%)$ & $17(29 \%)$ \\
\hline III & $12(43 \%)$ & $10(33 \%)$ & $22(38 \%)$ \\
\hline IV & $7(25 \%)$ & $12(40 \%)$ & $19(33 \%)$ \\
\hline Latency time, years ${ }^{\mathrm{b}}$ & $7(4-11)$ & $16(12-21)$ & $13(6-18)$ \\
\hline \multicolumn{4}{|l|}{ Clinical details } \\
\hline Number of PAA & 42 & 38 & 80 \\
\hline Proximal pseudo PAA & 9 & 10 & 19 \\
\hline Proximal true PAA & 0 & 0 & 0 \\
\hline Distal pseudo PAA & 7 & 25 & 32 \\
\hline Distal true PAA & 26 & 3 & 29 \\
\hline
\end{tabular}

ASA = American Society of Anesthesiologists; PAA = paraanastomotic aneurysm .

${ }^{a}$ Other than previous aneurysmal or occlusive aortic disease; ${ }^{b}$ Time between initial open prosthetic surgery and endovascular paraanastomotic aneurysm repair. 


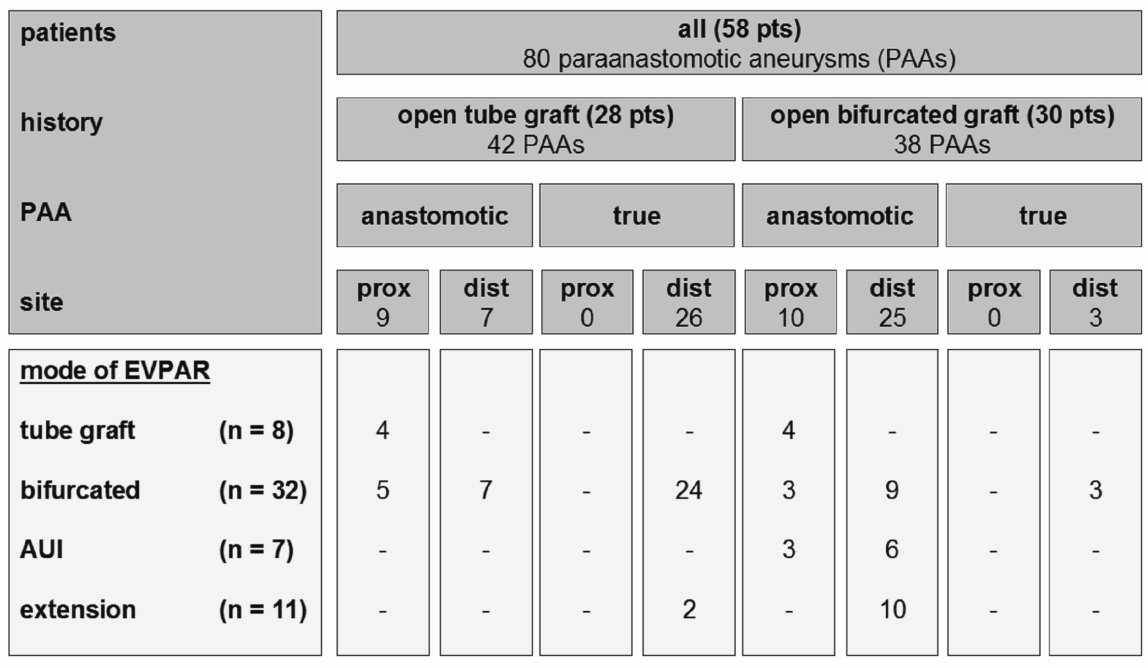

Figure 6.1 Flowchart showing the types of stent graft (grey) used for different localizations of anastomotic and true paraanastomotic aneurysms after previous open tube or bifurcated graft (dark grey).

\section{Endovascular intervention}

The median interval between the initial open reconstruction and EVPAR was 12.5 years (range, 1-25 years). Endovascular repair was performed under general anesthesia in 38 patients, spinal anesthesia in 17, and under local anesthesia in 3. An endovascular tube graft was used in 8 patients, a bifurcated stent graft in 32 , an aortouniiliac stent graft in 7 , and an iliac extension graft in 11 (Figure 6.1). Devices that were used are listed in Table 6.2. Median procedure time was 120 minutes (range, 45-355 minutes) and median blood loss was $250 \mathrm{ml}$ (range, 30-1900 ml). The median radiation time was 23 minutes (range, 3-66 minutes), and median contrast dose administration was $87 \mathrm{ml}$ (range, 20-150 ml).

None of the patients died during the EVPAR procedure. Stent graft deployment was successful in 55 patients (technical success rate, 95\%). One patient needed an adjunctive surgical procedure. In this patient, access to the retroperitoneum was gained to ligate the contralateral limb of the previous open bifurcated graft after successful aortouniiliac endoprosthesis placement for a ruptured proximal paraanastomotic aneurysm. In three patients (5\%), primary stent graft deployment was unsuccessful, of whom one needed an additional laparotomy. In this patient, the short contralateral leg of the bifurcated stent graft was 
deployed accidentally in the ipsilateral limb of the primary existing bifurcated graft. The bifurcated stent graft was then converted into an aortouniiliac stent graft by extending the graft to the right external iliac artery. Subsequently, a suitable endovascular occluder was not available, so a laparotomy was performed for ligation of the right hypogastric artery and the left common iliac artery to prevent back bleeding into the aneurysm sac. A femorofemoral crossover bypass was placed to restore blood flow in the left leg.

Table 6.2 Types of endovascular stent grafts that were used.

\begin{tabular}{lcccc}
\hline Device & Tube graft & Bifurcated graft & Aortouniliac graft & Extension \\
\hline AneuRx & 1 & 8 & 0 & 1 \\
Talent & 3 & 19 & 7 & 6 \\
Endurant & 0 & 1 & 0 & 0 \\
Valiant & 1 & 0 & 0 & 0 \\
Zenith & 1 & 1 & 0 & 1 \\
Quantum LP & 0 & 1 & 0 & 0 \\
Gore excluder & 1 & 2 & 0 & 3 \\
Relay & 1 & 0 & 0 & 0 \\
Total & 8 & 32 & 7 & 11 \\
\hline
\end{tabular}

The secondary technical success rate was $97 \%$. In the two other patients with unsuccessful stent graft deployment, one $(n=1)$ or both $(n=1)$ renal arteries were inadvertently overstented during stent graft deployment by a tube and bifurcated stent graft, respectively. No type I or III endoleaks were observed at completion angiography.

There were no statistically significant differences in primary $(P=1.000)$ or secondary success rate $(P=1.000)$ between patients included in the first or final 5 years of the study period.

Other events during EVPAR were type II endoleaks at angiography at the end of the procedure in four patients, of which one type II endoleak was still present on predischarge CTA. Furthermore, the left hypogastric artery in one patient was inadvertently covered by the stent graft.

\section{Hospital stay}

Median hospital stay was 3 days (range, 1-122 days). The in-hospital and 30-day mortality rates were $6.9 \%(n=4)$ and $3.4 \%(n=2)$, respectively, all in patients with successful stent graft deployment. Two of these four patients were treated for a ruptured paraanastomotic aneurysm. Causes of death were pulmonary insufficiency (day 8), progressive cardiac failure (day 8), pulmonary insufficiency 
combined with a sepsis (day 55), and sepsis after repetitive infections and occlusion of a femorofemoral crossover bypass (day 122). This last patient underwent several reinterventions for critical limb ischemia.

The 30-day clinical success rate was $91 \%(n=53)$. In five patients, 30-day clinical success was not achieved due to death $(n=2)$, overstenting of both renal arteries causing progressive renal insufficiency $(n=1)$, distal type I endoleak present on predischarge CTA $(n=1)$ for which close observation was initiated, and hemodynamic shock $(n=1)$ due to rupture of the left external iliac artery after paraanastomotic aneurysm repair for which an extension cuff was placed successfully. An abdominal compartment syndrome developed in this last patient due to a retroperitoneal hematoma and abdominal decompression was required the next day.

\section{Follow-up}

Median follow-up was 41 months (range, 0-106 months). No patients were lost to follow-up. The cumulative mortality during hospital stay and follow-up was $19 \%(n=11)$. Overall, median follow-up until death was 13 months (range, 0-106 months). Patient survival is illustrated using a Kaplan-Meier curve (Figure 6.2 ), which shows the annual risk of mortality was $4.0 \%$. Two of seven deaths during follow-up were procedure-related. In one patient, slight aneurysm expansion $(3 \mathrm{~mm}$ ) without signs of an endoleak was observed on CTA at 12 months after endovascular treatment for a proximal paraanastomotic pseudoaneurysm using a tube stent graft. A wait-and-see policy was followed, but this resulted in acute aneurysm rupture at 18 months needing acute reintervention including explantation of the endovascular graft and placement of an open bifurcated prosthesis. The patient died the next day due to bowel ischemia. The other patient, whose renal artery was overstented during the endovascular procedure, suffered from postoperative progressive hemodialysisdependent renal insufficiency. At 51 months, successful conversion to open repair was performed for a type la endoleak. However, this patient decided to stop undergoing hemodialysis and died at 106 months of follow-up.

The overall complication rate during follow-up after discharge was $22 \%(n=13)$. Two patients died due to procedure-related complications, as described above. Hydronephrosis occurred in one patient as the result of external ureter compression by a paraanastomotic aneurysm in the iliac artery. In the other 10 patients $(17 \%)$, reinterventions were performed for stent graft occlusion in 4 patients that needed thrombectomy or thrombolysis, followed by percutaneous 
transluminal angioplasty (PTA) in 3 patients and replacement with a synthetic prosthesis in 1 patient; infection of a femorofemoral crossover bypass that was replaced by a venous bypass in 1 , access site infection and bleeding of a patch in the groin in 2, type B dissection for which an aortouniiliac stent graft was placed in 1, distal type I endoleak (which was already detected on predischarge CTA as described previously) of a bifurcated stent graft for which an iliac extension graft was placed in 1 , and endotension for which the stent graft was converted to a bifurcated prosthesis in 1.

Survival

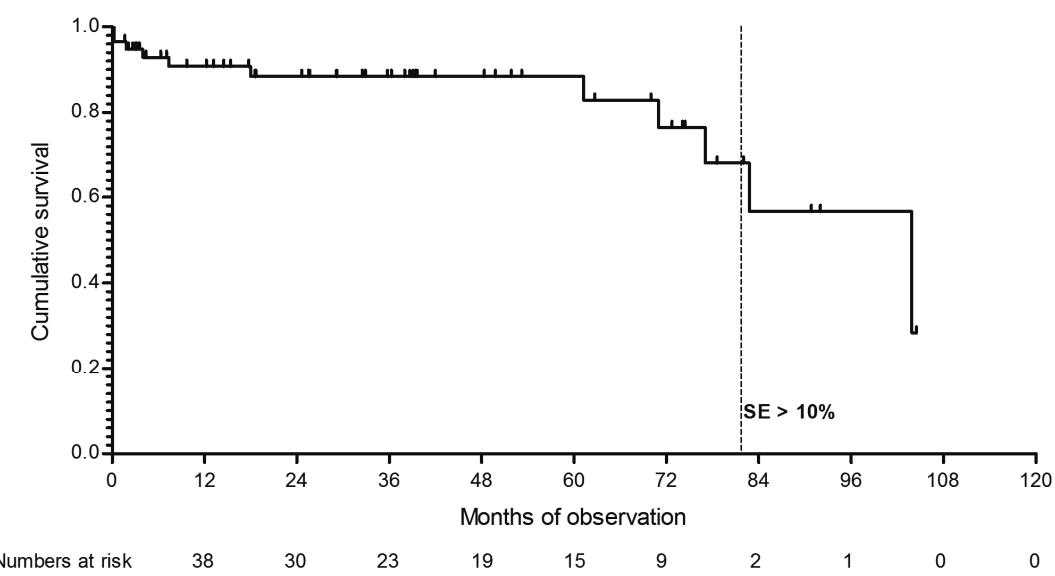

Figure 6.2 Kaplan-Meier curve showing survival after endovascular paraanastomotic aneurysm repair. The dashed line indicates when the standard error exceeds $10 \%$.

During total follow-up, including hospital stay, reintervention was performed in 15 patients (25.9\%) at a median of 11 months (range, 0-80 months). Figure 6.3 shows the Kaplan-Meier curve for freedom of reintervention after endovascular paraanastomotic aneurysm repair. The overall annual risk of reintervention was $5.8 \%$ (SE, 0.088). The log-rank test for equality of reintervention distributions between differences in original presentation of paraanastomotic aneurysms is visualized in Figure 6.4A, showing no significant differences in freedom from reintervention curves during follow-up ( $P=0.131)$. In Figure 6.4B, freedom from reintervention during follow-up is presented for different stent graft configurations, showing a significantly larger proportion of tube and 
aortouniiliac stent grafts needing reintervention during follow-up using the logrank test $(P<0.001)$. The annual reintervention risk was $3.2 \%(\mathrm{SE}, 0.098 \%)$ for bifurcated stent grafts, $16.6 \%$ (SE, 0.239\%) for tube grafts, $66.4 \%$ (SE, <0.001\%) for aortouniiliac stent grafts, and $19.1 \%$ (SE, 0.152\%) for distal iliac extension grafts.

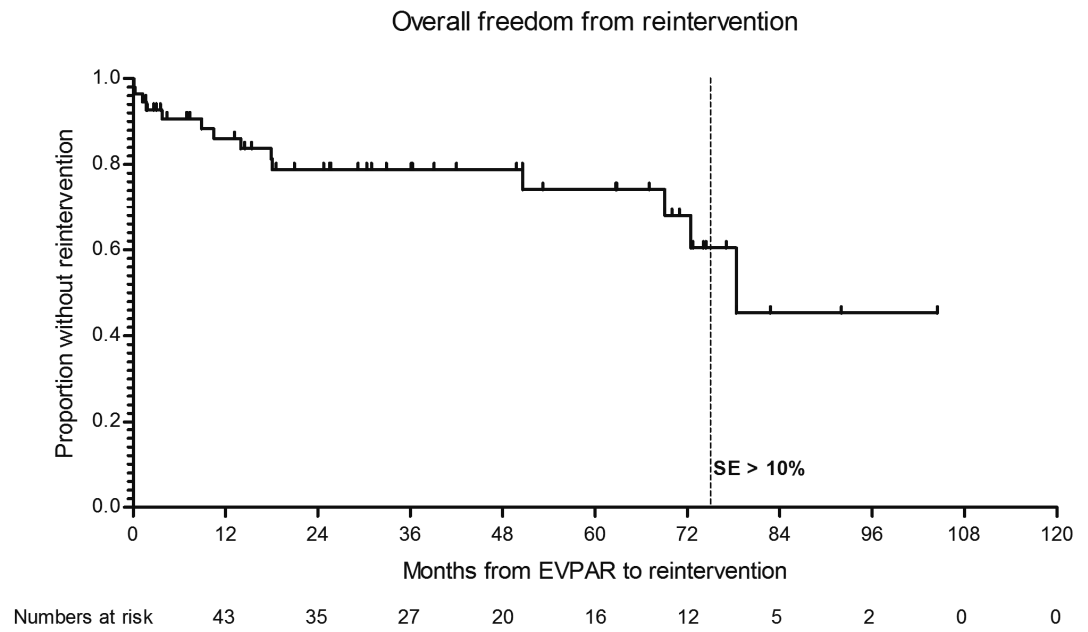

Figure 6.3 Kaplan-Meier curve showing freedom from reintervention after EVPAR for all stent grafts that were used. The dashed line shows when the standard error exceeded $10 \%$.

Furthermore, the reintervention rate in patients who were treated with endovascular repair during the first 5 years of the study period $(30 \%)$ was comparable with patients treated during the final 5 years $(23 \%),(P=0.560)$.

Four patients $(6.9 \%)$ required conversion to open repair at a median follow-up of 16 months (range, 4-51 months). Two patients needed conversion for endotension, which caused an aneurysm rupture in one patient. In one patient, an endovascular tube graft was replaced by an open tube graft at 51 months after EVPAR for persistent type la endoleak. Finally, an axillobifemoral prosthesis was placed in one patient for occlusion of a bifurcated stent graft at 4 months after placement for bilateral true iliac paraanastomotic aneurysms. Mortality was $50 \%$ ( 2 of 4 ) in patients who underwent conversion to open aneurysm repair vs $0 \%$ ( 0 of 5 ) in patients who underwent an endovascular reintervention $(P=0.167)$. 
A

Freedom from reintervention for different locations of PAA

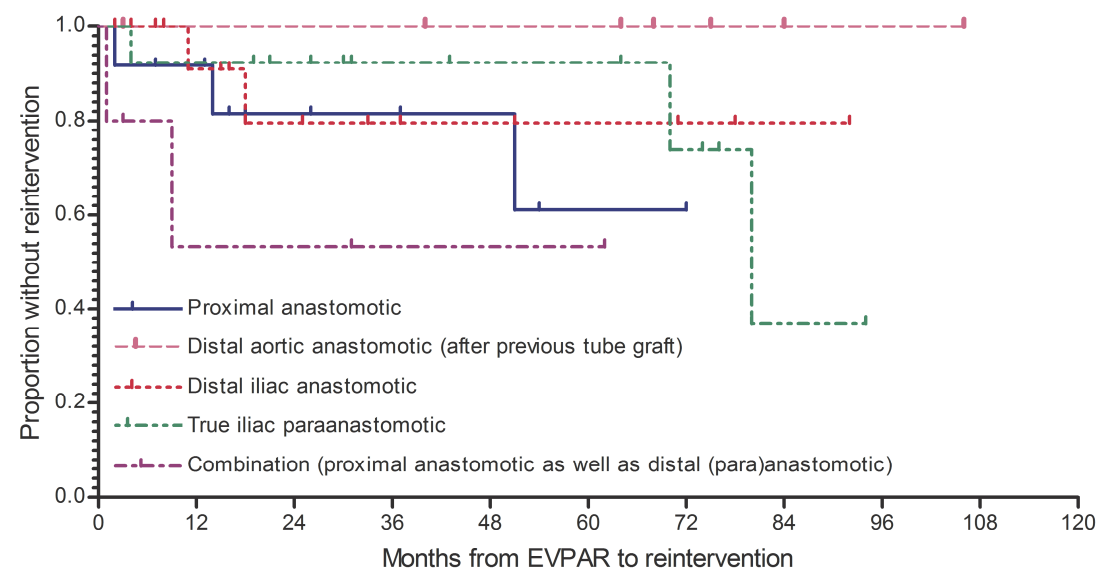

B

Freedom from reintervention for different types of stentgrafts

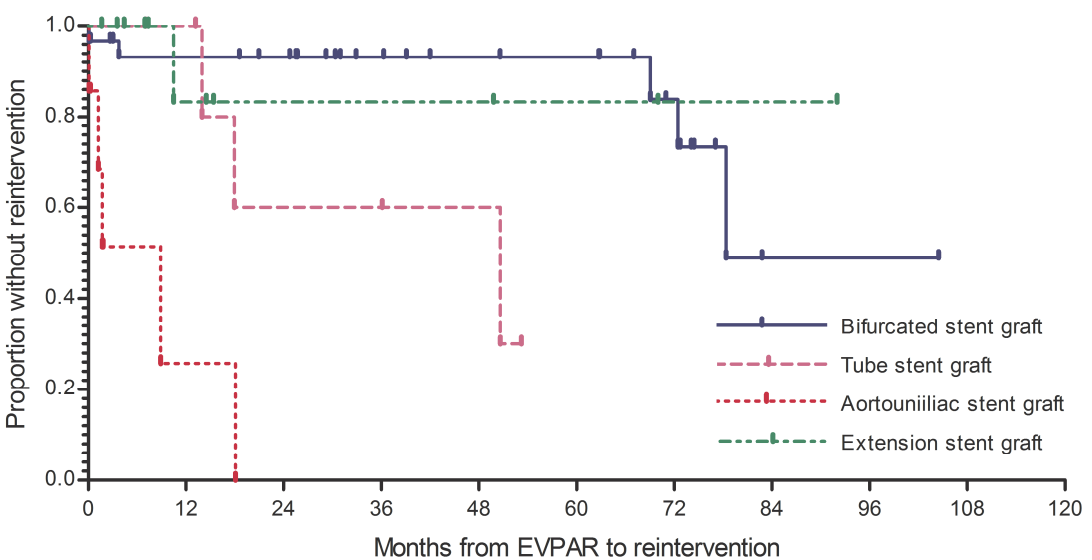

Figure 6.4 Kaplan-Meier curve showing freedom from reintervention after EVPAR for (A) different locations of paraanastomotic aneurysm formation and (B) the different types of stent grafts that were used.

During follow-up, CTA revealed nine endoleaks (1 type la, 2 type Ib, and six secondary type II endoleaks) in eight patients. In one patient, type la endoleak was observed after migration of the previously described bifurcated stent graft, which was converted to an aortouniiliac stent graft during EVPAR. Type Ib endoleak was observed in two patients at the distal fixation side of the 
endovascular tube graft, resulting in replacement of the stent graft by an open tube graft in one patient, as described above. Of the six secondary type II endoleaks, two disappeared spontaneously during follow-up, and the other four received close observation. None of these patients needed reintervention and AAA did not grow. Furthermore, endotension was observed in two patients treated with an endovascular tube graft for a proximal paraanastomotic aortic aneurysm, resulting in conversion to open surgical repair in one patient and acute aneurysm rupture in the other patient, as described previously.

\section{Discussion}

The reported incidence of paraanastomotic aneurysms after previous conventional aortic reconstruction varies widely, from 0.5 to $15 \%{ }^{17,18}$ This is probably an underestimation, because most patients who undergo open aortic repair do not receive regular imaging surveillance follow-up. Paraanastomotic aneurysms are associated with high rupture rates. The reported rupture rate ranges from $15 \%$ to $55 \%$ in patients who did not undergo revision surgery. ${ }^{8,19,20}$ Pseudoaneurysms might be even more unpredictable in terms of rupture risk compared with true paraanastomotic aneurysms, ${ }^{1}$ with a mortality rate of $61 \%$ in the absence of an intervention. ${ }^{5}$

EVPAR allows for local or regional anesthesia without requiring dissection through the scars of previous operative sites. ${ }^{9}$ However, EVPAR has some drawbacks, including inadequate proximal or distal fixation zones ${ }^{21}$, showing the importance of accurate pre-operative sizing and planning, and potential stent graft deformation in patients with previous end-to-side anastomoses.

Several case series describing endovascular management of paraanastomotic aortic and iliac aneurysms have considered this treatment as feasible and

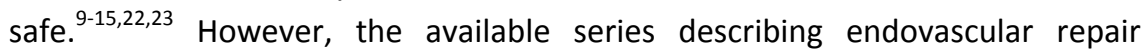
included a small number of patients, and follow-up time is relatively short. The report by Sachdev et al. included 53 patients with paraanastomotic aneurysms treated with endovascular repair at a mean follow-up of 18.1 months, excluding patients who were lost to follow-up. ${ }^{16}$ However, they studied a mixture of thoracic and abdominal paraanastomotic aneurysms.

Reported mortality rates of open paraanastomotic aneurysm reconstruction vary widely from $8 \%$ to $70 \%$ with morbidity rates of $70 \%$ to $83 \%$ reported for open paraanastomotic aneurysm reconstruction. ${ }^{4-8}$ One report compared 16 
open repairs with 10 EVPAR procedures in patients who were candidates for endovascular repair, showing higher morbidity and complication rates after open repair than with endovascular repair. ${ }^{24}$ Furthermore, blood loss, procedural time, and hospital length of stay were significantly reduced for endovascular repair. The results of the present study focus on durability of endovascular repair with different types of stent grafts for paraanastomotic aneurysms, with extended follow-up time and more patients.

The present study, with a follow-up up to 106 months, showed endovascular management of paraanastomotic aortic and iliac aneurysms is a feasible and durable alternative to open reconstruction. In $95 \%$ of patients treated with EVPAR after previous open aortic reconstruction, stent graft deployment was successful (primary technical success rate). Perioperative mortality and morbidity rates in patients $(70 \%$ with ASA class $\geq 11$ ) were acceptable, with an intraoperative mortality of $0 \%, 30$-day mortality of $3.4 \%$, and in-hospital mortality of $6.9 \%$. Exclusion was successfully maintained during follow-up, without signs of endoleak, in $86 \%$ of the paraanastomotic aneurysms. Furthermore, in patients who needed conversion to open repair after EVPAR, there was a clear trend towards a higher mortality rate compared with patients who underwent an endovascular reintervention.

The technical success rates and effective aneurysm exclusion rates reported in the present study are notable since 13 patients with either symptomatic or ruptured paraanastomotic aneurysms were included in this experience. This observation suggests that while careful adherence to stringent selection criteria for endovascular repair is important, this approach can be applied in more urgent settings where preoperative planning may be less thorough.

Several patients in the present study who had paraanastomotic aortoiliac aneurysms with relatively small diameters were treated with endovascular repair. Indications for treatment in these patients were symptoms or rupture of the aneurysm, or aneurysm growth during routine follow-up after primary open prosthetic reconstruction.

In the present study, there were no statistical significant differences in durability between endovascular repair in proximal aortic anastomotic, distal aortic anastomotic, distal iliac anastomotic and true distal paraanastomotic aneurysms after previous open aortic reconstruction (Figure 6.4A). However, the studied numbers were low for subgroup analysis and Figure 6.4A gives the 
impression of a slight non-significant trend towards better durability in terms of freedom from reintervention after endovascular repair of anastomotic distal aortic aneurysms (after previous open tube graft placement) and anastomotic distal iliac aneurysms.

When comparing different types of stent grafts in all included patients, as represented in Figure 6.4B, the endovascular reconstruction was less durable in patients treated with aortouniiliac and tube stent grafts for proximal paraanastomotic aortic aneurysms. The main causes for reintervention in aortouniiliac stent grafts were infections of the femorofemoral crossover bypass and stent graft occlusion. In patients treated with an endovascular tube graft, the main cause of reintervention was endoleak type I, caused by insecure distal anchoring of the endovascular stent graft in the previous polyester graft, or endotension. Therefore, when endovascular tube grafts are used for proximal anastomotic aneurysms, the distal fixation site has to be long enough for secure distal anchoring of the tube graft in the previous polyester prosthesis. Or when the proximal anchoring site is short, efforts have to be done to implant a bifurcated stent graft. Follow-up showed the proximal fixation site of the aortouniiliac or bifurcated stent grafts in the previous polyester graft was secure, probably due to the longitudinal columnar support in these types of stent grafts. Stent grafts that were fixated proximally and distally in the native aorta or iliac vessels were all secure.

Although original anatomical presentation of paraanastomotic aneurysms did not influence long-term durability results significantly (Figure 6.4A), results from different types of stent grafts that were used (Figure 6.4B) have to be interpreted with caution due to the limited numbers of cases and anatomical variation influencing stent graft selection. Stent graft selection for endovascular paraanastomotic aneurysm repair should not merely be based on the reported differences in outcome between various types of stent grafts as demonstrated in the present study, but rather be an individualized approach in which these results are addressed in the view of anatomical considerations.

\section{Conclusions}

The present multi-center study confirms that EVPAR after initial prosthetic aortic surgery is a feasible and safe alternative to open reconstruction with relatively low perioperative mortality and morbidity in selected cases. At longterm follow-up, treatment with bifurcated stent grafts showed to be durable with low reintervention rates. Aortouniiliac stent grafts and endovascular tube grafts appeared less durable, requiring more reinterventions. Based on the 
long-term results of EVPAR in this series of 58 patients, endovascular exclusion of anatomically suitable paraanastomotic aneurysms with bifurcated stent grafts can be considered as the first-choice treatment option. Though, EVPAR requires an individualized approach taking anatomical considerations into account. 


\section{References}

1. Abou-Zamzam AM, Jr., Ballard JL. Management of sterile para-anastomotic aneurysms of the aorta. Semin Vasc Surg. 2001;14:282-291.

2. Biancari F, Ylonen K, Anttila V, Juvonen J, Romsi P, Satta J, et al. Durability of open repair of infrarenal abdominal aortic aneurysm: a 15-year follow-up study. J Vasc Surg. 2002;35:87-93.

3. Hallett JW, Jr., Marshall DM, Petterson TM, Gray DT, Bower TC, Cherry KJ, Jr., et al. Graftrelated complications after abdominal aortic aneurysm repair: reassurance from a 36-year population-based experience. J Vasc Surg. 1997;25:277-284; discussion 85-6.

4. Locati P, Socrate AM, Costantini E. Paraanastomotic aneurysms of the abdominal aorta: a 15-year experience review. Cardiovasc Surg. 2000;8:274-279.

5. Mulder EJ, van Bockel JH, Maas J, van den Akker PJ, Hermans J. Morbidity and mortality of reconstructive surgery of noninfected false aneurysms detected long after aortic prosthetic reconstruction. Arch Surg. 1998;133:45-49.

6. Kraus TW, Paetz B, Hupp T, Allenberg JR. Revision of the proximal aortic anastomosis after aortic bifurcation surgery. Eur J Vasc Surg. 1994;8:735-740.

7. Allen RC, Schneider J, Longenecker L, Smith RB, 3rd, Lumsden AB. Paraanastomotic aneurysms of the abdominal aorta. J Vasc Surg. 1993;18:424-431; discussion 31-2.

8. Treiman GS, Weaver FA, Cossman DV, Foran RF, Cohen JL, Levin PM, et al. Anastomotic false aneurysms of the abdominal aorta and the iliac arteries. J Vasc Surg. 1988;8:268-273.

9. van Herwaarden JA, Waasdorp EJ, Bendermacher BL, van den Berg JC, Teijink JA, Moll FL. Endovascular repair of paraanastomotic aneurysms after previous open aortic prosthetic reconstruction. Ann Vasc Surg. 2004;18:280-286.

10. Lagana D, Carrafiello G, Mangini M, Recaldini C, Lumia D, Cuffari S, et al. Endovascular treatment of anastomotic pseudoaneurysms after aorto-iliac surgical reconstruction. Cardiovasc Intervent Radiol. 2007;30:1185-1191.

11. Zhou W, Bush RL, Bhama JK, Lin PH, Safaya R, Lumsden AB. Repair of anastomotic abdominal aortic pseudoaneurysm utilizing sequential AneuRx aortic cuffs in an overlapping configuration. Ann Vasc Surg. 2006;20:17-22.

12. Mitchell JH, Dougherty KG, Strickman NE, Mortazavi A, Krajcer Z. Endovascular repair of paraanastomotic aneurysms after aortic reconstruction. Tex Heart Inst J. 2007;34:148-153.

13. Cerna $M$, Kocher M, Utikal P, Koutna J, Drac $P$, Bachleda $P$, et al. Endovascular treatment of abdominal aortic paraanastomotic pseudoaneurysms after surgical reconstruction. Eur J Radiol. 2009;71:333-337

14. Di Tommaso L, Monaco M, Piscione F, Sarno G, lannelli G. Endovascular stent grafts as a safe secondary option for para-anastomotic abdominal aortic aneurysm. Eur J Vasc Endovasc Surg. 2007;33:91-93.

15. Piffaretti G, Tozzi M, Lomazzi C, Rivolta N, Caronno R, Castelli P. Endovascular treatment for para-anastomotic abdominal aortic and iliac aneurysms following aortic surgery. J Cardiovasc Surg (Torino). 2007;48:711-717.

16. Sachdev U, Baril DT, Morrissey NJ, Silverberg D, Jacobs TS, Carroccio A, et al. Endovascular repair of para-anastomotic aortic aneurysms. J Vasc Surg. 2007;46:636-641.

17. Edwards JM, Teefey SA, Zierler RE, Kohler TR. Intraabdominal paraanastomotic aneurysms after aortic bypass grafting. J Vasc Surg. 1992;15:344-350; discussion 51-3.

18. Szilagyi DE, Smith RF, Elliott JP, Hageman JH, Dall'Olmo CA. Anastomotic aneurysms after vascular reconstruction: problems of incidence, etiology, and treatment. Surgery. 1975;78:800-816.

19. Curl GR, Faggioli GL, Stella A, D'Addato M, Ricotta JJ. Aneurysmal change at or above the proximal anastomosis after infrarenal aortic grafting. J Vasc Surg. 1992;16:855-859; discussion 859-860.

20. Crawford ES, Beckett WC, Greer MS. Juxtarenal infrarenal abdominal aortic aneurysm. Special diagnostic and therapeutic considerations. Ann Surg. 1986;203:661-670. 
21. Pearce BJ, Baldwin Z, Bassiouny H, Gewertz BL, McKinsey JF. Endovascular solutions to complications of open aortic repair. Vasc Endovascular Surg. 2005;39:221-228.

22. Liewald F, Kapfer X, Gorich J, Halter G, Tomczak R, Scharrer-Pamler R. Endograft treatment of anastomotic aneurysms following conventional open surgery for infrarenal aortic aneurysms. Eur J Vasc Endovasc Surg. 2001;21:46-50.

23. Tiesenhausen K, Hausegger KA, Tauss J, Amann W, Koch G. Endovascular treatment of proximal anastomotic aneurysms after aortic prosthetic reconstruction. Cardiovasc Intervent Radiol. 2001;24:49-52.

24. Gawenda M, Zaehringer M, Brunkwall J. Open versus endovascular repair of para-anastomotic aneurysms in patients who were morphological candidates for endovascular treatment. J Endovasc Ther. 2003;10:745-751. 



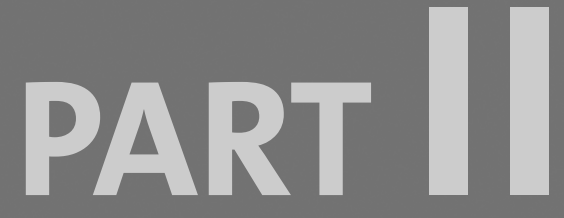

Follow-up after endovascular aneurysm repair, depicting stent graft related complications 



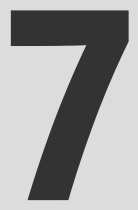

Strategies for detection of endoleaks after endovascular abdominal aortic aneurysm repair

JA Ten Bosch

FAMVI Hellenthal

MRHM van Sambeek

MW de Haan

GWH Schurink

JAW Teijink

Submitted 



\section{Introduction}

Open surgical repair has been the established treatment option in the prevention of rupture in patients with an abdominal aortic aneurysm (AAA). In 1991, Parodi et al. introduced a less invasive alternative to conventional open surgical repair in selected patients with an AAA, endovascular aneurysm repair (EVAR). ${ }^{1}$ By means of a catheter based system a synthetic stent graft is introduced from the groin up to the AAA neck. When positioned correctly just below the renal arteries, the stent graft is unfolded, excluding the aneurysm sac from systemic blood pressure, but leaving the aneurysm sac in situ. Gradually decreasing AAA diameter after endovascular repair is presumed to reflect successful treatment and low rupture risk, ${ }^{2,3}$ whereas increasing AAA diameters at follow-up indicates incomplete exclusion and therefore continued rupture risk. ${ }^{4}$ Stent graft related complications might cause re-establishment of pressure in the aneurysm sac resulting in aneurysm expansion and ongoing rupture risk. ${ }^{5}$ Therefore, long term surveillance is required for detection of these stent graft related complications, including migration, kinking, and endoleakage. Surveillance could be in the form of an imaging modality or a systemic blood marker.

According to the practical guidelines of the Society of Interventional Radiology, three parameters should be included for imaging surveillance: diameter measurements of the aortic aneurysm, detection of morphologic details of the stent grafts, and detection and classification of endoleaks. ${ }^{6}$ In order to followup aneurysm size, aneurysm diameter as well as volume measurements can be used. Currently, maximal anterior-posterior diameter is the most widely used parameter for aneurysm size measurements. Aortic lumen volume and thrombus volume might be more appropriate to discriminate successful from failed exclusion. ${ }^{7}$ However, their association with the presence of an endoleak does not appear to be substantially stronger according to Wolf et al. ${ }^{8}$ Furthermore, changes in volume seem to be parallel with changes in maximal aneurysm diameter. ${ }^{8}$ Bley et al. showed that volumetric increase on nonenhanced CT serves as an adequate screening test for endoleak. ${ }^{9}$

Alteration of stent grafts morphology, including migration, kinking and fracture, are the result of hemodynamic stress, aortic morphologic changes and/or device inadequacy. These stent graft deformations may cause endoleakage, continued rupture risk or obstruction of blood flow through the device.

Endoleak formation, defined as a blood flow outside the stent graft and inside the aneurysm sac, ${ }^{3,10,11}$ is the most common complication of EVAR with a reported incidence varying from 2 to $45 \% .{ }^{12-15}$ Persistent endoleak is often 
considered a procedural failure because it may cause enlargement and eventual rupture of the aneurysm. It represents the main indication for late surgical conversion. ${ }^{16}$ Endoleak can be organized into four categories, based on the origin of the leak, as described by Veith et al. ${ }^{3}$ The reported incidence of type I and II endoleak after EVAR is $8.2-18.0 \%$ and $7.8-23.4 \%$, respectively. ${ }^{17-20}$ Due to stent graft improvements, type III and IV endoleaks are currently fairly unusual with reported incidence of $0.7-3.8 \% .{ }^{17-20}$ Endotension is defined as persistent or recurrent increased intrasac pressure after endovascular aneurysm repair without evidence of endoleak. ${ }^{3,21}$ Endotension remains an important yet controversial concept, since its etiology and clinical consequences are not fully understood. $^{22}$

Since endoleakage may cause aneurysm expansion and ongoing rupture risk, modalities in order to identify them are essential in the post-EVAR surveillance. Among various imaging modalities, computed tomography angiography (CTA) is the most widely used technique for post-EVAR surveillance. ${ }^{13}$ However, magnetic resonance angiography, (contrast enhanced) ultrasonography, digital subtraction angiography, plain abdominal X-ray, and possibly also biomarkers might all have a role in endoleak detection.

This review will discuss the strategies for endoleak detection in the follow-up after EVAR in terms of imaging techniques and biochemical assays.

\section{Strategies for surveillance}

\section{CT Angiography}

Contrast-enhanced helical CTA is generally considered the gold standard in the follow-up of patients after stent graft implantation. ${ }^{14,16}$ Improvements in contrast injection methods and timing have resulted in superior aortic enhancement. $^{23,24}$ Furthermore, the introduction of multidetector scanners has allowed CTA to be performed with a substantial reduction of contrast medium dose and scanning duration, and with higher longitudinal spatial resolution. ${ }^{25,26}$ Currently, the widespread availability, rapid acquisition, reproducibility, and high spatial and contrast resolution of CTA have made this the imaging modality of choice for post-EVAR follow-up. ${ }^{27}$ CTA allows for correct detection and classification of endoleaks with higher sensitivity for endoleak detection than conventional angiography (92\% versus 63\%). ${ }^{14,28-30}$ However, repetitive CTA has several important drawbacks, including cumulative radiation dose, nephrotoxic contrast load, and high cost. ${ }^{31,32}$ Furthermore, CTA is inadequate in determining 
the direction of blood flow in the vessel feeding the endoleak, thereby limiting the role for this modality in endoleak classification. ${ }^{27}$

Since endoleaks occur at variable flow rates, detection is possible at variable times after the administration of contrast. Therefore, multiphasic CTA imaging is performed routinely in most institutions. In addition to arterial phase acquisition (imaging just after contrast administration), an unenhanced (prior to contrast administration) and delayed (post contrast) phase acquisition can be acquired. Non-enhanced acquisitions might be useful for differentiation of endoleaks from calcifications or the metallic portion of a stent graft. ${ }^{33}$ Arterialphase imaging can be helpful to determine the access site for endoleak intervention. ${ }^{27}$ Delayed CT acquisitions enable the detection of additional endoleaks who were not depicted on arterial phase imaging, especially low-flow endoleaks. . $^{2,28,33,34}$ However, the optimal timing for detection of low-flow endoleaks is unknown since this is (endoleak) flow-rate dependent. Although a minimum delay of 1 minute is recommended, the reported delays in literature varies widely from 60 to 300 seconds. $^{6}$ The specific role of nonenhanced, arterial and delayed phase acquisition in the detection of endoleaks is uncertain. Therefore, the optimal CT image acquisition protocol is still a subject of debate. ${ }^{27}$ Golzarian et al. concluded that the diagnostic value of biphasic helical CT (nonenhanced and arterial phase acquisition) is superior to arterial phase acquisition alone for follow-up after EVAR. ${ }^{13}$ In a study of Rozenblit et al. the combination of an unenhanced acquisition with either an arterial phase and delayed phase acquisition contributed to accurate diagnosis of endoleaks. ${ }^{33}$ lezzie et al. found that the delayed enhanced imaging phase did not significantly increase sensitivity for detection of endoleaks, but it did depict low-flow endoleaks not seen at the arterial phase. ${ }^{34}$ Macari et al. on the other hand, indicated that the arterial enhanced imaging phase may not be necessary for the routine detection of endoleaks and therefore be eliminated from the protocol, saving $36.5 \%$ of the effective radiation dose delivered. ${ }^{35}$

Modern CT techniques, such as the recently introduced dual-energy dual-source CT system consisting of two x-ray tubes operating at different tube voltages and two corresponding detectors, make it possible to reconstruct virtual nonenhanced images from contrast-enhanced dual-energy CT data. ${ }^{36}$ Consequently, nonenhanced imaging is made unnecessary, which reduces radiation dose. Stolzmann et al. have assessed the diagnostic performance of dual-energy dual-source CT for the detection of endoleaks after EVAR and found a high accuracy with considerably lower radiation dose. ${ }^{37}$ Additionally, a phantom study of Szucs-Farkas et al. suggests that reduced radiation exposure 
without increased risk of missing significant endoleaks can also be achieved with lower tube-voltage CTA. ${ }^{38}$

Not only the optimal CT image acquisition protocol is still controversial, but also the ideal frequency of $\mathrm{CT}(\mathrm{A})$ follow-up is debatable. The intensive imaging follow-up provides a great amount of information, but the relevance of the information acquired has not been evaluated in relation to improving results obtained with successive generations of stent grafts. ${ }^{39,40}$ In two recent studies, it is suggested that less-frequent CT follow-up is sufficient in the majority of patients. ${ }^{41,42}$ Contrast-enhanced CT scans continue to be critical when reinterventions are planned. ${ }^{42}$

\section{(Contrast-Enhanced) Color Duplex Ultrasound}

Color duplex ultrasound (US) imaging is convenient, noninvasive, inexpensive, widely available, and involves no exposure to radiation. A number of studies have indicated that color duplex ultrasound may be used for post-EVAR surveillance. ${ }^{43-48}$ Aneurysm sac size differences over time as assessed with US correlate well with $\mathrm{CT}^{43,47,49-51}$ However, poor agreement in absolute AAA diameter was observed. ${ }^{52}$ When compared to orthogonal CT, US measurements agrees better than axial CT measurements, since US measurements are not

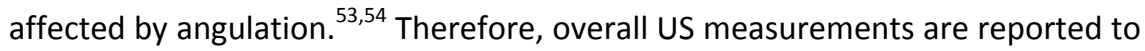
be slightly smaller than those with axial $\mathrm{CT}^{51,52,55}$ and might even be a better approximation of true perpendicular AAA diameter as determined by orthogonal CT compared to axial CT. ${ }^{53,54}$

For the detection of endoleaks, color duplex US has reported low sensitivity and low positive predictive value compared to conventional CT angiography. ${ }^{46,50-52,56,57}$ Reported sensitivity and specificity of US in the detection of endoleak varies considerably, from $43 \%$ to $97 \%$ and $25 \%$ to $96 \%$, respectively. ${ }^{46,51,52,58}$ A review of Ashoke et al. showed a pooled sensitivity and specificity of $69 \%$ and $91 \%$, respectively. ${ }^{56}$ Manning et al., Raman et al., and Sato et al. found low positive and high negative predictive values of $45-66 \%$ and 94-98\%, respectively. ${ }^{46,51,58}$ Despite its low sensitivity and positive predicting values, frequent US monitoring might identify an unstable aneurysm that requires further intervention. ${ }^{57}$

Sonographic contrast agents enhance the capability of color duplex to detect endoleaks. $^{45,48,59-63}$ lezzi et al. assessed the diagnostic accuracy of real-time contrast-enhanced US imaging (CEUS) in the detection of endoleaks compared with non-enhanced US imaging in 84 patients. CEUS imaging significantly improved the diagnostic accuracy in the detection of endoleaks compared to 
non-enhanced US studies, in terms of sensitivity ( $98 \%$ vs. $63 \%)$, specificity ( $82 \%$ vs. $64 \%$ ), and negative predictive value (97\% vs. $65 \%) .{ }^{45}$ In a systematic review of Sun et al. containing 21 studies, sensitivity in the detection of endoleak was significantly improved with contrast material-enhanced color duplex US compared with non-enhanced color duplex US. ${ }^{63}$ However, no significant difference was found regarding the specificity, positive predictive value, negative predictive value, and accuracy between unenhanced and enhanced color duplex US. With recent improvements, such as newly developed contrast agents and tissue harmonic imaging, ${ }^{64}$ diagnostic results will improve and contrast-enhanced US might even depict endoleaks when depiction fails in other imaging modalities. ${ }^{48,62,65}$

Through the use of spectral Doppler analysis, intrasac Doppler velocities and Doppler scan waveform patterns can be used to predict whether a type II endoleak will spontaneously seal. ${ }^{66,67}$ Another great advantage of US is that, in contrast with CTA, no adverse events, such as nephropathy, have been reported for ultrasound contrast agents so far. Limitations for clinical applicability of US investigation may be operator-dependent variability, as demonstrated by the considerable variation in sensitivity and specificity results. However, a recent report showed low inter-operator variability for AAA size measurements. ${ }^{65}$ Second, inadequate aneurysm sac visualization is seen in $1.7 \%$ of patients, predominantly due to patient physical habitus such as obesity. ${ }^{46}$ In the study of Elkouri et al. only $74 \%$ of US imaging was considered technically adequate. ${ }^{52,68}$ Although US is highly dependent on well trained operators and is subject to inter-operator variability, improving diagnostic results of CEUS are promising.

\section{Magnetic Resonance Angiography}

For aortic diameter measurements magnetic resonance (MR) imaging has comparable reliability with $\mathrm{CT}^{69}$ Nowadays, MR angiography (MRA) with intravenous administration of paramagnetic contrast agent is a commonly accepted MR technique to evaluate abdominal aorta and its main branches. ${ }^{68}$ Several studies comparing CTA with MRA for the detection of endoleaks showed that MRA is more sensitive than, ${ }^{69-73}$ or at least as sensitive as CTA, ${ }^{74-76}$ particularly in patients with Type II endoleaks. This might be due to the relative higher signal generation from lower concentrations of contrast as present in endoleaks. One case report describes a patient with a persistent growing aneurysm sac without signs of an endoleak (i.e. endotension) detected by CTA follow-up, where additional MRA revealed a type II endoleak which was treated percutaneously. ${ }^{77}$ 
Classification of endoleaks by MRA is better when based on three-dimensional contrast-enhanced dynamic and delayed gradient-echo sequences compared to nondynamic scans. ${ }^{78}$ In 1996, the first description of contrast enhanced timeresolved MRA (TR-MRA) was published, allowing visualization of changes in the direction of blood flow over time during an MR examination, analogous to a conventional angiogram. ${ }^{79}$ Lookstein et al. $^{80}$ and recently Cohen et al. ${ }^{81}$ described the initial use of TR-MRA in the characterization of endoleaks and compared these results with conventional digital subtraction angiography (DSA). Both studies found that TR-MRA allows for a noninvasive and effective diagnostic tool for classification of endoleaks following EVAR when compared to DSA. Recently, a new non-enhanced sequence has been introduced in clinical practice: the true-fast imaging with steady-state precession (true-FISP). This is a hybrid high speed T2/T1-weighted acquisition in which anatomy and morphology of organs and vessels are imaged with high detail. ${ }^{82}$ lozzelli et al. demonstrated that true-FISP is a fast (non-breath-hold) and powerful sequence for improvements in diagnostic information with good details of abdominal arteries when added to a standard MRA. ${ }^{83}$ Therefore, this imaging technique might have a future role in follow-up after EVAR, but further investigation is required. Other potential improvements of MRA could be found in the use of contrast agents. So far, most studies relied on gadolinium or iodine enhanced $M R$ imaging, but excretion and redistribution of these contrast agents into the extracellular fluid compartments degrade delayed images restraining low flow endoleaks. Ferumoxyto, a blood pool contrast agent, might be a promising method for better detection and characterization of small and low flow endoleaks, due to permission of acquisition of delayed MR images without degradation. $^{70}$

Advantages of $M R(A)$ imaging includes the lack of exposure to ionizing radiation and low nephrotoxicity of MR contrast medium. However, in a study of Broome et al. the development of nephrogenic systemic fibrosis (NSF), a multisystemic fibrosing disorder that principally affects the skin but may affect other organs of patients with renal insufficiency, was associated with gadolinium administration in the setting of dialysis-dependent chronic renal insufficiency and acute hepatorenal syndrome. ${ }^{84}$ However, NFS has never been reported in patients with adequate renal function. Furthermore, gadolinium-containing contrast agents have different properties that affect their behavior in the body. Contrast agents such as Omniscan and OptiMARK that carry no molecular charge and are arranged in a linear structure with excess chelate seem to be more likely to release free gadolinium ions $\left(\mathrm{Gd}_{3}+\right)$ into the body. Those that carry a molecular 
charge and have a linear structure (eg, Magnevist, MultiHance, Primovist, and Vasovist), and those that carry no molecular charge and have a cyclical structure (eg, Gadovist and ProHance), seem to be less likely to release free Gd3+ into the body. Dotarem has a molecular charge and a cyclical structure, and is least likely to release free $\mathrm{Gd} 3+$ into the body. The exact mechanism by which free gadolinium ions that might be deposited in tissues and organs can stimulate NSF is unknown, but is thought to trigger fibrosis (formation of fibrous tissues). There are a few other limitations of using MR angiography for detection and classification of endoleaks after EVAR. Stainless steel devices, pacemakers, or coils placed during prior embolization procedures cause significant metallic artifacts and risk of malfunctioning, moving and heating of the device during MR angiography imaging, whereas stent grafts composed of nitinol are generally more suitable for $M R$ imaging. ${ }^{74}$ However, new technologies may enable scanning of pacemaker and ICD patients with reduced concerns regarding the short- and long-term effects of MR imaging. ${ }^{85}$ Other limitations are prolonged procedure time compared to CT (angiography), poor visualization of vascular calcification and device integrity, and the spatial resolution of MR angiography may not be adequate to permit accurate classification. ${ }^{81}$ Other general disadvantages are limited availability, high costs, and claustrophobia.

So far, MRA has both advantages and disadvantages compared to CTangiography without exposure to ionizing radiation and with low nephrotoxicity of MR contrast medium. Despite limited availability and high costs, MR might have a future role in the follow-up after EVAR.

\section{Plain abdominal X-ray}

Plain radiographs are considered to be a useful adjunct to $\mathrm{CT}$ for detecting structural changes in the stent graft, like migration, kinking/deformity, limb dislocation, hook and stent fracture, anchor stent separation, and progressive dilatation of native vessels. ${ }^{86,87}$ Graft migration might potentially lead to limb kinking as well as proximal Type I endoleaks ${ }^{88}$ and can be accurately assessed by plain abdominal X-ray if a standardized protocol in taking and comparing images over time is used as described in the "Liverpool protocol". ${ }^{89,90}$ However, plain abdominal X-ray cannot be used as a stand-alone imaging modality, as it clearly does not assess for changes in the size of the excluded aneurysm sac or for presence of endoleak, and therefore does not meet guideline criteria outlined by the Society of Interventional Radiology. ${ }^{6}$ Furthermore, three-dimensional postprocessed CTA images can provide equal information, ${ }^{86}$ in addition to 
detecting endoleak formation and changes in aneurysm size. Advances in threedimensional visualization tools may render plain radiographs redundant, and its traditional role as an adjunct examination to CTA should be carefully reevaluated.

\section{Circulating biomarkers}

Several circulating biomarkers have been related to AAA presence, expansion and eventual rupture. ${ }^{91-93}$ These biomarkers represent the pathological changes of the aortic wall. ${ }^{94,95}$ Matrix metalloproteinases (MMP) represent extracellular matrix degeneration of the aortic wall and increased circulating levels of MMP have been demonstrated in patients with AAA. ${ }^{91}$ Increased circulating levels of MMP-2, -9 and tissue inhibitor of the MMP type-1 (TIMP-1) are associated with presence and size of AAA. ${ }^{94}$ The concept of EVAR is the exclusion of the aneurysm sac from the systemic circulation, eventually leading to aneurysm sac reduction. Endoleak is associated with continuous sac pressurization, aneurysm growth, and increased risk of rupture, i.e. normal AAA natural history. These facts have lead to the idea that a postoperative decrease in the levels of biomarkers, such as MMP, could represent a simple marker of successful EVAR. Conversely, elevations of circulating biomarkers, could serve as a marker of persistent sac pressurization or endoleak. Reports on significant decrease in circulating levels of MMP-9 after surgical exclusion of AAA, ${ }^{96-99}$ suggest that circulating MMP-9 may provide a biologically relevant marker of successful aneurysm repair. In 2001 Sangiorgi et al. were the first to report on the usefulness of biomarkers for assessment of the response to EVAR. ${ }^{99}$ Their welldesigned study resulted in four major findings. First, they found that the circulating plasma levels of MMP-3 and -9 were significantly elevated in AAA patients compared to healthy controls. Second, they demonstrated a continuous decrease in both MMP-3 and -9 after successful EVAR up to 6 months of follow-up. This decrease was to a similar level to that after surgical treatment. Third, they showed that an increase in circulating MMP levels after EVAR represents a reliable marker of endoleak. Fourth, after endoleak treatment, circulating MMP levels decreased significantly compared with 6-month pre-treatment values, suggesting a complete AAA exclusion at this time. These observations were confirmed by others, ${ }^{97,100}$ and Monaco et al. have shown comparable results in EVAR for thoracic abdominal aneurysms. ${ }^{98}$ However, none of these studies reported on diagnostic value of these biochemical assays (sensitivity and specificity). Our research group did report diagnostic values, ${ }^{101}$ but a large randomized clinical trial is necessary to 
ascertain the true diagnostic value of these assays. Hence, to date none of these assays are clinically applied.

Now we can only speculate on the clinical implications of a simple and readily available assay. Such an assay would provide evidence of successful EVAR only regarding aneurysm sac exclusion. Migration, kinking or other complications not (yet) leading to aneurysm sac pressurization would not be detected by this assay. This suggests that the assay should be supplemented by a type of imaging that provides information on stent graft integrity and location.

Two studies have reported on the additional effects of pharmacotherapeutical agents on levels of circulating biomarkers after EVAR. A randomized, placebo controlled, trial of Hackmann et al. showed that doxycycline (a MMP inhibitor) significantly decreased plasma levels of MMP-9 in the treatment group at 6 months. ${ }^{100}$ Nakamura et al. compared plasma levels of MMP-9 at 1 and 3 months after EVAR between patients receiving Azelnidipine (a calcium channel blocker) and controls. ${ }^{102}$ Patients with endoleak showed no significant decrease in plasma levels of MMP-9 at 1 and 3 months follow-up. In patients without endoleak Azelnidipine treatment after EVAR was associated with a significant decrease in mean plasma MMP-9.

\section{Necessity of surveillance for endoleaks}

Sternbergh et al. reported that absence of endoleak at short-term follow-up greatly predicts the future development of an endoleak. ${ }^{103}$ Based on this early outcome they have recommended a new EVAR follow-up regimen that modulates the intensity and frequency of postoperative imaging. In patients without early endoleak, the 6-month surveillance is eliminated, and aortic US is suggested for long-term surveillance $>1$ year. They suggest that in most patients, this reduced follow-up regimen would be appropriate and could improve patient safety by reducing the cumulative deleterious effects of intravenous contrast and radiation exposure while also reducing health care costs.

In addition, Houbballah et al. reported that significant sac retraction after EVAR was accurately predictive of durable success with better survival, decreased frequency of endoleaks, and lower secondary reintervention rates. ${ }^{2}$ Therefore, less intensive follow-up seems to be safe in these patients. Contrary, Schlösser et al. recently identified 270 ruptures detailed in the literature with a mean time to rupture of $24 \pm 18$ months. ${ }^{104}$ In 35 patients imaging surveillance showed no prior abnormalities in terms of history of endoleak, migration or sac 
enlargement during follow-up. These findings showed that even benign findings do not nullify the possibility of late rupture and emphasize the importance of close patient follow-up. However, data used in their study was collected from various reports without re-evaluation of CTA scans by an independent reviewer. Type I and III endoleaks are significantly related to a high risk of aneurysmal rupture, and it is therefore a general consensus that these should be treated when discovered. ${ }^{19,105}$

Type II endoleaks are the most common endoleak and occur in $20 \%$ to $30 \%$ of patients following EVAR. ${ }^{106,107}$ The presence of a type II endoleak during EVAR significantly increases the likelihood of a postoperative endoleak and should prompt a high degree of suspicion during follow-up. ${ }^{108}$ However, long-term significance of type II endoleaks is still subject to debate, since contrary results have been published. In a report of Silverberg et al. approximately $75 \%$ of type II endoleaks sealed spontaneously within a 5-year period. ${ }^{109}$ Most investigators advocate a more conservative approach, due to both very low incidence of aneurysm rupture associated with type II endoleaks and lower costs of sequential radiographic follow-up compared to early reintervention. ${ }^{3,26,110}$ Adversely, Jones et al. reported that persistent type II endoleak is associated with an increased incidence of adverse outcomes, including aneurysm sac growth, the need for conversion to open repair, reintervention rate, and rupture. ${ }^{106}$

The optimal follow-up regimens and techniques have not yet been defined. Current lifelong surveillance after EVAR is not only due to potential aneurysmrelated complications but also lack of data on long-term endograft durability.

\section{Discussion}

EVAR has reduced perioperative mortality compared with open repair, but is associated with a higher rate of subsequent reinterventions. ${ }^{111-113}$ Consequently, long-term follow-up after EVAR is considered mandatory to identify patients requiring reintervention. However, the reported reintervention rate is lower in contemporary EVAR series, ${ }^{103,114}$ reflecting the improvements in stent graft design and the adoption of a more conservative approach to type II endoleaks.

In order to minimize the need for early secondary reinterventions following EVAR, introduction of intraoperative imaging modalities allowing for immediate treatment of significant stent-related complications might have a future role. Kopp et al. showed that intraoperative CEUS-assisted EVAR represents a new 
intraoperative visualization option for proximal or distal fixation zones and identified more endoleaks in comparison to conventional EVAR using intraoperative iodine-based contrast angiography. In one symptomatic patient, proximal stent graft extension was required based on a type la endoleak that was only identified by intraoperative CEUS. ${ }^{115}$ Intraoperative CTA (DynaCT) is able to generate $\mathrm{CT}$ like images from rotational angiographic acquisitions and is feasible of imaging the aortic aneurysm during elective EVAR successfully. ${ }^{116}$ The clinical application for DynaCT in detecting intraoperative device-related anomalies is reported by Biasi et al. by detecting and immediately treating a type la endoleak which was not seen on completion angiography. ${ }^{117}$ Future studies will clarify the role of these intraoperative imaging modalities and whether perioperative incidence of secondary reinterventions will be reduced. The present report discusses the strategies for endoleak detection in the followup after EVAR in terms of imaging techniques and biochemical assays. CTA follow-up after EVAR is considered the gold standard, with high sensitivity for endoleak detection combined with widespread availability, rapid acquisition and reproducibility. ${ }^{27}$ However, cumulative radiation dose and nephrotoxic contrast agent underline the importance of upcoming alternative imaging modalities. Although operator- and patient-dependent, CEUS is excellent for monitoring the evolution of the aneurysm sac during follow-up without disadvantages of radiation dose and the use of nephrotoxic contrast agent. It captures a significant majority of endoleaks and this sensitivity is likely underestimated by comparing it against CT as the reference standard. Some true endoleaks depicted by CEUS will be categorized as "false positives" because they were not visualized by $\mathrm{CT}^{65,118} \mathrm{MR}$ imaging in the follow-up after EVAR has its limitations such as unsuitability in a number of patients, limited availability, and high costs. However, with increasing availability and improving technologies for i.e. pacemaker suitability, MR access is expanding. ${ }^{85}$ Evolving MR techniques are able to detect and classify endoleaks with increasing sensitivity and specificity, reserving a potential prominent role in future postEVAR follow-up. Plain abdominal X-ray is considered to be a useful adjunct to CT for detecting structural stent changes, but it does not assess for aneurysm sac size changes or for presence of endoleak. ${ }^{6}$ In 2001 Sangiorgi et al. reported on the usefulness of biomarkers for assessment of the response to EVAR. ${ }^{119}$ They found decreased circulating plasma levels of MMP-3 and -9 after successful EVAR and increased levels after endoleak presence. Plasma MMP-9 levels appear to discriminate between patient with and without an endoleak with 
both high sensitivity and specificity. ${ }^{101}$ However, a large randomized clinical trial is necessary to ascertain the true diagnostic value of these assays.

In conclusion, US and MR imaging are promising modalities for detection and classification of endoleaks after EVAR without radiation exposure and nephrotoxic contrast load. Based on present studies, true recommendations for ideal follow-up after EVAR cannot be made. Continuing technical improvements and future prospective comparative research might eventually lead to an imaging modality other than CTA as the gold standard in the follow-up of patients after stent graft implantation. Furthermore, a prospective clinical trial is necessary to validate the clinical applicability of circulating biomarkers in selecting patients for imaging. 


\section{References}

1. Parodi JC, Palmaz JC, Barone HD. Transfemoral intraluminal graft implantation for abdominal aortic aneurysms. Ann Vasc Surg. 1991;5:491-499.

2. Houbballah R, Majewski M, Becquemin JP. Significant sac retraction after endovascular aneurysm repair is a robust indicator of durable treatment success. J Vasc Surg. 2010;52: 878-883.

3. Veith FJ, Baum RA, Ohki T, Amor M, Adiseshiah M, Blankensteijn JD, et al. Nature and significance of endoleaks and endotension: summary of opinions expressed at an international conference. J Vasc Surg. 2002;35:1029-1035.

4. Buth J, Harris PL, van Marrewijk C. Causes and outcomes of open conversion and aneurysm rupture after endovascular abdominal aortic aneurysm repair: can type II endoleaks be dangerous? J Am Coll Surg. 2002;194(1 Suppl):S98-102.

5. EVAR-trial-participants. Endovascular aneurysm repair versus open repair in patients with abdominal aortic aneurysm (EVAR trial 1): randomised controlled trial. Lancet. 2005;365: 2179-2186.

6. Geller SC. Imaging guidelines for abdominal aortic aneurysm repair with endovascular stent grafts. J Vasc Interv Radiol. 2003;14:S263-S264.

7. Balm R, Kaatee R, Blankensteijn JD, Mali WP, Eikelboom BC. CT-angiography of abdominal aortic aneurysms after transfemoral endovascular aneurysm management. Eur J Vasc Endovasc Surg. 1996; 12:182-188.

8. Wolf YG, Tillich M, Lee WA, Fogarty TJ, Zarins CK, Rubin GD. Changes in aneurysm volume after endovascular repair of abdominal aortic aneurysm. J Vasc Surg. 2002;36:305-309.

9. Bley TA, Chase PJ, Reeder SB, Francois CJ, Shinki K, Tefera G, et al. Endovascular abdominal aortic aneurysm repair: nonenhanced volumetric CT for follow-up. Radiology. 2009;253: 253-262.

10. Baum RA, Carpenter JP, Cope C, Golden MA, Velazquez OC, Neschis DG, et al. Aneurysm sac pressure measurements after endovascular repair of abdominal aortic aneurysms. J Vasc Surg. 2001;33:32-41.

11. Walschot LH, Laheij RJ, Verbeek AL. Outcome after endovascular abdominal aortic aneurysm repair: a meta-analysis. J Endovasc Ther. 2002;9:82-89.

12. Drury D, Michaels JA, Jones L, Ayiku L. Systematic review of recent evidence for the safety and efficacy of elective endovascular repair in the management of infrarenal abdominal aortic aneurysm. Br J Surg. 2005; 92:937-946.

13. Golzarian J, Dussaussois L, Abada HT, Gevenois PA, Van Gansbeke D, Ferreira J, et al. Helical CT of aorta after endoluminal stent-graft therapy: value of biphasic acquisition. AJR Am J Roentgenol. 1998;171:329-331.

14. Gorich J, Rilinger N, Sokiranski R, Orend KH, Ermis C, Kramer SC, et al. Leakages after endovascular repair of aortic aneurysms: classification based on findings at $\mathrm{CT}$, angiography, and radiography. Radiology. 1999;213:767-772.

15. Blackman JA, Lindgren SD, Hein HA, Harper DC. Long-term surveillance of high-risk children. Am J Dis Child. 1987;141: 1293-1299.

16. Vallabhaneni SR, Harris PL. Lessons learnt from the EUROSTAR registry on endovascular repair of abdominal aortic aneurysm repair. Eur J Radiol. 2001;39:34-41.

17. Faries PL, Cadot H, Agarwal G, Kent KC, Hollier LH, Marin ML. Management of endoleak after endovascular aneurysm repair: cuffs, coils, and conversion. J Vasc Surg. 2003;37:1155-1161.

18. Harris PL, Vallabhaneni SR, Desgranges P, Becquemin JP, van Marrewijk C, Laheij RJ. Incidence and risk factors of late rupture, conversion, and death after endovascular repair of infrarenal aortic aneurysms: the EUROSTAR experience. European Collaborators on Stent/graft techniques for aortic aneurysm repair. J Vasc Surg. 2000;32:739-749.

19. van Marrewijk C, Buth J, Harris PL, Norgren L, Nevelsteen A, Wyatt MG. Significance of endoleaks after endovascular repair of abdominal aortic aneurysms: The EUROSTAR experience. J Vasc Surg. 2002;35:461-473. 
20. Zarins CK, White RA, Hodgson KJ, Schwarten D, Fogarty TJ. Endoleak as a predictor of outcome after endovascular aneurysm repair: AneuRx multicenter clinical trial. J Vasc Surg. 2000;32:90-107.

21. Gilling-Smith G, Brennan J, Harris P, Bakran A, Gould D, McWilliams R. Endotension after endovascular aneurysm repair: definition, classification, and strategies for surveillance and intervention. J Endovasc Surg. 1999;6:305-307.

22. Toya N, Fujita T, Kanaoka Y, Ohki T. Endotension following endovascular aneurysm repair. Vasc Med. 2008;13:305-311.

23. Bae KT, Heiken JP, Brink JA. Aortic and hepatic peak enhancement at CT: effect of contrast medium injection rate--pharmacokinetic analysis and experimental porcine model. Radiology. 1998;206:455-464.

24. Platt JF, Reige KA, Ellis JH. Aortic enhancement during abdominal CT angiography: correlation with test injections, flow rates, and patient demographics. AJR Am J Roentgenol. 1999;172: 53-56.

25. Lawler LP, Fishman EK. Multidetector row computed tomography of the aorta and peripheral arteries. Cardiol Clin. 2003;21:607-629.

26. Rubin GD, Shiau MC, Leung AN, Kee ST, Logan LJ, Sofilos MC. Aorta and iliac arteries: single versus multiple detector-row helical CT angiography. Radiology. 2000;215:670-676.

27. Stavropoulos SW, Charagundla SR. Imaging techniques for detection and management of endoleaks after endovascular aortic aneurysm repair. Radiology. 2007;243:641-655.

28. Armerding MD, Rubin GD, Beaulieu CF, Slonim SM, Olcott EW, Samuels SL, et al. Aortic aneurysmal disease: assessment of stent-graft treatment-CT versus conventional angiography. Radiology. 2000;215:138-146.

29. Baum RA, Stavropoulos SW, Fairman RM, Carpenter JP. Endoleaks after endovascular repair of abdominal aortic aneurysms. J Vasc Interv Radiol. 2003;14:1111-1117.

30. Rozenblit A, Marin ML, Veith FJ, Cynamon J, Wahl SI, Bakal CW. Endovascular repair of abdominal aortic aneurysm: value of postoperative follow-up with helical CT. AJR Am J Roentgenol. 1995;165:1473-1479.

31. McCullough PA, Soman SS. Contrast-induced nephropathy. Crit Care Clin. 2005;21:261-280.

32. Prinssen $M$, Wixon $C L$, Buskens $E$, Blankensteijn JD. Surveillance after endovascular aneurysm repair: diagnostics, complications, and associated costs. Ann Vasc Surg. 2004;18:421-427.

33. Rozenblit AM, Patlas M, Rosenbaum AT, Okhi T, Veith FJ, Laks MP, et al. Detection of endoleaks after endovascular repair of abdominal aortic aneurysm: value of unenhanced and delayed helical CT acquisitions. Radiology. 2003;227:426-433.

34. lezzi R, Cotroneo AR, Filippone A, Di Fabio F, Quinto F, Colosimo C, et al. Multidetector CT in abdominal aortic aneurysm treated with endovascular repair: are unenhanced and delayed phase enhanced images effective for endoleak detection? Radiology. 2006;241:915-921.

35. Macari M, Chandarana H, Schmidt B, Lee J, Lamparello P, Babb J. Abdominal aortic aneurysm: can the arterial phase at CT evaluation after endovascular repair be eliminated to reduce radiation dose? Radiology. 2006;241:908-914.

36. Flohr TG, McCollough CH, Bruder H, Petersilka M, Gruber K, Suss C, et al. First performance evaluation of a dual-source CT (DSCT) system. Eur Radiol. 2006;16:256-268.

37. Stolzmann P, Frauenfelder T, Pfammatter T, Peter N, Scheffel H, Lachat M, et al. Endoleaks after endovascular abdominal aortic aneurysm repair: detection with dual-energy dual-source CT. Radiology. 2008;249:682-691.

38. Szucs-Farkas Z, Semadeni M, Bensler S, Patak MA, von Allmen G, Vock P, et al. Endoleak detection with $\mathrm{CT}$ angiography in an abdominal aortic aneurysm phantom: effect of tube energy, simulated patient size, and physical properties of endoleaks. Radiology. 2009;251: 590-598.

39. May J, White GH, Waugh R, Stephen MS, Chaufour X, Arulchelvam M, et al. Comparison of first- and second-generation prostheses for endoluminal repair of abdominal aortic aneurysms: a 6-year study with life table analysis. J Vasc Surg. 2000;32:124-129.

40. Resch T, Malina M, Lindblad B, Ivancev K. The impact of stent-graft development on outcome of AAA repair--a 7-year experience. Eur J Vasc Endovasc Surg. 2001;22:57-61. 
41. Black SA, Carrell TW, Bell RE, Waltham M, Reidy J, Taylor PR. Long-term surveillance with computed tomography after endovascular aneurysm repair may not be justified. $\mathrm{Br} J \mathrm{Surg}$. 2009;96:1280-1283.

42. Dias NV, Riva L, Ivancev K, Resch T, Sonesson B, Malina M. Is there a benefit of frequent CT follow-up after EVAR? Eur J Vasc Endovasc Surg. 2009;37:425-430.

43. Bendick PJ, Zelenock GB, Bove PG, Long GW, Shanley CJ, Brown OW. Duplex ultrasound imaging with an ultrasound contrast agent: the economic alternative to CT angiography for aortic stent graft surveillance. Vasc Endovascular Surg. 2003;37:165-170.

44. Chaer RA, Gushchin A, Rhee R, Marone L, Cho JS, Leers S, et al. Duplex ultrasound as the sole long-term surveillance method post-endovascular aneurysm repair: a safe alternative for stable aneurysms. J Vasc Surg. 2009;49: 845-849; discussion 9-50.

45. lezzi R, Basilico R, Giancristofaro D, Pascali D, Cotroneo AR, Storto ML. Contrast-enhanced ultrasound versus color duplex ultrasound imaging in the follow-up of patients after endovascular abdominal aortic aneurysm repair. J Vasc Surg. 2009;49:552-560.

46. Manning BJ, O'Neill SM, Haider SN, Colgan MP, Madhavan P, Moore DJ. Duplex ultrasound in aneurysm surveillance following endovascular aneurysm repair: a comparison with computed tomography aortography. J Vasc Surg. 2009;49:60-65.

47. Wolf YG, Johnson BL, Hill BB, Rubin GD, Fogarty TJ, Zarins CK. Duplex ultrasound scanning versus computed tomographic angiography for postoperative evaluation of endovascular abdominal aortic aneurysm repair. J Vasc Surg. 2000;32:1142-1148.

48. Cantisani V, Ricci P, Grazhdani H, Napoli A, Fanelli F, Catalano C, et al. Prospective comparative analysis of colour-Doppler ultrasound, contrast-enhanced ultrasound, computed tomography and magnetic resonance in detecting endoleak after endovascular abdominal aortic aneurysm repair. European journal of vascular and endovascular surgery : the official journal of the European Society for Vascular Surgery. 2011;41:186-192.

49. AbuRahma AF, Welch CA, Mullins BB, Dyer B. Computed tomography versus color duplex ultrasound for surveillance of abdominal aortic stent-grafts. J Endovasc Ther. 2005;12: 568-573.

50. Pages S, Favre JP, Cerisier A, Pyneeandee S, Boissier C, Veyret C. Comparison of color duplex ultrasound and computed tomography scan for surveillance after aortic endografting. Ann Vasc Surg. 2001;15:155-162.

51. Raman KG, Missig Carroll N, Richardson T, Muluk SC, Makaroun MS. Color-flow duplex ultrasound scan versus computed tomographic scan in the surveillance of endovascular aneurysm repair. J Vasc Surg. 2003;38:645-651.

52. Elkouri S, Panneton JM, Andrews JC, Lewis BD, McKusick MA, Noel AA, et al. Computed tomography and ultrasound in follow-up of patients after endovascular repair of abdominal aortic aneurysm. Ann Vasc Surg. 2004;18:271-279.

53. Sprouse LR, 2nd, Meier GH, 3rd, Parent FN, DeMasi RJ, Glickman MH, Barber GA. Is ultrasound more accurate than axial computed tomography for determination of maximal abdominal aortic aneurysm diameter? Eur J Vasc Endovasc Surg. 2004;28:28-35.

54. Han SM, Patel K, Rowe VL, Perese S, Bond A, Weaver FA. Ultrasound-determined diameter measurements are more accurate than axial computed tomography after endovascular aortic aneurysm repair. J Vasc Surg. 2010;51:1381-1387; discussion 1387-1389.

55. d'Audiffret A, Desgranges $P$, Kobeiter DH, Becquemin JP. Follow-up evaluation of endoluminally treated abdominal aortic aneurysms with duplex ultrasonography: validation with computed tomography. J Vasc Surg. 2001;33:42-50.

56. Ashoke R, Brown LC, Rodway A, Choke E, Thompson MM, Greenhalgh RM, et al. Color duplex ultrasonography is insensitive for the detection of endoleak after aortic endografting: a systematic review. J Endovasc Ther. 2005;12:297-305.

57. Nagre SB, Taylor SM, Passman MA, Patterson MA, Combs BR, Lowman BG, et al. Evaluating outcomes of endoleak discrepancies between computed tomography scan and ultrasound imaging after endovascular abdominal aneurysm repair. Ann Vasc Surg. 2011;25:94-100. 
58. Sato DT, Goff CD, Gregory RT, Robinson KD, Carter KA, Herts BR, et al. Endoleak after aortic stent graft repair: diagnosis by color duplex ultrasound scan versus computed tomography scan. J Vasc Surg. 1998;28:657-663.

59. Bendick PJ, Bove PG, Long GW, Zelenock GB, Brown OW, Shanley CJ. Efficacy of ultrasound scan contrast agents in the noninvasive follow-up of aortic stent grafts. J Vasc Surg. 2003;37: 381-385.

60. Heilberger P, Schunn C, Ritter W, Weber S, Raithel D. Postoperative color flow duplex scanning in aortic endografting. J Endovasc Surg. 1997;4:262-271.

61. McWilliams RG, Martin J, White D, Gould DA, Rowlands PC, Haycox A, et al. Detection of endoleak with enhanced ultrasound imaging: comparison with biphasic computed tomography. J Endovasc Ther. 2002;9:170-179.

62. Napoli V, Bargellini I, Sardella SG, Petruzzi P, Cioni R, Vignali C, et al. Abdominal aortic aneurysm: contrast-enhanced US for missed endoleaks after endoluminal repair. Radiology. 2004;233:217-225.

63. Sun Z. Diagnostic value of color duplex ultrasonography in the follow-up of endovascular repair of abdominal aortic aneurysm. J Vasc Interv Radiol. 2006;17:759-764.

64. Henao EA, Hodge MD, Felkai DD, McCollum CH, Noon GP, Lin PH, et al. Contrast-enhanced Duplex surveillance after endovascular abdominal aortic aneurysm repair: improved efficacy using a continuous infusion technique. J Vasc Surg. 2006;43:259-264.

65. Ten Bosch JA, Rouwet EV, Peters CT, Jansen L, Verhagen HJ, Prins MH, et al. Contrastenhanced ultrasound versus computed tomographic angiography for surveillance of endovascular abdominal aortic aneurysm repair. J Vasc Interv Radiol. 2010;21:638-643.

66. Arko FR, Filis KA, Siedel SA, Johnson BL, Drake AR, Fogarty TJ, et al. Intrasac flow velocities predict sealing of type II endoleaks after endovascular abdominal aortic aneurysm repair. J Vasc Surg. 2003; 37:8-15.

67. Parent FN, Meier GH, Godziachvili V, LeSar CJ, Parker FM, Carter KA, et al. The incidence and natural history of type I and II endoleak: a 5-year follow-up assessment with color duplex ultrasound scan. J Vasc Surg. 2002;35:474-481.

68. Prince MR, Yucel EK, Kaufman JA, Harrison DC, Geller SC. Dynamic gadolinium-enhanced three-dimensional abdominal MR arteriography. J Magn Reson Imaging. 1993;3:877-881.

69. Ayuso JR, de Caralt TM, Pages M, Riambau V, Ayuso C, Sanchez M, et al. MRA is useful as a follow-up technique after endovascular repair of aortic aneurysms with nitinol endoprostheses. J Magn Reson Imaging. 2004;20:803-810.

70. Ersoy $H$, Jacobs $P$, Kent $C K$, Prince MR. Blood pool MR angiography of aortic stent-graft endoleak. AJR Am J Roentgenol. 2004;182:1181-1186.

71. Haulon S, Lions C, McFadden EP, Koussa M, Gaxotte V, Halna P, et al. Prospective evaluation of magnetic resonance imaging after endovascular treatment of infrarenal aortic aneurysms. Eur J Vasc Endovasc Surg. 2001;22:62-69.

72. Pitton MB, Schweitzer H, Herber S, Schmiedt W, Neufang A, Kalden P, et al. MRI versus helical CT for endoleak detection after endovascular aneurysm repair. AJR Am J Roentgenol. 2005; 185:1275-1281.

73. van der Laan MJ, Bartels LW, Viergever MA, Blankensteijn JD. Computed tomography versus magnetic resonance imaging of endoleaks after EVAR. Eur J Vasc Endovasc Surg. 2006;32: 361-365.

74. Cejna M, Loewe C, Schoder M, Dirisamer A, Holzenbein T, Kretschmer G, et al. MR angiography vs CT angiography in the follow-up of nitinol stent grafts in endoluminally treated aortic aneurysms. Eur Radiol. 2002;12:2443-2450.

75. Engellau L, Larsson EM, Albrechtsson U, Jonung T, Ribbe E, Thorne J, et al. Magnetic resonance imaging and $\mathrm{MR}$ angiography of endoluminally treated abdominal aortic aneurysms. Eur J Vasc Endovasc Surg. 1998;15:212-219.

76. Insko EK, Kulzer LM, Fairman RM, Carpenter JP, Stavropoulos SW. MR imaging for the detection of endoleaks in recipients of abdominal aortic stent-grafts with low magnetic susceptibility. Acad Radiol. 2003;10:509-513. 
77. Wicky S, Fan CM, Geller SC, Greenfield A, Santilli J, Waltman AC. MR angiography of endoleak with inconclusive concomitant CT angiography. AJR Am J Roentgenol. 2003;181:736-738.

78. van der Laan MJ, Bakker CJ, Blankensteijn JD, Bartels LW. Dynamic CE-MRA for endoleak classification after endovascular aneurysm repair. Eur J Vasc Endovasc Surg. 2006;31:130-135.

79. Korosec FR, Frayne R, Grist TM, Mistretta CA. Time-resolved contrast-enhanced 3D MR angiography. Magn Reson Med. 1996;36:345-351.

80. Lookstein RA, Goldman J, Pukin L, Marin ML. Time-resolved magnetic resonance angiography as a noninvasive method to characterize endoleaks: initial results compared with conventional angiography. J Vasc Surg. 2004;39:27-33.

81. Cohen EI, Weinreb DB, Siegelbaum RH, Honig S, Marin M, Weintraub JL, et al. Time-resolved MR angiography for the classification of endoleaks after endovascular aneurysm repair. J Magn Reson Imaging. 2008;27:500-503.

82. Duerk JL, Lewin JS, Wendt M, Petersilge C. Remember true FISP? A high SNR, near 1-second imaging method for T2-like contrast in interventional MRI at .2 T. J Magn Reson Imaging. 1998;8:203-208.

83. Iozzelli A, D'Orta G, Aliprandi A, Secchi F, Di Leo G, Sardanelli F. The value of true-FISP sequence added to conventional gadolinium-enhanced MRA of abdominal aorta and its major branches. Eur J Radiol. 2009;72:489-493.

84. Broome DR, Girguis MS, Baron PW, Cottrell AC, Kjellin I, Kirk GA. Gadodiamide-associated nephrogenic systemic fibrosis: why radiologists should be concerned. AJR Am J Roentgenol. 2007;188:586-592.

85. Jung W, Zvereva V, Hajredini B, Jackle S. Safe magnetic resonance image scanning of the pacemaker patient: current technologies and future directions. Europace. 2012;14:631-637.

86. Fearn S, Lawrence-Brown MM, Semmens JB, Hartley D. Follow-up after endovascular aortic aneurysm repair: the plain radiograph has an essential role in surveillance. $J$ Endovasc Ther. 2003;10:894-901.

87. May J, White GH, Yu W, Sieunarine K. Importance of plain x-ray in endoluminal aortic graft surveillance. Eur J Vasc Endovasc Surg. 1997;13:202-206.

88. Sampaio SM, Panneton JM, Mozes G, Andrews JC, Noel AA, Kalra M, et al. AneuRx device migration: incidence, risk factors, and consequences. Ann Vasc Surg. 2005;19:178-185.

89. Hodgson R, McWilliams RG, Simpson A, Gould DA, Brennan JA, Gilling-Smith GL, et al. Migration versus apparent migration: importance of errors due to positioning variation in plain radiographic follow-up of aortic stent-grafts. J Endovasc Ther. 2003;10:902-910.

90. Murphy M, Hodgson R, Harris PL, McWilliams RG, Hartley DE, Lawrence-Brown MM. Plain radiographic surveillance of abdominal aortic stent-grafts: the Liverpool/Perth protocol. J Endovasc Ther. 2003;10:911-912.

91. Hovsepian DM, Ziporin SJ, Sakurai MK, Lee JK, Curci JA, Thompson RW. Elevated plasma levels of matrix metalloproteinase- 9 in patients with abdominal aortic aneurysms: a circulating marker of degenerative aneurysm disease. J Vasc Interv Radiol. 2000;11:1345-1352.

92. Lindholt JS, Vammen S, Fasting H, Henneberg EW, Heickendorff L. The plasma level of matrix metalloproteinase 9 may predict the natural history of small abdominal aortic aneurysms. A preliminary study. Eur J Vasc Endovasc Surg. 2000;20:281-285.

93. Sakalihasan N, Delvenne P, Nusgens BV, Limet R, Lapiere CM. Activated forms of MMP2 and MMP9 in abdominal aortic aneurysms. J Vasc Surg. 1996;24:127-133.

94. Hellenthal FA, Buurman WA, Wodzig WK, Schurink GW. Biomarkers of AAA progression. Part 1: extracellular matrix degeneration. Nat Rev Cardiol. 2009;6:464-474.

95. Hellenthal FA, Buurman WA, Wodzig WK, Schurink GW. Biomarkers of abdominal aortic aneurysm progression. Part 2: inflammation. Nat Rev Cardiol. 2009;6:543-552.

96. Watanabe T, Sato A, Sawai T, Uzuki M, Goto H, Yamashita H, et al. The elevated level of circulating matrix metalloproteinase- 9 in patients with abdominal aortic aneurysms decreased to levels equal to those of healthy controls after an aortic repair. Ann Vasc Surg. 2006;20:317-321. 
97. Lorelli DR, Jean-Claude JM, Fox CJ, Clyne J, Cambria RA, Seabrook GR, et al. Response of plasma matrix metalloproteinase- 9 to conventional abdominal aortic aneurysm repair or endovascular exclusion: implications for endoleak. J Vasc Surg. 2002;35:916-922.

98. Monaco M, Stassano P, Di Tommaso L, lannelli G. Response of plasma matrix metalloproteinases and tissue inhibitor of metalloproteinases to stent-graft surgery for descending thoracic aortic aneurysms. J Thorac Cardiovasc Surg. 2007;134:925-931.

99. Sangiorgi G, D'Averio R, Mauriello A, Bondio M, Pontillo M, Castelvecchio S, et al. Plasma levels of metalloproteinases-3 and -9 as markers of successful abdominal aortic aneurysm exclusion after endovascular graft treatment. Circulation. 2001;104(12 Suppl 1):1288-1295.

100. Hackmann AE, Rubin BG, Sanchez LA, Geraghty PA, Thompson RW, Curci JA. A randomized, placebo-controlled trial of doxycycline after endoluminal aneurysm repair. J Vasc Surg. 2008;48:519-526; discussion 526.

101. Hellenthal FA, Ten Bosch JA, Pulinx B, Wodzig WK, de Haan MW, Prins MH, et al. Plasma levels of matrix metalloproteinase-9: a possible diagnostic marker of successful endovascular aneurysm repair. Eur J Vasc Endovasc Surg. 2012;43:171-172.

102. Nakamura E, Akashi H, Hiromatsu S, Tanaka A, Onitsuka S, Aoyagi S. Azelnidipine decreases plasma matrix metalloproteinase-9 levels after endovascular abdominal aortic aneurysm repair. Kurume Med J. 2009;56:25-32.

103. Sternbergh WC, 3rd, Greenberg RK, Chuter TA, Tonnessen BH. Redefining postoperative surveillance after endovascular aneurysm repair: recommendations based on 5-year followup in the US Zenith multicenter trial. J Vasc Surg. 2008;48:278-284; discussion 284-285.

104. Schlosser FJ, Gusberg RJ, Dardik A, Lin PH, Verhagen HJ, Moll FL, et al. Aneurysm rupture after EVAR: can the ultimate failure be predicted? Eur J Vasc Endovasc Surg. 2009;37:15-22.

105. Liewald F, Ermis C, Gorich J, Halter G, Scharrer-Pamler R, Sunder-Plassmann L. Influence of treatment of type II leaks on the aneurysm surface area. Eur J Vasc Endovasc Surg. 2001;21:339-343.

106. Jones JE, Atkins MD, Brewster DC, Chung TK, Kwolek CJ, LaMuraglia GM, et al. Persistent type 2 endoleak after endovascular repair of abdominal aortic aneurysm is associated with adverse late outcomes. J Vasc Surg. 2007;46:1-8.

107. van Marrewijk CJ, Fransen G, Laheij RJ, Harris PL, Buth J. Is a type II endoleak after EVAR a harbinger of risk? Causes and outcome of open conversion and aneurysm rupture during follow-up. Eur J Vasc Endovasc Surg. 2004;27:128-137.

108. Jung Y, Bauer G, Nolta JA. Concise review: Induced pluripotent stem cell-derived mesenchymal stem cells: progress toward safe clinical products. Stem Cells. 2012;30:42-47.

109. Silverberg D, Baril DT, Ellozy SH, Carroccio A, Greyrose SE, Lookstein RA, et al. An 8-year experience with type II endoleaks: natural history suggests selective intervention is a safe approach. J Vasc Surg. 2006;44:453-459.

110. Steinmetz E, Rubin BG, Sanchez LA, Choi ET, Geraghty PJ, Baty J, et al. Type II endoleak after endovascular abdominal aortic aneurysm repair: a conservative approach with selective intervention is safe and cost-effective. J Vasc Surg. 2004;39:306-313.

111. Endovascular aneurysm repair versus open repair in patients with abdominal aortic aneurysm (EVAR trial 1): randomised controlled trial. Lancet. 2005;365:2179-2186.

112. Blankensteijn JD, de Jong SE, Prinssen M, van der Ham AC, Buth J, van Sterkenburg SM, et al. Two-year outcomes after conventional or endovascular repair of abdominal aortic aneurysms. N Engl J Med. 2005;352:2398-2405.

113. Prinssen M, Verhoeven EL, Buth J, Cuypers PW, van Sambeek MR, Balm R, et al. A randomized trial comparing conventional and endovascular repair of abdominal aortic aneurysms. N Engl J Med. 2004; 351:1607-1618.

114. Black SA, Carrell TW, Bell RE, Waltham M, Reidy J, Taylor PR. Long-term surveillance with computed tomography after endovascular aneurysm repair may not be justified. Br J Surg. 2009;96:1280-1283.

115. Kopp R, Zurn W, Weidenhagen R, Meimarakis G, Clevert DA. First experience using intraoperative contrast-enhanced ultrasound during endovascular aneurysm repair for infrarenal aortic aneurysms. J Vasc Surg. 2010;51:1103-1110. 
116. Eide KR, Odegard A, Myhre HO, Haraldseth O. Initial observations of endovascular aneurysm repair using Dyna-CT. J Endovasc Ther. 2007;14:50-53.

117. Biasi L, Ali T, Hinchliffe R, Morgan R, Loftus I, Thompson M. Intraoperative DynaCT detection and immediate correction of a type la endoleak following endovascular repair of abdominal aortic aneurysm. Cardiovasc Intervent Radiol. 2009;32:535-538.

118. Bakken AM, Illig KA. Long-term follow-up after endovascular aneurysm repair: is ultrasound alone enough? Perspect Vasc Surg Endovasc Ther. 2010;22:145-151.

119. Sangiorgi G, D'Averio R, Mauriello A, Bondio M, Pontillo M, Castelvecchio S, et al. Plasma levels of metalloproteinases-3 and -9 as markers of successful abdominal aortic aneurysm exclusion after endovascular graft treatment. Circulation. 2001;104(12 Suppl 1):I288-295. 



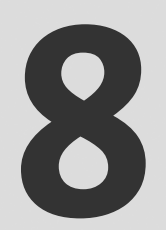

Contrast-enhanced ultrasound versus computed tomographic angiography for surveillance of endovascular abdominal aortic aneurysm repair

JA Ten Bosch

EV Rouwet

CTH Peters

L Jansen

HJM Verhagen

MH Prins

JAW Teijink

J Vasc Interv Radiol. 2010;21:638-643 


\section{Abstract}

\section{Objective}

The aim of this study was to compare the diagnostic accuracy between contrastenhanced ultrasound and computed tomographic angiography (CTA) to detect changes in abdominal aortic aneurysm (AAA) size and endoleaks during follow-up after endovascular aneurysm repair (EVAR).

\section{Materials and Methods}

Between May 2006 and December 2008, 83 patients were consecutively enrolled for contrast-enhanced ultrasound and CTA imaging during surveillance after EVAR, yielding 127 paired examinations. Comparative analysis was performed for the anteroposterior and transverse maximal diameters of the aneurysm sac, and for the presence or absence of endoleak, as determined by ultrasound and CTA.

\section{Results}

Contrast-enhanced ultrasound demonstrated significantly more endoleaks, predominantly type II, as compared with CTA ( $53 \%$ vs. $22 \%$ of cases). The number of observed agreements was $77 / 127(61 \%)$, indicating a low level of agreement ( $\kappa=0.237)$. Ultrasound was as accurate as CTA in the assessment of maximal aneurysm sac diameters, as shown by Bland-Altman analyses and low coefficients of variation $(8.0 \%$ and $8.6 \%$ respectively). The interobserver variability for AAA size measurement by ultrasound was low, given the interclass correlation coefficients of 0.99 and 0.98 for anteroposterior and transverse maximal diameters, respectively.

\section{Conclusion}

This study shows that contrast-enhanced ultrasound may be an alternative to CTA in the follow-up of patients after EVAR. Since ultrasound reduces exposure to the biological hazards associated with lifelong annual CTA, including cumulative radiation dose and nephrotoxic contrast load, contrast-enhanced ultrasound might be considered as a substitute to CTA in the surveillance of patients after EVAR. 


\section{Introduction}

Endovascular aortic aneurysm repair (EVAR) is a less invasive alternative to open surgical repair in selected patients with abdominal aortic aneurysms (AAA). As elegantly demonstrated, EVAR has an initial postoperative benefit over open AAA repair due to decreased early morbidity and mortality. ${ }^{1-3}$ However, as is shown in the EVAR trial 1, stent graft related complications are observed in approximately $40 \%$ of patients by 4 years after EVAR, resulting in a $20 \%$ reintervention rate to reduce the ongoing rupture risk. ${ }^{1}$ Long-term imaging surveillance of patients is required to detect stent graft related complications, including aneurysm growth, endoleak, migration, and kinking after EVAR. ${ }^{4}$ Among various imaging modalities, computed tomographic angiography (CTA) is the most widely used technique for post-EVAR surveillance. ${ }^{5}$ However, repetitive CTA has several important drawbacks, including cumulative radiation dose, nephrotoxic contrast load, and high cost. ${ }^{6}$

A number of studies have indicated that color Duplex ultrasound may be used for post-EVAR surveillance. ${ }^{7-10}$ Noncontrast-enhanced ultrasound correlates with CTA in determining change in AAA sac size over time, but has low sensitivity and positive predictive value in endoleak detection compared to conventional CTA. ${ }^{9,11-13}$ Sonographic contrast agents enhance the capability of color duplex to detect endoleaks. ${ }^{14-18}$ Second-generation sonographic contrast agents consist of stabilized microbubbles of sulphur hexafluoride gas, which is eliminated through the respiratory system, surrounded by a phospholipid-shell. These microbubbles improve blood flow echogenicity by resonating with lowintensity ultrasound, which enhances backscatter and thereby increases the detected signal. ${ }^{19}$ Bubble destruction during imaging is minimized, allowing real-time scanning for several minutes. ${ }^{17,20}$ No adverse events, such as nephropathy, have been reported for ultrasound contrast agents. The clinical applicability of ultrasound investigation may be limited by operator-dependent variability as well as by patient-related limitations such as obesity. The aim of the present study was to investigate the accuracy of contrast-enhanced ultrasound as an alternative to CTA in the follow-up of patients after EVAR with regard to detection of endoleaks and changes in AAA dimensions. 


\section{Materials and Methods}

\section{Patients}

Patients who underwent endovascular repair for infrarenal AAA after April 2001 were consecutively enrolled for dual modality post-EVAR imaging surveillance between May 2006 and December 2008 in a non-academic teaching hospital. All patients were treated in the department of vascular surgery with a commercially available endovascular graft (Talent, Medtronic, Minneapolis, MN, USA). The routine surveillance regimen consisted of an intravenous contrastenhanced CT scan at 3 and 12 months post-procedure and yearly thereafter. During the study period, contrast-enhanced ultrasound examinations were added to this regimen. Data were prospectively collected in this consecutive series of participants. Patients who could not undergo CTA due to severe iodinated contrast allergy or severe renal insufficiency were excluded from participation. There were no exclusion criteria for contrast-enhanced ultrasound examination. The study was approved by the institutional ethics committee and informed consent was obtained prior to enrollment.

\section{CTA}

Triple-phase (unenhanced, and contrast-enhanced in arterial and delayed phases) CT angiography was performed from the diaphragm to the common femoral arteries after continuous intravenous administration of iodinated contrast agent (Xenetix ${ }^{\circledR} 300$, Guerbet, Cedex, France). Diluted contrast solution was obtained by mixing $120 \mathrm{ml}$ contrast with $30 \mathrm{ml}$ saline, and was administered with a flow rate of $4 \mathrm{ml} / \mathrm{s}$. A multidetector 16 slice spiral CT scanner (Somaton sensation; Siemens, Forccheim, Germany) was used with the following parameters: high-speed mode capability, rotation time 0.5 seconds, table speed $24 \mathrm{~mm}$ per rotation, collimation $1.5 \mathrm{~mm}$, and a slice thickness of $3 \mathrm{~mm}$. Images were acquired in both the arterial phase, triggered by contrast passing the aorta, and the delayed phase 70 seconds after intravenous contrast medium injection. Patients with mild iodinated contrast allergy or renal insufficiency were prepared for CTA according to the guidelines of the Dutch Institute for Healthcare Improvement. ${ }^{21}$ Patients with a history of iodinated contrast allergy received oral corticosteroids and antihistamines prior to CTA. Preparation for patients with renal insufficiency consisted of intravenous hydration and oral acetylcysteine before and after the CTA. 


\section{Contrast-enhanced ultrasound}

Ultrasound investigation was performed with an abdominal 3.5 $\mathrm{MHz}$ curved array transducer (Biomedic, Aloka SSD-5000). The examinations were performed by three well-trained vascular technicians dedicated to ultrasound imaging, who were blinded to the results of each other as well as to CTA. Patients were instructed to fast in the morning of the contrast-enhanced ultrasound investigation. The abdominal aorta was scanned from the diaphragm to below the iliac limb attachment sites in long-axis and cross-sectional views in supine position through an anterior approach. First, standard noncontrastenhanced B-mode ultrasound investigation with grey-scale and color Duplex were performed for measurement of aneurysm sac diameter. Next, diluted sonographic contrast solution was administered by continuous intravenous infusion $(240 \mathrm{ml} / \mathrm{h})$ for a period of 15 minutes. Sonographic contrast solution was obtained by mixing $5 \mathrm{ml} \mathrm{SonoVue}{ }^{\circledR}$ (Bracco, Milan, Italy) containing $8 \mu \mathrm{l}$ sulfur hexafluoride microbubbles per $\mathrm{mL}$ with $55 \mathrm{ml}$ saline. Continuous realtime tissue harmonic imaging for endoleak detection was performed for 15 minutes during sonographic contrast agent infusion at a mechanical index of $0.4-0.5$ and at low acoustic power.

\section{Parameters}

Both imaging techniques were used to determine anteroposterior maximal diameter and transverse maximal diameter of the aneurysm sac, as well as to assess the presence or absence of an endoleak. All diameters were measured outer wall to outer wall on both CTA and contrast-enhanced ultrasound. Endoleak was defined as the presence of persistent intrasac flow outside the graft. ${ }^{22}$ An endoleak on CTA was defined as contrast enhancement outside the endograft within the aneurysm sac in the arterial and/or venous phase. An endoleak was identified on contrast-enhanced ultrasound by flow and spectral signals within the aneurysm sac during infusion of sonographic contrast agent. Endoleaks were classified as type IA/B, II, III, or IV. ${ }^{23,24}$ AAA diameter measurements and endoleak assessment on CTA were performed by the two principal investigators (J.T.B., E.R.), blinded to the results of contrast-enhanced ultrasound and to each other. As for contrast-enhanced ultrasound, each of the three vascular technicians independently measured AAA sac diameters and reported the presence or absence of endoleak at the end of each contrastenhanced ultrasound examination, blinded to the results of CTA. AAA dimensions on contrast-enhanced ultrasound were recorded as the means of the three 3 measurements. 


\section{Statistics}

Comparisons of aneurysm size measurements between CTA and contrastenhanced ultrasound were performed by Bland-Altman plots $^{25}$ and by calculating the coefficients of variation. The coefficient of variation, expressed as a percentage, was determined by dividing the standard deviation of the differences between the two measurements by the mean of the averages for the study population. Interobserver variability for AAA size measurement by contrast-enhanced ultrasound was determined by calculating the interclass correlation coefficient for absolute agreement. To determine the level of agreement between CTA and contrast-enhanced ultrasound for identifying endoleaks, kappa was calculated. A McNemar chi square test was performed to identify differential endoleak detection by the two imaging modalities. Continuous data were reported as mean and $95 \%$ confidence interval $(\mathrm{Cl})$, unless stated otherwise, whereas categorical data were reported as frequencies or percentages. Statistical significance was defined as $P<0.05$. Statistical analysis was performed with SPSS version 15.0 for Windows.

\section{Results}

Between May 2006 and December 2008, a total number of 113 patients presented at the outpatient clinic of our non-academic teaching hospital for imaging surveillance after EVAR. Seven of these patients were excluded from participation in the study because of severe iodinated contrast allergy $(n=3)$ or severe renal insufficiency $(n=4)$, which precluded CTA. The remaining 106 patients who were eligible for the study were prospectively enrolled for dual modality imaging after consent. Overall, 62 out of 189 potential paired examinations were excluded from comparative analysis for one of the following reasons: time interval between CTA and ultrasound examinations exceeding 30 days as a consequence of logistic problems $(n=53)$, failure to perform ultrasound due to obesity $(n=2)$ or bowel gas $(n=1)$, failure to receive CTA due to study protocol violation $(n=6)$. Overall, 127 out of 189 potential paired examinations in 83 patients were available for comparative analysis. Mean age at the time of EVAR was $71 \pm 9$ (SD) years; $92 \%$ of patients were male $(n=76)$. Devices used for EVAR were 16 aorto-uni-iliac endografts and 67 bifurcated endografts. The median number of follow-up evaluations was 1 (interquartile range 1-2) with a maximum of 3 over a period ranging from 1 to 77 months after EVAR (mean 19 months). The median interval between examinations was 0 days (interquartile range $0-2$ ). 


\section{Diameter}

The agreement between anteroposterior and transverse maximal diameter measurements by CTA and contrast-enhanced ultrasound was visualized in Bland-Altman plots (Figures 8.1A and 8.1B). These plots depict the difference between the CTA and contrast-enhanced ultrasound diameter measurements in relation to the average diameter as determined by the two imaging modalities. As shown by the Bland-Altman plots there was good correspondence in both anteroposterior and transverse maximal diameters as determined by the two imaging modalities. The mean difference in AAA sac diameters as measured by CTA and contrast-enhanced ultrasound was $3.2 \mathrm{~mm}(95 \% \mathrm{Cl}-5.8-12.3)$ for anteroposterior and $4.1 \mathrm{~mm}(95 \% \mathrm{Cl}$-6.4-14.6) for transverse maximal diameters, both in favor of CTA. The good agreement between the two methods was confirmed by a coefficient of variation of $8.0 \%$ and $8.6 \%$ for anteroposterior and transverse maximal diameters, respectively. The interclass correlation coefficient for absolute agreement with respect to AAA size measurement using contrast-enhanced ultrasound was 0.993 (95\% Cl 0.989$0.996)$ for the anteroposterior and $0.984(95 \% \mathrm{Cl} 0.974-0.991)$ for the transverse maximal diameter, indicating low interobserver variability between the three vascular technicians.

\section{Endoleak}

Comparison of endoleak detection between CTA and contrast-enhanced ultrasound is displayed in Table 8.1. Endoleak was detected by CTA in $22 \%$ $(27 / 127)$ and by contrast-enhanced ultrasound in $53 \%(67 / 127)$ of successful cases. The number of observed agreements was $77 / 127$ (61\%) with a number of agreements expected by chance of $61(48 \%)$. The strength of agreement was considered to be low (kappa=0.237, 95\% Cl 0.072-0.402). In 45 cases an endoleak was visualized by ultrasound but not by CTA, whereas in 5 cases an endoleak was detected by CTA but not by ultrasound. The differential detection of endoleaks by the two imaging modalities was confirmed by the McNemar chi square value $(P<0.001)$. 
A

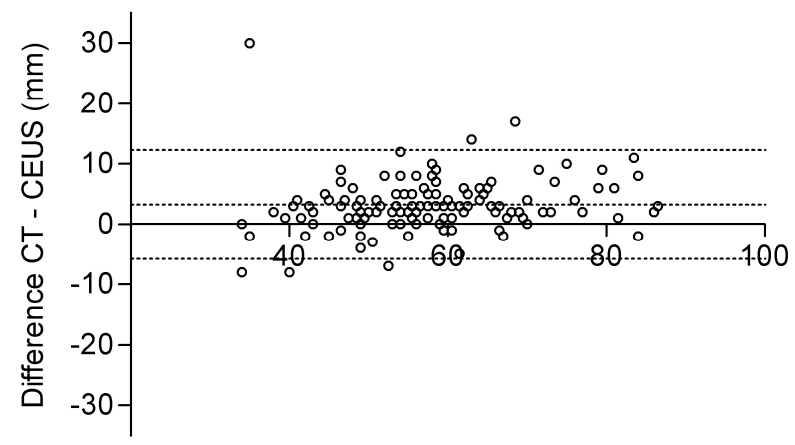

Average CT and CEUS (mm)

B

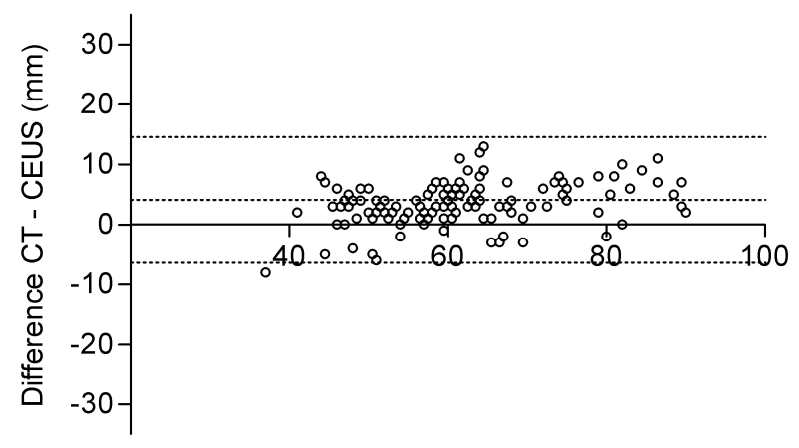

Average CT and CEUS (mm)

Figure 8.1 A. Bland-Altman plot of the anteroposterior maximal diameter. B. Bland-Altman plot of the transverse maximal diameter. Note that 2 data points are outside the axis limits.

CEUS=contrast-enhanced ultrasound.

Table 8.1 Endoleak detection by contrast-enhanced ultrasound (CEUS) and CTA. Data are presented as number of cases.

\begin{tabular}{lrrc}
\hline & & CTA & \\
\cline { 2 - 4 } CEUS & Yes & No & Total \\
\hline Yes & 22 & 45 & 67 \\
No & 5 & 55 & 60 \\
Total & 27 & 100 & 127 \\
\hline
\end{tabular}


Detection of different types of endoleaks by contrast-enhanced ultrasound and CTA is listed in Table 8.2. The majority of the endoleaks were type II (Figure 8.2), however, contrast-enhanced ultrasound also detected two additional type I endoleaks. No type III or IV were detected in this study population by either CTA or contrast-enhanced ultrasound.

Table 8.2 Classification of endoleaks as detected by contrast-enhanced ultrasound and CTA. Data are presented as number of cases.

\begin{tabular}{lcr}
\hline Endoleak & Contrast-enhanced ultrasound & CTA \\
\hline No & 60 & 100 \\
Yes & 67 & 27 \\
Type I & 3 & 1 \\
Type II & 64 & 26 \\
Type III & 0 & 0 \\
Type IV & 0 & 0 \\
\hline
\end{tabular}

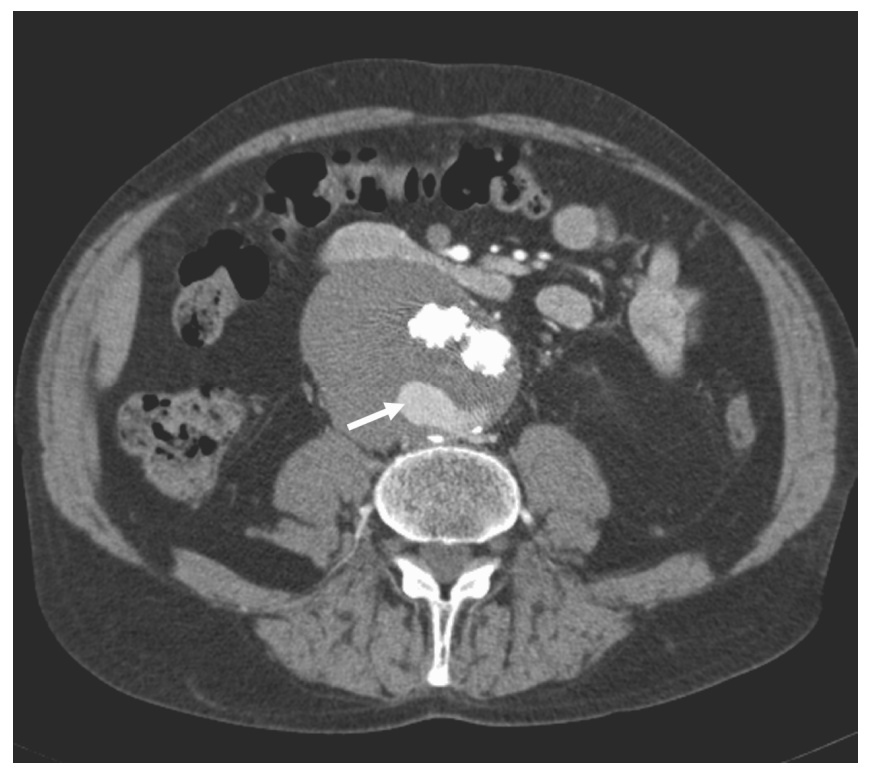

Figure 8.2 Clear type II endoleak (arrow) in arterial phase of CTA.

To exclude a potential bias in favor of contrast-enhanced ultrasound due to repetitive yearly examinations in the same patient, statistical analysis was subsequently performed for the first paired examination in all 83 patients. This analysis revealed a similar endoleak detection rate of $20 \%(17 / 83)$ by CTA and 
of $47 \%(39 / 83)$ by contrast-enhanced ultrasound. The number of observed agreements was $51 / 83(61 \%)$ with a number of agreements expected by chance of $43(52 \%)$. The strength of agreement in these 83 paired examinations was comparable to that of the complete group of 127 paired examinations (kappa $=0.200,95 \% \mathrm{Cl}-0.017-0.418$ ). These results indicate that there is no potential bias in favor of contrast-enhanced ultrasound due to repetitive examinations.

\section{Discussion}

Contrast-enhanced CT is generally considered the gold standard in the followup of patients after stent graft implantation. ${ }^{26}$ However, the lifelong requirement for patient surveillance accentuates certain drawbacks of CTA, including ionizing radiation burden and nephrotoxic contrast load. Contrastenhanced Duplex ultrasound requires neither ionizing radiation nor nephrotoxic contrast. The present study suggests that contrast-enhanced Duplex ultrasound may be a diagnostic alternative to CTA in the follow-up of patients after endovascular aneurysm repair. The criteria developed by the Standards for Reporting of Diagnostic Accuracy (STARD) steering group were used to report this study of diagnostic accuracy. ${ }^{27}$

Accurate measurement of AAA dimensions in the follow-up after EVAR is essential in order to identify either shrinkage or growth of the aneurysm sac and assists in defining the success or failure, respectively, of aneurysm exclusion. In the present study, Bland-Altman analyses of aneurysm sac diameters demonstrated good agreement between ultrasound and CTA. In support of this, the coefficients of variation for the anteroposterior and transverse diameters of the aneurysm sac as measured by the two imaging modalities were less than $10 \%$, which is generally regarded as acceptable accuracy for diagnostic tests.

The present study shows a large discrepancy between CTA and contrastenhanced ultrasound with regard to detection of endoleaks. In $20 \%$ of cases an endoleak was detected with CTA in our study, which corresponds to previous reported rates of CT-detected endoleakage. ${ }^{16}$ The significantly higher rate of endoleak detection with contrast-enhanced ultrasound may be explained by the continuous dynamical real-time contrast-enhanced scanning for 15 minutes in contrast with CTA showing two (arterial and delayed phase) static temporal angiographic images. ${ }^{28}$ 
The majority of additional endoleaks identified by contrast-enhanced ultrasound were type II, the importance of which is still subject of debate. ${ }^{29}$ However, ultrasound also revealed two extra type I endoleaks. The detection of an endoleak by contrast-enhanced ultrasound that was not visualized by CTA resulted in an intervention in 2 out of 45 cases, including coiling of the internal iliac artery in one patient and aortic banding of the proximal aneurysm neck in the other. In the latter case, CTA showed a significant increase in aneurysm sac size of $>5 \mathrm{~mm}$, in spite of the absence of a demonstrable endoleak. Although this is traditionally classified as a type $V$ endoleak, or endotension, an endoleak was clearly depicted on contrast-enhanced ultrasound (Figure 8.3). Thus, endotension may not necessarily be a separate entity, but the mere effect of inadequate imaging, which may be improved by contrast-enhanced ultrasound. ${ }^{17}$

Only in 5 cases, ultrasound did not reveal an endoleak that was detected by CTA, which might be classified as false-negative ultrasound results. In these cases no aneurysm sac growth was observed and no interventions were needed. Given the lack of a gold standard, is it not possible to compare sensitivities and specificities for endoleak detection between contrastenhanced ultrasound and CTA. We suggest that endoleaks detected by one or the other imaging modality should be considered as real endoleaks. Based on this assumption, the number of endoleaks detected by contrast-enhanced ultrasound greatly outweighs CTA.

The use of ultrasound as the preferred imaging modality in the follow-up of patients can reduce the biological hazards associated with CTA. ${ }^{19}$ First, the EVAR procedure and lifelong annual CT follow-up carry a substantial ionizing radiation burden. Patients receive a total effective dose of about $60 \mathrm{mSv}$ within the first year of EVAR, taking into account both procedure-related fluoroscopy and follow-up CT angiographies. ${ }^{30}$ The mean effective dose of CTA for EVAR followup results is approximately $15 \mathrm{mSv}$. The stochastic risk of a fatal radiationinduced tumor is estimated to be $5 \% / \mathrm{Sv}$ radiation. Thus, the risk of cancer induction of one CTA is about 1 in $1500,{ }^{31}$ indicating the relevance of reliable alternatives to annual CTA for post-EVAR follow-up, particularly in younger patients. Second, CTA requires the administration of iodinated contrast agents, which are associated with nephrotoxic effects. ${ }^{32}$ Renal dysfunction is a comorbidity found in $80 \%$ of aneurysm patients, and is the most important risk factor for contrast-induced nephrotoxicity. ${ }^{32,33}$ Since no major side effects, including nephrotoxic effects, have been reported for ultrasound contrast 
agents, this favors the use of contrast-enhanced ultrasound for post-EVAR follow-up.

In general, ultrasound examinations may carry a number of well-known limitations. First, operator dependency might limit reproducibility of the results. It is clearly true that assessment of a CT scan is less operator dependent. However, as indicated by the interobserver analysis in the present study, variability in AAA sac dimensions as measured by contrast-enhanced ultrasound was low when performed by well-trained vascular technicians. Unfortunately, interobserver variability for endoleak detection by contrast-enhanced ultrasound could not be assessed since this would require repetitive sonographic contrast agent infusions. Second, patient habitus may interfere with ultrasound imaging. However, in the present study contrast-enhanced ultrasound was unsuccessful in only 3 out of 130 cases (2\%), due to patients' obesity $(n=2)$ or bowel gas $(n=1)$. A potential drawback of contrast-enhanced ultrasound is the inability to detect kinking and migration of the stent graft. Plain abdominal radiography may be used for the detection of graft migration and structural failure. ${ }^{34,35}$ In addition, sonographic contrast agents are not worldwide available yet, which may limit the applicability of contrast-enhanced ultrasound techniques.

The long-term outcome of endovascular repair is yet unknown. A recent retrospective analysis of AAA ruptures following EVAR showed that most ruptures occur within the first 3 year after the procedure, with a mortality rate of $60 \% .{ }^{36}$ Although AAA rupture occurred even if no predisposing abnormalities were present, the majority of these ruptures were preceded by endoleaks. Strikingly, in only $35 \%$ of the patients endoleaks were detected before rupture, i.e. during regular follow-up. These findings underline the importance of a sensitive and reliable post-EVAR follow-up regimen to reduce the AAA rupture rate.

In line with recent reports, ${ }^{7-10}$ the results of the current study support the notion that contrast-enhanced ultrasound may be equivalent to CTA for the assessment of aneurysm sac dimensions and the detection of endoleaks. Since ultrasound precludes the risks of contrast-induced nephropathy and ionizing radiation load, contrast-enhanced ultrasound might be considered as a substitute to CTA as the primary imaging modality in the surveillance of patients after EVAR in those patients who are suitable for abdominal/pelvic US and when highly trained ultrasound operators are available. 


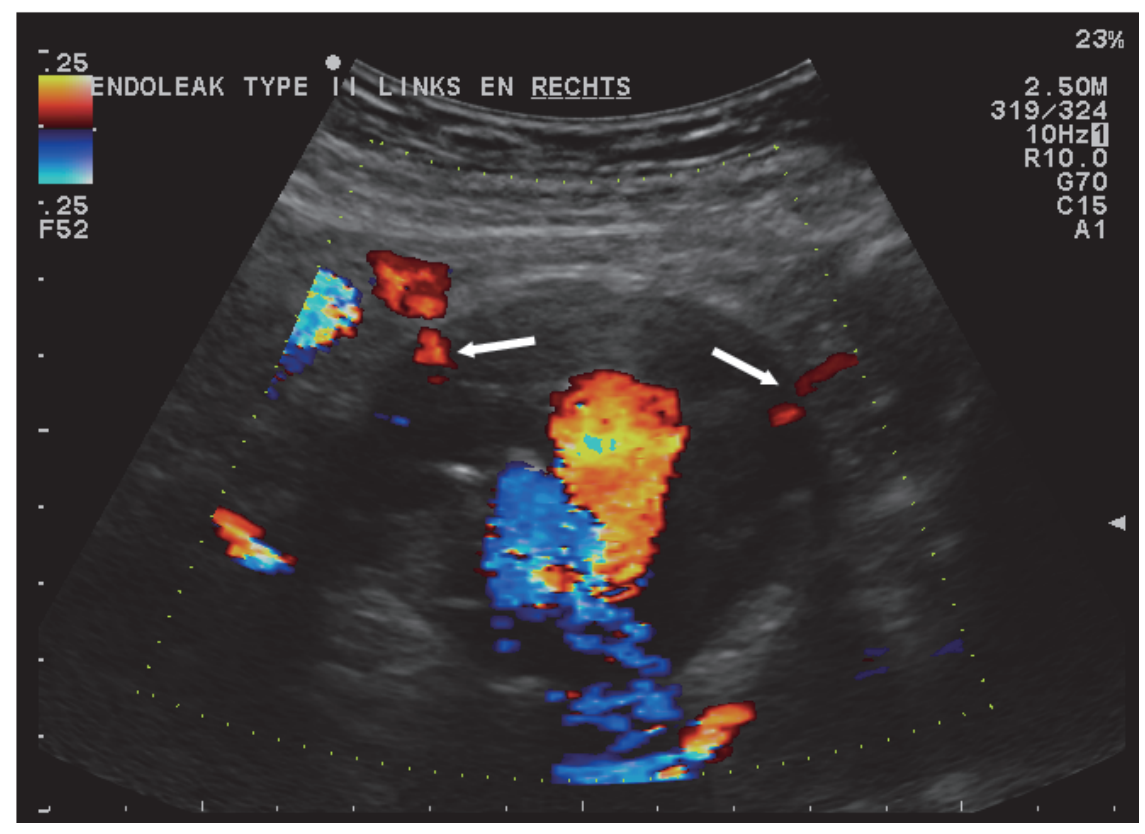

Figure 8.3 Contrast-enhanced ultrasound demonstrating two type II endoleaks (arrows), which were not detected by CTA. 


\section{References}

1. Endovascular aneurysm repair versus open repair in patients with abdominal aortic aneurysm (EVAR trial 1): randomised controlled trial. Lancet 2005;365:2179-2186.

2. Lederle FA, Kane RL, MacDonald R, Wilt TJ. Systematic review: repair of unruptured abdominal aortic aneurysm. Ann Intern Med. 2007;146:735-741.

3. Prinssen $\mathrm{M}$, Verhoeven $\mathrm{EL}$, Buth J, et al. A randomized trial comparing conventional and endovascular repair of abdominal aortic aneurysms. N Engl J Med 2004;351:1607-1618.

4. Veith FJ, Baum RA, Ohki T, et al. Nature and significance of endoleaks and endotension: summary of opinions expressed at an international conference. J Vasc Surg 2002;35: 1029-1035.

5. Golzarian J, Dussaussois L, Abada HT, et al. Helical CT of aorta after endoluminal stent-graft therapy: value of biphasic acquisition. AJR Am J Roentgenol 1998;171:329-331.

6. Prinssen M, Wixon CL, Buskens E, Blankensteijn JD. Surveillance after endovascular aneurysm repair: diagnostics, complications, and associated costs. Ann Vasc Surg 2004;18:421-427.

7. Wolf YG, Johnson BL, Hill BB, Rubin GD, Fogarty TJ, Zarins CK. Duplex ultrasound scanning versus computed tomographic angiography for postoperative evaluation of endovascular abdominal aortic aneurysm repair. J Vasc Surg 2000;32:1142-1148.

8. lezzi R, Basilico R, Giancristofaro D, Pascali D, Cotroneo AR, Storto ML. Contrast-enhanced ultrasound versus color duplex ultrasound imaging in the follow-up of patients after endovascular abdominal aortic aneurysm repair. J Vasc Surg. 2009;49:552-560.

9. Manning BJ, O'Neill SM, Haider SN, Colgan MP, Madhavan P, Moore DJ. Duplex ultrasound in aneurysm surveillance following endovascular aneurysm repair: a comparison with computed tomography aortography. J Vasc Surg 2009;49:60-65.

10. Chaer RA, Gushchin A, Rhee R, et al. Duplex ultrasound as the sole long-term surveillance method post-endovascular aneurysm repair: a safe alternative for stable aneurysms. J Vasc Surg 2009;49:845-849; discussion 849-850.

11. Elkouri S, Panneton JM, Andrews JC, et al. Computed tomography and ultrasound in follow-up of patients after endovascular repair of abdominal aortic aneurysm. Ann Vasc Surg 2004; 18:271-279.

12. Raman KG, Missig Carroll N, Richardson T, Muluk SC, Makaroun MS. Color-flow duplex ultrasound scan versus computed tomographic scan in the surveillance of endovascular aneurysm repair. J Vasc Surg 2003;38:645-651.

13. Pages S, Favre JP, Cerisier A, Pyneeandee S, Boissier C, Veyret C. Comparison of color duplex ultrasound and computed tomography scan for surveillance after aortic endografting. Ann Vasc Surg 2001;15:155-162.

14. Bendick PJ, Bove PG, Long GW, Zelenock GB, Brown OW, Shanley CJ. Efficacy of ultrasound scan contrast agents in the noninvasive follow-up of aortic stent grafts. J Vasc Surg 2003; 37:381-385.

15. Heilberger P, Schunn C, Ritter W, Weber S, Raithel D. Postoperative color flow duplex scanning in aortic endografting. J Endovasc Surg 1997;4:262-271.

16. McWilliams RG, Martin J, White D, et al. Detection of endoleak with enhanced ultrasound imaging: comparison with biphasic computed tomography. J Endovasc Ther 2002;9:170-179.

17. Napoli V, Bargellini I, Sardella SG, et al. Abdominal aortic aneurysm: contrast-enhanced US for missed endoleaks after endoluminal repair. Radiology 2004;233:217-225.

18. Sun Z. Diagnostic value of color duplex ultrasonography in the follow-up of endovascular repair of abdominal aortic aneurysm. J Vasc Interv Radiol 2006;17:759-764.

19. Carrafiello G, Recaldini C, Lagana D, Piffaretti G, Fugazzola C. Endoleak detection and classification after endovascular treatment of abdominal aortic aneurysm: value of CEUS over CTA. Abdom Imaging 2008;33:357-362.

20. Carrafiello G, Lagana D, Recaldini C, et al. Comparison of contrast-enhanced ultrasound and computed tomography in classifying endoleaks after endovascular treatment of abdominal aorta aneurysms: preliminary experience. Cardiovasc Intervent Radiol 2006;29:969-974. 
21. van Dijk R, van Croonenborg JJ, van Logtestijn SI, et al. Richtlijn Voorzorgsmaatregelen bij jodiumhoudende contrastmiddelen. Utrecht: Kwaliteitsinstituut voor de Gezondheidszorg; 2007.

22. Henao EA, Hodge MD, Felkai DD, et al. Contrast-enhanced Duplex surveillance after endovascular abdominal aortic aneurysm repair: improved efficacy using a continuous infusion technique. J Vasc Surg 2006;43:259-264.

23. White GH, May J, Waugh RC, Chaufour X, Yu W. Type III and type IV endoleak: toward a complete definition of blood flow in the sac after endoluminal AAA repair. J Endovasc Surg 1998;5:305-309.

24. White GH, May J, Waugh RC, Yu W. Type I and Type II endoleaks: a more useful classification for reporting results of endoluminal AAA repair. J Endovasc Surg 1998;5:189-191.

25. Bland JM, Altman DG. Statistical methods for assessing agreement between two methods of clinical measurement. Lancet 1986;1:307-310.

26. Gorich J, Rilinger N, Sokiranski R, et al. Leakages after endovascular repair of aortic aneurysms: classification based on findings at $\mathrm{CT}$, angiography, and radiography. Radiology 1999;213:767-772.

27. Bossuyt PM, Reitsma JB, Bruns DE, et al. Towards complete and accurate reporting of studies of diagnostic accuracy: The STARD Initiative. Radiology 2003;226:24-28.

28. Haulon S, Lions C, McFadden EP, et al. Prospective evaluation of magnetic resonance imaging after endovascular treatment of infrarenal aortic aneurysms. Eur J Vasc Endovasc Surg 2001;22:62-69.

29. Sternbergh WC, 3rd, Greenberg RK, Chuter TA, Tonnessen BH. Redefining postoperative surveillance after endovascular aneurysm repair: recommendations based on 5-year followup in the US Zenith multicenter trial. J Vasc Surg 2008;48:278-284.

30. Kalef-Ezra JA, Karavasilis S, Ziogas D, Dristiliaris D, Michalis LK, Matsagas M. Radiation burden of patients undergoing endovascular abdominal aortic aneurysm repair. J Vasc Surg 2009;49:283-287; discussion 287.

31. The 2007 Recommendations of the International Commission on Radiological Protection. ICRP publication 103. Ann ICRP 2007;37:1-332.

32. Rao QA, Newhouse JH. Risk of nephropathy after intravenous administration of contrast material: a critical literature analysis. Radiology 2006;239:392-397.

33. Nakamura S, Yoshihara F, Kamide K, et al. Renal function in patients with abdominal aortic aneurysm. Comparison with hypertensive patients. Kidney Blood Press Res 2006;29:67-73.

34. Fearn S, Lawrence-Brown MM, Semmens JB, Hartley D. Follow-up after endovascular aortic aneurysm repair: the plain radiograph has an essential role in surveillance. J Endovasc Ther 2003;10:894-901.

35. Murphy M, Hodgson R, Harris PL, McWilliams RG, Hartley DE, Lawrence-Brown MM. Plain radiographic surveillance of abdominal aortic stent-grafts: the Liverpool/Perth protocol. J Endovasc Ther 2003;10:911-912.

36. Schlosser FJ, Gusberg RJ, Dardik A, et al. Aneurysm rupture after EVAR: can the ultimate failure be predicted? Eur J Vasc Endovasc Surg 2009;37:15-22. 



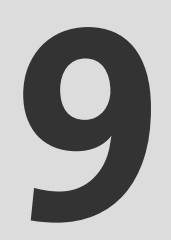

Plasma levels of matrix metalloproteinase-9:

a possible diagnostic marker of successful endovascular aneurysm repair

JA Ten Bosch

FAMVI Hellenthal

B Pulinx

WKWH Wodzig

MW de Haan

MH Prins

RJThJ Welten

JAW Teijink

GWH Schurink

Eur J Vasc Endovasc Surg. 2012;43:171-172 


\title{
Abstract
}

\author{
Objective \\ Identification of endoleakage by a blood test with high sensitivity could spare \\ endovascular aortic aneurysm repair (EVAR) patients to undergo repetitive computed \\ tomography angiography (CTA). Our objective was to evaluate the value of plasma levels \\ of matrix metalloproteinase (MMP)-2, -9 , and tissue inhibitor of MMP-1 (TIMP-1) as a \\ diagnostic tool to discriminate between patients with and without endoleak.
}

\section{Materials and Methods}

Consecutive patients ( $n=17)$ who visited the outpatients clinics of two Dutch medical centers and who had an endoleak present on post-EVAR CTA surveillance between January and July 2008 were prospectively enrolled in the study. Controls $(n=20)$ were EVAR patients without endoleak on CTA, frequency matched for age and gender. Plasma levels of MMP- 2, -9 and TIMP-1 were determined in duplicate. Main outcome measures were sensitivity and specificity for different biomarker plasma concentration cut-off points.

\section{Results}

Increased levels of MMP-9 were observed in patients with an endoleak $(P<0.001)$ compared to patients without endoleak. The ROC curve of plasma MMP-9 levels showed that a cut-off value of $55.18 \mathrm{ng} / \mathrm{ml}$ resulted in $100 \%$ sensitivity and $96 \%$ specificity. The AUC was $0.988(P<0.001)$.

\section{Conclusions}

The present study shows that plasma levels of MMP-9 can accurately discriminate between patients with and without an endoleak with both high sensitivity and specificity. 


\section{Introduction}

Endovascular aortic aneurysm repair (EVAR) is a safe and effective method to treat patients with suitable abdominal aortic aneurysm (AAA). ${ }^{1}$ Compared to conventional open aortic aneurysm repair, EVAR has decreased early mortality and length of hospital stay. ${ }^{2,3}$ However, during 4 years of follow up stent graft related complications have been observed in approximately $40 \%$ of patients, resulting in a $20 \%$ reintervention rate. ${ }^{4}$ Therefore, long term imaging surveillance is required for detection of stent graft related complications, including migration, kinking, and endoleakage.

EVAR excludes the AAA from the circulation but the AAA sac is left in situ. A minority of cases show persistent flow in the aneurysm sac due to endoleak. ${ }^{5}$ Endoleak is the most common complication of EVAR with a reported incidence varying from 2 to $45 \%{ }^{1,6-9}$ Endoleak is clinically important since it may cause enlargement with eventually rupture of the aneurysm sac. Hence, reinterventions are frequently required. Computed tomography angiography (CTA) is considered the gold standard for detection of these graft related complications in the follow-up of patients after EVAR. ${ }^{9,10}$ The European Collaborators on Stent/Graft Techniques for Aortic Aneurysm Repair (EUROSTAR) Registry recommends a CTA surveillance regime scheduled at 3, 6 and 12 months and subsequently yearly thereafter. ${ }^{11}$ However, repetitive CTA has known disadvantages such as cumulative radiation dose, nephrotoxic contrast agent and high costs. ${ }^{12}$ Therefore, a less harmful and less costly alternative for follow-up after EVAR is desirable. Previous investigations have focused on biochemical assays and alternative imaging modalities such as (contrast-enhanced) ultrasonography ((CE)US) and magnetic resonance angiography (MRA). ${ }^{13-15}$ Increased circulating plasma levels of matrix metalloproteinase (MMP)-2, -9 and tissue inhibitor of MMP-1 (TIMP-1) are associated with presence and size of AAA. ${ }^{16-18}$ Sangiorgi et al. were the first to report that a decrease of plasma MMP-3 and MMP-9 during post EVAR surveillance indicates successful EVAR and that an increase in MMP concentration after EVAR may help to identify patients with aneurysm sac growth and/or endoleakage. ${ }^{19}$ These observations were confirmed by others. $^{20,21}$ However, none of these studies reported on diagnostic value of these biochemical assays (sensitivity and specificity). Hence, to date none of these assays are clinically applied. The objective of this study was to evaluate the potential clinical applicability of MMP-2, -9 , and TIMP-1 as a diagnostic tool for presence of endoleakage. 


\section{Materials and Methods}

\section{Patients}

At the Maastricht University Medical Center (Maastricht, the Netherlands) and the Atrium Medical Center (Heerlen, the Netherlands) surveillance after endovascular AAA repair consisted of CTA scheduled at 1 month, 6 months, and yearly thereafter. All consecutive patients who visited the vascular outpatients clinic of the participating centers between January $1^{\text {st }}$ and July $1^{\text {st }} 2008$ with endoleak present on CTA were prospectively enrolled in the study. Controls were EVAR patients without endoleak on CTA, frequency matched for age and gender. EVAR procedures were performed between May $1^{\text {st }} 2006$ and August $1^{\text {st }}$ 2008. Mean follow-up time was 15 months. After patients provided written informed consent, blood samples for assessment of biochemical assays were collected within a week after CTA imaging. Cardiovascular risk factors as well as smoking history and drug use were recorded. The study was approved by both institutional ethics committees and the patients gave informed consent.

\section{Blood collection}

Venous blood was drawn via an antecubital vein puncture and collected in EDTA buffered (K2E $7.2 \mathrm{mg}$ ) vacutainer ${ }^{\circledR}$ for plasma. Exactly thirty minutes after collection, blood was centrifuged $\left(15\right.$ minutes, $\left.3000 \mathrm{~g}, 4^{\circ} \mathrm{C}\right)$ and multiple aliquots were stored at $-80^{\circ} \mathrm{C}$ pending analysis. As demonstrated by others, concentration and activity of MMP is stable during long term storage at $-80^{\circ} \mathrm{C}^{22}$

\section{Assays}

Plasma levels of MMP- 2, -9 and TIMP-1 were determined by means of a commercially available enzyme linked immunosorbent assay (GE Healthcare/lifesciences, Upssala, Sweden) according to the manufacturer's guidelines and were determined in duplicate. Duplicates with less than $10 \%$ within assay variation in concentration were accepted and means were determined for further analysis.

The between-assay variation (7\% for MMP-2, 10\% for both MMP-9 and TIMP-1) was determined by the manufacturer.

\section{Imaging}

During follow-up after EVAR, CTA was performed by a multidetector 16 slice helical CT scanner. CT scanning was performed with an in-plane resolution of 
$512 \times 512$ pixels and a slice-thickness of either 1 or $3 \mathrm{~mm}$, due to the use of different protocols in the two hospitals. Scanning occurred from the diaphragm to the common femoral arteries after continuous intravenous administration of iodinated contrast agent (Xenetix ${ }^{\circledR}$ 300, Guerbet, Cedex, France). Images were either acquired as a native CT scan followed by an a arterial phase scan, triggered by contrast passing the aorta, or by arterial phase followed by a delayed phase after 30 seconds. Maximal anterior-posterior diameter (Dmax) of the aneurysm sac was determined and presence of endoleak, migration, and component separation was assessed.

\section{Statistical analysis}

Statistical analyses were performed by means of SPSS 15.0 software. The characteristics of patients with or without endoleak were compared with Pearson Chi-Squared or Fisher's Exact test for nominal variables and MannWhitney $U$ test for continuous variables. The ability of plasma MMP-2, -9 , and TIMP-1 to distinguish patients with an endoleak from patients without endoleak was investigated using receiver operating characteristic (ROC) curve and area under the curve (AUC). In a ROC curve the true positive rate (sensitivity) is plotted in function of the false positive rate (100-specificity) for different cut-off points. ${ }^{23}$ Our objective was to identify a cut-off value related to high sensitivity in order to reduce the risk of false negative results.

\section{Results}

\section{Patients}

Thirty-seven patients were included in the study. Seventeen patients had an endoleak as detected on CTA, which included 4 type I, 12 type II and 1 type III endoleaks. Four of the patients' endoleaks were primary and were present at the completion angiography of the original EVAR operation. The demographic and clinical characteristics of patients with and without endoleak are listed in Table 9.1. The maximal AAA diameter was higher among patients who presented with an endoleak.

\section{Assays}

Mean plasma levels of MMP-2, -9, and TIMP-1 are listed in Table 9.2. Plasma levels of MMP-2 and TIMP-1 did not differ significantly for patients with endoleak compared to patients without endoleak. On the other hand, an 
increased concentration of MMP-9 was observed in patients with an endoleak $(P<0.001)$ (Figure 9.1), as compared to patients without endoleak.

Table 9.1 Patient and aneurysm characteristics.

\begin{tabular}{lccc}
\hline & $\begin{array}{c}\text { Endoleak } \\
(\mathrm{n}=20)\end{array}$ & $\begin{array}{c}\text { Endoleak + } \\
(\mathrm{n}=17)\end{array}$ & $\boldsymbol{P}$-value \\
\hline Male gender (\%) & $19(95)$ & $16(94)$ & $\mathrm{ns}$ \\
Age - years (mean (SD)) & $74(9.5)$ & $73(7.0)$ & $\mathrm{ns}$ \\
Smoking history (\%) & $20(100)$ & $17(100)$ & $\mathrm{ns}$ \\
$\quad$ Current smokers (\%) & $5(25)$ & $4(24)$ & \\
$\quad 15(75)$ & $13(76)$ & \\
Ex smokers (\%) & $7(35)$ & $11(65)$ & $\mathrm{ns}$ \\
Motin use (\%) & $18(15)$ & $21(15)$ & $\mathrm{ns}$ \\
Maximal AP AAA diameter - mm (mean (SD)) & $57(17)$ & $72(19)$ & 0.038 \\
Right introduction of main device (\%) & $18(90)$ & $17(100)$ & $\mathrm{ns}$ \\
Neck diameter - mm (mean (SD)) & $24(4.2)$ & $24(3.7)$ & $\mathrm{ns}$ \\
Neck length - mm (mean (SD)) & $35(14)$ & $37(16)$ & $\mathrm{ns}$ \\
Unfavorable angulation of neck (\%) & $3(15)$ & $2(12)$ & $\mathrm{ns}$ \\
Diameter ipsilateral CIA - mm (mean (SD)) & $17(6.1)$ & $15(3.2)$ & $\mathrm{ns}$ \\
Diameter contralateral CIA - mm (mean (SD)) & $18(7.3)$ & $17(4.5)$ & $\mathrm{ns}$ \\
Tortuosity of iliac axis & $3(15)$ & $4(24)$ & $\mathrm{ns}$ \\
Patent IMA (\%) & $5(25)$ & $4(24)$ & $\mathrm{ns}$ \\
\hline
\end{tabular}

$\mathrm{AP}=$ Anterior-posterior, $\mathrm{mm}=$ millimeter, $\mathrm{SD}=$ standard deviation, $\mathrm{CI} A=$ common iliac artery, IMA=inferior mesenteric artery

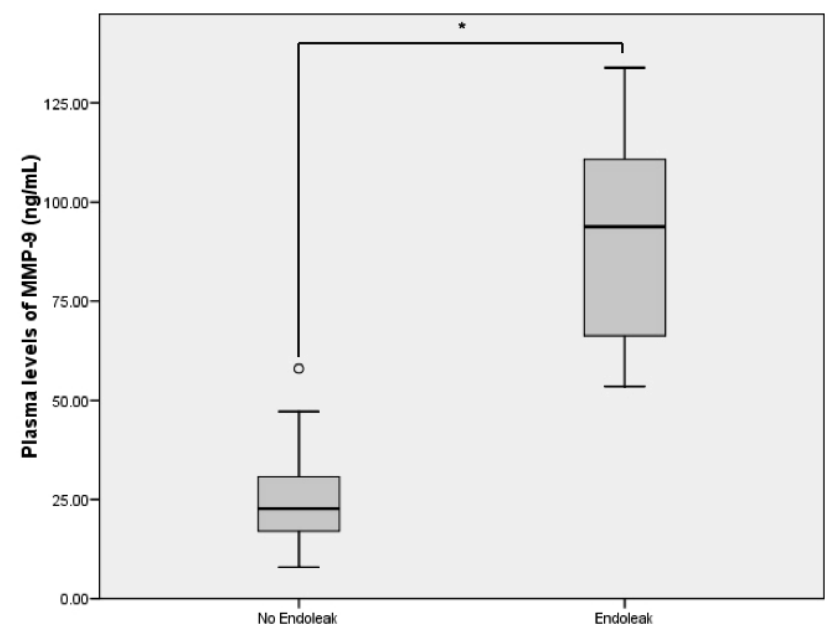

Figure 9.1 Plasma MMP-9 levels of patients without and with endoleak.

* Indicates a statistically significant difference $(P<0.001)$ of MMP-9 plasma levels observed in patients with an endoleak as compared to patients without endoleak. The open dot represents the only patient without endoleak on CTA that overlapped with the values of those with endoleak on CTA. 
The ROC curve of plasma MMP-9 levels for the discrimination of patients with and without an endoleak is shown in Figure 9.2. A cut-off value of MMP-9 plasma concentration of 55.18 resulted in a sensitivity of $100 \%(95 \% \mathrm{Cl} 80.5$ $100 \%)$ and a specificity of $96 \%$ (95\% Cl 75.1-99.9\%). The AUC was 0.988 $(P<0.001)$. However, differentiation between different types of endoleaks could not be made based on plasma MMP-9 levels (Figure 9.3).

Table 9.2 Mean (SD) Plasma levels of candidate biomarkers.

\begin{tabular}{lccc}
\hline Biomarkers & Endoleak - (SD) & Endoleak + (SD) & P-value \\
\hline MMP-2 (pg/ml) & $1006.58(285.76)$ & $1110.37(370.23)$ & $\mathrm{ns}$ \\
MMP-9 (pg/ml) & $25.02(13.40)$ & $89.54(26.46)$ & 0.000 \\
TIMP-1 $(\mathrm{pg} / \mathrm{ml})$ L & $138.14(69.08)$ & $142.51(63.29)$ & $\mathrm{ns}$ \\
\hline
\end{tabular}

MMP-2 = matrix metalloproteinase -2, MMP-9 = matrix metalloproteinase -9 , TIMP-1 = tissue inhibitor of matrix metalloproteinase type 1.

Mean Dmax of the endoleak group was significantly larger than the group with endoleak (72 mm vs. $57 \mathrm{~mm}$ ). Figure 9.4 and 9.5 show that the plasma levels of MMP-9 were dependent on presence of endoleak and not Dmax or intraluminal thrombus (ILT) volume. Furthermore, no statistical differences in aneurysm characteristics between the endoleak and the control group were present (Table 9.1).

Blood samples of two patients that underwent intervention to eliminate type II endoleak showed significant decrease in plasma levels of MMP-9 at one month post intervention (102.95 to $16.23 \mathrm{ng} / \mathrm{ml}$ and 121.97 to $20.28 \mathrm{ng} / \mathrm{ml}$ ). Furthermore we determined MMP- 9 levels in fluid aspirated from the aneurysm sac of these patients. These showed greatly increased levels of MMP-9, 386.34 and $343.78 \mathrm{ng} / \mathrm{ml}$, respectively. 


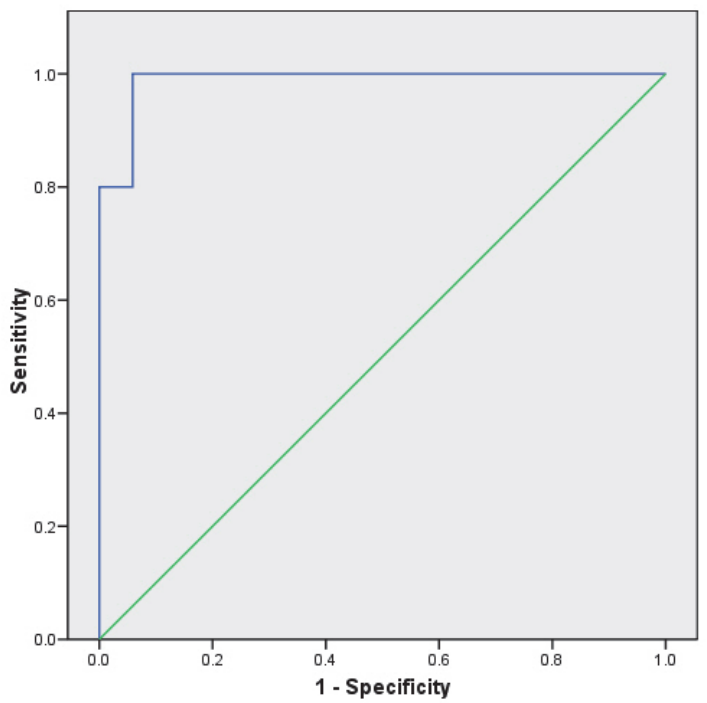

Figure 9.2 ROC curve for plasma MMP-9 levels.

At a cut-off value of MMP-9 plasma concentration of 55.18 a sensitivity of $100 \%$ (95\% $\mathrm{Cl} 80.5-100 \%)$ and a specificity of $96 \%$ (95\% Cl 75.1-99.9\%) were found. The AUC was $0.988(P<0.001)$.

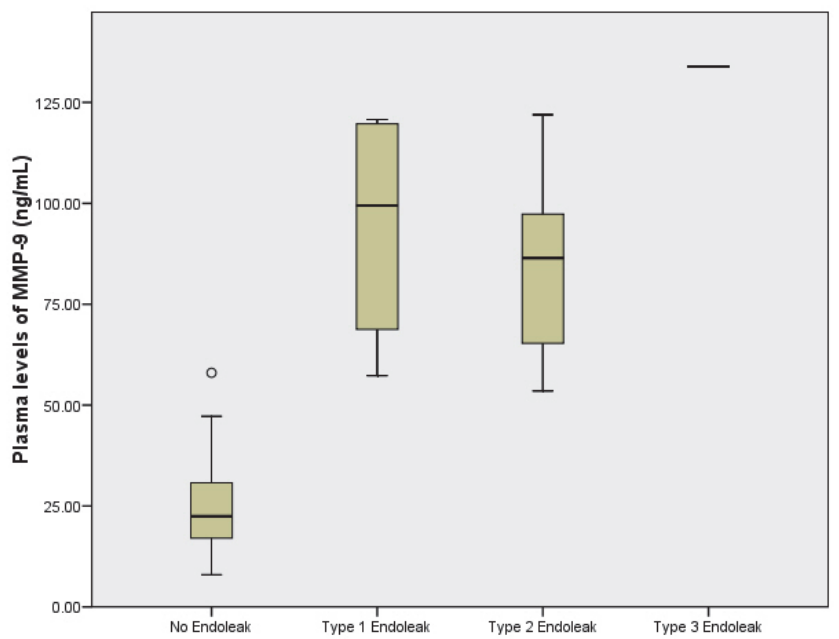

Figure 9.3 Plasma MMP-9 levels of patients with different types of endoleak. Differences in MMP-9 plasma levels between different types of endoleak were not statistically significant. 


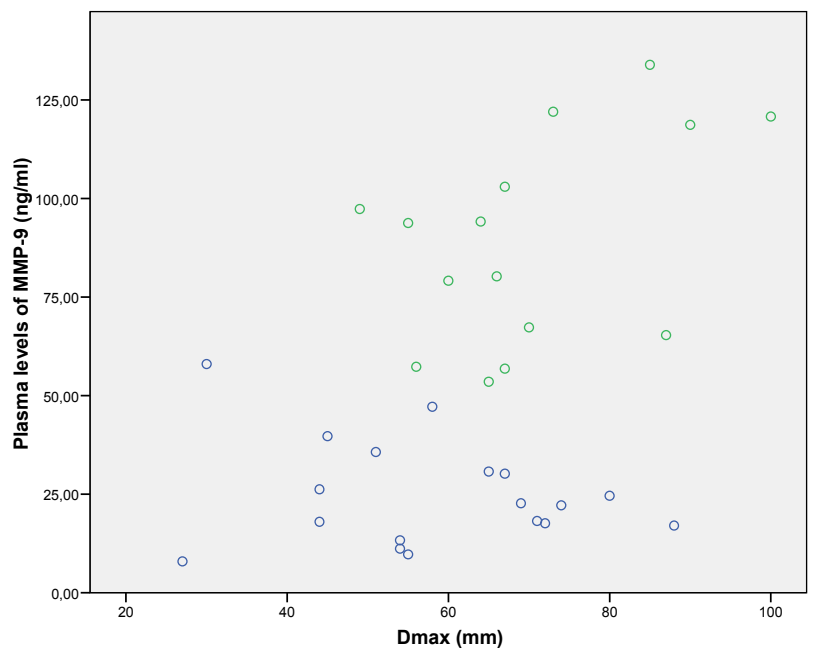

Figure 9.4 Plasma MMP-9 levels of patients with and without endoleak and Dmax.

Blue dots represent patients without endoleak and green dots represent patients with endoleak. MMP-9 levels were dependent on the presence of an endoleak and not on Dmax. Patients with large Dmax and without endoleak displayed low levels of MMP-9.

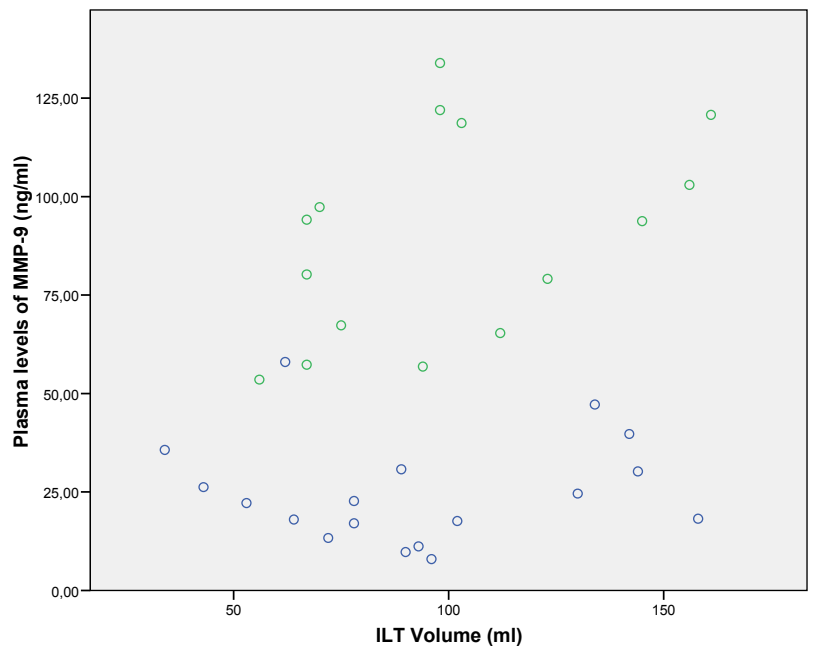

Figure 9.5 Plasma MMP-9 levels of patients with and without endoleak and ILT volume.

Blue dots represent patients without endoleak and green dots represent patients with endoleak. MMP-9 levels were dependent on the presence of an endoleak and not on ILT volume. Patients with large ILT volume and without endoleak displayed low levels of MMP-9. 


\section{Discussion}

The present study showed that plasma levels of MMP-9 could accurately discriminate between patients with and without an endoleak with both high sensitivity and specificity. The ROC and the AUC demonstrated that plasma MMP-9 is an excellent test for the determination of endoleak presence. The implication of a clinical applicable blood test for differentiation between patients with and without endoleak is of major clinical importance. Patients without an endoleak could be spared to undergo CTA with the aforementioned additional hazards and cost. Reports on short and medium term outcome of EVAR show incidences of endoleak up to $10 \%{ }^{1,6}$ When patients with an endoleak can be identified by a simple blood test with high sensitivity (eg MMP-9), a potential $90 \%$ of follow up CT scans can be spared. Besides individual benefits, like less exposure to cumulative radiation doses and nephrotoxic contrast loads, health care costs are vastly reduced. Over 100.000 EVAR procedures are performed in Europe and the United States each year and the number is rising. Most of these patients are submitted to a follow-up surveillance regime of long term annual CTA, as recommended by the EUROSTAR Registry. ${ }^{11}$ This regime imposes a major contribution to the overall costs of EVAR treatment and strain on the medical system. Subject of debate is whether the costs of EVAR, including the long term costs for endoleak surveillance, could outweigh the benefits of this treatment strategy as compared to conventional open surgical repair. ${ }^{24}$ Therefore, it seems that cost reduction of post EVAR surveillance is of vital importance for the future of EVAR. Recently, the necessity of surveillance after EVAR has been questioned as reports show that interventions after EVAR were initiated by symptoms rather than by surveillance imaging. ${ }^{25,26}$ Black et al. suggest a follow-up regime of CTA at three months, followed by routine ultrasonography therafter. ${ }^{25}$ From a costeffectiveness perspective they even argued that long-term surveillance is not justified at all. Karthikesalingam et al. suggested to curtail surveillance to patients at high risk of reintervention after EVAR. ${ }^{26}$ MMP-9 plasma levels could be suitable for differentiation of patients with low and high risk of reintervention.

Plasma MMP levels decrease within the first 3 months after EVAR. ${ }^{20}$ Sangiorgi et al. and Lorelli et al. previously reported on plasma MMP-9 levels for the evaluation of the successfulness of EVAR procedures and showed proof of concept. ${ }^{19,20}$ Monaco et al. have shown the potential of MMP-3, -9 and TIMP-1 in the differentiation between successful thoracic EVAR (TEVAR) and endoleak after TEVAR. ${ }^{21}$ The current study is the first to report on the diagnostic value of 
the MMP-9 assay for post EVAR surveillance. We also showed that MMP-9 levels were dependent on the presence of endoleak and not on Dmax. Although this case control study has a limited number of patients, sensitivity and specificity rates are impressive and the confidence intervals are reassuring. Nevertheless, an adequately powered prospective clinical trial is necessary to validate the applicability of plasma MMP-9 levels for the differentiation of patients with and without endoleak in clinical practice and the potential role of plasma MMP-9 levels in the selection of EVAR patients that need CTA. Furthermore, standardization of the assay (e.g. monoclonal antibody and calibrators) will be necessary for the application of one standard cut-off value. Endoleak is a derivative or sign of failed EVAR with circulation in the aneurysm sac, thus pressurization of the aneurysm sac. Since we only report on the diagnostic value of the MMP-9 assay for the discrimination of the presence or absence of endoleak, additional diagnostics will be necessary in order to detect other potential complications of EVAR, such as migration and kinking. A widely accepted imaging modality for detection of these mechanical stent graft related complications is plain abdominal X-ray, which imposes far less radiation and costs than CTA. ${ }^{27,28}$ Hypothetically, complications of EVAR can be detected by combination of MMP-9 plasma levels and plain abdominal X-ray, but the most important derivative of EVAR complication, aneurysm sac expansion, can not be assessed. For detection of AAA growth after EVAR additional ultrasound measurement of Dmax could be added. Besides the evaluation of Dmax, ultrasound can be used to access the presence of endoleak, although regular ultrasound and color duplex has poor sensitivity for detection of endoleak. However, contrast-enhanced ultrasound imaging (CEUS) has significantly improved the diagnostic accuracy in the detection of endoleaks. ${ }^{29}$ CEUS has been reported as the preferred test on which to base an intervention for endoleak. ${ }^{30}$ Drawback of endoleak detection by means of duplex or CEUS is the requirement of a dedicated vascular laboratory, which is not widespread available. Plasma levels of MMP-9 are not observer-dependent and lower in cost. Future studies most evaluate EVAR follow-up by means of one and 6 month CTA followed by yearly combination of plain abdominal X-ray, ultrasound and MMP-9 plasma levels.

In conclusion, the present study shows that plasma levels of MMP-9 can accurately discriminate between patients with and without an endoleak with both high sensitivity and specificity. A prospective clinical trial in order to validate the clinical applicability of this assay is in progress. 


\section{References}

1. Drury D, Michaels JA, Jones L, Ayiku L. Systematic review of recent evidence for the safety and efficacy of elective endovascular repair in the management of infrarenal abdominal aortic aneurysm. Br J Surg 2005;92:937-946.

2. Prinssen M, Verhoeven EL, Buth J, Cuypers PW, van Sambeek MR, Balm R, Buskens E, Grobbee $\mathrm{DE}$, Blankensteijn JD. A randomized trial comparing conventional and endovascular repair of abdominal aortic aneurysms. N Engl J Med 2004;351:1607-1618.

3. Lederle FA, Kane RL, MacDonald R, Wilt TJ. Systematic review: repair of unruptured abdominal aortic aneurysm. Ann Intern Med 2007;146:735-741.

4. Endovascular aneurysm repair versus open repair in patients with abdominal aortic aneurysm (EVAR trial 1): randomised controlled trial. Lancet 2005;365:2179-2186.

5. White GH, Yu W, May J, Chaufour X, Stephen MS. Endoleak as a complication of endoluminal grafting of abdominal aortic aneurysms: classification, incidence, diagnosis, and management. J Endovasc Surg 1997;4:152-168.

6. Schurink GW, Aarts NJ, van Bockel JH. Endoleak after stent-graft treatment of abdominal aortic aneurysm: a meta-analysis of clinical studies. Br J Surg 1999;86:581-587.

7. Cuypers P, Buth J, Harris PL, Gevers E, Lahey R. Realistic expectations for patients with stentgraft treatment of abdominal aortic aneurysms. Results of a European multicentre registry. Eur J Vasc Endovasc Surg 1999;17:507-516.

8. Golzarian J, Dussaussois L, Abada HT, Gevenois PA, Van Gansbeke D, Ferreira J, Struyven J. Helical CT of aorta after endoluminal stent-graft therapy: value of biphasic acquisition. AJR Am J Roentgenol 1998;171:329-331.

9. Gorich J, Rilinger N, Sokiranski R, Orend KH, Ermis C, Kramer SC, Brambs HJ, SunderPlassmann L, Pamler R. Leakages after endovascular repair of aortic aneurysms: classification based on findings at CT, angiography, and radiography. Radiology 1999;213:767-772.

10. Makaroun MS, Deaton $\mathrm{DH}$. Is proximal aortic neck dilatation after endovascular aneurysm exclusion a cause for concern? J Vasc Surg 2001;33(2 Suppl):S39-45.

11. Vallabhaneni SR, Harris PL. Lessons learnt from the EUROSTAR registry on endovascular repair of abdominal aortic aneurysm repair. Eur J Radiol 2001;39:34-41.

12. Prinssen $\mathrm{M}$, Wixon $\mathrm{CL}$, Buskens $\mathrm{E}$, Blankensteijn JD. Surveillance after endovascular aneurysm repair: diagnostics, complications, and associated costs. Ann Vasc Surg 2004;18:421-427.

13. Manning BJ, O'Neill SM, Haider SN, Colgan MP, Madhavan P, Moore DJ. Duplex ultrasound in aneurysm surveillance following endovascular aneurysm repair: a comparison with computed tomography aortography. J Vasc Surg 2009;49:60-65.

14. Carrafiello G, Recaldini C, Lagana D, Piffaretti G, Fugazzola C. Endoleak detection and classification after endovascular treatment of abdominal aortic aneurysm: value of CEUS over CTA. Abdom Imaging 2008;33:357-362.

15. van der Laan MJ, Bartels LW, Viergever MA, Blankensteijn JD. Computed tomography versus magnetic resonance imaging of endoleaks after EVAR. Eur J Vasc Endovasc Surg 2006;32: 361-365.

16. Hovsepian DM, Ziporin SJ, Sakurai MK, Lee JK, Curci JA, Thompson RW. Elevated plasma levels of matrix metalloproteinase- 9 in patients with abdominal aortic aneurysms: a circulating marker of degenerative aneurysm disease. J Vasc Interv Radiol 2000;11:1345-1352.

17. Lindholt JS, Vammen S, Fasting H, Henneberg EW, Heickendorff L. The plasma level of matrix metalloproteinase 9 may predict the natural history of small abdominal aortic aneurysms. A preliminary study. Eur J Vasc Endovasc Surg 2000;20:281-285.

18. Sakalihasan N, Delvenne P, Nusgens BV, Limet R, Lapiere CM. Activated forms of MMP2 and MMP9 in abdominal aortic aneurysms. J Vasc Surg 1996;24:127-133.

19. Sangiorgi G, D'Averio R, Mauriello A, Bondio M, Pontillo M, Castelvecchio S, Trimarchi S, Tolva V, Nano G, Rampoldi V, Spagnoli LG, Inglese L. Plasma levels of metalloproteinases-3 and - 9 as markers of successful abdominal aortic aneurysm exclusion after endovascular graft treatment. Circulation 2001;104(12 Suppl 1):1288-295. 
20. Lorelli DR, Jean-Claude JM, Fox CJ, Clyne J, Cambria RA, Seabrook GR, Towne JB. Response of plasma matrix metalloproteinase- 9 to conventional abdominal aortic aneurysm repair or endovascular exclusion: implications for endoleak. J Vasc Surg 2002;35:916-922.

21. Monaco M, Stassano P, Di Tommaso L, lannelli G. Response of plasma matrix metalloproteinases and tissue inhibitor of metalloproteinases to stent-graft surgery for descending thoracic aortic aneurysms. J Thorac Cardiovasc Surg 2007;134:925-931.

22. Sulik A, Wojtkowska M, Oldak E. Preanalytical factors affecting the stability of matrix metalloproteinase-2 concentrations in cerebrospinal fluid. Clin Chim Acta 2008;392:73-75.

23. Zweig $\mathrm{MH}$, Campbell G. Receiver-operating characteristic (ROC) plots: a fundamental evaluation tool in clinical medicine. Clin Chem 1993;39:561-577.

24. Raithel D. Surveillance of patients after abdominal aortic aneurysm repair with endovascular grafting or conventional treatment. J Mal Vasc 1998;23:390-392.

25. Black SA, Carrell TW, Bell RE, Waltham M, Reidy J, Taylor PR. Long-term surveillance with computed tomography after endovascular aneurysm repair may not be justified. $\mathrm{Br} \mathrm{J}$ Surg 2009;96:1280-1283.

26. Karthikesalingam A, Holt PJ, Hinchliffe RJ, Nordon IM, Loftus IM, Thompson MM. Risk of reintervention after endovascular aortic aneurysm repair. Br J Surg. 2010;97:657-663.

27. Fearn S, Lawrence-Brown MM, Semmens JB, Hartley D. Follow-up after endovascular aortic aneurysm repair: the plain radiograph has an essential role in surveillance. J Endovasc Ther 2003;10:894-901.

28. Murphy M, Hodgson R, Harris PL, McWilliams RG, Hartley DE, Lawrence-Brown MM. Plain radiographic surveillance of abdominal aortic stent-grafts: the Liverpool/Perth protocol. J Endovasc Ther 2003;10: 911-912.

29. Sun Z. Diagnostic value of color duplex ultrasonography in the follow-up of endovascular repair of abdominal aortic aneurysm. J Vasc Interv Radiol 2006;17:759-764.

30. Schmieder GC, Stout CL, Stokes GK, Parent FN, Panneton JM. Endoleak after endovascular aneurysm repair: duplex ultrasound imaging is better than computed tomography at determining the need for intervention. J Vasc Surg 2009;50:1012-1017; discussion 1017-1018. 



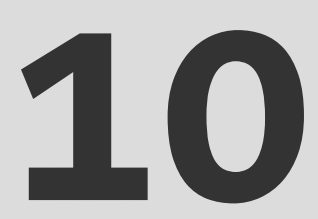

General discussion 



\section{General discussion}

Technical advancements in treatment as well as follow-up of patients with abdominal aortic aneurysms (AAA) affect daily clinical practice. Increasing numbers of patients are treated with minimally invasive endovascular aneurysm repair (EVAR). In patients with an acute AAA or paraanastomotic aneurysm after previous open reconstruction, perioperative mortality rates after open repair are known to be high. In section one of this thesis, the general objective was to assess potential early and midterm mortality reduction of EVAR compared with open surgical repair in patients with an acute AAA or paraanastomotic aneurysm after previous open reconstruction.

Once EVAR (acute and elective) has been performed, it has its own specific complications, which include migration, kinking, and endoleakage. Endoleak formation is the most common complication of EVAR. Computed tomography angiography (CTA) is the gold standard in detecting these endoleaks, but important drawbacks are its cumulative radiation dose and the use of nephrotoxic contrast agents. Technical advancements in follow-up of patients after EVAR have lead to multiple alternative imaging modalities and biochemical assays. The objective in section two of this thesis was to assess potential alternatives to CTA in post-EVAR surveillance.

In this chapter we describe the main findings of the studies presented in this thesis including methodological considerations, implications for clinical practice, and suggestions for future research. Finally, the overall conclusions are presented.

\section{Main findings}

An acute abdominal aortic aneurysm (aAAA) can either present as a symptomatic (nonruptured) AAA or as a ruptured AAA. Despite progression in surgical techniques, anesthetic management, vascular prostheses and perioperative care over the past decades, the mortality rate in patients with an aAAA treated with conventional open surgery remains high. ${ }^{1-3}$ In 1991 , Parodi et al. introduced a new minimally invasive technique for elective AAA repair, EVAR. In the elective setting, EVAR has proved its short and midterm effectiveness in terms of mortality risk reduction. ${ }^{45}$ Since 1994, emergency EVAR (eEVAR) has become an accepted treatment option, which is increasingly being performed to treat aAAA. However, the potential reduction in peri- 
operative mortality of eEVAR compared to conventional open repair in patients with an aAAA is still open to debate.

In an era where endovascular repair is increasingly performed, the indications have been extended. A few small case series have been published regarding endovascular repair for paraanastomotic aneurysms after previous open prosthetic reconstruction, without requiring dissection through previous scarred operative sites. ${ }^{6-9}$

The studies described in section one of this thesis focus on the role of endovascular repair in patients with an aAAA (symptomatic and ruptured) and in patients with a paraanastomotic aneurysm after previous open prosthetic reconstruction.

\section{PART ONE - ACUTE AND PARAANASTOMOTIC ABDOMINAL AORTIC ANEURYSMS, EVAR OR OPEN SURGERY?}

So far, studies comparing eEVAR with conventional open surgery in patients with a ruptured $A A A$ are flawed by methodological inadequacies such as selection bias and lack of randomization. ${ }^{10}$ Selection bias is created by selecting patients for eEVAR constituting a lower-risk category, presumably because they need to be hemodynamically more stable for preoperative imaging and have a more favorable (EVAR suitable) anatomic configuration. In chapter $\mathbf{2}$ we compared eEVAR with conventional open surgery in patients with a ruptured AAA who all underwent the same preoperative imaging protocol (CT angiography) and who were all judged suitable for endovascular repair by an independent external blinded group of experts. A 30-day mortality reduction of $25.5 \%$ in favor of eEVAR was found. This advantage maintained at 6 months of follow-up, with comparable complication and reintervention rates. Furthermore, a reduced length of hospital stay was observed after eEVAR. Therefore, we conclude that eEVAR is a valuable treatment option for EVAR suitable patients with a ruptured AAA.

Chapter 3 describes early and midterm (up to one year of follow-up) outcomes for eEVAR versus open repair of both symptomatic and ruptured AAA, in a large cohort of 246 patients (111 symptomatic and 129 ruptured AAA). It shows reduced early as well as midterm all cause mortality rates of eEVAR compared with open surgery in patients with a ruptured AAA, while comparable mortality results are observed in patients with a symptomatic AAA. Late aneurysm related mortality occurred only in the eEVAR group, which might be due to a significant increase in the need for late surgical re-interventions after eEVAR owing to an ongoing rupture risk in case of endoleak or stent graft migration. 
There is a theoretical possibility that anatomical suitability for EVAR is independently associated with improved mortality outcome as stated in Chapter 3. In chapter 4, we compared mortality results of open ruptured aneurysm repair in EVAR suitable patients versus patients that were not suitable for EVAR, as assessed on preoperative CTA. This study suggests that for all included patients who underwent preoperative CTA imaging, anatomical suitability for EVAR was not associated with a lower 30-day or 6-month mortality rate after open rAAA repair. It is remarkable that the lower limit of the 95\% confidence interval of the 30-day mortality (28\%) in EVAR suitable patients who were treated with open repair is higher than the mortality rates of $18-24 \%$ as reported for eEVAR in chapter 2 and 3 of this thesis as well as in literature. ${ }^{11-15}$ Therefore, it is unlikely that the reported difference in mortality between eEVAR and open repair can be explained by treating patients with a favorable anatomic configuration with eEVAR.

A symptomatic AAA generally represents imminent rupture, ${ }^{16}$ and therefore acute treatment is generally performed in order to prevent rupture with associated poor prognosis, as readily described in the previous chapters. ${ }^{17,18}$ However, since there is uncertainty of the time interval between initiation of symptoms and rupture in these patients, postponing surgery in order to optimize patients' and operative conditions might be permitted. Chapter $\mathbf{5}$ describes acute symptomatic AAA repair compared to delayed surgery after patient optimization. Aneurysm rupture occurred in 1 patient in the acute group $(2.7 \%)$ versus 4 patients in the delayed treatment group $(7.7 \%)$, which was not statistically significantly different. A trend was seen toward lower early mortality rates in patients who received delayed surgery. Consequently, chapter 5 shows that postponed surgical treatment in order to optimize patients' and operative conditions does not result in higher mortality rates in a substantial amount of patients presenting with a symptomatic AAA and might therefore be justified.

There are several theoretical advantages of EndoVascular Paraanastomotic Aneurysm Repair after previous open reconstruction (EVPAR). It allows for local or regional anesthesia without requiring dissection through the scar tissue of previous operative sites. ${ }^{8}$ Chapter 6 describes the long-term clinical course in a relatively large number of patients $(n=58)$ who underwent EVPAR. This chapter confirms that EVPAR is a feasible and durable alternative to open reconstruction, with a high primary technical success rate of $95 \%$, acceptable perioperative mortality and morbidity rates, and good long-term exclusion rates. Especially bifurcated stent grafts showed to be durable with low 
reintervention rates compared to aorto-uni-iliac stent grafts and endovascular tube grafts.

\section{PART TWO - FOLLOW-UP AFTER ENDOVASCULAR ANEURYSM REPAIR, DEPICTING STENT GRAFT RELATED COMPLICATIONS}

Endovascular repair for AAA is increasingly performed in both acute and elective situations. When a stent graft is positioned correctly, the aneurysm sac is excluded from systemic blood pressure. Stent graft related complications might cause re-establishment of pressure in the aneurysm sac, thereby resulting in aneurysm expansion and ongoing rupture risk. ${ }^{4}$ Therefore, longterm surveillance is required for detection of alterations in stent graft morphology, including migration, kinking (with subsequent limb occlusion), and endoleakage. Endoleak formation, defined as blood flow outside the stent graft and inside the aneurysm sac, ${ }^{21-23}$ is the most common complication of EVAR. ${ }^{24-27}$ It represents the main indication for late surgical conversion. ${ }^{28}$ Therefore, modalities for detection of endoleaks are essential in the post-EVAR surveillance.

In chapter 7 various strategies for endoleak detection in the follow-up after EVAR in terms of imaging techniques and biochemical assays are discussed. CTA follow-up after EVAR is considered the gold standard, with high sensitivity, widespread availability, rapid acquisition, and reproducibility. ${ }^{29}$ However, drawbacks are the cumulative radiation dose and nephrotoxic contrast agent. Promising alternative modalities for endoleak detection without ionizing radiation burden and the use of nephrotoxic contrast load are contrast enhanced ultrasound, magnetic resonance (angiography) imaging, and circulating biomarkers. ${ }^{30-32}$ These evolving techniques are able to detect and often classify endoleaks with increasing sensitivity and specificity, reserving a potential, prominent role in future post-EVAR follow-up. However, based on available evidence, true recommendations for ideal follow-up after EVAR cannot be made at this moment.

Sonographic contrast agents enhance the capability of color duplex to detect endoleaks. ${ }^{33-37}$ Chapter 8 compares the diagnostic accuracy between contrastenhanced ultrasound (CEUS) and computed tomographic angiography (CTA) in order to detect endoleaks and changes in AAA size during post-EVAR follow-up. Good agreement between the two imaging modalities was demonstrated for maximal aneurysm sac diameter measurements with low inter-observer variability for CEUS. Adversely, a significant discrepancy was observed with regard to detection of endoleaks. In $22 \%$ of cases CTA detected an endoleak, 
which corresponds with results in the available literature, ${ }^{35}$ versus $53 \%$ with CEUS. The level of agreement was low $(\mathrm{k}=0.237)$. The majority of additional endoleaks identified by contrast-enhanced ultrasound were type II, of which the clinical importance is still subject of debate. ${ }^{38}$ However, ultrasound also revealed two extra type I endoleaks. These results support the notion that contrast-enhanced ultrasound may be a substitute for CTA in the assessment of aneurysm sac dimensions and the detection of endoleaks, in suitable patients and when performed by highly trained ultrasound operators.

Increased circulating levels of plasma matrix metalloproteinase (MMP)-2, -9 and tissue inhibitor of MMP-1 (TIMP-1) are known to be associated with both the presence as well as the size of AAA. ${ }^{39-41}$ Some data show that a decrease of MMP concentration during post EVAR surveillance might indicate successful EVAR. $^{42-44}$ Chapter 9 evaluates the potential clinical applicability of MMP-2, -9 , and TIMP-1 as a diagnostic tool for the presence of endoleakage. An increased concentration of MMP-9 was observed in patients with an endoleak, as compared to patients without endoleak. A cut-off value of 55.18 resulted in a sensitivity of $100 \%$ and a specificity of $96 \%$. However, differentiation between different types of endoleaks could not be made based on plasma MMP-9 levels. Nevertheless, this chapter shows that plasma levels of MMP-9 can accurately discriminate between patients with and without an endoleak with both high sensitivity and specificity.

\section{Methodological considerations}

\section{PART ONE}

In the first part of this thesis we compare emergency EVAR with open repair in patients with an aAAA in terms of early and midterm mortality and morbidity. Well-conducted randomized controlled trails in an acute severe condition as aAAA are difficult to perform, as we can learn from Hinchcliffe et al. and the Amsterdam Acute Aneurysm Trial. ${ }^{45,46}$ Problems include obtaining informed consent in hemodynamically unstable patients, inclusion of patients unsuitable for either open surgery or EVAR, instant accessibility of a CT-scanner at all times, permanent availability of a vascular surgeon who is capable of performing emergency EVAR, permanent availability of a vascular team dedicated to EVAR, availability of an OR that is adequately equipped to perform EVAR, and availability of a variety 'off-the-shelf' stent-grafts. ${ }^{46-48}$ The only randomized controlled trail available, which showed identical 30-day mortality rates in both treatment groups, was underpowered and served as a pilot study 
for future randomized studies. ${ }^{46}$ In a large prospective observational study with long-term follow-up, as described in chapter 3 , the nonrandomized allocation of patients might result in differences in baseline characteristics (e.g. gender) and in selection bias. Selection bias is based on the allocation of patients to the EVAR group who are hemodynamically stable enough to undergo preoperative imaging and who have a potentially more favorable anatomic (EVAR suitable) configuration. In chapter 2 we took advantage of the fact that one vascular surgeon performed EVAR in the acute setting. eEVAR was performed in EVARsuitable cases when the eEVAR vascular surgeon was on call and open surgery was performed when the eEVAR vascular surgeon was not on call, making the previously described selection bias unlikely and providing a better comparison. However, similar results were obtained in both chapters, namely reduced early and midterm mortality rates of eEVAR compared to open surgery in patients with a ruptured aAAA. Therefore, we could ask ourselves whether selection bias really affects mortality results and prevents a proper comparison. A recent small retrospective study of Perrott et al. showed that anatomical suitability for EVAR might beneficially affect outcome following open repair in patients with a ruptured AAA. ${ }^{49}$ However, chapter 4 shows that the reported reduction in mortality between eEVAR and open repair, as observed in observational studies, is unlikely, due to selection bias based on anatomical AAA configuration. In this study, all patients underwent preoperative imaging, making selection bias based on hemodynamic conditions unlikely. Furthermore, anatomical suitability for EVAR was assessed afterwards by two independent experts, blinded for earlier evaluation, intervention, and outcome. Though, results of chapter 4 should be treated with some caution. At baseline, significantly more patients in the EVAR suitable group were male. This might theoretically influence mortality results, since women with a ruptured AAA are reported to have an increased mortality risk after EVAR compared to men. ${ }^{50}$ Secondly, patients who were anatomically unsuitable for EVAR were treated with open repair by all three participating vascular surgeons whether EVAR suitable patients were only treated with open repair by the vascular surgeon who was experienced in performing emergency EVAR.

Chapter 5 is based on the question why treatment of symptomatic non ruptured AAA is accompanied with higher mortality rates when compared to elective surgery. ${ }^{20,51,52}$ Potentially, these patients might suffer from a higher perioperative risk, due to the generally performed acute treatment with little time for preoperative optimization of patients' and operative conditions. In an ideal situation, patients would benefit from surgery under optimized conditions, 
with an acceptable risk of rupture prior to surgery. In chapter 5, the 30-day mortality rates in patients with a sAAA are lower in patients who were operated on more than 12 hours after presentation compared with patient who received acute treatment within 12 hours, though these results were not significant. Our conclusion that delayed treatment in certain patients with a SAAA in order to optimize conditions may be justified is mild due to several methodological limitations. First, there is lack of statistical power, which might be due to lower mortality rates in SAAA patients, approaching those of elective aneurysm repair, needing more patients in order to reach statistical significance. Secondly, since analyses were performed retrospectively on a prospective database and since an intention to treat by eEVAR protocol was not part of the study design, selection bias is likely to have occurred and heterogeneity might be present. In order to adjust for confounders, a logistic regression analyses was performed with type of operation as well as other potential confounders as variables, which showed similar results. Thirdly, since there is no fixed protocol available in literature for preoperative optimization of patients' and operative conditions in case of a SAAA, this was tailor-made by best individual clinical care. Finally, a sAAA was defined as the existence of an AAA with acute onset of abdominal and/or back pain combined with pain at aneurysm palpation, as described by Peppelenbosch et al. $^{53}$ However, abdominal pain and pain at aneurysm palpation might have other causes than an aneurysm in a state of pending rupture indicating potential false positive diagnoses.

Besides acute AAA repair, EVAR might theoretically be the preferred treatment option for paraanastomotic aneurysm repair after previous open reconstruction, since it allows for local or regional anesthesia without requiring dissection through the scars of previous operations. ${ }^{8}$ In chapter 6 we describe the long-term clinical course in patients who underwent EVPAR after previous open reconstruction. In comparison to available studies and given the fact that paraanastomotic aneurysms are rather uncommon, a relatively large cohort of patients is included in this multicenter study. Though, the studied numbers are too low for subgroup analysis on aneurysm site. Also the results from different types of stent grafts that were used have to be interpreted with caution due to the limited numbers of cases and anatomical variation influencing stent graft selection.

\section{PART TWO}

Chapter 7 gives an overview of the available studies on strategies for endoleak detection in the follow up after EVAR in terms of imaging techniques and 
biochemical assays. CTA follow-up after EVAR is considered the gold standard. Therefore, in comparative clinical studies, other imaging techniques are compared against the results of CT as the reference standard. A methodological problem is that some true endoleaks depicted by any imaging modality will be categorized as "false positives" because CTA did not visualize them. ${ }^{54,55}$ Therefore, results of the index test in comparative studies might be flawed by potential invalid results of the reference test.

The aim of chapter 8 was to investigate the accuracy of contrast-enhanced ultrasound as an alternative to CTA in the follow-up of patients after EVAR with regard to the detection of endoleaks and changes in AAA dimensions. Given the lack of a proper reference test, we did not report on sensitivity and specificity results for endoleak detection with contrast-enhanced ultrasound compared to CTA. We suggest that endoleaks detected by one or the other imaging modality should be considered as real endoleaks. Based on this assumption, the level of agreement between CTA and contrast-enhanced ultrasound for identifying endoleaks was calculated using kappa. A McNemar chi square test was performed to identify differential endoleak detection by the two imaging modalities. Methodological considerations in this chapter mainly consists of limitations in performing ultrasound examinations, such as operator dependency, which might limit reproducibility, and patient habitus, which may interfere with ultrasound imaging.

Other than contrast-enhanced ultrasound, several biochemical assays might have an additional role as a diagnostic tool for presence of endoleakage. In chapter 9, the potential clinical applicability of MMP-2, -9, and TIMP-1 was assessed using a receiver operating characteristic curve and area under the curve. Our objective was to identify a cut-off value related to high sensitivity in order to reduce the risk of false negative results, and we found a cut-off value of MMP-9 plasma concentration resulting in both high sensitivity and specificity with an almost maximal area under the curve. We are aware that this is a case control study with a limited number of patients, though sensitivity and specificity rates are impressive and the confidence intervals are reassuring. However, in the absence of a standardized assay protocol, widespread application might not yet be achievable. 


\section{Implications for clinical practice}

\section{PART ONE}

The proportion of patients with a rAAA treated by eEVAR increased significantly over the last decade. Together with the improvement of new generation devices, skills of the physicians improved, as well as their enthusiasm for the procedure. eEVAR offers many theoretical advantages over open repair. It is less invasive, eliminates damage to peri-aortic and abdominal structures, decreases bleeding from surgical dissection, minimizes hypothermia, and lessens the requirement for deep anesthesia. Several retrospective series demonstrate a potential survival advantage with mortality rates of $8-40 \%{ }^{56-59}$ Prospective trials had also shown this potential benefit before, but are limited by sample size. ${ }^{60-63}$ Only one randomized trial is available, demonstrating equivalent results and therefore challenging the benefit of EVAR in patients with a rAAA. However, this study showed lack of statistical power due to the small sample size. More than two-thirds of patients were excluded from the study because of hemodynamic instability or staff unavailability. Furthermore, there were 13 patients in the eEVAR group and only 11 completed eEVAR, due to open surgical repair crossover or preoperative death. ${ }^{46}$

The most complete and recent review included data from 13 selected centers that were committed to treat all rAAA patients who were anatomically suitable with eEVAR, irrespective of patients' hemodynamic or risk status. ${ }^{58}$ For this update a total of 1443 patients were included of which 680 received eEVAR (47\%) and 763 underwent open repair (53\%). In these centers, the 30-day mortality rate for eEVAR was $19.7 \%$, compared to $36.3 \%$ for open repair $(P<0.001)$. The percentage of rAAA patients who were treated by eEVAR was high, with a mean of $49.1 \% \pm 12.9 \%( \pm S D)$. However, the reported wide variability in 30-day eEVAR mortality might reflect case-mix and differences in risk stratification as well as treatment details in the various centers. Also potential selection bias might be a factor preventing a proper comparison.

In our own series, described in chapter 2, we found similar results in favor of eEVAR. Based on the design of the logistics that constituted our series, although not randomized, selection bias for anatomical or hemodynamic criteria was highly unlikely. Despite mounting level 2 evidence for survival advantage in patients undergoing eEVAR for rAAA, the vascular world is looking forward to the results of the first multicenter randomized controlled trial on this subject. During the $34^{\text {th }}$ International Charing Cross Symposium 2012 in London the preliminary results of the AJAX trial were presented. ${ }^{64}$ During the AJAX trial, in 
an area covering 1.2 million inhabitants, 520 patients with a rAAA were enrolled between April 2004 and February 2011. The preferred eEVAR technique was the use of an aorto-uni-iliac graft with contralateral occluder and femoro-femoral crossover bypass. A total of 116 patients were randomized: 57 to eEVAR and 59 to open repair. The primary endpoint was the combined and severe complications rate at 30 days which was $42 \%(24 / 57)$ in the eEVAR group and $47 \%(28 / 59)$ in the open group [ARR $5.4 \%(95 \% \mathrm{Cl}-13$ to +23$)$ ]. With regard to the secondary endpoints, ICU stay was 28 hours following eEVAR and 48 hours after open repair $(P=0.14)$; hospital stay was nine days following eEVAR and 13 days after open repair $(P=0.57) ; 39$ patients had to use a mechanical ventilator following eEVAR while 52 did so after open repair $(P=0.002)$; blood loss was 500 $\mathrm{ml}$ following eEVAR and $3500 \mathrm{ml}$ after open repair $(P<0.001)$. Finally, the mortality rate associated with eEVAR was $21 \%$ (12/57) versus $25 \%$ following open repair (15/59).

These preliminary results of the AJAX trial show no clear advantage for eEVAR in patients with a rAAA, although a significant reduction in blood loss and the need for mechanical ventilation in the eEVAR group can be seen as major advantages. Nevertheless, the AJAX trial raises, in some respect, more questions than answers. The eEVAR results were relatively consistent with current literature, but how come the results in the open repair group were, compared with the rest of the world, exceptionally favorable? Secondly, exclusion rates were high, since only $24.9 \%$ of patients were randomized (116 patients of the 466 patients that were initially enrolled in one of three trial centers). Reasons given for this high exclusion rate were lack of preoperative CTA scanning $(n=71)$, unfavorable anatomic configuration for EVAR $(n=240)$, unfitness for open surgery $(n=16)$, logistical reasons $(n=11)$, hemodynamic instability $(n=7)$, and patients refusing surgery $(n=5)$. Furthermore, 240 patients (61\% of the patients who underwent preoperative CTA scanning) were deemed anatomically unfavorable for EVAR, which is high compared to the $<50 \%$ as reported in literature. ${ }^{56,65}$ Together with the $15 \%$ of patients who did not receive a preoperative CTA scan, results in a group of 311 patients need to be clarified in the awaited publication, to put these preliminary results in a clear perspective and, moreover, to make sure that there was no selection prior to randomization.

Despite the on-going debate regarding the need for randomized controlled trials of eEVAR versus open repair, the issue of one treatment being superior to another may be less relevant than the evaluation of the impact on mortality of a service combining both open and endovascular operations compared to a 
service supplying open treatment alone. Data from the Nationwide Inpatient Sample (NIS) demonstrate reduced overall mortality after rAAA repair since EVAR was introduced in de United States. ${ }^{66}$ Also Hoornweg et al. showed in a meta-analysis, that the impact of the introduction of an endovascular program for rAAA has a positive effect on operative mortality with an Odds Ratio of 0.37 (95\% $\mathrm{Cl} 0.22$ to 0.63$)$. $^{67}$

This accumulation of superior results after the introduction of eEVAR, supports the increasing trend of centers adopting an eEVAR-first approach. ${ }^{48,68,69}$ Especially since the reported reduction in mortality in cohort observational studies is unlikely due to selection bias based on anatomical AAA configuration, as described in chapter 4 of this thesis. However, an eEVAR-first approach has great implications for clinical practice, since it requires instant and permanent accessibility of a CT-scanner, continual availability of an endovascular specialist capable of performing emergency EVAR, constant availability of a vascular team dedicated to eEVAR, availability of an OR that is adequately equipped to perform eEVAR, and the availability of a variety 'off-the-shelf' stent-grafts. ${ }^{46-48}$ The indications for performing endovascular repair are expanding. Patients with a paraanastomotic aneurysm after previous open AAA or aAAA prosthetic reconstruction might also gain from an EVAR first approach. In chapter 6 , so called EVPAR is confirmed to be a feasible, durable, and safe alternative to open reconstruction, especially when using bifurcated stent grafts. However, in these patients stent graft selection should not merely be based on the reported differences in outcome between various types of stent grafts, but should rather be individualized in the view of anatomical considerations.

On a larger scale, an EVAR-first approach for acute and paraanastomotic aneurysms might indicate centralization of AAA care. Centralization of complex surgical procedures has the potential to improve patient outcomes and particularly reduce mortality. ${ }^{70,71}$ Surgeon experience, support staff, infrastructure and recognition of complications may all be important factors in this regard. ${ }^{69,72,73}$ Vascular surgery is a specialty where centralization could be beneficial due to its complex procedures and multi-disciplinary requirements, especially with regard to interventional procedures such as eEVAR. ${ }^{58,74}$

Next to type and quality of surgery, timing of surgery might also be clinically relevant in acute AAA care. In patients with a symptomatic AAA, the contemporary assumption to treat patients acutely in order to prevent rupture might have to be adjusted. Delayed surgical treatment with preoperative optimization of patients' and operative condition could improve prognosis in selected patients with a symptomatic AAA. Admission to a medium care unit 
with bed rest, close blood pressure monitoring, and optimization of patients' operative conditions are indicated.

\section{PART TWO}

Chapter 7 showed that true recommendations for ideal post-EVAR surveillance cannot be made based on the current available evidence. Among various imaging modalities, computed tomography angiography (CTA) is the most widely used technique for follow-up after EVAR. ${ }^{25}$ However, the risk of cancer induction of one CTA is about 1 in $1500 .{ }^{75}$ Furthermore, renal dysfunction is a comorbidity found in $80 \%$ of aneurysm patients, and is the most important risk factor for contrast-induced nephrotoxicity. ${ }^{76,77}$ The cumulative radiation dose, nephrotoxic contrast load, and high costs indicate the relevance of reliable alternatives to annual CTA in daily clinical practice. ${ }^{78,79}$ Furthermore, a recent retrospective analysis of AAA ruptures following EVAR showed that most ruptures occur within the first 3 years after the procedure and rupture is mostly preceded by endoleaks. ${ }^{80}$ These findings underline the importance of a sensitive and reliable post-EVAR follow-up regimen to reduce the AAA rupture rate.

Although ultrasound is dependent on well-trained operators and is subject to inter-operator variability, improving diagnostic results of CEUS are promising. Moreover, no major side effects have been reported for ultrasound contrast agents. In chapter 8 , we showed that contrast-enhanced ultrasound might be equivalent to CTA for the assessment of aneurysm sac dimensions, while the number of endoleaks detected by contrast-enhanced ultrasound greatly outweighs those diagnosed on CTA. Therefore, contrast-enhanced ultrasound might be considered as a substitute to CTA as the primary imaging modality in the surveillance of patients after EVAR for those patients who are suitable for abdominal/pelvic ultrasound and when highly trained ultrasound operators are available.

In chapter 9, we showed that plasma concentrations of MMP-9 can accurately discriminate between patients with and without an endoleak, with both high sensitivity and specificity. The availability of a clinical applicable blood test for differentiation between patients with and without endoleak has major clinical implications, since patients without an endoleak could be spared to undergo CTA with the aforementioned additional hazards. A potential $90 \%$ of follow-up CT scans could be spared when taking the $10 \%$ incidence of endoleaks into account. $^{81,82}$ Besides individual benefits, health care costs might be greatly reduced. Increasing numbers of EVAR procedures are performed with over 100.000 in Europe and the United States each year. When all these patients 
would be submitted to the follow-up surveillance regime of long-term annual CTA, as recommended by the EUROSTAR Registry, ${ }^{28}$ a major contribution to the overall costs of EVAR treatment and a strain on the medical system is imposed.

\section{Implications for future research}

\section{PART ONE}

Thus far, studies comparing emergency EVAR versus open surgery in patients with an acute AAA are flawed by methodological inadequacies such as selection bias. ${ }^{10}$ Based on these methodological limitations, results from a randomized controlled trial are needed. However, a pilot study showed that it is challenging to perform a randomized study in an acute condition like ruptured AAA. ${ }^{46}$

Furthermore, since mortality results of rAAA repair as described in chapter 2 and chapter 3 are comparable, and while the potential effect of selection bias on mortality is further flawed as explained in chapter 4, the next question might be: do we really need a randomized controlled trial in order to confirm these observational results? Especially considering the observation of Benson et al. in the New England Journal of Medicine, that observational studies and randomized controlled trials usually produce similar results. ${ }^{83}$ When taking this into account and given the accumulation of superior short term results of emergency EVAR compared with conventional open surgery in observational studies, there might even be a potential ethical issue associated with trials that randomize patients to these treatments. ${ }^{59}$ However, since EVAR is known for its ongoing mortality risk due to stent graft related complications, longer-term results of emergency EVAR for acute AAA and clinical results are required.

Concerning paraanastomotic aneurysms after previous abdominal aorto-iliac surgery, only a few small case series have suggested that endovascular exclusion is feasible, with low perioperative mortality and morbidity. ${ }^{6-9.84-86}$ Based on the long-term results as provided in chapter 6, endovascular exclusion of paraanastomotic aneurysms with bifurcated stent grafts can be considered as the first-choice of treatment when feasible. However, a proper conducted clinical trail is desirable in order to confirm these results of EVAR for patients with paraanastomotic aneurysms.

\section{PART TWO}

In an era where endovascular treatment is evolving due to improvements in devices, skills, and expanding suitability ranges, there is an overall shift towards 
endovascular repair in AAA patients. Subject of debate is whether the costs of EVAR, including the long term costs for endoleak surveillance, could outweigh the benefits of this treatment strategy as compared to conventional open surgical repair. ${ }^{87}$ Therefore, it seems that cost reduction of post EVAR surveillance is of vital importance for the future of EVAR. This incorporates potential alternative surveillance modalities as well as the ideal interval scheme and total duration of surveillance programs. These are important topics that cannot be answered based on present available reports and creates an important role for future research.

CTA follow-up after EVAR is considered the gold standard, with high sensitivity for endoleak detection combined with widespread availability, rapid acquisition and reproducibility. ${ }^{29}$ However, high costs, cumulative radiation dose, and nephrotoxic contrast agent underline the importance of upcoming alternative imaging modalities. Continuing technical improvements and future prospective comparative research might eventually lead to an imaging modality other than CTA as the gold standard in the follow-up of patients after stent-graft implantation.

To be more specific, in this thesis we showed that CEUS might be equivalent to CTA for the post EVAR assessment of aneurysm sac dimensions and the detection of endoleaks. However, results of CEUS are mainly based on patients with a type 2 endoleak, which are largely benign, ${ }^{88}$ in contrast to type 1 and type 3 endoleaks for which there is consensus that intervention is required. ${ }^{89,90}$ As we can learn from Mirza et al., the relative sensitivity of CEUS for detecting the specific group of endoleaks requiring reintervention remains unknown. ${ }^{91}$ Since the role of surveillance is to enable the treatment of stent graft-related complications that would otherwise lead to aneurysm-related death, there is a need for reappraisal of the diagnostic accuracy of CEUS, focusing on detection of clinically relevant types 1 and 3 endoleaks.

We showed that plasma MMP-9 levels appear to discriminate between patient with and without an endoleak with both high sensitivity and specificity. However, despite reassuring confidence intervals, we are aware that this is a case control study with a limited number of patients. Therefore, an adequately powered prospective clinical trial is necessary to validate the applicability of plasma MMP-9 concentrations for the differentiation of patients with and without an endoleak in clinical practice and, moreover, to investigate the potential role of plasma MMP-9 concentrations in the selection of EVAR patients for imaging. Furthermore, standardization of the assay will be necessary for the application of one standard cut-off value in future clinical use. 


\section{Conclusions}

In conclusion, data presented in this thesis show that EVAR is a valuable treatment option for anatomically suitable patients with an acute (ruptured or symptomatic) or paraanastomotic AAA. Delayed treatment in certain patients with a symptomatic AAA might be justified in order to optimize conditions. In case endovascular repair is performed, contrast-enhanced ultrasound may be a substitute to CTA for the assessment of aneurysm sac dimensions and the detection of endoleaks in post-EVAR surveillance. Plasma levels of MMP-9 can accurately discriminate between patients with and without an endoleak and might have a future role in the selection of EVAR patients for imaging. 


\section{References}

1. Bown MJ, Sutton AJ, Bell PR, Sayers RD. A meta-analysis of 50 years of ruptured abdominal aortic aneurysm repair. Br J Surg. 2002;89:714-730.

2. Heller JA, Weinberg A, Arons R, Krishnasastry KV, Lyon RT, Deitch JS, et al. Two decades of abdominal aortic aneurysm repair: have we made any progress? J Vasc Surg. 2000;32: 1091-1100.

3. Leo E, Biancari F, Kechagias A, Ylonen K, Rainio P, Romsi $P$, et al. Outcome after emergency repair of symptomatic, unruptured abdominal aortic aneurysm: results in 42 patients and review of the literature. Scand Cardiovasc J. 2005;39:91-95.

4. EVAR-trial-participants. Endovascular aneurysm repair versus open repair in patients with abdominal aortic aneurysm (EVAR trial 1): randomised controlled trial. Lancet. 2005;365:2179-2186.

5. Prinssen M, Verhoeven EL, Buth J, Cuypers PW, van Sambeek MR, Balm R, et al. A randomized trial comparing conventional and endovascular repair of abdominal aortic aneurysms. N Engl J Med. 2004;351:1607-1618.

6. Cerna M, Kocher M, Utikal P, Koutna J, Drac P, Bachleda P, et al. Endovascular treatment of abdominal aortic paraanastomotic pseudoaneurysms after surgical reconstruction. Eur J Radiol. 2009;71:333-337.

7. Di Tommaso L, Monaco M, Piscione F, Sarno G, lannelli G. Endovascular stent grafts as a safe secondary option for para-anastomotic abdominal aortic aneurysm. Eur J Vasc Endovasc Surg. 2007; 33:91-93.

8. van Herwaarden JA, Waasdorp EJ, Bendermacher BL, van den Berg JC, Teijink JA, Moll FL. Endovascular repair of paraanastomotic aneurysms after previous open aortic prosthetic reconstruction. Ann Vasc Surg. 2004;18:280-286.

9. Zhou W, Bush RL, Bhama JK, Lin PH, Safaya R, Lumsden AB. Repair of anastomotic abdominal aortic pseudoaneurysm utilizing sequential AneuRx aortic cuffs in an overlapping configuration. Ann Vasc Surg. 2006;20:17-22.

10. Dillon M, Cardwell C, Blair PH, Ellis P, Kee F, Harkin DW. Endovascular treatment for ruptured abdominal aortic aneurysm. Cochrane Database Syst Rev. 2007(1):Cd005261.

11. Harkin DW, Dillon M, Blair PH, Ellis PK, Kee F. Endovascular ruptured abdominal aortic aneurysm repair (EVRAR): a systematic review. Eur J Vasc Endovasc Surg. 2007;34:673-681.

12. Mastracci TM, Garrido Olivares L, Cina CS, Clase CM. Endovascular repair of ruptured abdominal aortic aneurysms: a systematic review and meta-analysis. J Vasc Surg. 2008;47:214-221.

13. Rayt HS, Sutton AJ, London NJ, Sayers RD, Bown MJ. A systematic review and meta-analysis of endovascular repair (EVAR) for ruptured abdominal aortic aneurysm. Eur J Vasc Endovasc Surg. 2008; 36:536-544.

14. Sadat U, Boyle JR, Walsh SR, Tang T, Varty K, Hayes PD. Endovascular vs open repair of acute abdominal aortic aneurysms--a systematic review and meta-analysis. J Vasc Surg. 2008;48:227-236.

15. Visser JJ, van Sambeek MR, Hamza TH, Hunink MG, Bosch JL. Ruptured abdominal aortic aneurysms: endovascular repair versus open surgery--systematic review. Radiology. 2007; 245:122-129.

16. Franks S, Lloyd G, Fishwick G, Bown M, Sayers R. Endovascular treatment of ruptured and symptomatic abdominal aortic aneurysms. Eur J Vasc Endovasc Surg. 2006;31:345-350.

17. Buss RW, Clagett GP, Fisher DF, Jr., Fry RE, Eidt JF, Humble TH, et al. Emergency operation in patients with symptomatic abdominal aortic aneurysms. Am J Surg. 1988;156:470-473.

18. Tambyraja AL, Raza Z, Stuart WP, Murie JA, Chalmers RT, Tambyraja AL, et al. Does immediate operation for symptomatic non-ruptured abdominal aortic aneurysm compromise outcome? Eur J Vasc Endovasc Surg. 2004;28:543-546. 
19. Cambria RA, Gloviczki P, Stanson AW, Cherry KJ, Jr., Hallett JW, Jr., Bower TC, et al. Symptomatic, nonruptured abdominal aortic aneurysms: are emergent operations necessary? Ann Vasc Surg. 1994;8:121-126.

20. Johnson G, Jr., McDevitt NB, Proctor HJ, Mandel SR, Peacock JB, Johnson G, Jr., et al. Emergent or elective operation for symptomatic abdominal aortic aneurysm. Arch Surg. 1980;115:51-53.

21. Veith FJ, Baum RA, Ohki T, Amor M, Adiseshiah M, Blankensteijn JD, et al. Nature and significance of endoleaks and endotension: summary of opinions expressed at an international conference. J Vasc Surg. 2002;35:1029-1035.

22. Baum RA, Carpenter JP, Cope C, Golden MA, Velazquez OC, Neschis DG, et al. Aneurysm sac pressure measurements after endovascular repair of abdominal aortic aneurysms. J Vasc Surg. 2001;33:32-41.

23. Walschot LH, Laheij RJ, Verbeek AL. Outcome after endovascular abdominal aortic aneurysm repair: a meta-analysis. J Endovasc Ther. 2002;9:82-89.

24. Drury D, Michaels JA, Jones L, Ayiku L. Systematic review of recent evidence for the safety and efficacy of elective endovascular repair in the management of infrarenal abdominal aortic aneurysm. Br J Surg. 2005;92:937-946.

25. Golzarian J, Dussaussois L, Abada HT, Gevenois PA, Van Gansbeke D, Ferreira J, et al. Helical CT of aorta after endoluminal stent-graft therapy: value of biphasic acquisition. AJR Am J Roentgenol. 1998;171: 329-331.

26. Gorich J, Rilinger N, Sokiranski R, Orend KH, Ermis C, Kramer SC, et al. Leakages after endovascular repair of aortic aneurysms: classification based on findings at $\mathrm{CT}$, angiography, and radiography. Radiology. 1999;213:767-772.

27. Blackman JA, Lindgren SD, Hein HA, Harper DC. Long-term surveillance of high-risk children. Am J Dis Child. 1987;141:1293-1299.

28. Vallabhaneni SR, Harris PL. Lessons learnt from the EUROSTAR registry on endovascular repair of abdominal aortic aneurysm repair. Eur J Radiol. 2001;39:34-41.

29. Stavropoulos SW, Charagundla SR. Imaging techniques for detection and management of endoleaks after endovascular aortic aneurysm repair. Radiology. 2007;243:641-655.

30. lezzi R, Basilico R, Giancristofaro D, Pascali D, Cotroneo AR, Storto ML. Contrast-enhanced ultrasound versus color duplex ultrasound imaging in the follow-up of patients after endovascular abdominal aortic aneurysm repair. J Vasc Surg. 2009;49:552-560.

31. van der Laan MJ, Bartels LW, Viergever MA, Blankensteijn JD. Computed tomography versus magnetic resonance imaging of endoleaks after EVAR. Eur J Vasc Endovasc Surg. 2006;32: 361-365.

32. Sangiorgi G, D'Averio R, Mauriello A, Bondio M, Pontillo M, Castelvecchio S, et al. Plasma levels of metalloproteinases-3 and -9 as markers of successful abdominal aortic aneurysm exclusion after endovascular graft treatment. Circulation. 2001;104(12 Suppl 1):1288-295.

33. Bendick PJ, Bove PG, Long GW, Zelenock GB, Brown OW, Shanley CJ. Efficacy of ultrasound scan contrast agents in the noninvasive follow-up of aortic stent grafts. J Vasc Surg. 2003;37:381-385.

34. Heilberger P, Schunn C, Ritter W, Weber S, Raithel D. Postoperative color flow duplex scanning in aortic endografting. J Endovasc Surg. 1997;4:262-271.

35. McWilliams RG, Martin J, White D, Gould DA, Rowlands PC, Haycox A, et al. Detection of endoleak with enhanced ultrasound imaging: comparison with biphasic computed tomography. J Endovasc Ther. 2002;9:170-179.

36. Napoli V, Bargellini I, Sardella SG, Petruzzi P, Cioni R, Vignali C, et al. Abdominal aortic aneurysm: contrast-enhanced US for missed endoleaks after endoluminal repair. Radiology. 2004;233:217-225.

37. Sun Z. Diagnostic value of color duplex ultrasonography in the follow-up of endovascular repair of abdominal aortic aneurysm. J Vasc Interv Radiol. 2006;17:759-764.

38. Sternbergh WC, 3rd, Greenberg RK, Chuter TA, Tonnessen BH. Redefining postoperative surveillance after endovascular aneurysm repair: recommendations based on 5-year followup in the US Zenith multicenter trial. J Vasc Surg. 2008;48:278-284. 
39. Hovsepian DM, Ziporin SJ, Sakurai MK, Lee JK, Curci JA, Thompson RW. Elevated plasma levels of matrix metalloproteinase- 9 in patients with abdominal aortic aneurysms: a circulating marker of degenerative aneurysm disease. J Vasc Interv Radiol. 2000;11:1345-1352.

40. Lindholt JS, Vammen S, Fasting H, Henneberg EW, Heickendorff L. The plasma level of matrix metalloproteinase 9 may predict the natural history of small abdominal aortic aneurysms. A preliminary study. Eur J Vasc Endovasc Surg. 2000;20:281-285.

41. Sakalihasan N, Delvenne P, Nusgens BV, Limet R, Lapiere CM. Activated forms of MMP2 and MMP9 in abdominal aortic aneurysms. J Vasc Surg. 1996;24:127-133.

42. Sangiorgi G, D'Averio R, Mauriello A, Bondio M, Pontillo M, Castelvecchio S, et al. Plasma levels of metalloproteinases-3 and -9 as markers of successful abdominal aortic aneurysm exclusion after endovascular graft treatment. Circulation. 2001;104(12 Suppl 1):1288- 1295.

43. Lorelli DR, Jean-Claude JM, Fox CJ, Clyne J, Cambria RA, Seabrook GR, et al. Response of plasma matrix metalloproteinase-9 to conventional abdominal aortic aneurysm repair or endovascular exclusion: implications for endoleak. J Vasc Surg. 2002;35:916-922.

44. Monaco M, Stassano P, Di Tommaso L, lannelli G. Response of plasma matrix metalloproteinases and tissue inhibitor of metalloproteinases to stent-graft surgery for descending thoracic aortic aneurysms. J Thorac Cardiovasc Surg. 2007;134:925-931.

45. Amsterdam Acute Aneurysm trial: background, design, and methods. Vascular. 2006;14: 130-135.

46. Hinchliffe RJ, Bruijstens L, MacSweeney ST, Braithwaite BD. A randomised trial of endovascular and open surgery for ruptured abdominal aortic aneurysm - results of a pilot study and lessons learned for future studies. Eur J Vasc Endovasc Surg. 2006;32:506-513.

47. Collaborators AAAT. Amsterdam Acute Aneurysm trial: background, design, and methods. Vascular. 2006;14:130-135.

48. Mehta M, Taggert J, Darling RC, 3rd, Chang BB, Kreienberg PB, Paty PS, et al. Establishing a protocol for endovascular treatment of ruptured abdominal aortic aneurysms: outcomes of a prospective analysis. J Vasc Surg. 2006;44:1-8.

49. Perrott S, Puckridge PJ, Foreman RK, Russell DA, Spark JI. Anatomical suitability for endovascular AAA repair may affect outcomes following rupture. Eur J Vasc Endovasc Surg. 2010;40:186-190.

50. Mureebe L, Egorova N, McKinsey JF, Kent KC. Gender trends in the repair of ruptured abdominal aortic aneurysms and outcomes. J Vasc Surg. 2010;51(4 suppl):9S-13S.

51. Haug ES, Romundstad P, Aadahl P, Myhre HO, Haug ES, Romundstad P, et al. Emergency nonruptured abdominal aortic aneurysm. Eur J Vasc Endovasc Surg. 2004;28:612-618.

52. Sullivan CA, Rohrer MJ, Cutler BS, Sullivan CA, Rohrer MJ, Cutler BS. Clinical management of the symptomatic but unruptured abdominal aortic aneurysm. J Vasc Surg. 1990;11:799-803.

53. Peppelenbosch N, Yilmaz N, van Marrewijk C, Buth J, Cuypers P, Duijm L, et al. Emergency treatment of acute symptomatic or ruptured abdominal aortic aneurysm. Outcome of a prospective intent-to-treat by EVAR protocol. Eur J Vasc Endovasc Surg. 2003;26:303-310.

54. Bakken AM, Illig KA. Long-term follow-up after endovascular aneurysm repair: is ultrasound alone enough? Perspect Vasc Surg Endovasc Ther. 2010;22:145-151.

55. Ten Bosch JA, Rouwet EV, Peters CT, Jansen L, Verhagen HJ, Prins MH, et al. Contrastenhanced ultrasound versus computed tomographic angiography for surveillance of endovascular abdominal aortic aneurysm repair. J Vasc Interv Radiol. 2010;21:638-643.

56. Brandt M, Walluscheck KP, Jahnke T, Graw K, Cremer J, Muller Hulsbeck S. Endovascular repair of ruptured abdominal aortic aneurysm: feasibility and impact on early outcome. J Vasc Interv Radiol. 2005;16:1309-1312.

57. Lee WA, Hirneise CM, Tayyarah M, Huber TS, Seeger JM. Impact of endovascular repair on early outcomes of ruptured abdominal aortic aneurysms. J Vasc Surg. 2004;40:211-215.

58. Veith FJ, Lachat M, Mayer D, Malina M, Holst J, Mehta M, et al. Collected world and single center experience with endovascular treatment of ruptured abdominal aortic aneurysms. Ann Surg. 2009;250:818-824.

59. Nedeau AE, Pomposelli FB, Hamdan AD, Wyers MC, Hsu R, Sachs T, et al. Endovascular vs open repair for ruptured abdominal aortic aneurysm. J Vasc Surg. 2012;56:15-20. 
60. Alsac JM, Desgranges $P$, Kobeiter H, Becquemin JP. Emergency endovascular repair for ruptured abdominal aortic aneurysms: feasibility and comparison of early results with conventional open repair. Eur J Vasc Endovasc Surg 2005;30:632-639.

61. Dalainas I, Nano G, Bianchi P, Stegher S, Casana R, Malacrida G, et al. Endovascular techniques for the treatment of ruptured abdominal aortic aneurysms: 7-year intention-to-treat results. World J Surg 2006;30:1809-1814; discussion 1815-1816.

62. Peppelenbosch N, Geelkerken RH, Soong C, Cao P, Steinmetz OK, Teijink JAW, et al. Endograft treatment of ruptured abdominal aortic aneurysms using the Talent aortouniiliac system: an international multicenter study. J Vasc Surg 2006;43:1111-1123.

63. Yilmaz N, Peppelenbosch N, Cuypers PW, Tielbeek AV, Duijm LE, Buth J. Emergency treatment of symptomatic or ruptured abdominal aortic aneurysms: the role of endovascular repair. J Endovasc Ther 2002;9:449-457.

64. AJAX confirms no difference between EVAR and open repair for ruptured aneurysms. 34th Charing Cross International Symposium. 2012.

65. Ten Bosch JA, Teijink JA, Willigendael EM, Prins MH. Endovascular aneurysm repair is superior to open surgery for ruptured abdominal aortic aneurysms in EVAR-suitable patients. J Vasc Surg. 2010;52: 13-18.

66. Giles KA, Pomposelli F, Hamdan A, Wyers M, Jhaveri A, Schermerhorn ML. Decrease in total aneurysm-related deaths in the era of endovascular aneurysm repair. J Vasc Surg. 2009;49:543-550; discussion 550-551.

67. Hoornweg LL, van Nieuwehuizen R, Vahl AC, Koelemay MJW, Legemate DA. Meta-analysis on endovascular versus open repair for ruptured abdominal aortic aneurysms. Aortic ruptures; acute endovascular management. Amsterdam, 2008:86-98.

68. Moore R, Nutley M, Cina CS, Motamedi M, Faris P, Abuznadah W. Improved survival after introduction of an emergency endovascular therapy protocol for ruptured abdominal aortic aneurysms. J Vasc Surg. 2007;45:443-450.

69. Hodgson KJ. EVAR for Ruptured Aneurysms: Are the Data Complete? Semin Vasc Surg. 2012;25: 217-226.

70. Holt PJ, Poloniecki JD, Loftus IM, Michaels JA, Thompson MM. Epidemiological study of the relationship between volume and outcome after abdominal aortic aneurysm surgery in the UK from 2000 to 2005. Br J Surg. 2007;94:441-448.

71. Veith FJ, Cayne NS, Berland TL, Mayer D, Lachat M. Current role for endovascular treatment of ruptured abdominal aortic aneurysms. Semin Vasc Surg. 2012;25:174-176.

72. Holt PJ, Michaels JA. Does volume directly affect outcome in vascular surgical procedures? Eur J Vasc Endovasc Surg. 2007;34:386-389.

73. Ghaferi AA, Birkmeyer JD, Dimick JB. Variation in hospital mortality associated with inpatient surgery. N Engl J Med. 2009;361:1368-1375.

74. Earnshaw JJ, Hamilton G. Vascular surgery by numbers. Ann R Coll Surg Engl. 2007;89: 653-654.

75. The 2007 Recommendations of the International Commission on Radiological Protection. ICRP publication 103. Ann ICRP. 2007;37:1-332.

76. Rao QA, Newhouse JH. Risk of nephropathy after intravenous administration of contrast material: a critical literature analysis. Radiology. 2006;239:392-397.

77. Nakamura S, Yoshihara F, Kamide K, Horio T, Nakahama H, Inenaga T, et al. Renal function in patients with abdominal aortic aneurysm. Comparison with hypertensive patients. Kidney Blood Press Res. 2006;29:67-73.

78. McCullough PA, Soman SS. Contrast-induced nephropathy. Crit Care Clin. 2005;21:261-280.

79. Prinssen M, Wixon CL, Buskens E, Blankensteijn JD. Surveillance after endovascular aneurysm repair: diagnostics, complications, and associated costs. Ann Vasc Surg. 2004;18:421-427.

80. Schlosser FJ, Gusberg RJ, Dardik A, Lin PH, Verhagen HJ, Moll FL, et al. Aneurysm rupture after EVAR: can the ultimate failure be predicted? Eur J Vasc Endovasc Surg. 2009;37:15-22.

81. Drury D, Michaels JA, Jones L, Ayiku L. Systematic review of recent evidence for the safety and efficacy of elective endovascular repair in the management of infrarenal abdominal aortic aneurysm. Br J Surg. 2005;92:937-946. 
82. Schurink GW, Aarts NJ, van Bockel JH. Endoleak after stent-graft treatment of abdominal aortic aneurysm: a meta-analysis of clinical studies. Br J Surg. 1999;86:581-587.

83. Benson K, Hartz AJ. A comparison of observational studies and randomized, controlled trials. N Engl J Med. 2000;342:1878-1886.

84. Lagana D, Carrafiello G, Mangini M, Recaldini C, Lumia D, Cuffari S, et al. Endovascular treatment of anastomotic pseudoaneurysms after aorto-iliac surgical reconstruction. Cardiovasc Intervent Radiol. 2007;30:1185-1191.

85. Mitchell JH, Dougherty KG, Strickman NE, Mortazavi A, Krajcer Z. Endovascular repair of paraanastomotic aneurysms after aortic reconstruction. Tex Heart Inst J. 2007;34:148-153.

86. Piffaretti G, Tozzi M, Lomazzi C, Rivolta N, Caronno R, Castelli P. Endovascular treatment for para-anastomotic abdominal aortic and iliac aneurysms following aortic surgery. J Cardiovasc Surg (Torino). 2007;48:711-717.

87. Raithel D. Surveillance of patients after abdominal aortic aneurysm repair with endovascular grafting or conventional treatment. J Mal Vasc. 1998;23:390-392.

88. Karthikesalingam A, Thrumurthy SG, Jackson D, Phd EC, Sayers RD, Loftus IM, et al. Current evidence is insufficient to define an optimal threshold for intervention in isolated type II endoleak after endovascular aneurysm repair. J Endovasc Ther. 2012;19:200-208.

89. Moll FL, Powell JT, Fraedrich G, Verzini F, Haulon S, Waltham M, et al. Management of abdominal aortic aneurysms clinical practice guidelines of the European society for vascular surgery. Eur J Vasc Endovasc Surg. 2011;41 Suppl 1:S1-S58.

90. Boyle JR, Thompson MM, Vallabhaneni SR, Bell RE, Brennan JA, Browne TF, et al. Pragmatic minimum reporting standards for endovascular abdominal aortic aneurysm repair. J Endovasc Ther. 2011;18: 263-271.

91. Mirza TA, Karthikesalingam A, Jackson D, Walsh SR, Holt PJ, Hayes PD, et al. Duplex ultrasound and contrast-enhanced ultrasound versus computed tomography for the detection of endoleak after EVAR: systematic review and bivariate meta-analysis. Eur J Vasc Endovasc Surg. 2010;39:418-428. 
Summary 



\section{Summary}

Part one of this thesis is dedicated to evaluate the potential value of emergency endovascular aneurysm repair (eEVAR) in patients with an acute abdominal aortic aneurysm (AAA). It also addresses the potential value of EVAR treatment for paraanastomotic aneurysms. Additionally, in part two, alternatives to computed tomography angiography (CTA) in post-EVAR surveillance were explored.

In chapter 1, the rationale for this research is presented. Currently, eEVAR has become an accepted treatment option, which is increasingly performed to treat acute AAA. Nonetheless, the potential reduction in peri-operative mortality of eEVAR compared with conventional open repair in patients with an acute AAA is still questionable.

\section{PART ONE - ACUTE AND PARAANASTOMOTIC ABDOMINAL AORTIC ANEURYSMS, EVAR OR OPEN SURGERY?}

The first decision in patients presenting with an acute or paraanastomotic AAA, is whether to offer treatment at all (i.e. selective treatment policy). When decided to perform an intervention, two treatment options are available: conventional "open" AAA repair or the minimally invasive emergency endovascular AAA repair (eEVAR).

So far, observational studies comparing endovascular aneurysm repair with open surgery in patients with a ruptured AAA are flawed by methodological inadequacies. Selection bias occurs mainly by selecting patients with a lowerrisk profile to undergo eEVAR, presumably because these patients need to be hemodynamically stable in order to undergo preoperative imaging and have a more favorable (i.e. EVAR suitable) anatomic configuration. In order to minimize the effect of selection bias, chapter 2 describes a comparison of eEVAR with open surgery in patients with a ruptured AAA who all underwent the same preoperative imaging protocol and who were all defined anatomically suitable for EVAR by two independent experts. Main outcome parameters were mortality (intra-operative, 30-day, and 6-month) and length of hospital stay. In total, 25 patients underwent eEVAR and 33 EVAR-suitable patients underwent an open procedure. An absolute perioperative mortality reduction of $25.5 \%$ in patients undergoing eEVAR over open surgery was found $(P=0.04)$, which was still present after 6 months of follow-up $(P=0.04)$. The median length of hospital 
stay was 9.5 days (interquartile range 5.0-20.5) after eEVAR and 17.0 days (interquartile range 9.5-28.0) after open surgery $(P=0.03)$. These data suggest that eEVAR is a superior treatment option compared to open surgery for patients with a ruptured AAA that is anatomically suitable for EVAR.

In chapter 3, early and midterm outcomes for eEVAR versus open surgery were prospectively described in patients with an acute AAA, both unruptured (symptomatic) and ruptured. A total of 240 patients were enrolled in this study, 111 patients with an unruptured acute $A A A$ and 129 patients with a ruptured AAA. Of the patients with an unruptured acute AAA, 47 (42\%) underwent eEVAR and the all cause mortality as well as the aneurysm-related mortality did not differ significantly when compared to open surgical repair at 30-day, 6-, and 12month follow-up. Though, increasing aneurysm-related mortality results during follow-up were observed in the eEVAR group, whereas aneurysm-related mortality in the open repair group remained stable. In patients with a ruptured AAA, 25 (19\%) underwent eEVAR and the intra-operative, 30-day, 6- and 12month mortality rates were $4 \%, 20 \%, 28 \%$, and $36 \%$ versus $8 \%(P>0.999), 45 \%$ $(P=0.021), 60 \%(P=0.004)$, and $63 \%(P=0.014)$ for patients treated with open surgery, respectively. Again, aneurysm-related mortality was observed only in the eEVAR group during follow-up, but significant differences in aneurysmrelated mortality remained. Furthermore, the length of hospital stay after eEVAR compared with length of stay following open surgery in patients with either an unruptured aAAA or a ruptured aAAA was significantly reduced by 5 and 6.5 days, respectively. Based on these results we concluded that a reduced 30-day, 6- and 12-month mortality of eEVAR was observed compared with open surgery in all patients with an acute AAA, probably due to a lower mortality in the ruptured AAA group. Late aneurysm-related mortality occurred only in the eEVAR group. Nevertheless, results have to be interpreted with caution due to several limitations, including selection bias.

The reported mortality reduction of eEVAR compared with open repair in patients with a ruptured $A A A$, as described in chapter 3 , might be flawed by selection bias based on anatomical suitability for EVAR. In chapter 4 we compared mortality results in EVAR suitable versus non EVAR suitable patients with a ruptured AAA, who all underwent preoperative CTA imaging and who were all treated with conventional open repair. Anatomical suitability for EVAR was determined by two independent experienced reviewers who were blinded for earlier evaluation, intervention, and outcome. A total of 82 consecutive 
patients with a ruptured AAA on pre-operative CTA received open repair and were therefore included in this study. CTA revealed an EVAR suitable ruptured AAA in 33 patients (40.2\%) and a non EVAR suitable ruptured AAA in 49 patients. At baseline, significantly more male patients were considered EVAR suitable on CTA. Intra-operative, 30-day, and 6-month mortality results as well as postoperative days of hospital stay were comparable for both groups. Therefore, anatomical suitability for EVAR seems not to be associated with lower early and midterm mortality in patients treated with open ruptured AAA repair. We concluded that the reported reduction in mortality after eEVAR compared to open repair is not likely due to selection bias based on anatomical AAA configuration.

In chapter $\mathbf{5}$ we focused on the symptomatic AAA, defined as the existence of an AAA with acute onset of abdominal and/or back pain in combination with pain at aneurysm palpation and with no signs of rupture on a CTA scan. Traditionally this condition requires acute treatment, since it might represent imminent rupture. In this chapter, we compared acute symptomatic AAA repair with delayed surgery after optimization of patients' operative conditions. We used 12 hours as a cut-off point and adjusted for type of operation and potential confounders. A total of 89 patients were included of which 37 patients received acute surgery. Although rupture occurred in 1 patient in the acute group $(2.7 \%)$ versus 4 patients in the delayed treated group $(7.7 \%)$, a trend was seen toward lower early mortality rates in patients who received delayed surgery. In the group operated within 12 hours, 30-day mortality rate was $16.2 \%$ versus $5.8 \%$ in patients treated after 12 hours (odds ratio $0.316 ; \mathrm{Cl}$ 0.074-1.358). When adjusted for type of surgery (open versus EVAR) and other potential confounders, the adjusted odds ratios were $0.305(\mathrm{Cl} 0.066-1.405)$ and $0.270(\mathrm{Cl} 0.015-4.836)$, respectively. When using 24 hours as a cut-off point, (adjusted) odds ratios were comparable. We concluded that in a substantial amount of patients with an alleged symptomatic AAA, delayed surgery with patient optimization might be justified. However, it is important to realize that the study described in chapter $\mathbf{5}$ was underpowered and that selection bias might have occurred. Further investigation is instigated in order to select patients who might benefit from delayed surgery based on specific criteria.

Chapter 6 describes a multicenter study in which we described the long-term clinical course in an expanded number of patients who underwent endovascular 
paraanastomotic aneurysms repair (EVPAR) after previous open reconstruction. Initial open reconstruction included a tube graft or a bifurcated prosthesis. A total of 58 patients with 80 aortic or iliac pseudo or true paraanastomotic aneurysms, or both, were treated with an endovascular stent graft. An endovascular tube graft was used in 8 patients, a bifurcated stent graft in 32, an aortouniiliac stent graft in 7, and an iliac extension graft in 11 patients. Stent graft deployment was successful in 55 patients (technical success rate: 95\%). Median hospital stay was 3 days (range, 1-122 days) and the 30-day mortality rate was $3.4 \%(n=2)$. The median follow-up was 41 months (range, 0-106 months). Exclusion was successfully maintained in $86 \%$ of the paraanastomotic aneurysms. Kaplan-Meier curves showed an annual risk of mortality of $4.0 \%$ during follow-up and an annual risk of reintervention of $5.8 \%$. A log-rank test for equality of reintervention distributions between differences in original anatomical presentation of paraanastomotic aneurysms showed no significant differences $(P=0.131)$. However, regarding different stent graft configurations, a significantly larger proportion of tube and aortouniiliac stent grafts needed reintervention during follow-up $(P<0.001)$. The annual reintervention risk was $3.2 \%$ (SE, $0.098 \%$ ) for bifurcated stent grafts, $16.6 \%$ (SE, $0.239 \%$ ) for tube grafts, $66.4 \%$ (SE, <0.001\%) for aortouniiliac stent grafts, and $19.1 \%$ (SE, $0.152 \%$ ) for distal iliac extension grafts. We concluded that endovascular exclusion of anatomically suitable paraanastomotic aneurysms is feasible and durable. Especially patients who received bifurcated stent grafts had lower reintervention rates and might be considered as the first-choice treatment option. Care should be taken that EVPAR requires an individualized approach taking anatomical considerations into account.

\section{PART TWO - FOLLOW-UP AFTER ENDOVASCULAR ANEURYSM REPAIR, DEPICTING STENT GRAFT RELATED COMPLICATIONS}

In an era where (emergency) EVAR is increasingly performed, shortcomings of this minimally invasive technique, such as the requirement of long-term imaging surveillance in order to detect stent graft related complications, are becoming more relevant. CTA is the most widely used technique for post-EVAR surveillance. However, repetitive CTA has several important drawbacks, including cumulative radiation dose, and nephrotoxic contrast load. Therefore, less harmful alternatives in the follow-up after EVAR in terms of imaging modalities or biochemical assays are desirable. 
In chapter 7 various strategies for endoleak detection in terms of imaging techniques and biochemical assays in the follow up after EVAR were discussed. CTA follow-up after EVAR is considered the gold standard, with high sensitivity, widespread availability, rapid acquisition, and reproducibility. However, drawbacks are the cumulative radiation dose and nephrotoxic contrast agent. Furthermore, the optimal CT image acquisition protocol is still controversial. Promising alternative modalities for endoleak detection without ionizing radiation burden and the use of nephrotoxic contrast load are contrast enhanced ultrasound (CEUS), magnetic resonance (angiography) imaging (MRA), and circulating biomarkers (matrix metalloproteinase). These evolving techniques are able to detect and classify endoleaks with increasing sensitivity and specificity, reserving a potential prominent role in future post-EVAR followup. However, based on present studies, true recommendations for ideal followup after EVAR cannot be made.

The accuracy of CEUS as an alternative to CTA in the follow-up of patients after EVAR with regard to changes in AAA dimensions and detection of endoleaks was described in Chapter 8. During EVAR surveillance, 83 patients were consecutively enrolled for both CEUS and CTA imaging, yielding 127 paired examinations. Good correspondence between the two imaging modalities was observed in both anteroposterior and transverse maximal diameters with a coefficient of variation of $8.0 \%$ and $8.6 \%$, respectively. The interobserver variability was low with an interclass correlation coefficient of $>0.98$ in both dimensions. CEUS was able to detect significantly more endoleaks (38 additional type II and 2 type I endoleaks) when compared with CTA (53\% versus $22 \%$ ), resulting in an intervention in two patients. The number of observed agreements was $77 / 127$ (61\%), indicating a low level of agreement ( $k=0.237$ ). The results as reported in chapter 8 indicate that CEUS might be equivalent to CTA in post-EVAR surveillance without the risks of contrast-induced nephropathy and ionizing radiation load.

In chapter 9 we focused on biochemical assays and the potential clinical applicability of MMP-2, -9 , and TIMP-1 as a diagnostic tool for the presence of endoleakage. In 37 included patients, plasma levels of MMP-2, -9, and TIMP-1 were determined using enzyme-linked immunosorbent assay. In 17 patients, an endoleak was detected on CTA (4 type I, 12 type II and 1 type III endoleak) and the other 20 patients were matched controls. In patients with an endoleak MMP-9 levels were significantly higher than in patients without an endoleak 
$(P<0.001)$. The ROC curve of plasma MMP-9 concentrations showed that a cutoff value of $55.18 \mathrm{ng} / \mathrm{ml}$ resulted in a $100 \%$ sensitivity and a $96 \%$ specificity with an area under the curve of $0.988(P<0.001)$. However, plasma MMP-9 levels could not differentiate between different types of endoleak. The study described in chapter 9 shows that plasma concentrations of MMP-9 can accurately discriminate between patients with and without an endoleak with both high sensitivity and specificity. A prospective clinical trial is needed in order to validate the clinical applicability of this assay. 
Samenvatting 



\section{Samenvatting}

Dit proefschrift behandelt de positie van de endovasculaire herstelmethode (EVAR - EndoVascular Aneurysm Repair) bij patiënten met een acuut (symptomatisch of geruptureerd) aneurysma van de abdominale aorta (AAA) of een paraanastomotisch aneurysma. Na EVAR is langdurige, misschien wel levenslange controle geïndiceerd. Verschillende alternatieven voor de gebruikelijke computed tomography angiography (CTA) scan in de follow-up na EVAR worden uiteengezet.

In hoofdstuk 1 wordt het doel van dit proefschrift gepresenteerd. Momenteel is EVAR een geaccepteerde behandeloptie om het acute AAA te behandelen. Wel bestaat nog discussie over de potentiële reductie in perioperatieve mortaliteit wanneer deze wordt vergeleken met de conventionele open operatie bij patiënten met een acuut AAA.

\section{DEEL EEN - ACUTE EN PARA-ANASTOMOTISCHE ANEURYSMA'S VAN DE ABDOMINALE AORTA: EVAR OF OPEN CHIRURGIE?}

Bij patiënten die zich presenteren met een acuut of paraanastomotisch AAA moet worden beslist of een behandeling al dan niet gewenst dan wel zinvol is. Wanneer besloten wordt een interventie te verrichten, bestaan twee behandelopties: de conventionele "open" operatie of de minimaal invasieve endovasculaire behandeling oftewel EVAR. Tot nu toe worden observationele studies die beide behandelmethoden bij patiënten met een geruptureerd AAA vergelijken afgezwakt door methodologische tekortkomingen waarbij selectiebias een grote rol speelt. Selectiebias kan enerzijds ontstaan door de veronderstelling dat patiënten die in aanmerking komen voor emergency EVAR (eEVAR) hemodynamisch stabieler dienen te zijn om de noodzakelijke preoperatieve beeldvorming te kunnen ondergaan. Anderzijds, doordat enkel patiënten met een minder gecompliceerde anatomie van het aneurysma in aanmerking komen voor eEVAR. Om de genoemde oorzaken van selectiebias te minimaliseren wordt in hoofdstuk 2 eEVAR vergeleken met de open procedure bij anatomisch vergelijkbare patiëntgroepen met een geruptureerd AAA. Alle patiënten hebben hetzelfde preoperatieve beeldvormingsprotocol doorlopen en werden retrospectief door onafhankelijke experts anatomisch geschikt bevonden voor eEVAR. Door de opzet van deze studie is tevens de kans op selectiebias aangaande hemodynamische instabiliteit of andere demografische patiëntkenmerken minimaal tot afwezig. De belangrijkste parameters zijn 
mortaliteit (intra-operatieve, 30-dagen en 6-maanden mortaliteit) en opnameduur. Van de 58 anatomisch eEVAR-geschikte patiënten hebben 25 de eEVAR-procedure ondergaan en 33 de open procedure. De studie laat een absolute reductie van $25,5 \%$ in perioperatieve mortaliteit zien in de eEVARgroep vergeleken met de groep die de open procedure heeft ondergaan $(P=0,04)$. Dit positieve effect van eEVAR blijkt na 6 maanden onveranderd aanwezig $(P=0,04)$. De mediane opnameduur is 9,5 dagen (interkwartiel afstand 5,0-20,5) na eEVAR en 17 dagen (interkwartiel afstand 9,5-28,0) na open chirurgie $(P=0,03)$. Hieruit kunnen we concluderen dat eEVAR een superieure behandelmethode is in vergelijking met de open procedure bij patiënten met een geruptureerd AAA.

In hoofdstuk 3 worden de vroege- en lange termijnresultaten van eEVAR bij zowel symptomatische als geruptureerde AAA's afgezet tegen de open procedure. In totaal zijn 240 patiënten geïncludeerd, waarvan 111 patiënten met een symptomatisch AAA en 129 patiënten met een geruptureerd AAA. In de groep met een symptomatisch AAA hebben 47 patiënten een eEVAR ondergaan (42\%) en 54 kregen een open procedure (48\%). Op de drie followup-momenten (30 dagen, 6 en 12 maanden) kan geen significant verschil worden aangetoond in algehele en AAA-gerelateerde mortaliteit tussen eEVAR en de open procedure. Wel wordt gedurende de follow-up een toename in aneurysma-gerelateerde mortaliteit gezien in de eEVAR-groep, terwijl deze in de groep met de open procedure stabiel blijft.

In de groep met een geruptureerd AAA hebben 25 patiënten een eEVAR ondergaan (19\%) en 104 kregen een open procedure (81\%). De studie laat hier een intra-operatieve, 30 dagen, 6 maanden en 12 maanden mortaliteit zien van respectievelijk $4 \%, 20 \%, 28 \%$ en $36 \%$ na eEVAR versus respectievelijk $8 \%$ $(P=1,000), 45 \% \quad(P=0,021), 60 \%(P=0,004)$ en $63 \%(P=0,014)$ na een open procedure. Ook hier is enkel in de eEVAR-groep een toename in aneurysmagerelateerde mortaliteit aangetoond gedurende de follow-up, maar de verschillen in aneurysma-gerelateerde mortaliteit blijven significant. Verder blijkt de opnameduur na eEVAR significant korter dan na een open procedure voor zowel patiënten met een symptomatisch als met een geruptureerd AAA met respectievelijk 5 en 6,5 dagen. Op basis van bovenstaande resultaten kan worden geconcludeerd dat eEVAR als behandeling voor het geruptureerde AAA gepaard gaat met een reductie in 30 dagen, 6 maanden en 12 maanden mortaliteit ten opzichte van de open procedure. Deze resultaten komen overeen met een meerderheid van de vergelijkbare internationale studies. 
Echter, het is aannemelijk dat selectiebias is opgetreden. Bovenstaande resultaten dienen dan ook met enige voorzichtigheid geïnterpreteerd te worden.

De mogelijke invloed van selectie op basis van anatomische criteria op de gevonden reductie in mortaliteit ten gunste van eEVAR bij patiënten met een geruptureerd AAA (hoofdstuk 3), is het onderwerp van studie in hoofdstuk 4. Hierin vergelijken we de mortaliteit van eEVAR-geschikte versus eEVARongeschikte patiënten met een geruptureerd AAA. Alle patiënten zijn behandeld met een open procedure. eEVAR geschiktheid werd door twee onafhankelijke en ervaren beoordelaars bepaald aan de hand van een preoperatieve CTA. Beiden waren geblindeerd voor eerdere evaluatie, interventie en uitkomst. In totaal zijn 82 patiënten geïncludeerd. De preoperatieve CTA toont een eEVAR-geschikt geruptureerd AAA in 33 patiënten $(40,2 \%)$ en een eEVAR-ongeschikt geruptureerd AAA in 49 patiënten $(59,8 \%)$. De mortaliteit in beide groepen blijkt niet significant te verschillen met een verschil in intra-operatieve, 30 dagen en 6 maanden mortaliteit van respectievelijk 4,1\% (95\% BI: 0,7-20,2\%), 3,5\% (95\% BI: $-24,7-18,2 \%$ ) en 4,7\% (95\% BI: -25,9-16,6). We concluderen dat in deze analyse anatomische geschiktheid voor eEVAR niet geassocieerd is met een vermindering in mortaliteit op vroege en middellange termijn bij patiënten die behandeld zijn met een open procedure voor een geruptureerd AAA. Hieruit kunnen we mogelijk extrapoleren dat de gerapporteerde reductie in mortaliteit na eEVAR vergeleken met de open procedure niet of nauwelijks het gevolg is van selectiebias op basis van anatomische AAA configuratie.

In hoofdstuk 5 focussen we op het symptomatische AAA, gedefinieerd als de aanwezigheid van een AAA met acute aanvang van buik en/of rugklachten in combinatie met pijn bij palpatie van het aneurysma en zonder tekenen van ruptuur op CTA. Deze aandoening representeert mogelijk een dreigende ruptuur waarvoor een acute operatie geïndiceerd is. In dit hoofdstuk vergelijken we de acute behandeling van het symptomatische AAA met de uitgestelde behandeling na optimalisatie van de preoperatieve condities van de patiënt. We gebruiken hiervoor 12 uur als afkappunt en hebben gecorrigeerd voor type operatie en mogelijke confounders. In de studie zijn 89 patiënten geïncludeerd waarvan 37 patiënten een acute operatie hebben ondergaan. De andere 52 patiënten zijn eerst geoptimaliseerd en daarna (uitgesteld) behandeld. In de acuut geopereerde groep is bij 1 patiënt een ruptuur opgetreden $(2,7 \%)$ 
vergeleken bij 4 patiënten in de uitgesteld geopereerde groep (7,7\%). De 30 dagen mortaliteit in de groep die binnen 12 uur is geopereerd betreft $16,2 \%$ versus 5,8\% in de groep die na 12 uur is geopereerd (OR: 0,316; BI: 0,0741,358). Na correctie voor type operatie (open of eEVAR) en andere potentiële confounders zijn de gecorrigeerde odds ratio's respectievelijk 0,305 (BI: 0,0661,405) en 0,270 (BI: 0,015-4,836). Wanneer men 24 uur als afkappunt kiest, blijven de (gecorrigeerde) odds ratio's onveranderd. Hieruit hebben wij geconcludeerd dat het verantwoord lijkt patiënten met een symptomatisch AAA een uitgestelde behandeling te geven, indien de beschikbaar gekomen tijdspanne wordt aangewend ter optimalisatie van de patiënt. Vervolgonderzoek is aangewezen om patiënten te kunnen selecteren die op basis van specifieke criteria voordeel hebben van een uitgestelde operatie.

Hoofdstuk 6 beschrijft de lange termijn resultaten van een multicenter-studie naar de uitkomsten van de endovasculaire behandeling van het paraanastomotische aneurysma na een eerdere open reconstructie. Deze initiële open reconstructie kan zowel uit een aortabuis of een aorta-bifurcatie-prothese bestaan. In totaal zijn 58 patiënten met 80 pseudo- en/of ware aneurysmata van de aorta en/of iliacale arteriën endovasculair behandeld met een endoprothese. Een endovasculaire buisprothese is gebruikt bij 8 patiënten, een bifurcatie endoprothese bij 32 patiënten, een aorta-uni-iliacale-endoprothese bij 7 patiënten en een iliacale extensie bij 11 patiënten. Bij 55 patiënten is een succesvolle procedure verricht met een technisch succespercentage van $95 \%$. De mediane opnameduur bedraagt 3 dagen (Range: 1-122 dagen) en de 30 dagen mortaliteit bedraagt $3,4 \%(n=2)$. De mediane follow-up is 41 maanden met een range van 0-106 maanden. Tijdens de follow-up wordt een jaarlijks mortaliteitsrisico van $4,0 \%$ en een reïnterventierisico van $5,8 \%$ gezien. De preoperatieve anatomische presentatie van het para-anastomotische aneurysma lijkt geen invloed te hebben op het reïnterventierisico $(P=0,131)$. Echter, voor wat betreft de verschillende configuraties van de gebruikte endoprotheses zien we wel een significant verschil in reïnterventies na plaatsing van een aortabuis of aorta-uni-iliacale endoprothese gedurende de follow-up $(P<0,001)$. Het jaarlijkse risico op een reïnterventie is 3,2\% (SE: 0,098\%) voor de bifurcatie endoprothese, $16,6 \%$ (SE: 0,239\%) voor een endovasculaire buisprothese, $66,4 \%$ (SE: <0,001\%) voor aorta-uni-iliacale endoprotheses en 19,1\% (SE: 0,152\%) voor distale iliacale extensies. We concluderen dat endovasculaire exclusie van anatomisch geschikte para-anastomotische aneurysmata uitvoerbaar en duurzaam is; met name de bifurcatie endo- 
prothese laat een stabiele follow-up zien en mag daarom beschouwd worden als eerste-keus-behandeling. Echter, de endovasculaire behandeling van het para-anastomotische aneurysma vereist een individuele benadering waarin zowel de anatomische configuratie van het aneurysma als de gewenste configuratie van de endoprothese moeten worden meegenomen.

\section{DEEL TWEE - FOLLOW-UP NA ENDOVASCULAIRE ANEURYSMA BEHANDELING, DETECTIE VAN STENTGRAFT GERELATEERDE COMPLICATIES}

In een periode waarin (acute) EVAR in toenemende mate wordt toegepast, is het belangrijk de keerzijde van deze minimaal invasieve techniek te belichten, zoals de noodzaak van langdurige follow-up om stentgraft gerelateerde complicaties op te sporen. CTA is de meest gebruikte techniek in de follow-up na EVAR. Echter, het herhaaldelijk uitvoeren van een CTA heeft belangrijke nadelen waaronder cumulatieve stralingsdosis en het gebruik van nefrotoxisch contrast. Minder schadelijke alternatieven in de follow-up na EVAR zijn dan ook gewenst. Deze zouden gevonden kunnen worden in de ontwikkeling van alternatieve beeldvorming of adequate biomarkers.

In hoofdstuk 7 worden verschillende strategieën voor de detectie van endoleaks tijdens de postoperatieve follow-up na EVAR met behulp van alternatieve beeldvorming en adequate biomarkers behandeld. CTA follow-up na EVAR wordt beschouwd als de gouden standaard. CTA is hoog-sensitief, breed toegankelijk, snel en heeft een grote mate van reproduceerbaarheid. Echter, de nadelen zijn de cumulatieve stralingsdoses en het herhaald gebruik van nefrotoxisch contrastmiddel. Daarnaast is het optimale protocol voor follow-up in deze patiëntenpopulatie nog niet uitgekristalliseerd. Veelbelovende alternatieve modaliteiten voor de detectie van endoleaks zonder röntgenstraling of nefrotoxisch contrastmiddel zijn: contrastversterkte duplex (CEUS), magnetische resonantie angiografie (MRA) en circulerende biomarkers (matrix metalloproteïnases). Deze technieken zijn in staat endoleaks met toenemende sensitiviteit en specificiteit te detecteren en te classificeren. Hiermee nemen ze een optie op een prominente rol in de follow-up na EVAR. Echter, harde aanbevelingen voor de ideale follow-up na EVAR kunnen op basis van de hedendaagse literatuur nog niet worden gedaan.

In hoofdstuk 8 gaan we verder in op de rol van CEUS als alternatief voor CTA in de follow-up van patiënten na EVAR waarbij we AAA-dimensies en endoleak 
detectie behandelen. Er zijn 83 opeenvolgende patiënten geïncludeerd gedurende de follow-up na EVAR. Deze hebben in totaal 127 gepaarde beeldvormende onderzoeken ondergaan in de vorm van zowel CEUS als CTA. Er is een goede overeenkomst tussen de twee beeldvormende technieken gevonden in zowel antero-posterieure als transversale maximale diameter met een variatiecoëfficiënt van respectievelijk $8,0 \%$ en $8,6 \%$. De interobserver variabiliteit is laag met een interclass correlatiecoëfficiënt van meer dan 0,98 in beiden richtingen. CEUS blijkt in vergelijking tot CTA significant meer endoleaks te detecteren (53\% versus 22\%). Additioneel laat CEUS 38 type II en 2 type I endoleaks zien, welke bij twee patiënten geresulteerd hebben in een reïnterventie. Er blijkt dan ook sprake van een geringe mate van overeenkomst $(\kappa=0,237)$ waarbij slechts $61 \%$ van de onderzoeken corresponderen (77/127). De resultaten laten zien dat CEUS mogelijk gelijkwaardig is aan CTA in de followup na EVAR zonder de risico's van contrastnefropathie en blootstelling aan radiatie.

In hoofdstuk 9 focussen we op de potentiële klinische toepasbaarheid van de biomarkers MMP-2, MMP-9 en TIMP-1 als diagnostische middelen om endoleaks aan te tonen. Er zijn 37 patiënten geïncludeerd, 17 patiënten met een endoleak op CTA ( 4 type I, 12 type II en 1 type III endoleak) en 20 gepaarde controlepatiënten zonder endoleak. Plasmaconcentraties van MMP-2, MMP-9 en TIMP-1 zijn bepaald door gebruik te maken van enzyme-linked immunosorbent assay. Patiënten met een endoleak hebben een significant hogere plasmaconcentratie van MMP-9 dan patiënten zonder endoleak $(P<0,001)$. De ROC-curve van de plasmaconcentraties van MMP-9 laat bij een afkapwaarde van $55,18 \mathrm{ng} / \mathrm{ml}$ een $100 \%$ sensitiviteit en $96 \%$ specificiteit zien met een oppervlakte onder de curve $(A \cup C)$ van $0,988(P<0,001)$. Echter, het blijkt niet mogelijk om op basis van plasmaconcentraties van MMP-9 te differentiëren tussen de verschillende typen endoleaks. Deze studie laat zien dat de plasmaconcentratie van MMP-9 in staat is om met hoge sensitiviteit en specificiteit te discrimineren tussen patiënten met en zonder endoleak. Een prospectieve klinische studie is vereist om de klinische toepasbaarheid van deze analyse te valideren. 
Dankwoord 



\section{Dankwoord}

\section{Eindelijk, het is af...!}

Toch grappig, hetgeen dat het meest gelezen wordt in een wetenschappelijk proefschrift is het dankwoord, het enige hoofdstuk dat geen enkel cijfer, tabel of figuur bevat. Dit onderstreept maar weer dat je een proefschrift niet kunt schrijven door je vier jaar eenzaam op te sluiten. Veel mensen hebben direct of indirect een onmisbare bijdrage geleverd aan de uiteindelijke totstandkoming van "het boekje". Ik vind het dan ook heerlijk dat ik een heel hoofdstuk kan weiden aan het bedanken van deze mensen, en een paar in het bijzonder.

Allereerst wil ik alle patiënten en hun familie bedanken dat zij in tijden van spanning en onzekerheid bereid zijn geweest deel te nemen aan onze studies. Zonder jullie was dit proefschrift er überhaupt nooit geweest!

\section{Prof. dr. J.A.W. Teijink, beste Joep,}

Daar zat ik dan op die foeilelijke rode leren bank tijdens mijn sollicitatie als semi-arts. Ik had nooit durven hopen dat dit het begin zou worden van zo'n mooie en vruchtbare samenwerking. Qua energie doen we misschien niet voor elkaar onder, maar jij hebt me laten zien hoe je die energie ook voor productieve dingen in kunt zetten. Dit heeft bij mij geleid tot dit boekje en bij jou tot een hoogleraarschap dit jaar, iets wat we stiekem allemaal al zagen aankomen.

Joep, al had ik dat boekje nooit afgeschreven, vanaf het moment op die rode bank heb ik er een maat voor het leven bij. Zet twee wervelwinden bij elkaar en dat staat garant voor de nodige brakke congresdagen, dwaze onderzoeks-trips en honderden verhalen die ik beter niet in een serieus proefschrift kan schrijven, maar waar ik met gemak een tweede boekje mee kan vullen.

Joep, heel veel succes als Prof in Eindhoven, ontzettend bedankt voor de volle overgave waarin je me hebt gesteund en begeleid afgelopen jaren en ik hoop dat ik nog vaak pannenkoeken kan komen eten bij jou, Inez en de kids!

\section{Prof . dr. M.H. Prins, beste Martin}

Nog voor de eerste kop thee op was bij jou thuis in de 'Rozenheuvel' had je de onderzoeksvinger al op de zere plek. Daar waar ik weken mijn hoofd op zat te breken leek na een bezoek aan jou een makkie. Jij maakte iedere analyse zelfs voor mij begrijpelijk en inzichtelijk en daarmee onderzoek doen toegankelijk. Toch was een meeting van 1 uur voer voor minimaal twee maanden werk. 
Martin, jouw ideeën, manier van orde scheppen, rust en bescheidenheid werkte inspirerend en ik heb zowel als onderzoeker als persoon veel van je geleerd.

\section{Dr. E.M. Willigendael, beste Edith, mijn onderzoeks-mamma}

Je heb je taak volbracht, je kind gaat promoveren! Wie had gedacht dat we zo'n hecht team zouden vormen, een Raver zij aan zij met een Alto, Nike Air Max-jes hand in hand met Dr Martens! Je bent me voorgegaan als onderzoeker van Joep en weet als geen ander dat achterover leunen geen optie is. Je oppeppende mailtjes waren altijd van onschatbare waarde. Je bent een geweldige copromotor, je stond samen met Jan altijd direct klaar als ik je nodig had en ik hoop dat je in Alkmaar deze rol als onderzoeks-mamma voort kan zetten! Ik weet al lang wat je volgende mail gaat zijn: "En nu genieten manneke!" Nou, laat jullie motor maar vast warmdraaien dan...

\section{Leden van de beoordelingscommissie}

Graag zou ik de leden van de beoordelingscommissie, voorzitter Prof. dr. G.W. Schurink, Prof. dr. R. De Bie, Prof. dr. M.W. de Haan, Dr. J.A. van Herwaarden en Dr. M.R.H.M. van Sambeek enorm willen bedanken voor de tijd die u heeft willen besteden aan de beoordeling van mijn proefschrift.

\section{Dr. S.P.A. Nicolai, beste Sas}

Met zijn tweeën hebben we heel wat dagen gesleten in de bezemkast op de AOA, het aquarium. Vaak hebben we de vraag gehad, "wat doen jullie daar eigenlijk de hele dag". Dat heb ik me ook vaak afgevraagd, want we hebben zoveel lopen ouwehoeren dat er veel dagen voorbij gingen dat mijn computer niet eens aan is geweest. Sasje, je bent een geweldige roommate geweest en ik wil je bedanken voor alle mooie momenten!

\section{Dr. L.M. Kruidenier, beste Lottie}

Mijn tweede roommate in het aquarium op de AOA. Wat ik zo heerlijk aan je vindt is dat je als klein vrouwtje op je hakjes letterlijk 6 trippel-pasjes moet zetten waar ieder ander 1 pas zet, maar je in werkelijkheid iedereen als een razende voorbij stoomt door je efficiënte en kordate manier van aanpakken. Daar heb ik stiekem een hoop van afgekeken. Je was dan wel het zoveelste meisje in de onderzoeks-reeks van Joep, maar voor mij deed je qua schuine humor, voetbalpraat (als enige FC-twente Hooligan in Limburg), bierdrinkend vermogen en heerlijk nuchtere kijk op het leven niet onder voor een goeie vent. Ik heb dan ook, naast een berg statistische hulp, met name een hele fijne tijd 
met je gehad! Blijf een vrouwtje maar sta je mannetje, dan weet ik zeker dat je een grote vaatchirurg gaat worden!

\section{Dr. E.V. Rouwet, Elliebellie}

Met name tijdens het schrijven van de CEUS studie hebben we intensief samengewerkt. Je opgewekte persoonlijkheid, lekkere directe aanpak en nononsense mentaliteit maakte samen sparren niet alleen gezellig maar ook uitermate efficiënt. Telkens kwam je de AOA weer binnengevlogen met kritische noten, nieuwe inzichten en waardevolle verbeteringen. Elliebellie, ik heb van je genoten en onthoud: "Een dag niet gegiecheld is een dag niet geleefd."

\section{Dr. F.A.M.V.I. Hellenthal, beste Femke}

We hebben zowel wetenschappelijk als klinisch samen mogen werken. En hoewel we heel verschillend zijn hebben we een klik samen. Ik heb erg veel bewondering hoe je de afronding van je promotie hebt kunnen combineren met je klinische werk en met moeder zijn. Houd je heerlijke nuchtere droge humor en kijk op het leven vast! Je gaat een grote maar vooral relaxte vaatchirurg worden!

\section{Drs. R.A. Stokmans, beste Rutger}

Als opvolger binnen het aneurysma-onderzoek in het Catharina Ziekenhuis onder leiding van Joep ga je zoals verwacht als een speer. Daarnaast heb je nu ook je welverdiende opleidingsplek binnen! Heel veel succes met de afronding van je eigen promotie, ik ben ervan overtuigt dat jouw laatste loodjes vlotter gaan dan die van mij, nog effekes jonguh!

Drs. S.W. Koning, beste Sam, Samwise the brave, ouwe levensgenieter. Toen ik als ANIOS begon en de kliniek nog nauwelijks kon bijbenen heb jij je als semiarts en tevens als m'n AAA-onderzoeks-mattie vol op de sAAA database gestort. En met succes, we hebben er een mooi artikel uit weten te persen, maar bovenal een te gekke tijd gehad als Jut en Jul van het AAA onderzoek. Ik zit nu tijdens het schrijven van dit stukje onze continue stroom van idiote mailconversaties van destijds te bekijken, heerlijk! Sam, ik ben je enorm dankbaar voor je tomeloze inzet! Heel veel succes met je eigen onderzoek en je verdere carrière! 
Graag zou ik enkelen in het bijzonder bedanken voor de directe bijdrage aan diverse hoofdstukken. Allereerst Dr. M.R.H.M. van Sambeek, beste Marc, dank voor de kritische noten bij meerdere artikelen, je was nooit te beroerd om mee te denken. Altijd dacht ik achteraf: "ja, het is echt beter geworden". Dr. Ph.W.M. Cuypers, beste Philip, Dr. J.P.P.M. de Vries, beste Jean-Paul, Prof. dr. M.W. de Haan, beste Michiel, en Prof. dr. H.J.M. Verhagen, beste Hence, ook jullie wil ik enorm bedanken voor de actieve bijdrage aan verschillende hoofdstukken in dit boekje. Jullie mailtjes met gevat commentaar en de nodige tips and tricks waren van grote waarde!

\section{Dr. J.A. van Herwaarden, beste Joost}

Ik heb je leren kennen als een toegewijde vaatchirurg die enorm betrokken is bij zijn onderzoekers. Ik ben dan ook erg blij dat ik gedurende de naadaneurysmastudie onderdeel mocht zijn van jouw club onderzoekers met als absolute hoogtepunt het SVS in Boston, een onvergetelijke trip! Joost, dank voor het gespreide warme bedje in het UMCU ten tijden van het inkloppen van de data voor de naadaneurysma-studie en dank voor je positieve perfectionisme bij ons artikel!

Dr. E.J. Waasdorp, beste Evert, je nam me in het UMCU aan de hand om de Utrechtse naadaneurysma data in te kloppen en vervolgens hebben we heel wat lopen sparren om het artikel te perfectioneren. Ik heb veel waardering voor de snelheid waarmee jij je eigen promotie hebt kunnen afronden naast je klinische werk en wil je bedanken voor de gezellige samenwerking! Veel succes als vaatchirurg en we zullen elkaar op de nodige feestjes nog wel tegenkomen!

Prof. dr. F.L. Moll, beste Frans, u ziet zo veel jonge onderzoekers voorbij komen en ik vond het dan ook erg bijzonder dat u zoveel tijd en aandacht had voor mijn onderzoek toen ik in Utrecht 'langswipte' om de data van de naadaneurysma studie te verzamelen. Het was bijzonder om even deel uit te mogen maken van jullie team.

Prof. dr. Schurink, beste Geert Willem, jij had al ruime ervaring met het begeleiden van basaal-wetenschappelijk en aneurysma-onderzoek waardoor ik op een rijdende, zeg maar gerust racende MMP-trein kon stappen. Heel veel dank hiervoor! Ik vond het mooi om je de eerste drie jaar van mijn opleiding in de kliniek 'in actie' te zien en heb veel van je mogen leren. 
Jeroen van den Akker, Toon van der Krieken, Gio Tuerlings, Gaby de Bresser en Viola Conradi van Medtronic, wat hebben we plezier gehad op OK, op congressen, op de EVAR themadagen en op de nodige feestjes. Ik dacht altijd dat ik goed was in doortrekken...

Peter van Gendt, van W.L. Gore, bedankt voor de toptijd in Miami samen met Joep, het was dat ik een praatje moest geven anders hadden we het congresgebouw überhaupt niet gezien vrees ik...

\section{Semi-artsen club 2007-2008 van het Atrium MC}

36 weken deelden we samen ons hokkie met 9 computers, toen nog op de bovenste verdieping van het Atrium ziekenhuis naast de beddencentrale, waarvan de chirurgen zelf op dat moment geen enkel idee hadden waar het zich bevond (yesssss). Rik Dassen, Roy Sauren, Pascal Buijs, Anne Schellekens, Sophie Litjens, Kim van Pul, Judith Bek en Marieke Verspaget. Wat hebben wij een mooi jaar gehad, gelachen, gezopen en samen onze eerste wetenschappelijke stapjes gezet, hetgeen voor mij de basis werd voor dit proefschrift. Rik Dassen, zonder jou en die gruwelijke kerstman op z'n slee was dit boekje er minimaal driekwart jaar eerder geweest, maar was mijn stage niet half zo leuk.

\section{Chirurgen en arts-assistenten Heelkunde in het Atrium MC}

Als semi-arts, onderzoeker en later als ANIOS hebben jullie dit groentje klaargestoomd voor de opleiding chirurgie. Het is bij jullie niet moeilijk om onderdeel te worden van het team. De werksfeer, vrijdagmiddagoverdrachten, borrels en natuurlijk de onvergetelijke winterbijscholingen hebben hier zeker aan bijgedragen. Ik kijk er dan ook erg naar uit om de laatste drie jaar van mijn opleiding 'thuis' te komen.

Mijn speciale dank gaat uit naar een aantal chirurgen in het bijzonder:

Dr. R.J.Th.J. Welten, beste Rob, bedankt voor het vertrouwen en de steun bij mijn keuze voor de chirurgische opleiding, dit heb ik enorm gewaardeerd. Ik ben ervan overtuigd dat we van de laatste drie jaar van mijn opleiding een toptijd tegemoet gaan! Dr. E.C.M. Bollen, beste Ewald, ik heb je interesse in het onderzoek en in mij altijd als bijzonder ervaren, evenals je wijze lessen van een 'oude' vaatchirurg. Drs. B. Meesters, beste Berry, jouw gave om naast presteren op de werkvloer vol in het bruisende leven te staan werkt echt inspirerend. We gaan mooie jaren tegemoet, als $\mathrm{m}^{\prime} \mathrm{n}$ baas maar zeker ook als m'n maatje! Drs. E.R. de Loos, beste Erik, jij stond mede aan het begin van dit onderzoek en gaf me de ruimte om het onder leiding van Joep en Martin verder 
af te maken. Toch hebben we menig jaartje in dezelfde tent doorgebracht. Ik vind het dan ook te gek we de laatste drie jaar van mijn opleiding opnieuw samen aan de overdrachtstafel zitten! Dr. M.N. Sosef, beste Meindert, je had me binnen 5 minuten overtuigd om mijn semi-arts stage in het Atrium te komen doen, $\mathrm{m}$ 'n beste beslissing ooit! Ik vind het dan ook bijzonder dat ik de laatste fase van mijn opleiding onder jouw hoede mag afronden.

Verder wil ik graag de voltallige assistentenpoel ten tijden van mijn semi-arts stage, onderzoeksjaar en ANIOS-periode in het Atrium MC bedanken voor de toptijd! In het bijzonder Zwelgje m'n party buddy, Ruuubschen, Zandhaas, Oerlemansje, Castelijnsje, Jean Paul, Frenkie, Speigner, Kimmie, Elfedalli, Joep en Woutje.

Maar er zijn nog tientallen mensen uit het Atrium die ik graag zou willen bedanken en een dikke vette knuffel wil geven. Allereerst de heldinnen van het Vaatlab, Cecile Peters en Linda Jansen, the queens of CEUS! Het voltallige polipersoneel met in het bijzonder Ali en Christel, jullie maken van poli draaien een feestje! Ik heb eindeloos patiënten lopen includeren op jullie poli, klinkt saai, maar zodra ik de spreekkamer uitkwam was het non-stop lachen gieren brullen. Bedankt en tot de laatste drie jaar van mijn opleiding! De vepleegkundigen van de AOA, de 11 en de 12, bedankt voor de mooie tijd, you rock! Simone, de OKplanster met nadruk op STER! Wat ben je toch een heerlijk gek wijf, een topper! Wanneer gaan we weer beschuitjes eten? Het secretariaat chirurgie, het gezelligste kippenhok van het ziekenhuis, Jolanda, Margot, Marlies, Caroline en Nancy, ik kon altijd bij jullie aankloppen, voor hulp, voor advies, maar ook altijd voor een praatje. Ik heb jullie gemist afgelopen 3 jaar!!!

\section{MUMC}

Allereerst de assistentenpoel, de meest gestoorde club assistenten ooit, iedereen maar dan ook iedereen van de afgelopen 3 jaar wil ik enorm bedanken voor deze dolle dwaze jaren. Als ik niet elke dag met zo'n dikke smile en buikpijn van het lachen thuiskwam had ik me er nooit toe kunnen zetten om dit boekje in de avonduren af te ronden! Een speciale dikke lebber aan de bende van ellende: Woutje, Hillybilly, Basje, Bransen, Smeetsje, Berende, Reinders en vd Pas.

Maar natuurlijk ook de chirurgen, wat was het een mooie tijd en wat moest ik nog veel leren de eerste drie jaar van mijn opleiding. Ik wil iedereen bedanken voor de geweldige werksfeer, opleiding en stabiele basis om me verder te kunnen ontwikkelen. De winterbijscholingen, jaarlijkse BBQ en tussentijdse 
feestjes en uitstapjes waren geweldig! Mijn speciale dank gaat ook uit naar Prof. dr. L.P.S. Stassen, beste Laurents, ik ben blij dat ik als AIOS mocht profiteren van jouw passie voor opleiding en onderwijs afgelopen jaren. Jouw bijzonder hoogleraarschap dit jaar is dan ook niet voor niets! Bedankt!

Ook wil ik graag van deze gelegenheid gebruik maken om het secretariaat chirurgie, Tonneke, Manon, Claudia, Ingrid, Sandra, Evelien, Sabeth, Monique, Joyce, Mariëlle, en ook office manager Marianne Siep en natuurlijk niet te vergeten Marieke Koenen te bedanken. Het lukte me nooit om jullie tuintjes op de stafgang te passeren zonder veeeeeel te lang te blijven plakken. Ik heb nog nooit zo veel mamma's gehad. Jullie stonden altijd vol overgave voor me klaar als ik jullie weer kwam bekogelen met (domme) vragen.

\section{Café 1900}

Lieve Gemma, vanaf de introductieweek in mijn eerste studiejaar kom ik met veel plezier DE daghap bij je eten. Jij hebt mij van broekie af aan 'volwassen' zien worden. En waar we ook komen te wonen later, jullie daghap zal op ons menu blijven staan! Boy, veel succes en maak je moeder trots!

Tiny Wouters, je bent een bijzonder mens en ik weet niet hoe ik de 'laatste loodjes' van mijn boekje zonder jou had moeten volbrengen. Het was altijd leuk om je kamertje binnen te wandelen en niet alleen voor de snoepjes. Tiny, het is echt bijzonder om zoveel mensen te mogen ondersteunen in de afrondende fase van een van hun meest bijzondere levens-momenten. Ik wil je in ieder geval bedanken voor alles wat je voor mij hebt gedaan, ik zal het nooit vergeten!

\section{Nondejuke}

Maastrichts bruutste herendispuut, een grote club volslagen idioten. Samen met jullie heb ik gepiekt en letterlijk de goot gezien, en er vaak genoeg in gelegen. De wekelijkse borrels en zijn rituelen zijn aan geen mens uit te leggen, maar hebben mijn studentenleven gemaakt.

\section{HS, homies for life}

Echte vrienden hebben aan weinig woorden genoeg. Jossos Kolossos, Face en $T_{\text {, }}$ zieke tijden waarin we létterlijk ALLES met elkaar hebben gedeeld! Wat prijs ik me gelukkig dat ik dan ook meerdere huizen met jullie heb mogen delen, Mufassa zou trots zijn. Joost van der Vorst, Jos, Jossos Kolossos, Renpaard, 'Orse, da pussyfillah, wij versterken elkaar in alle opzichten, zoeken geen 
grenzen op maar gaan er vol overtuiging overheen, je bent en blijft mijn mattie for life! Rick van de Langenberg, Face, the prettiest boy on planet earth, 'Jae...', ik verbleek naast iedere glimp van jou, dat jij het onze hele studententijd hebt uitgehouden in het HB en HS getuigt van de grootste vriendschapsband die er voor te stellen is. Ik heb nog nooit zo veel met en om iemand gelachen, ik hoop dat we altijd in elkaars stadje blijven wonen! Thijs van Herpt, T_, TTW Diherpio, Mr sorry, 'prulleke', jouw eeuwige enthousiasme en vermogen om chaos in orde te scheppen is werkelijk ongeëvenaard. Als je denkt dat het niet extremer kan kom jij om de hoek kijken en daarom maak jij ons viertal helemaal compleet!

Zoals Face al in zijn proefschrift zei: waarom mag je maar twee paranimfen kiezen...?

\section{Schoonfamilie}

Een vriendin kun je 'kiezen' (hoewel ik voor die van mij toch nogal wat moeite heb moeten doen), je schoonfamilie krijg je er gratis bij. Wat is het dan toch heerlijk om in zo'n warme familie terecht te komen. Steph en Ellen, ook jullie wil ik enorm bedanken voor jullie oprechte interesse, alle steun en mooie momenten van afgelopen jaren. Ik ben enorm blij met jullie!

Renéetje, mijn schoonzusje, ik kan met niemand zo goed stoeien, mensen irriteren en lachen als met jou. Je bent een topzusje!

Svennieboy, schoonbroertje, hoe bijzonder is het dat je schoonbroer een van je beste maten wordt met (toevallig) dezelfde passie: draaien. Als 'Brothers in Law' - Sven Feijen B2B Jean de la Foret hebben we wekelijks het publiek (en menig organisator) gek gemaakt! Hierbij mocht één iemand nooit ontbreken, onze ras-positivist MC Handsome, Rob Vervoort. Rob, ik ken niemand met zoveel zelfspot als jij en ik geniet daar ieder moment dat we samen zijn van! Laten we elkaar in ieder geval blijven steunen in de strijd tegen onze kaalheid.

(Schoon)opa en oma, ik vind het een eer dat jullie dit nog mogen meemaken, zeker gezien het feit dat jullie altijd zo enorm geïnteresseerd zijn en dat ik jullie stiekem ook een beetje als mijn eigen opa en oma zie. Ik hoop samen met Michelle nog heel lang van jullie te mogen genieten!

\section{Familie}

Lieve paps en mams, jullie hebben ons een onbezorgde jeugd gegeven en jullie hebben jezelf volledig weggecijferd om ons alle mogelijkheden te bieden om ons te kunnen ontwikkelen, op alle vlakken. Jullie wisten ons te motiveren en we hebben de perfecte balans meegekregen tussen genieten en presteren, 
zowel in de sport als in de muziek als in het dagelijkse leven. 'Het maakt niet uit wat je doet, als je maar je best doet'. Zonder jullie onvoorwaardelijke steun en zorgzaamheid was ik nooit gekomen waar ik nu sta. En al woon ik in het Zuidelijkste puntje van het Land, het blijft altijd fijn om weer even thuis te komen. Ik ben jullie ontzettend dankbaar en ik hoop dat ik mijn toekomstige kinderen hetzelfde kan bieden als wat jullie mij geboden hebben. Dit boekje is voor jullie!

Pleun en Neeltje, hoe sterk kan een broer-zusjes band zijn, familie en tegelijk beste maatjes. Als wij samen zijn is het gegarandeerd feest. We hebben dezelfde mentaliteit en doorzettingsvermogen, maar bovenal dezelfde slechte humor, wat voor veel mensen rete irritant is. Pleunie, jouw gave om ondanks je eigen drukke praktijk en sociale leven ALTIJD oog en interesse te hebben voor iedereen om je heen vind ik echt bewonderenswaardig! Nelus, de manier waarop jij je omgeving kan inspireren met jouw onuitputtelijke positieve energie is minstens zo bijzonder. Ik ben zo trots op jullie en ik zal mijn hele leven proberen jullie grote broer te zijn. Onze band is niet kapot te krijgen!

Jacolien Schellekens, tante Sjaco, als peettante heb je mijn hele leven zo dicht bij me gestaan en alles op de voet gevolgd. Ik ben me er heel erg van bewust dat ik enorm bof met zo'n betrokken, zorgzame en lieve peettante!!!

En... wat was het mooi geweest als beide opa's en oma's dit hadden mogen meemaken, stiekem is dit boekje ook een beetje voor jullie.

Lieve, lieve Michelle, mijn soulmate en allerlekkerste vriendinnetje! Jij bent mijn schot in de roos! Afgelopen jaren waren niet altijd even makkelijk, promoveren naast het dagelijkse werk gaat ten koste van een heleboel qualitytime samen. Nooit heb je gezeurd, nooit een droevig gezicht; altijd heb je me vol overgave gesteund, me geholpen waar nodig, allerlei taken op je genomen zodat ik weer eens aan 'het boekje' kon werken en me de energie en motivatie gegeven om door te zetten. En dat alles naast jouw eigen drukke baan en leven. $\mathrm{Nu}$ is het jouw tijd, want dat heb jij als geen ander verdiend! Schatje, ik hoop dat al onze jaren die komen gaan net zo mooi mogen zijn als onze afgelopen jaren. Ik ben ongelofelijk trots op je, ik geniet nog iedere minuut van je en je wordt een geweldige moeder van ons kindje! 'Het past'. 

List of publications 



\section{List of publications}

\section{Papers}

Ten Bosch JA, Koning SW, Willigendael EM, van Sambeek MR, Stokmans RA, Prins $\mathrm{MH}$, Teijink JA. Symptomatic abdominal aortic aneurysms, to wait or not to wait. J Cardiovasc Surg. Accepted for publication.

Stokmans RA, Willigendael EM, Teijink JA, Ten Bosch JA, van Sambeek MR, Cuypers PW. Challenging the evidence for pre-emptive coil embolisation of the internal iliac artery during Endovascular Aneurysm Repair. Eur J Vasc Endovasc Surg. 2013;41:647-651.

Ten Bosch JA, Hellenthal FA, Pulinx B, Wodzig WK, Schurink GW. Re: Utility of Plasma Matrix Metalloproteinase-9 as a Possible Diagnostic Marker of Endoleak Post Endovascular Aneurysm Repair. Eur J Vasc Endovasc Surg. 2012;43: 610-611.

Ten Bosch JA, Willigendael EM, Kruidenier LM, de Loos ER, Prins MH, Teijink JA. Early and mid-term results of a prospective observational study comparing emergency endovascular aneurysm repair with open surgery in both ruptured and unruptured acute abdominal aortic aneurysms. Vascular. 2012;20:72-80.

Ten Bosch JA, Hellenthal FA, Pulinx B, Wodzig WK, de Haan MW, Prins $\mathrm{MH}$, Welten RJ, Teijink JA, Schurink GW. Plasma levels of matrix metalloproteinase9: a possible diagnostic marker of successful endovascular aneurysm repair. Eur J Vasc Endovasc Surg. 2012;43:171-172.

Ten Bosch JA, Cuypers PW, van Sambeek M, Teijink JA. Current insights in endovascular repair of ruptured abdominal aortic aneurysms. Eurolntervention. 2011;7:852-858.

Ten Bosch JA, Waasdorp EJ, de Vries JP, Moll FL, Teijink JA, van Herwaarden JA. The durability of endovascular repair of para-anastomotic aneurysms after previous open aortic reconstruction. J Vasc Surg. 2011;54:1571-1578.

Ten Bosch JA, Willigendael EM, van Sambeek MR, de Loos ER, Prins MH, Teijink JA. EVAR suitability is not a predictor for early and midterm mortality after open ruptured AAA repair. Eur J Vasc Endovasc Surg. 2011;41:647-651. 
Ten Bosch JA, Teijink JA, Willigendael EM, Prins MH. Endovascular aneurysm repair is superior to open surgery for ruptured abdominal aortic aneurysms in EVAR-suitable patients. J Vasc Surg. 2010;52:13-18.

Ten Bosch JA, Rouwet EV, Peters CT, Jansen L, Verhagen HJ, Prins MH, Teijink JA. Contrast-enhanced ultrasound versus computed tomographic angiography for surveillance of endovascular abdominal aortic aneurysm repair. J Vasc Interv Radiol. 2010;21:638-643.

Ten Bosch JA, Legemate DA, Teijink JA. Endovascular treatment of ruptured abdominal aortic aneurysms. Ned Tijdschr Geneeskd. 2009;153;A506.

Kruidenier LM, Nicolaï SPA, Ten Bosch JA, de Bie RA, Prins MH, Teijink JAW. Predictors of walking distance after supervised exercise therapy in patients with intermittent claudication. Eur J Vasc Endovasc Surg. 2009;38:449-455.

Ten Bosch JA, Hellenthal FA, van Sambeek MR, de Haan MW, Schurink GW, Teijink JA. Strategies for detection of endoleaks after endovascular abdominal aortic aneurysm repair. Submitted.

Hellenthal FA, Martens R, Ten Bosch JA, Pulinx B, Wodzig WK, Heeneman S, Welten RJ, Schurink GW. Regional differences in histology and biomarker expression of the Abdominal Aortic Aneurysm; implications for prediction of AAA growth. Submitted.

\section{Book contributions}

Kruidenier LM, Nicolaï SPA, Ten Bosch JA, van Pul KM, Prins MH, Teijink JAW. Community based exercise therapy for intermittent claudication. Proceedings of the 16th European Congress of Physical and Rehabilitation Medicine 2008, 126128. Edizioni Minerva Medica, ISBN 9788877116161.

Ten Bosch JA, Willigendael EM, Cuypers PW, van Sambeek MRHM, Teijink JAW. Treatment of ruptured abdominal aortic aneurysms. Aortic Aneurysm. Intech 2011, ISBN 978-953-307-524-2. 
Curriculum Vitae 



\section{Curriculum Vitae}

Jan A. Ten Bosch was born on August 3, 1984, in Breda, The Netherlands. After obtaining his gymnasium degree cum laude at the Stedelijk Gymnasium in Breda in 2002, he started his Medical study at the University of Maastricht that same year. During the final year of his Medical study he was introduced to vascular research as a student of Prof. dr. J.A.W. Teijink, focusing on acute endovascular aneurysm repair. This resulted in the Research Award 2008 provided by the Foundation of Research Practice and formed the basis for this thesis. After receiving his Medical Degree in 2008 he continued his research in a one year PhD program at the Atrium Medical Center in Heerlen, resulting in a poster prize of the Foundation For Aneurysm Rupture Research that year. In 2009 he started working as a surgical resident at the Atrium Medical Center under supervision of dr. R.J.Th.J. Welten. In July 2010 he commenced his surgical training at the Maastricht University Medical Center under supervision of Prof. dr. L.P.S. Stassen and he will continue his training at the Atrium Medical Center in July 2013 under supervision of dr. M.N. Sosef. 
